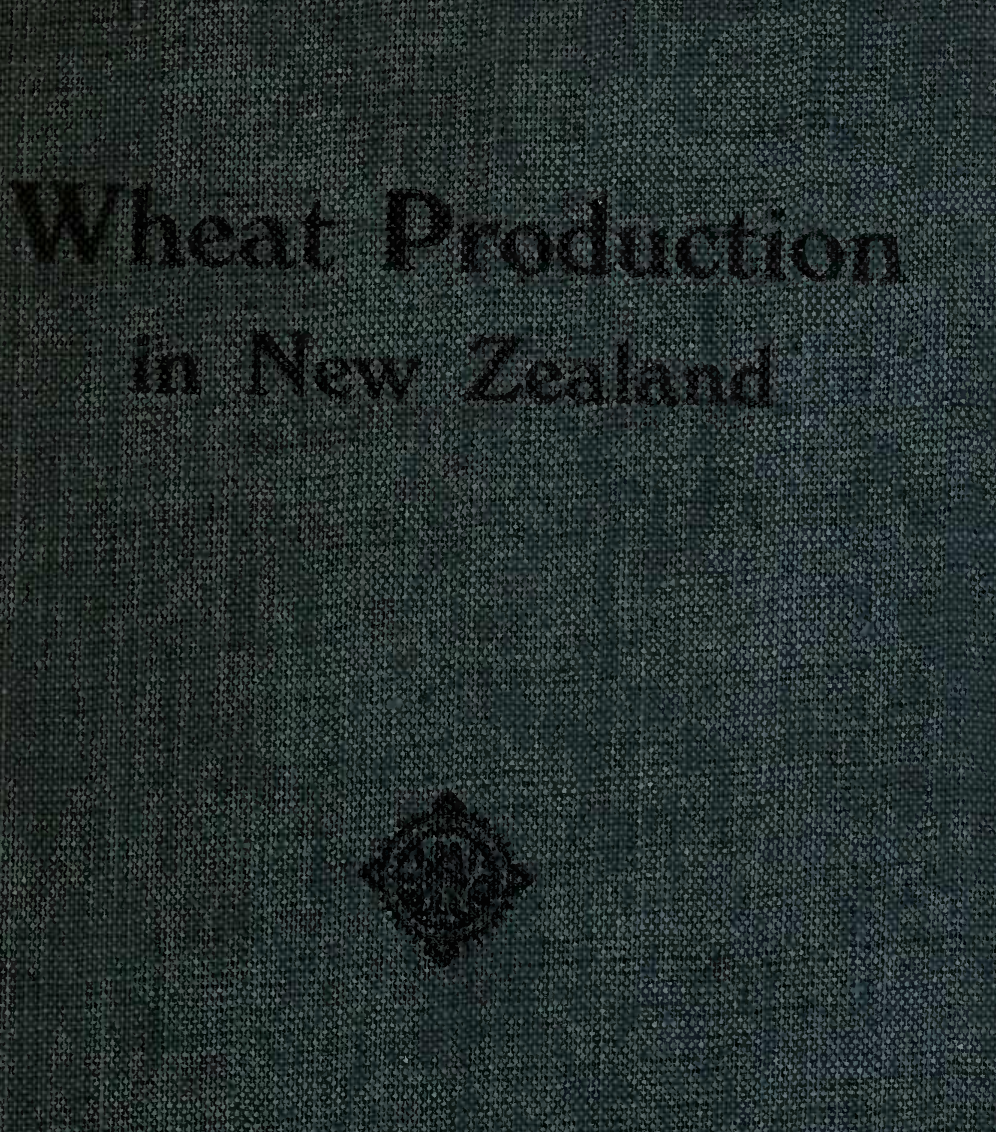



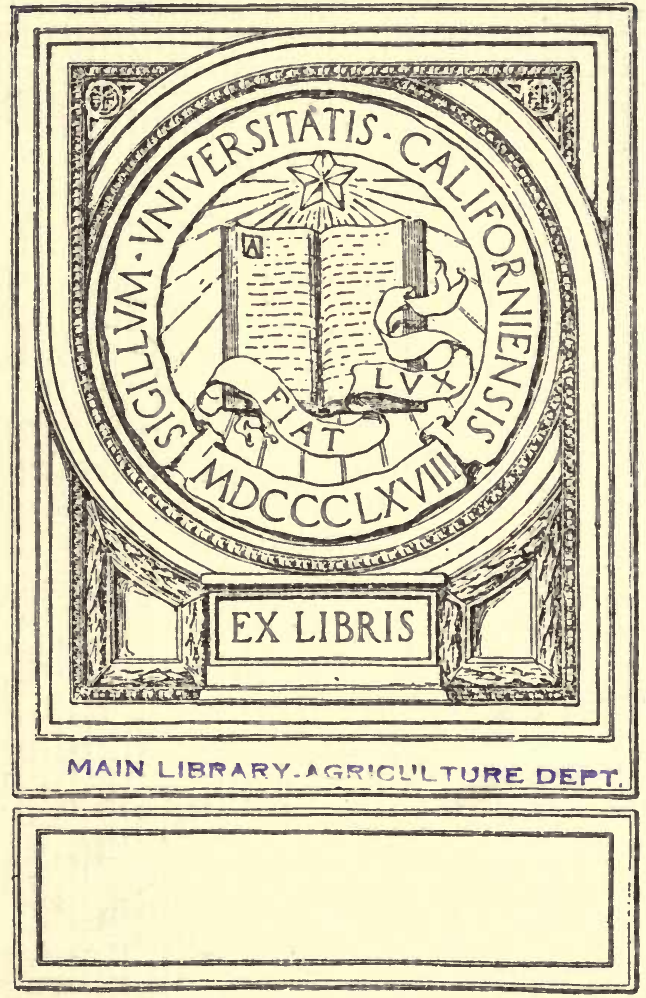




\section{WHEAT PRODUCTION}

\section{IN NEW ZEALAND}

A STUDY IN THE ECONOMICS OF NEW ZEALAND AGRICULTURE

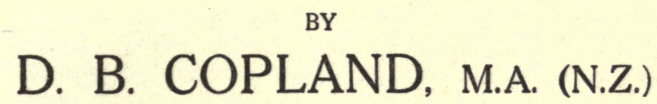

Lecturer in History and Economics in the University of Tasmania

WITH A CHAPTER ON

Improvement in Wheat by Selection in N.Z.

contributed by

F. W. HILGENDORF, D.Sc.

Biologist to the Canterbury Agricultural College

And an Introduction by

JAMES HIGHT, M.A., Lit.D.

Professor of History and Economics in Canterbury University College

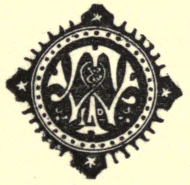




$$
\begin{aligned}
& \text { SB|9| } \\
& \text { W5C7 }
\end{aligned}
$$

MAIN LIBRARYA GEIC' TIRE DEPT. 


\section{PREFACE.}

In 1915 I presented the results of an investigation into "The Progress and Importance of Wheat Production in New Zealand" as a thesis being part of the work required for Honours in Economies at the annual examinations conducted by the University of New Zealand. I was subsequently encouraged to publish the work. After much delay, occasioned by the pressure of other interests, I have revised it, and I now present it for consideration (and criticism) to all who are interested in the rural industries of New Zealand.

Dr. Hilgendorf has greatly added to the value of the work by contributing a chapter on "The Improvement of Wheat by Selection in New Zealand," which contains an account of his work in this problem at the Canterbury Agricultural College. An Introduction by Dr. Hight, explanatory of the nature and purpose of the work, completes the volume.

It is indeed fitting that the wheat industry in New Zealand should receive attention at this particular time. A stage has been reached in the rural industries of the Dominion which is causing some anxiety. The present tendency towards pastoral farming, it is said, is causing such an efflux of labour and capital from purely agricultural pursuits that these are becoming endangered. The persistent decline in wheat production during the past decade has occasioned much apprehension in the community generally, and it is thought that our home supply will not satisfy the demands of local consumers. The expectation of a large permanent importation has brought the problems eonnected with the wheat industry prominently before the public mind, and has recently induced much discussion by all classes of the community. But there is need of reliable information and general principles to assist discussion, and the hope that this work may do something towards achieving this end, is the main motive for presenting it to the public. It may be claimed that the investigation is not merely of particular interest to the individual industry in which it is undertaken; for although the opportunity and necessity for research work are equally great, very little has been done in the sphere of scientific economic research in New Zealand. "We have no sufficient means of forming a precise estimate of our 
economic condition except in the most general outline," and there is little reliable information at the service of those "anxious to frame equitable measures adequate to a given set of conditions and eager to persuade the people of their efficiency." Recently, a number of investigations into economic questions in New Zealand has clearly illustrated the disadvantages under which we are working, and proved adequately the necessity for such research work. It is claimed for this work that it is one of a number which have for their purpose the dissemination of accurate information on the economic life of the Dominion, the lack of which, at present exposes us to severe criticism.

The rural industries have been sadly neglected in this matter, though they offer a comparatively easy field to the enterprising research student, and are subject, more than any other group, to unenlightened criticism by the general mass of men. They are, indeed, our primary industries, forming the basis of our national life. The present work must be regarded as merely a prelude to further work, both intensive and extensive, on such a vast field, and if it is the means of stimulating greater interest in such important problems as those of the wheat industry, the author will be encouraged to extend its scope and usefulness, when the opportunity offers.

The culmination of a great decline in wheat production, co-existent with the disturbing social and economic conditions caused by the titanic struggle in the Old World, should give to the work an element of practical value in the immediate future.

The work is by no means an exhaustive treatment of so great a question. At many points I have been forced to abandon interesting and profitable lines of discussion, in the endeavour to solve completely the main issues, which the problem presented at the outset. But the extent and complexity of these have exceeded expectations, and the results of the investigation, as far as it has gone, are increased interest in the work, and added enthusiasm to pursue it further.

I have endeavoured throughout to keep well in mind the possibility of forecasting from reliable data the probable tendencies in wheat production in both the immediate and the ultimate future. This is the main function of an historical investigation; to use a knowledge of the past for a better understanding of the present, in the hope that tendencies may be accurately indicated and measured. But $I$ have frequently sought indications of concrete representation of the $a$ priori 
conclusions of pure economics, while at the same time using theoretical knowledge for the explanation of particular phenomena. In this way the problem has been attacked from the two sides-deduction and induction-with, I hope, due appreciation of both pure theory and historical analysis.

The sources of information have been many and varied. The "Statisties of New Zealand," as published from year to year, contain statistics of production, acreage and yield, for the separate provinces since 1869; of importation and exportation since 1853; of population since 1853; and of rainfall, wind, temperature, etc., at several meteorological stations since the early sixties. It is not necessary to point out here the defects in this information. They are adequately indicated in the text. "The New Zealand Official Year Book," issued annually since 1892, gives a complete summary of the statistics, but does not contain adequate analysis and explanation. Useful articles, however, on agriculture and related subjects, appear from time to time, and these have been drawn on extensively. Much information has been collected directly from farmers, and though the result of the quest was not wholly encouraging, it was not altogether fruitless. The other sources of information I have set out in the Bibliography, where a complete list of the books and publications used is given. But I must mention particularly Dondlinger's "Book of Wheat," Hunt's "Cereals in America," and McIlraith's "Course of Prices in New Zealand,' all of which have been of the most valuable service. Where the work of others has been drawn upon, it has been duly acknowledged, though much of it is presented in different form. But most of the work of this essay is the result of first-hand information from official sources; as given in the "Statisties of New Zealand," and "The Official Year Book." The results of personal investigations among farmers and others connected with the industry, together with practical experience in rural work, have also proved very valuable, while the services rendered by investigators in other countries, notably Australia and the United States, are inestimable.

A treatise on rural economics for the Dominion should prove pleasant reading, quite apart from the wealth of information which it would contain for the economist, the student, and the general public. Such a work is scarcely yet contemplated in New Zealand, but it is hoped that the present study of only a small section of the whole field, may stimulate sufficient interest for the enterprising student to undertake the more 
ambitious task, if it does not, indeed, serve as an introduction. The practical value of the questions discussed, has strongly appealed to me, and it can fairly be claimed that the work is not merely of academic interest. Indeed, it is mainly in the hope that the treatment may prove helpful to farmers, public men, and all interested in the rural industries, that $I$ have decided to publish the work. Should this prove to be the case, it will bring only added pleasure to the author; for already the investigation has afforded more than adequate satisfaction for the labours of preparation.

My thanks are due to all who have helped me in the preparation of the work-and they are many. To the farmers of Canterbury I am grateful for the readiness with which they responded to the many requests $I$ made of them. The various Government Departments which I approached were also always anxious to assist me with statistical material and other information at their disposal. In particular I must acknowledge gratefully the help which Mr. Malcolm Fraser, Government Statistician, tendered me in this respect. My thanks are due also to Mr. Edwin Hall, of Onehunga, and Dr. Hilgendorf, of the Canterbury Agricultural College, both of whom read the MS., and made many valuable suggestions. Finally, I must tender my special thanks to my teacher, Dr. James Hight, of Canterbury University College, whose guidance and encouragement while I was preparing the work were invaluable. He read the MS., as it appeared, and afterwards undertook to watch the book through the press, and correct proofs. It may be stated that this work is but one of many on similar topies, which have been prepared recently at Canterbury University College under Dr. Hight's guidance.

D. B. COPLAND,

University of Tasmania,

Hobart,

June 30th, 1918. 


\section{INTRODUCTION}

This book is built on the results of one of a series of investigations by students of Canterbury University College whilst proceeding to the M.A. Degree in Economics. Its publication has long been delayed by conditions created by the war, and is possible now only through the public spirit of the author and the publishers who make it available in the hope that it may help to form a sound public opinion on an industry which has for the last few years been thrust unpleasantly into public notice through the shortage of home-grown supplies of wheat, difficulties of importation, high prices, and the inconveniences of government regulation.

Nearly nine years ago I wrote of a similar investigation, "As there is no University Press in New Zealand, the Government of the Dominion generously undertook to print and publish the essay,* and it is hoped that the official interest thus shown will grow and bear fruit in the national endowment of research." Since that time there has been much talk all the world over of "national endowment of research," but in New Zealand very little practical provision has been made, either by pubic institutions or privately, for the active encouragement and effective support of research in the economic sphere.

In selecting subjects for economic enquiries, students have been encouraged to choose from those presented by the primary industries of the Dominion, as these provide the great bulk of our wealth and control the common welfare. As a recent writer on this country has happily observed, $\dagger$ New Zealand is "a remote farm," with pastoral farming in its two main branches as its chief economic activity, and agriculture as the handmaid to the more profitable sheep-raising and dairying. Yet the economic side of the pastoral and agricultural industries has not received its due share

*Course of Prices in New Zealand, by Dr. J. W. McIlraith.

†J. B. Condliffe, in The Economic Journal, June, 1919, p. 167. 
of attention from the Government, either directly or indirectly through the University institutions. There is a marked tendency to increase the supply of expert technical knowledge, founded on the latest developments of physical, chemical, and biological researches, made available to the farmer by the national funds, and rightly so, but there has been a general failure to appreciate correctly the practical value of research in the economic factors of farming. To the farmer it should seem as important to attend to the selection of the right type of crop, to analyse relative costs, to compare marketing and transport methods and charges, as it is to study manuring and plant-breeding. From the point of view of the nation, there is a clear duty to see that every industry is functioning so as to co-operate with the others in reaching the highest possible degree of national welfare. Economic research to attain this end was never so much needed as to-day, when a large proportion of the lands of the country has passed into the hands of purchasers at values greatly inflated by expectations that the present good times will continue indefinitely, when experts tell us that the world as a whole is faced with the spectre of diminishing returns in agriculture, and when moral duty summons up every effort to rescue millions in the older lands from the brink of starvation. While New Zealand has been borne along on a constantly rising general level of prices of farming products, politicians have rarely recognised any obligation to analyse the organisation of our natural resources and the industries directly founded on them; but if, as now seems likely, we are to be faced with a continuous fall in the prices of our produce, it is essential to well-being that we should know how to utilise these resources in the best possible way. Not the least useful lesson to be drawn from comprehensive surveys of an industry like the following is the warning written plain in its history that a present wave of prosperity, however buoyant it may seem, should not be regarded as permanent or even likely to last through the experience of an ordinary business life. 
One of the most ultimately profitable steps the central or local governments could take is the institution of a comprehensive economic survey of the primary industries. This should reveal such results as the most suitable districts for each type of farming and the most economical size and general lay out of farms for each type. The problems of rural credit and finance, of transport, of co-operation, of costing and relative prices, of marketing, taxation, land-tenure, and land-values are questions primarily of economic investigation. At the present time the farmer must rest content, for lack of expert advice, to do what no other business man does in the same degree, produce in partial ignorance of his costs and market prospects.

Before there can be any really effective teaching of the farmer, there must be a great extension of research to provide the data. In order to direct research into the proper channels and make it adequate in amount and effective in quality and results, large funds are required to establish and equip lectureships in Rural Economics at the University Colleges and to ensure prompt publication of the results of research. Between the occupants of these posts and the farming community, on the one hand, and the Government Departments concerned with agriculture, on the other, there should be the closest relations so that theory and fact should go hand in hand. Such relations would be fostered by that frequent interchange between the professorial, Government, and business posts which has proved so generally beneficial in America both to the Universities and to business and farming practice.

It is hoped shortly to supplement the present work by a full enquiry into the history of the wheat and flour industry in New Zealand during the war, with special reference to the Government Wheat Control.

Canterbury University College, J. HIGHT.

Christchurch, July 29th, 1920. 



\section{CONTENTS.}

\section{Preface}

Introduction, by J. Hight, M.A., Lit.D.

Chapter I.-The Consumption of Wheat.

1. Uses of Wheat

2. Consumption in New Zealand ..

3. The Markets of the World

4. Technique of Marketing

5. Marketing in New Zealand

.$\cdot$

Chapter II.-The Production of Wheat.

1. Geographical Distribution of Wheat Producing

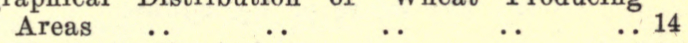

(a) Northern Hemisphere $\quad$. $\quad$. $\quad \ldots 14$

(b) Southern Hemisphere $\quad$. $\quad$. $\quad$. 15

2. Description and Explanation of Areas $\quad . . \quad 17$

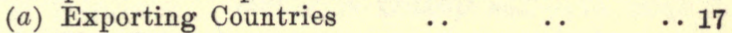

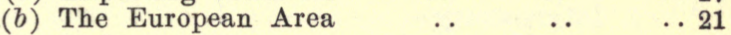

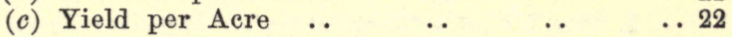

3. Conditions Necessary for Profitable Production .. 23

(a) Soil and its Amendments

(i.) Choice of Soil; (ii.) Use of Fertilisers.. 23

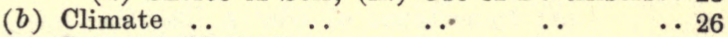

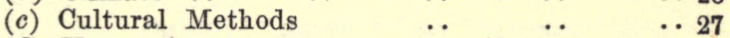

$\begin{array}{lllll}\text { (d) Harvesting } & \ldots & \ldots & \ldots & \ldots 28\end{array}$

$\begin{array}{lllll}\text { (e) } \text { Marketing } & \ldots & \ldots & \ldots & \end{array}$

Chapter III.-General Conditions in New Zealand.

1. Suitability for Wheat Production $\quad . . \quad \ldots 30$

(a) The North Island $\quad \ldots \quad$. $\quad \ldots 30$

(b) The South Island $\quad$. $\quad \ldots \quad \ldots 30$

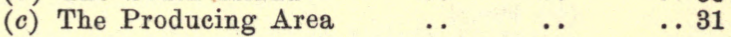

$\begin{array}{lllllll}\text { 2. Soils } & . & \ldots & \ldots & \ldots & \ldots & \ldots 33\end{array}$

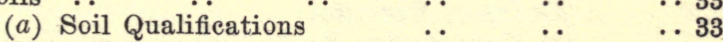

(b) A Soil Survey $\quad . \quad \ldots . \quad \ldots \quad \ldots 35$

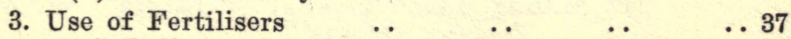

$\begin{array}{lllll}\text { (a) Indirect } \ldots & \ldots & \ldots & \ldots & \ldots 38\end{array}$

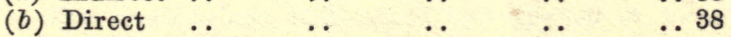




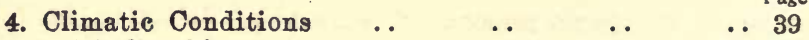

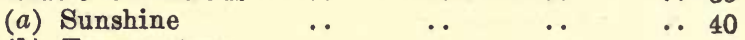

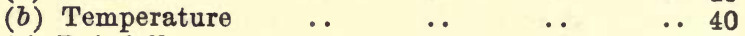

(c) Rainfall .. $\quad$.. $\quad \ldots \quad \ldots \quad \ldots 40$

(d) Observations on the Connection Between Yield and Rainfall ..

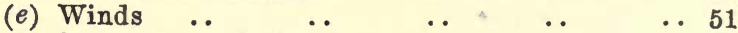

(f) Summary and Conclusions $\quad \ldots . \quad \ldots 5$

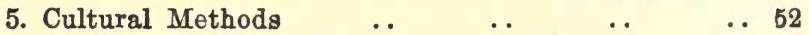

6. Harvesting $\ldots \quad \ldots \quad \ldots \quad \ldots 4$

Note on "the harvester" $\quad \ldots \quad \ldots 55$

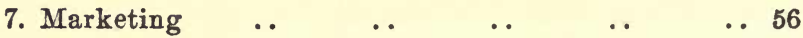

8. Labour Conditions $\quad \ldots \quad \ldots \quad \ldots \quad \ldots \quad \ldots 9$

(a) Necessity for Skilled Labour $\quad \ldots \quad$. . 59

(b) Characteristics of Farm Labour .. $\quad$.. 60

(c) Farm Labour and Trade-unionism .. $\quad \ldots 61$

(d) Labour Bureaux .. $\quad \ldots \quad \ldots 62$

(e) Seasonal Labour .. $\quad \ldots .62$

9. Government Encouragement $\quad \ldots \quad$. $\quad \ldots 63$

(a) Experimental Farms $\quad \ldots \quad \ldots 63$

(b) The Board of Agriculture $\quad \ldots \quad \ldots 65$

10. Survey and Conclusion $\quad \ldots \quad \ldots 66$

Chapter IV.-The Quality of Wheat.

1. Introductory $\quad \ldots \quad$.

2. The Miller's Coneeption of Quality $\quad \ldots \quad \ldots 68$

$\begin{array}{llllll}\text { (a) Impurities } & \ldots & \ldots & \ldots & \ldots & 69\end{array}$

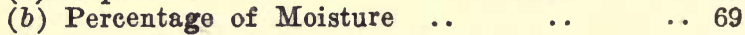

(c) Strength $\quad \ldots \quad$.

(d) Importance of Gluten Content $\quad \ldots \quad \ldots 70$

3. "Strong" and "Weak" Wheats .. .. 71

4. Factors Fostering Strength _. $\quad \ldots \quad$.. 72

$\begin{array}{llllll}\text { (a) Soil } & \ldots & \ldots & \ldots & \ldots & \ldots 72\end{array}$

(b) Climatic Conditions $\quad \ldots \quad \ldots 72$

(c) These Factors in New Zealand .. $\quad .73$

5. New Zealand Varieties $\quad$.

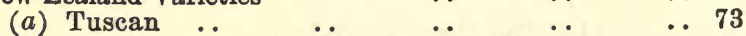

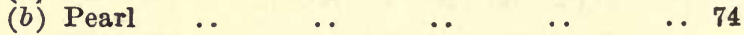

$\begin{array}{llllll}\text { (c) Hunter's } & \ldots & \ldots & \ldots & \ldots 75\end{array}$

(d) Other Varieties .. $\quad \ldots \quad$.

(e) Comparative Production of these Varieties .. 76

$(f)$ Milling Products and "Strength" of New

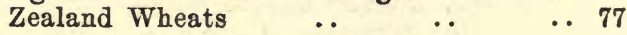

$\begin{array}{lllllll}\text { 6. Survey } & \ldots & \ldots & \ldots & \ldots & \ldots 78\end{array}$ 
Chapter V.-Improvement of Wheat by Selection in New Page Zealand (contributed by F. W. Hilgendorf, D.Sc.,

Biologist to the Canterbury Agricultural College).

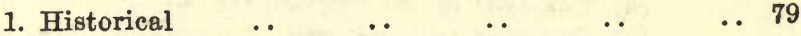

2. Choice of a System for New Zealand .. $\quad \ldots 82$

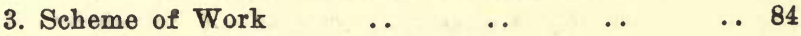

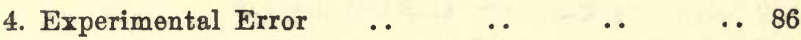

5. Details of Experimental Work .. $\quad \ldots \quad \ldots 88$

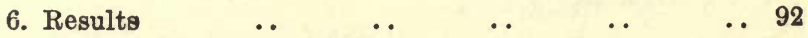

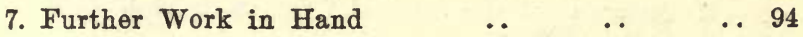

Chapter VI.-History of Wheat Production in New Zealand.

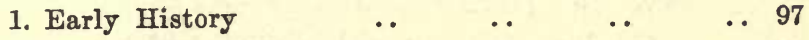

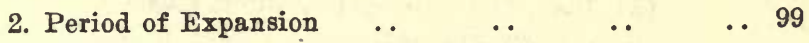

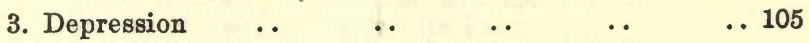

4. The Rise of "High" Farming .. $\quad \ldots \quad$.. 107

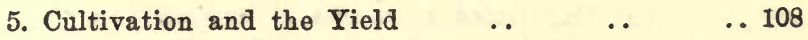

6. Cyclical Changes of Production $\quad . . \quad \ldots 115$

$\begin{array}{llllll}\text { (a) } 1869-1876 & \ldots & \ldots & \ldots & \ldots & 115\end{array}$

$\begin{array}{lllll}\text { (b) } 1877-1886 & \ldots & \ldots & \ldots & \ldots 115\end{array}$

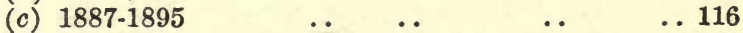

$\begin{array}{lllll}\text { (d) } 1896-1902 & \ldots & \ldots & \ldots & \ldots 116\end{array}$

(e) $1902-1913 \quad \ldots \quad \ldots 116$

7. Relation between Supply and Price $\quad . . \quad \ldots 118$ Correlation

.. 121

8. Competition of Other Industries for the Use of the
(a) Sheep-farming
(b) Dairy-farming

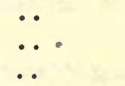
.. 123
.. 123

9. Competition of Other Countries

Effect of English Prices on the Export of Wheat from New Zealand ..

10. Conclusion $\quad \ldots \quad$..

Chapter VII.-The Price of Wheat.

1. General Remarks on Price Determination .. 133

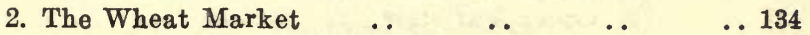

3. Supply and Demand .. $\quad \ldots \quad \ldots 137$

(a) Factors on the Supply Side $\quad$.. $\quad .138$

(b) Factors on the Demand Side $\quad . .139$

(c) The Equilibrium of Demand and Supply .. 139 
4. Reactions of Price: Normal Price $\quad \ldots \quad \ldots 141$

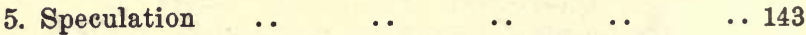

(a) The Rise of the Speculative Market $\quad \ldots 144$

(b) Speculative Functions $\quad \ldots \quad \ldots 146$

(c) Beneficial Effects of Speculation .. $\quad . .147$

(d) The Assumption of Risks by the Speculative Class

(e) Alleged Evils

.. 149

(f) Conclusion

.. 151

.. 153

6. Influence of the Area of Production on the Stability of Price .. $\quad$. $\quad$.. $\quad$.. $\quad \ldots 155$

7. Price of English Wheat $\quad \ldots \quad \ldots 157$

(a) The Period of 1860-75: Rising Prices ․ 159

(b) The Period 1876-95: Falling Prices .. 162

(i.) Relation of wheat prices to the general level; (ii.) Explanation of the position in the period; (iii.) Expansion in production 164

(c) The period from 1896: Rising Prices .. 166

(i.) Causes of the rise; (ii.) Absence of violent fluctuations; (iii.) Relation of wheat prices to the general level $\quad \ldots \quad \ldots 169$

8. Price of New Zealand Wheat .. $\quad \ldots \quad \ldots 170$

(a) 1860-73: Slightly Rising Prices .. . . 170

(b) 1873-94: Falling Prices . . $\quad \ldots \quad \ldots 172$

(c) The Period from 1895: Rising Prices .. 174

9. English and New Zealand Prices Compared .. 175

10. Price Steadiness $\quad \ldots \quad$.

Chapter VIII.-Leading Features of the Wheat Industry in the Last Period (1895-1914).

1. Retrospect .. 183

2. Reasons for Choosing 1895 as the Commencement of the New Period .. $\quad . . \quad$.. $\quad . .185$ 3. Land ..

(a) Definition of the Region under Investigation 186

(b) Supply of Land .. $\quad$. $\quad$. . $\quad \ldots 188$

(c) Occupation of Land $\quad \ldots \quad$.. $\quad \ldots 190$

(i.) Relation of freehold and leasehold .. 190

(ii.) Effects of 999 years land tenure system.. 191

(iii.) The present land tenure system .. 193

(d) Size of Holdings .. $\quad \ldots \quad \ldots 195$ 
4. Labour

(a) Rural Depopulation _. $\quad$.. $\quad \ldots 198$

(b) Movements in Rural Population .. .. 199

(c) Causes of the Relative Decrease in the Supply $\begin{array}{lllll}\text { of Labour } & \text {. . . . . } & & & \\ & & \end{array}$

(i.) The failure of the education system .. 200

(ii.) Increased demand for town labour .. 201

(iii.) Higher town wages .. .. .. 201

(iv.) Inadequate provision for married workers 202

(d) Some Remedies .. . . . .. ..203

(e) The Importance of the Labour Problem ..2 203

5. Capital

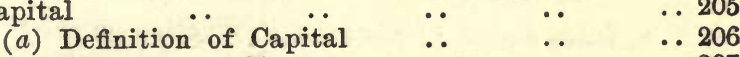

(b) Financing of Farmers _. . .

6. Organisation $\quad . \quad \ldots \quad \ldots \quad \ldots 209$

(a) Managing Capacity Necessary in Farming .. 209

(b) Methods of Cropping (. $\quad$.. $\quad . .210$

(c) A Rotation System $\quad$. $\quad \ldots \quad$.. 212

(d) General Lay-out of Farms $\quad$.. ..2 214

Chapter IX.-Cost of Production.

1. A Controversial Question _. $\quad \ldots \quad \ldots 217$

2. Meaning of Cost of Production .. $\quad$.. $\quad$..2 218

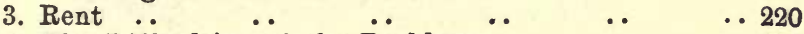

4. The Difficulties of the Problem .. $\quad . . \quad \ldots 222$

5. Previous Work in Estimating Cost of Production .. 225

6. The Presentation of Data from Representative Farms

8. Cost of Production and Market Price $\cdots$

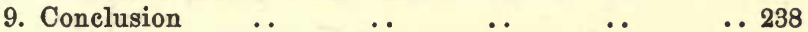

Chapter X.-Related Topics.

1. The Flour Millers' Association .. • .. $\quad . .242$

(a) The Origin and Nature of the Flour Millers'

Association $\quad . \quad$.. .. $\quad . .243$

(b) The Operations of the Association .. $\quad \ldots 245$

(c) Monopoly aimed at $\quad \ldots \quad \ldots 247$

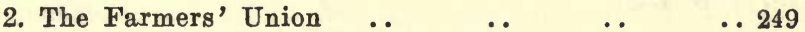

(a) General Principles $\quad$.. $\quad \ldots . \quad \ldots 249$

(b) The General Nature of the Union. 250

(c) The Objects of the Union $\quad \ldots \quad \ldots 252$

3. Protection for the Wheat Industry $\quad . . \quad \ldots 255$

(a) Protection in New Zealand .. ..255

(b) General Effects of Protection . . . 257

(c) Some Arguments for Protection to the Wheat Industry $\quad$. $\quad \ldots \quad$.. $\quad$.. 260

(d) General Freetrade would Beneft the Farmer 265 
4. Public Control of Prices

(a) Wheat Prices during the Wor

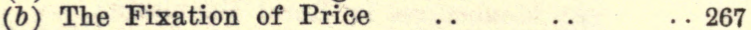

(c) The Causes of the Recent High Prices . 270

(d) The Problem of Price Control .. $\quad \ldots 273$

(e) The Policy of Commandeering the Supply . 279

Chapter XI.-Conclusion.

1. The Aim of the Investigation .. $\quad$.. $\quad$.. 282

2. The Importance of the Wheat Industry to New Zealand .. $\quad$.

3. Some Subjects for Further Treatment $\quad \ldots \quad$.. 287

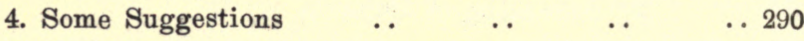

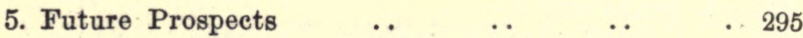

Appendix I.-Some New Zealand Wheat Statistics _.. 299

Table XXXVIII.-Exports, Imports, Total Production, Prices,

Price of Agricultural Land in New Zealand

Table XXXIX.-Areas in Acres for New Zealand, Canterbury and Otago, with Total Yields and Populations $\quad . .300$

Table XL.-Yields for New Zealand, Canterbury, and Otago in bushels per acre, with decennial moving averages

Table XLI.-Comparison of Index Numbers of Areas for New Zealand, Canterbury, and Otago, with Yields per acre

Appendix II.-The Meaning of Correlation

. 303

Appendix III.-The Calculation and the Use of Index Numbers

Bibliography

. 308

Index

.. 310 


\section{LIST OF TABLES}

I. Average Annual Production, and Average Annual Imports in Importing Countries $\quad \ldots \quad \ldots \quad \ldots \quad \ldots \quad 5$

II. Average Annual Production, and Average Annual

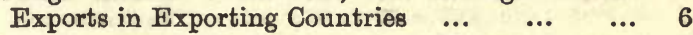

III. Monthly prices in Christchurch from February, 1898,

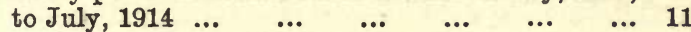

IV. Annual Average Production in Producing Areas

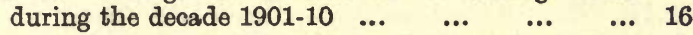

V. Possible Extension of Production in Australis ... 20

VI. Wheat Production in Australia 1916-17 ... $\ldots .21$

VII. Average Annual Yield per acre (1902-11) in leading $\begin{array}{llllllll}\text { countries } & \ldots & \ldots & \ldots & \ldots & \ldots & \ldots & 22\end{array}$

VIII. Available Plant Food in New Zealand Soils ... $\quad . .34$

IX. Temperature in Canterbury and Otago $\ldots$. $\quad 40$

X. Correlation between Yield per acre for Canterbury $\begin{array}{lllll}\text { and rainfall (May-November) } & \ldots & \ldots & \ldots & 42\end{array}$

XI. Correlation between Yield per acre for Victoria and composite winter rainfall (May-October) at $\begin{array}{lllllll}\text { several stations } & \ldots & \ldots & \ldots & \ldots & \ldots & 48\end{array}$

XII. Wheat Yield and Rainfall:

Canterbury (1871-1913), Victoria (1884-1913), Lincoln College (1906-1914), Roseworthy College (1904-14)

XIII. Moisture in Fallowed and Non-fallowed Land at Rutherglen College, Victoria ... ... ...

XIV. Yield of Wheat grown on Fallowed and Non-fallowed

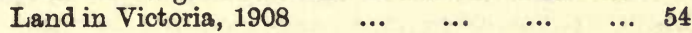

XV. Milling Products of New Zealand Wheats $\ldots . \quad \ldots \quad 77$

XVI. Strength of Flour from New Zealand Wheats $\quad \ldots \quad 77$

XVII. The New Zealand Varieties judged by Points $\ldots 78$

XVIII. Correlation between Supply and Price for New

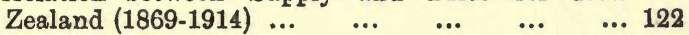

XIX. Increases in the Prices of Wool, Frozen Mutton and Wheat during the Decade 1900-1909 _.. $\quad$... 126

XX. Annual net Exports of Exporting Countries, which competed with New Zealand, during the last three Decades 
XXI. New Zealand and English Prices (1881-1900) _.. 130

XXII. European Weekly Distribution or Deliveries to Consumption of Imported Wheat ... $\quad \ldots \quad \ldots 157$

XXIII. Imports of Wheat into England in Million Cwts. Quinquennial Periods 1851-1880 $\ldots \quad$... $\quad \ldots 165$

XXIV. Average Annual World's Production of Wheat during the Decades 1881-90, 1891-99, 1900-9, and years

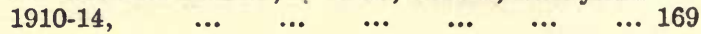

XXV. Annual Average Prices of English and New Zealand Wheat in years of low production in New Zealand 177

XXVI. Average Annual Prices of New Zealand and English Wheat in years of high yield in New Zealand ... 178

XXVII. English and New Zealand Wheat Prices, with Calculation of Co-efficient of Variation and Mean Yearly Movement, 1880-1914

XXVIII. Comparison of area under freehold with area under leasehold in Canterbury and Otago $\quad . . \quad$... 195

XXIX. Size of Holdings in Canterbury and Otago $\ldots . \quad \ldots 196$ XXX. Comparison of total breadwinners in New Zealand with the number in the rural industries in the census years $1901,1906,1911 \quad \ldots \quad \ldots \quad \ldots 198$

XXXI. Number of people occupied in the leading rural industries in the census years 1901, 1906, 1911 ... 199

XXXII. Analysis of the numbers occupied in the rural industries in the census years 1901, 1906, 1911 ... 199

XXXIII. Cost of Production : Estimate I $\quad \ldots \quad \ldots \quad$... 226 XXXIV. Cost of Production : Estimate II $\quad \ldots . \quad \ldots \quad \ldots 227$

XXXV. Cost of Production : Estimate III $\quad \ldots \quad$... $\quad \ldots 229$

XXXVI. Cost of Production on three "Representative Farms" 233

XXXVII. Monthly Prices of Wheat and Flour from January 1914 to June $1916 \quad \ldots \quad \ldots \quad \ldots \quad \ldots \quad \ldots 269$

XXXVIII. Exports, Imports, Total Production, Prices, Price of Agricultural Land in New Zealand $\quad . . \quad$... 299

XXXIX. Area in acres for New Zealand, Canterbury and Otago, with Total Yields and Populations... $\quad \ldots \quad \ldots 300$

XL. Yields for New Zealand, Canterbury and Otago in bushels per acre, with decennial moving averages 301

XII. Comparison of Index Numbers of areas for New Zealand, Canterbury and Otago, with yields per acre... 


\section{LIST OF GRAPHS}

I. Average Monthly Prices from February 1898 to January $\begin{array}{lllllllll}1914 & \ldots & \ldots & \ldots & \ldots & \ldots & \ldots & \ldots & \ldots\end{array}$

II. Area under Wheat in New Zealand compared with sum of areas for Canterbury and Otago (1869-1914) $\quad \ldots \quad 32$

III. Annual fluctuations in yield per acre, and rainfall (MayNovember) for Canterbury (1871-1917) ... $\quad \ldots \quad \ldots \quad 44$

IV. Yield per acre, total rainfall, and "useful" (MayNovember) rainfall at Lincoln College (1906-17) _.. 45

V. Yield per acre, and composite winter rainfall (MayOctober) for Victoria (1884-1913) $\quad \ldots \quad \ldots \quad \ldots \quad 47$

VI. Wheat Improvement at Lincoln College; Graph showing yields of Commercial Seed and three strains of Hunter's $\begin{array}{lllllllll}(1913-14) & \ldots & \ldots & \ldots & \ldots & \ldots & \ldots & \ldots\end{array}$

VII. Annual fluctuations in Imports with decennial moving

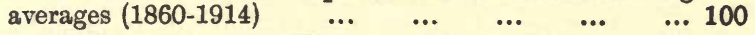

VIII. Annual fluctuations in Exports with decennial moving

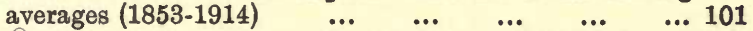

IX. Annual fluctuations in supply with General trend (decen-

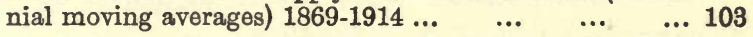

$X$. Annual fluctuations in Price of Agricultural Land in Canterbury (1870-1914)

(Compiled by Mr. F. R. Callaghan M.A., in his investigation into "The History of Land Values in $\begin{array}{llllllll}\text { Canterbury ") } & \ldots & \ldots & \ldots & \ldots & \ldots & \ldots & 104\end{array}$

XI. Decennial moving averages in acreage and yield per acre for Canterbury (1869-1914) $\quad \ldots \quad \ldots \quad \ldots \quad \ldots \quad 110$

XII. Decennial moving averages in acreage and yield per acre for Otago $(1869-1914) \quad \ldots \quad \ldots \quad \ldots \quad \ldots \quad \ldots 111$

XIII. Annual fluctuations in yield per acre for New Zealand with decennial moving averages (1869-1914) $\quad \ldots \quad$... 113

XIV. Annual fluctuations in Supply and Price (1869-1914) $\quad$... 120

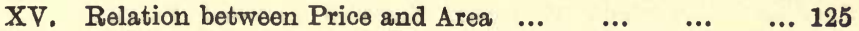

XVI. Annual fluctuations in English and New Zealand Wheat $\begin{array}{llllllll}\text { Prices }(1869-1914) & \ldots & \ldots & \ldots & \ldots & \ldots & \ldots & 158\end{array}$

XVII. Decennial moving averages in English and New Zealand

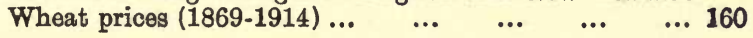




\section{STATISTICAL INVESTIGATIONS}

I. Table X.-Correlation between Yield per Acre for Canterbury

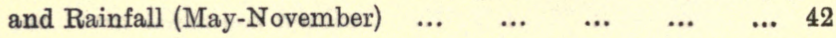

II. Table XI.-Correlation between Yield per Acre for Victoria and Composite Winter Rainfall (May-October) at several $\begin{array}{lllllllll}\text { stations } & \ldots & \ldots & \ldots & \ldots & \ldots & \ldots & \ldots & \ldots\end{array}$

III. Table XVIII.-Correlation between Supply and Price for New

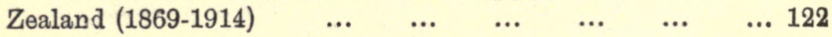

IV. Table XXVII.-Calculation of the Co-efficient of Variation for English and New Zealand Wheat Prices and Mean Yearly

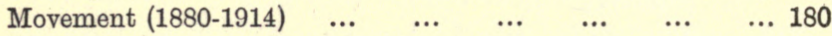

V. Tables XXXIII-V.-Calculation of Cost of Production of $\begin{array}{llllllllll}\text { Wheat } & \ldots & \ldots & \ldots & \ldots & \ldots & \ldots & \ldots & \ldots & 226\end{array}$ 


\section{Wheat Production in New Zealand.}

Chapter I.

\section{THE CONSUMPTION OF WHEAT.}

\section{Uses of Wheat.}

The wheat industry is so widely distributed, and its products are of such universal service, that it is necessary to consider briefly the important factors of marketing and consumption in the great wheat producing areas before discussing in greater detail the problems which the industry gives rise to in our own field of production. From the earliest time the product has been used as a human food. The traditional use of wheat for bread has not only blinded our vision to the variety of uses to which wheat may be adapted, but it has also deadened enterprise in the production of other foodstuffs.

The main product of the industry is flour, the chief ingredient in many varieties of foodstuffs other than bread. These foodstuffs owe their growing popularity not so much to their superiority in sustaining life as to their greater palatability and general attractiveness. The manufacture of crackers or biscuits, an important foodstuff from the wheat industry, is now a trade peculiar to itself, while macaroni, one of the latest products of the industry, in its numerous forms, is a palatable and nutritive food. It is relatively 
inexpensive, and is replacing to some extent those meat dishes which are becoming costly. Originating in Italy, its production is now practised extensively in the United States, where about 100,000,000 lbs. are made annually from home-grown Durum wheat, a quantity which supplies only about one-half the demand. Vermicelli is a kindred production which is becoming increasingly popular. A further important class of foods are the "ready to eat" or "breakfast" foods, which are manufactured in large quantities in the United States.

In addition to these products the wheat industry furnishes many useful by-products, the chief of which are bran, middlings, and sharps, the demand for which is increasing as knowledge of their value as food for stock is becoming more widely spread. Lastly, wheat straw, the strongest of straws, is in general demand for a variety of uses in most countries.

It is thus apparent that the products and byproducts of the wheat industry are of far-reaching importance to mankind. Their utility is enhanced greatly by the variety of the methods of their consumption, and it is certain that no other product is of such vital importance for the sustenance of life.

Statistics of consumption show not only that the wheat product is consumed widely, but also that its consumption per head is often very high.* Moreover, there is sufficient evidence to support the conclusion that the consumption of wheat is increasing at a greater rate than the population in most countries. $\dagger$

\section{Consumption in New Zealand.}

In New Zealand the use of wheat is confined mainly to the production of bread from flour. The more important by-products are also produced, while wheat

*Dondlinger, "The Book of Wheat," p. 302.

tSee Webb's "Dictionary of Statistics," and "The Statistics of the International Bureau of Agriculture at Rome," which is used extensively in this investigation. 
straw is of especial importance on the farm. The production of these commodities has given rise to a flour-milling industry employing 66 mills in 1910, with a production of flour to the value of $£ 1,248,000$, while the production of bran and pollard is considerable.

New Zealand is considered as an exporter of wheat, but very often her total supply is almost wholly consumed at home." For the years 1907-8 the quantities exported were only 1,374 and 1,385 bushels respectively, while, owing to a general scarcity at the close of 1914, the Government made arrangements for the purchase and import of considerable quantities from Australia and Canada to meet the local deficiency. The "New Zealand Official Year Book" for the past ten years $\cap$ has estimated the consumption per head of the population at six bushels. From more recent statistics it appears that there has been a rise in the per capita consumption. For the decade 1904-13 ! have estimated the average annual per capita consumption by using statistics of exportation, importation, production, acreage, and population in the following manner:-From the total of production and importation the amount exported has been deducted together with the amount used for seed for the new crop, calculated by taking the amount of seed wheat per acre at 2 bushels. This latter calculation is inclined to exaggerate the amount used for seed, but most land in New Zealand requires from $1 \frac{1}{2}$ to 2 bushels per acre, and as much is sown late in the year the amount is more often nearer 2 bushels than $1 \frac{1}{2}$, hence the exaggeration is but slight.

The amount obtained after these calculations is taken as the consumption for the Dominion, and the per capita consumption estimated from this.

The calculations thus obtained were as follows, the

*Circumstances which have rendered the importation of small quantities necessary during the past three years may be considered as extraordinary. 
average annual amounts for the period 1904-13 in bushels being given in each case :-

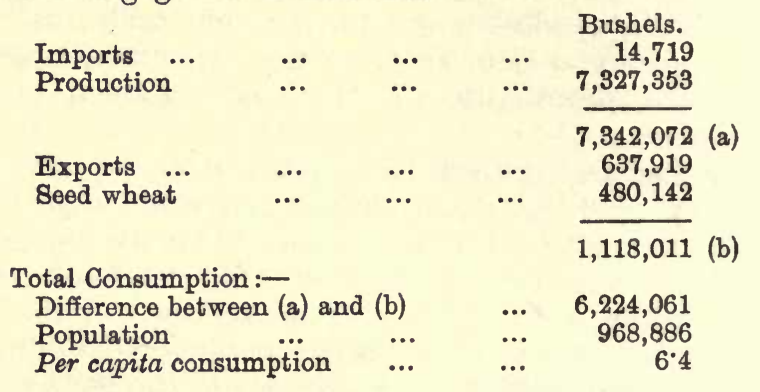

The calculation should prove a sufficiently close approximation to be reliable; for the period over which it was made is of such a length as to eliminate yearly disturbances, and, moreover, as shown by statisties of price and production, the period is a normal one. The exports at the beginning and end are not strictly relevant to the calculation, for it is not certain how far exports in 1904 were confined to the crop of that year, whereas the exports of 1914 may contain some of the crop of 1913. But these errors act in opposite directions, and as such, being unbiassed errors, their relative importance is not great.

From this calculation it appears that the amount required for home consumption is considerably more than six million bushels, and a glance at the statisties of production for recent years will show that this amount has not been reached at several harvests. Thus in 1902 only four million bushels were produced, while in 1907 and 1908, and again in 1913 and 1914, the amount fell short of what, according to my estimate, was required for consumption by about 500,000 bushels. Importation to this amount was not resorted to because of the relatively large supplies of previous years in each case, a certain amount of which apparently was held over. Nevertheless, it is obvious that on the occurrence of a number of "lean" years in succession such importation would be necessary. 


\section{The Markets of the World.}

The marketing of a commodity so universally consumed as wheat is certain to vary greatly in different countries. The market for wheat in some countries displays all the features of the most highly specialised market created by the mechanism of exchange under modern economic conditions, while in others it is wholly unorganised and little in advance of medieval conditions. Sale by grade, future dealings, the rise of speculative dealers, the modern corn exchange, these are the characteristics of a market such as that of Chicago. But the organisation of marketing does not concern us here so much as the geographical distribution of markets. The markets may be divided into two classes:-

(1) Those which require foreign supplies to meet the home demand. These markets are situated for the most part in Europe, but in the Far East a small demand for foreign wheat has grown up.

The comparative strengths of these markets may be seen from the following table, showing average annual production of wheat and average annual imports of the chief importing countries during the last three decades :-

TABLE I.

\begin{tabular}{|c|c|c|c|c|c|c|c|c|c|}
\hline \multirow{2}{*}{ COUNTRIES } & & \multicolumn{4}{|c|}{$\begin{array}{c}\text { Average Annual Pro- } \\
\text { duction in Millions of } \\
\text { Bushels }\end{array}$} & \multicolumn{4}{|c|}{$\begin{array}{l}\text { Average Annual } \\
\text { Imports in } \\
\text { Millions of Bushels }\end{array}$} \\
\hline & & $\begin{array}{c}1881 \\
\text { to } \\
1890\end{array}$ & $\begin{array}{c}1891 \\
\text { to } \\
1900\end{array}$ & $\begin{array}{c}1901 \\
\text { to } \\
1910\end{array}$ & $\begin{array}{c}1910 \\
\text { to } \\
1914\end{array}$ & $\begin{array}{c}1881 \\
\text { to } \\
1890\end{array}$ & $\begin{array}{c}1891 \\
\text { to } \\
1900\end{array}$ & $\begin{array}{c}1901 \\
\text { to } \\
1910\end{array}$ & $\begin{array}{c}1910 \\
\text { to } \\
1914\end{array}$ \\
\hline United Kingdom & ... & 76 & 60 & 55 & 59 & 144 & 177 & 209 & 201 \\
\hline German Empire & ... & 104 & 125 & 133 & 152 & 18 & 41 & 70 & 68 \\
\hline Belgium $\quad \ldots$ & ... & 18 & 16 & 13 & 15 & 21 & 39 & 46 & 49 \\
\hline Italian Peninsula & & 118 & 125 & 163 & 187 & 23 & 22 & 38 & 53 \\
\hline Holland $\quad .$. & ... & 6 & 5 & 5 & 5 & 11 & 15 & 20 & 22 \\
\hline Switzerland ... & ... & 3 & 4 & 4 & $3 \cdot 3$ & 12 & 15 & 17 & 16 \\
\hline Scandinavia & ... & 4 & 5 & 6 & 8 & 4 & 72 & 11 & 10 \\
\hline France & ... & 301 & 305 & 319 & 317 & 39 & 36 & 10 & 43 \\
\hline Iberian Peninsula & ... & 107 & 99 & 131 & 130 & 9 & 10 & 12 & 6 \\
\hline Union of 8 . Africa & .. & 2 & 2 & 3 & 一 & & - & 8 & 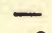 \\
\hline Egypt ... & $\ldots$ & 12 & 13 & 20 & 35 & 6 & 1 & 6 & 8 \\
\hline Japan ... & $\ldots$ & 13 & 19 & 20 & 24 & 0 & 1 & 5 & 4 \\
\hline
\end{tabular}


(2) In the second group of markets, that is, those in which the home supply exceeds the demand, are most countries of the New World, and in addition several of the Old World. The chief are the United States, Argentina, Dominion of Canada, Russia, Roumania, Australasia, India, their comparative strengths being shown by the following table:-

TABLE II.

Average annual production of wheat and average annual exports of the chief exporting countries during the past three decades :-

\begin{tabular}{|c|c|c|c|c|c|c|c|c|c|c|}
\hline \multirow{2}{*}{\multicolumn{3}{|c|}{ COUNTRIES }} & \multirow{2}{*}{\multicolumn{4}{|c|}{$\begin{array}{l}\text { Average Annual Pro- } \\
\text { duction in Millions of } \\
\text { Bushels }\end{array}$}} & \multirow{2}{*}{\multicolumn{4}{|c|}{$\begin{array}{c}\text { Average Annual } \\
\text { Exports in } \\
\text { Millions of Bushels }\end{array}$}} \\
\hline & & & & & & & & & & \\
\hline & & & $\begin{array}{c}1881 \\
\text { to } \\
1890\end{array}$ & $\begin{array}{l}1891 \\
\text { to } \\
1900\end{array}$ & $\begin{array}{l}1901 \\
\text { to } \\
1910\end{array}$ & $\begin{array}{c}1910 \\
\text { to } \\
1914\end{array}$ & $\begin{array}{c}1881 \\
\text { to } \\
1890\end{array}$ & $\begin{array}{c}1591 \\
\text { to } \\
1900 \\
\end{array}$ & $\begin{array}{c}1901 \\
\text { to } \\
1910\end{array}$ & $\begin{array}{c}1910 \\
\text { to } \\
1914\end{array}$ \\
\hline Russia & .. & ... & 244 & 300 & 461 & 817 & 87 & 104 & 142 & 164 \\
\hline United State & & ... & 427 & 559 & 657 & 685 & 116 & 178 & 125 & 107 \\
\hline Argentine & .. & $\cdots$ & 24 & 65 & 130 & 147 & 4 & 37 & 84 & 82 \\
\hline Canada & ... & ... & 38 & 55 & 110 & 197 & 2 & 13 & 42 & 95 \\
\hline Roumania & $\ldots$ & $\ldots$ & 42 & 52 & 73 & 88 & $2 \overline{1}$ & 27 & 42 & 55 \\
\hline Australasia & $\ldots$ & $\ldots$ & 35 & 37 & 63 & 98 & 9 & 7 & 29 & 53 \\
\hline India ... & ... & ... & 259 & 243 & 294 & 350 & 33 & 23 & 27 & 50 \\
\hline
\end{tabular}

From these tables may be drawn certain definite conclusions which will be of assistance in discussing the development of the wheat industry in New Zealand, despite the fact that the annual production of wheat in the Dominion has never been more than a fragment of the world's crop.

The great market for wheat lies in Western Europe, though that continent produces more than half the world's crop. The tendency in this area is for production to fall relatively to advances in total production, population, and the progress of civilisation, and even in some cases there has been an absolute decrease in production. Until recent years the United States of America was predominant in this market, but her exports are now on the decline, while those of Russia and Roumania are increasing, and there has been a remarkably rapid increase in production in Argentina, Canada, and Australia. This expansion is one of the 
features of the statistics, and there is evidence that as wheat-growing areas these three countries have a great future before them. Lastly, it is noticeable that although wheat production has increased greatly, the supply has never been too great to find a market, and it is becoming increasingly evident that the demand will become more intense as Western ideas and practice become more established in the East.

\section{Technique of Marketing.}

Before discussing the question of marketing in New Zealand a brief account of the American method of placing the wheat crop on the market should be of interest. The practice of marketing millions of bushels of wheat within six or eight weeks after harvesting, the storing of millions of bushels at the local elevators, primary markets, and seaboard, the rise of grain exchanges, are developments of recent times in the United States, and they form the basis of the complex but efficient method of marketing the great cereal crops. The use of elevators renders the cumbersome method of handling wheat in sacks unnecessary after it has left the farm. Further, it encourages the complete development of a grading system, which in turn gives rise to the grain exchange.

The buyer of wheat is always situated within hauling distance of the producer. Two great classes of buyers are in existence-the local grain dealers and the dealers representing the terminal grain buyers. The latter class has been the main controlling factor in the producer's grain market. The railroads generally rely upon these two classes to provide the country with elevator facilities for receiving and shipping grain, and co-operate with them in this by furnishing them with adequate transportation facilities.

The grain is delivered at the nearest railway station after threshing, and there it is graded by inspectors appointed by the Government or the Board of Trade. After the wheat has been assigned to a certain grade 
it is set aside for a few days prior to mixing with the rest of the wheat in that grade, for the purpose of allowing the producer to dispute the inspector's decision. At the end of these few days of grace the wheat is mixed with quantities of the same grade and intimation that it has been received is forwarded by telegraph to the great markets of the States. At the same time the producer is given a receipt for the amount he has delivered at the depôt. These official receipts can be readily turned into eash at the local banks, and thus are instruments of credit to the farmer. At the Central wheat markets most sales are made by grades in the absence of actual samples. The great markets of the United States are at Chicago, New York, Minneapolis, Duluth, and Kansas City, where vast quantities of wheat are bought and sold each year.

Chicago, though not strictly a world's market for wheat as indicated above, is the greatest wheat market in the world, the sales amounting to as much as $250,000,000$ bushels in a year. The actual wheat received at Chicago is probably about 25,000,000 bushels; but the system of dealing in futures is so well developed that the sales amount to about ten times this quantity.

The term "future" is defined by Emery as a "contract for the future delivery of some commodity, without reference to specific lots, made under the rules of some commercial body in a set form, by which the conditions as to the unit of amount, the quality and the time of delivery are stereotyped and only the determination of the total amount and the price is left open to the contracting parties.'

The different types of speculation which the system of "futures" gives rise to and the influence of these on prices is not strictly relevant to the present discussion, but will be returned to when the factors entering into the determination of price are being discussed. It 
remains here to indicate the way the system assists in the marketing of wheat.

By dealing in "futures" the merchant who buys large quantities for sale at a future time, can insure himself against loss in the event of a fall in price. Thus, suppose our merchant sells to a speculative buyer a similar quantity of wheat to be delivered at some future time, then, if prices drop, he can buy up a quantity at reduced prices to fulfil the engagement, and so recoup himself of any loss incurred by his former transaction. In practice he does not deliver the wheat to the speculative buyer, but the transaction would be completed by the speculator paying to the merchant the difference in value due to the fall in price.

At all the other great markets in the States, the system of "futures" is a distinctive characteristic, but has not reached such a stage of perfection as at Chicago. The marketing of wheat in the United States of America must be considered merely as local gathering, for no outside wheat is sold on the exchanges. Therefore, while Europe buys supplies of wheat on, say, the Chicago exchange, this exchange is not a world's wheat market in the same sense that London, Liverpool, and Amsterdam are.

The development of marketing in Canada follows closely that of her neighbour, and the Canadian system approaches that of the United States in efficiency. But in Russia the methods are very imperfect, though there is some progress towards the American system. The marketing of wheat in India and Argentina is similarly very cumbersome and uneconomical, and the opportunities for fraud and injustices are at a maximum. Until some progress along American lines is made these two countries will be under a great disadvantage in selling wheat.

\section{Marketing in New Zealand.}

The New Zealand system of marketing is somewhat cumbersome; but, while it causes inconvenience in many respects, it ensures justice and equity in most cases. The yearly production of wheat in New Zealand does 
not warrant the establishment of such institutions as exist in the United States of America for the marketing of wheat. Sales are carried on in the leading provincial towns by samples, the producers themselves approaching the buyers (millers for the most part) and endeavouring to secure a good price. The great disadvantage of the system arises from the fact that a great many farmers require immediate sale, and consequently there is generally a slump in prices in the late autumn, owing to the fact that millers have plenty of wheat. Reasoning a priori, it is obvious that the price should show little improvement during the winter months, but commence to rise slightly in the spring. In some years, on account of bad weather at threshing time, there may still be sufficient wheat on the market, owing to spring threshing, to stop this upward tendency or even to cause a slight fall. The summer months should witness a substantial rise owing to a general scarcity, but the approach of the harvest in autumn once more brings prices down.

Turning to statistics of actual price movement, we do not find these deductions represented in all respects. From a table of monthly prices covering the period from February, 1898, some interesting observations may be made. A glance at the table will show that in four single years the cereal years (February to January) $1902-3,1909-10,1911-12$, and 1913-14, the course of prices from month to month followed the directions indicated above. But in the other 12 years the result is vitiated by a fall commencing in summer, just at the time when scarcity is acute. Taking the average for the 16 years we get the following actual prices:-

Average monthly prices over the cereal years from February 1898, to January, 1914 :-

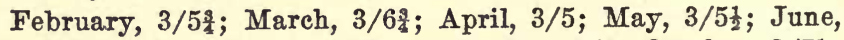

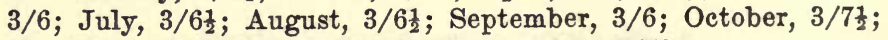
November, $3 / 7 \frac{1}{2}$; December, $3 / 6 \frac{3}{4}$; January, $3 / 5 \frac{9}{4}$. 
TABLE III.

\section{MONTHLY PRICES OF WHEAT IN CHRISTCHURCH}

From February, 1898, to July, 1915.

\begin{tabular}{|c|c|c|c|}
\hline 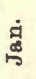 & $\begin{array}{l}\dot{0} \infty \mathrm{m} \\
\dot{\infty} \mathrm{N}\end{array}$ & 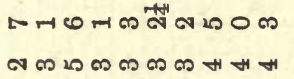 & 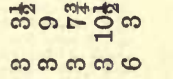 \\
\hline$\stackrel{\text { 巳̊ }}{\stackrel{0}{0}}$ & 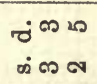 & 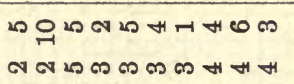 & 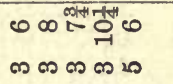 \\
\hline 官 & 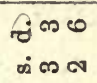 & 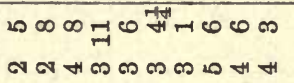 & 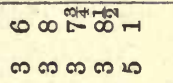 \\
\hline பீं & 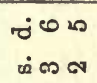 & 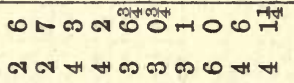 & 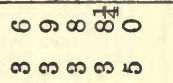 \\
\hline 悹 & $\begin{array}{l}\dot{\delta} \leftarrow \dot{r} \\
\dot{\infty} \curvearrowleft\end{array}$ & 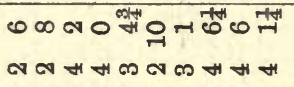 & $\cos \pi n \pi n$ \\
\hline$\sum_{0}^{00}$ & 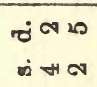 & 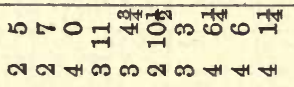 & 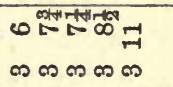 \\
\hline$\stackrel{D}{D}$ & $\begin{array}{l}\dot{\pi} \pi \\
\text { मा }\end{array}$ & 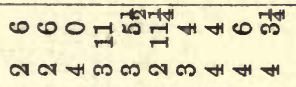 & 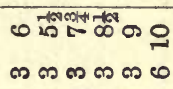 \\
\hline ฏ્̊ & 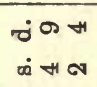 & 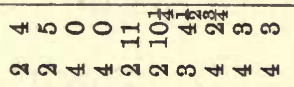 & 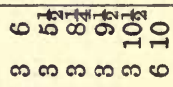 \\
\hline$\stackrel{d}{g}$ & $\begin{array}{l}\dot{\infty} \infty \\
\dot{\infty} \nleftarrow \infty\end{array}$ & 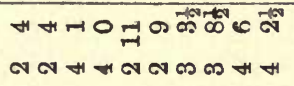 & 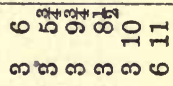 \\
\hline 랠 & $\begin{array}{l}\dot{0}+\pi \infty \\
\dot{\pi} \boldsymbol{m}\end{array}$ & 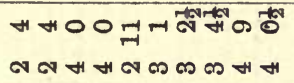 & 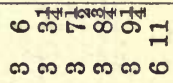 \\
\hline 政 & 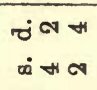 & 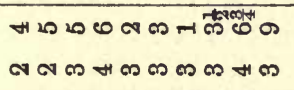 & 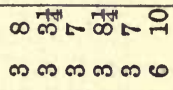 \\
\hline 追 & 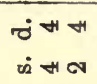 & 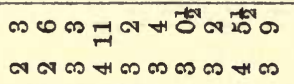 & 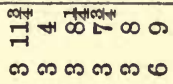 \\
\hline & $\prod_{\substack{\infty \\
\infty}}^{\infty}$ & 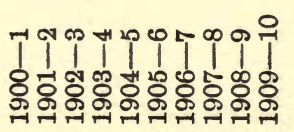 & 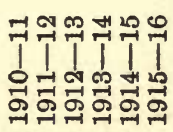 \\
\hline
\end{tabular}


-

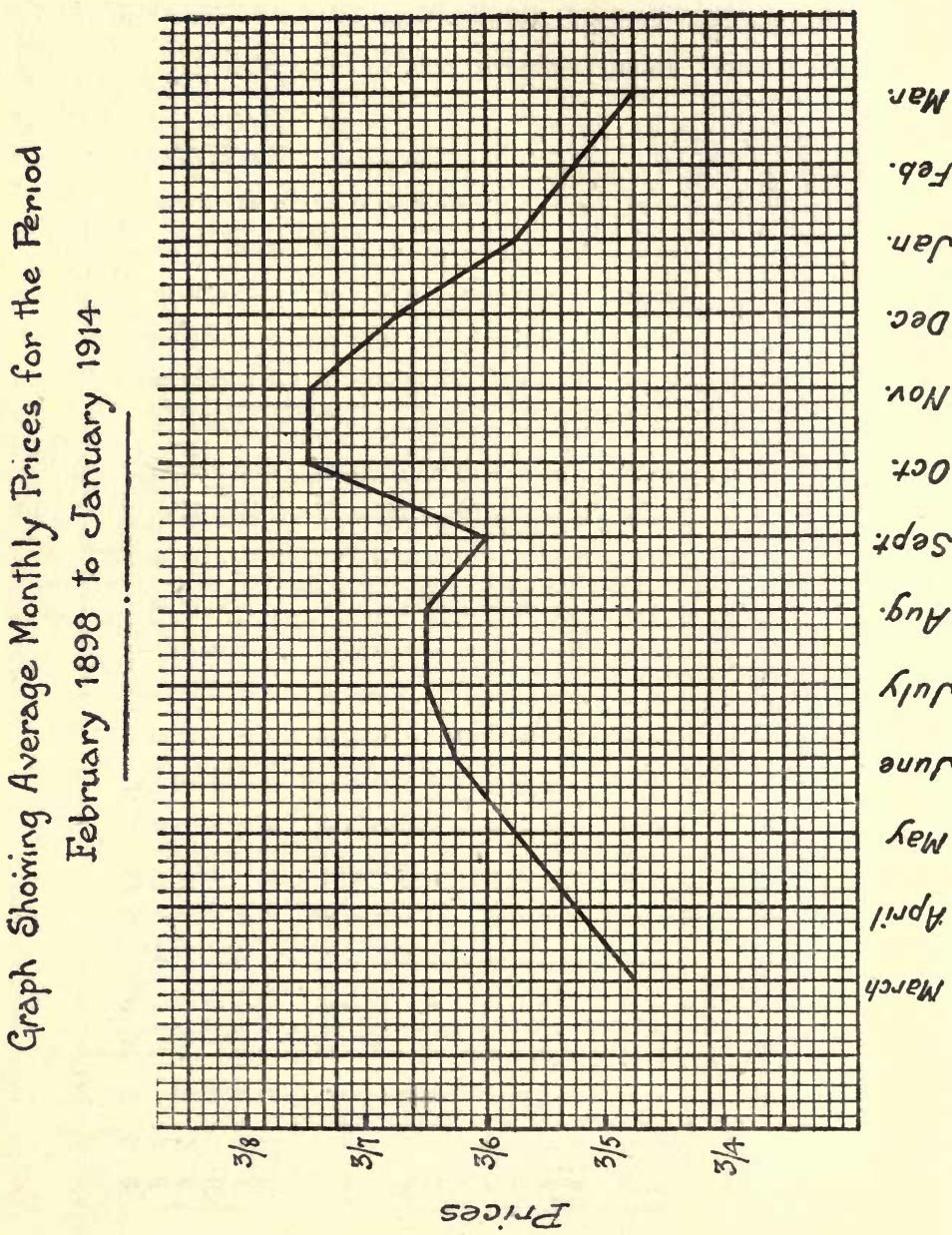


The movement can best be studied from the graph. Here a fall is noticed in the harvest when wheat is plentiful, after which a slight rise occurs until early spring when price drops a little. But the expected rise soon follows, and during November price is fairly steady, with a slightly falling tendency which develops into a rapid fall in December. This fall, which is maintained throughout January and February, and continued into March, may be accounted for by the fact that farmers are offering their crops in advance. It is significant that such a fall is distinctly in favour of the millers, who are able to command a strong position. But the influence of the Australian harvest on prices in New Zealand is an important factor in some seasons.

It is highly probable that the assurance of the success of the Commonwealth crop has a depressing effect on the market in New Zealand. But when all things are considered the conclusion is forced upon us that wheat prices vary only slightly from month to month in normal years, and it is doubtful whether it would pay the average farmer to store his wheat until the period of highest prices, which usually occurs in the early summer. 
Chapter II.

\section{THE PRODUCTION OF WHEAT.}

\section{Geographical Distribution of Wheat Producing Areas.}

Throughout the vast expanses of the temperate zones the production of wheat has been by far the most general agricultural pursuit, from the point of view, not only of the universality of its cultivation, but also from the absolute amount of land, capital, and labour devoted to its production. Practised by the Ancients when the seat of civilisation was centred in Southern Europe, its cultivation was the leading occupation of agriculturists in Western Europe in Medieval times. Finally, as the spread of civilisation moved to the Western World, wheat growing accompanied it, and indeed, almost preceded it.

For the present purposes of classifying producing areas, it will be best to divide the areas into two great subdivisions, viz., those in the Northern Hemisphere, and those in the Southern Hemisphere.

(a) Northern Hemisphere. - Two great producing areas are distinguishable in this sphere, one situated in the Old World, and the other in the New World. The former area has been the centre of wheat cultivation for nearly two thousand years, and at present produces more than half the world's wheat crop. Throughout the whole of Europe wheat growing is practised universally, and in most countries it is still the premier agricultural pursuit, despite the fact that wheat is imported in increasing quantities year by year.

The area further extends into Southern Asia and Northern Africa, while Japan in the Far East is assuming a position of increasing importance as a producer of wheat, and the unbounded resources of the Steppes of Siberia, even now producing more than 150 million bushels per annum, contain unknown possibilities 
for the culture of wheat. Of these areas the most important one is that of Siberia. Unfortunately, this country contains no immediate facilities for greater production at present, but expansion has been going on steadily, and, as the greater part of the soil is still in a virgin state, the progress of higher civilisation will soon more than double the output.

It will be seen that the producing area in the Old World cannot be defined within any precise limits, but is distributed evenly over the whole with the exception of Central Asia.

The second great area in the Northern Hemisphere is situated within more or less indefinite limits. The United States is well suited throughout for wheat production, and it is only in those States where a more lucrative pursuit is forthcoming that the annual output is small. While production is more or less general, two well defined areas are discernible at present:-

(1) One situated in the North Eastern States, extending about 800 miles inland, and south from the Great Lakes about 500 miles.

(2) One situated in the Central States, comprising a large oblong-shaped tract of land about 300 miles in width and 1000 miles in length.

Canada is the most advantageously situated country in the world for immediately increasing her output; for the wheat producing area is centred around the Great Lakes, only about 5 per cent. of the land available for wheat being used at present. The provinces of Saskatchewan, Alberta, and Manitoba, comprising some $150,000,000$ acres, are the best lands, and adequate transportation facilities are all that are necessary for full use being made of this land.

(b) The Southern Hemisphere.-Two great producing areas are found in this sphere, but the magnitude of their production is not fully realised in the old World on account of their somewhat isolated position, combined with inadequate facilities for the economic production and distribution of wheat.

Argentina is admirably suited for wheat culture on 
account of her rich virgin soil and temperate climate. Her importance as a wheat-growing country has doubled during the last decade, and is likely to increase still further at a rapid rate on account of ever increasing efficiency in production.

The area for the production of wheat in Australia is considerable; but distance from a foreign market diminishes the importance of this area. Nevertheless, considerable quantities are exported at a time when the new crops in the Northern Hemisphere are still growing, and consequently Australasia occupies a position of some importance among wheat growing countries of the world.

From a survey of the areas it will be seen that by far the majority are situated north of the Equator, and of these the greatest is in Europe. Official* figures show that the Northern Hemisphere produces about 95 per cent. of the World's wheat crop, while Europe itself produces over 50 per cent. The following table will show clearly the principal countries and their order of importance for the last decade:-

TABLE IV.

Annual Average Production of Wheat in each Country During the Years 1910-14.

Country.

United States

Russia (including Siberia)

France

India

Austria-Hungary

Italian Peninsula

Germany

Iberian Peninsula

Argentina ..

Canada

Roumania

Australasia

United Kingdom
Production in Million Bushels.

685

817

317

350

232

187

152

130

147

197

88

98

59

*The International Institute of Agriculture, Rome. 
Note on the Reasons for Discussing Wheat Production Abroad.

The discussion of the geographical distribution of wheat areas is of considerable importance in any work on the wheat industry, and more especially in the case of this particular essay, where the possibilities and probabilities of New Zealand in this direction are under consideration. For general purposes it is imperative to know what are likely to be the probable supplies available from month to month in any given market, and it is at once obvious that this can be gained only by considering how widely wheat producing areas are distributed over the world. For the partieular purpose of the present work the comprehension of many important problems will depend very largely on the complete understanding of our Dominion's relationships with the great wheat producing areas of the world, and many references will be made throughout to this branch of the work, and conclusions of profound importance drawn from it.

\section{Description and Explanation of Areas.}

For purposes of comparison a brief survey of the conditions prevailing in some of the great wheatproducing areas is relevant to the discussion. These conditions vary greatly in exporting countries, but the importing countries may be considered as a whole, as they represent a well defined area in Western Europe.

(a) Exporting Countries. - We shall consider the United States of America first, not because it occupies the premier position as a wheat producer, but on account of the fact that it is the most perfect in its organisation, and consequently serves, to some extent, as a standard for comparison.

The natural conditions in the United States of America are suitable for wheat culture. Vast expanses of natural prairie have been gradually broken up, and the fertility of the soil ranks among the best in the world. In the two great wheat producing areas noted above, the climate is continental, being sufficiently warm in summer to foster the growth of most cereals. For the Central States an average temperature of $72^{\circ}$ for the summer and from $35^{\circ}$ to $45^{\circ}$ for the winter is experienced. The rainfall 
is admirably suitable for the growth of wheat owing to the fact that abundant rains are common in spring and early summer, while a dry autumn renders harvest operations free of risk.

The method of cultivation has been extensive, and owing to diminishing returns the margin of production has gradually moved from East to West. But more intensive cultivation is being taken up owing to the economic pressure of an increasing population, and the evolutionary law of increasing returns is being illus. trated, resulting in the centre of production gradually coming back from West to East. Moreover, on account of the increase of population combined with the increase in consumption both absolutely and relatively, larger supplies are being required annually, and consequently the United States of America is already a declining factor in the world's wheat market.

In the wheat producing areas of Russia natural conditions are not less favourable to production than in the United States of America. Immense undeveloped tracts of land similar to those in the wheat belt of the United States of America constitute an ideal field for wheat production, while climatic conditions are equally advantageous. But this similarity to the United States of America in natural resources is counterbalanced by dissimilarity in political practice, social theory, and economic conditions. The general ignorance of the people, poverty combined with absolute indifference to improvements in cultivation and production, the depen. dence of the Russian proletariat, and the oppression of the wealthy, all engender inefficiency, and retard the rate of progress.*

Canadian land and climate are so favourably situated for the efficient production of wheat, that very high qualities are produced. Copious rainfall in the growing season followed by a dry autumn, are the chief features of the climate, while the soil is of the heavy black type, so favourable to the growth of wheat. In India and

*Written before the events of 1917. 
Argentina too, there are large areas suitable for wheat growing, but the methods of production and the lack of transportation and marketing facilities leave room for vast improvements in these areas.

Of great interest to New Zealand is wheat production in Australia. Neither the nature of the soil nor the general climatic conditions offer superior advantage to this country for the growth of wheat. The soil in the wheat districts is not of the rich black type found in Russia and Canada, but of a more light loamy character, while the rainfall in most parts is not only relatively light, but shows great fluctuations from year to year, thus causing wheat growing to be rather a precarious pursuit. The graph I have drawn for the composite winter rainfall at several stations in Victoria* is sufficiently illustrative on this point. Thus in 1902 and in 1907 very low rainfalls were recorded, while again in 1914 only some $2 \frac{1}{2}$ inches of rain fell in the periodMay to October. The average winter rainfall for the past 30 years (1884-1914) according to the graph is not quite 10 inches - a very low figure for wheat growing, as the period May to October is the full growing period in Australia, the crop being harvested in November and December. But profitable wheat production is the result of a number of miscellaneous factors, and despite the fact that Australian land and rainfall are not conducive to high yields, the country is able to maintain her position as a producer, and is indeed becoming of everincreasing importance.

To counterbalance the disadvantages which are experienced on account of relatively poor land and low rainfall with their consequent low yield, Australia has an advantage from the point of view of cost of production. The dry nature of the soil renders tillage cheap and easy, and the long spell of dry weather at harvest cheapens harvesting operations enormously. Harvesting is done for the most part by a combined

*And Victoria is favoured more than any other State by Nature in regard to rainfall. See page 47. 
harvester which "strips" the wheat crop and threshes it out immediately - the total cost for harvesting being about 6s. 6d. per acre, according to an estimate in the Agricultural Gazette of New South Wales for November, 1914. The total cost according to the same estimate is about 2s. 1d. per bushel. It is because of these cheap methods of production that Australia is able to maintain her position as a producer of wheat.

The extent of the possible area for wheat cultivation in Australia is shown by the following table taken from the Agricultural Gazette of New South Wales for June, 1915, and is based on the following assumptions:-

(1) That wheat cannot be grown profitably with less than 10 inches of rain during the period of growth.

(2) That the proportion of land suitable for, or available for wheat production is about one. fourth of the total area over which this 10-inch rainfall is experienced.

(3) That the average yields per acre for the past 10 years will be maintained.

(4) That only four out of the six States participate in the expansion.

\section{TABLE V.}

Possible areas (in million acres) and yields (in million bushels) in the four principal wheat producing States of Australia :-

\begin{tabular}{|c|c|c|c|c|c|}
\hline STATE. & $\begin{array}{c}\text { (1) } \\
\text { Area with } \\
\text { over } 10 \text { ins. } \\
\text { rain in } \\
\text { growing } \\
\text { season }\end{array}$ & $\begin{array}{c}\text { (2) } \\
\text { Ares Suit- } \\
\text { able for } \\
\text { wheat } \\
\text { growing }\end{array}$ & $\begin{array}{c}\text { (3) } \\
\text { Area } \\
\text { available } \\
\text { for grain }\end{array}$ & $\begin{array}{c}\text { (d) } \\
\text { Average } \\
\text { yield per } \\
\text { acre for } \\
\text { last 10 } \\
\text { years. } \\
\text { 1904-5 to } \\
\text { 1913-4: }\end{array}$ & $\begin{array}{c}(5) \\
\text { Annual } \\
\text { Possible } \\
\text { Production }\end{array}$ \\
\hline New Sou & $\begin{array}{c}\text { Acres } \\
105\end{array}$ & $\begin{array}{c}\text { Acres } \\
26\end{array}$ & $\begin{array}{c}\text { Acres } \\
21\end{array}$ & $\begin{array}{c}\text { Bushels } \\
11 \cdot 61\end{array}$ & $\begin{array}{c}\text { Bushels } \\
243\end{array}$ \\
\hline Victoria & 48 & 12 & 10 & $11 \cdot 55$ & 110 \\
\hline So & 30 & $\infty$ & 6 & $10 \cdot 19$ & 61 \\
\hline West Aus & 60 & 15 & 12 & 10.77 & 129 \\
\hline Total & 253 & 61 & 50 & $11 \cdot 21$ & 543 \\
\hline
\end{tabular}

In this table column (2) is taken as 25 per cent. of column (1) on account of waste land and poor soil within the 10-inch isohyet, while column (3) giving the 
actual area possible for grain is taken as 80 per cent. of column (1), because about one-fifth of the total crop each year is devoted to the production of hay and chaff. Column (5) is the product of columns (3) and (4).

The actual wheat production for Australia is given in the following table:-

TABLE VI.

WHEAT PRODUCTION IN AUSTRALIA, 1916-17.

\begin{tabular}{|c|c|c|c|c|c|}
\hline \multicolumn{3}{|c|}{ STATE } & $\begin{array}{c}\text { AREA } \\
\text { (Millions of } \\
\text { Acres) }\end{array}$ & $\begin{array}{c}\text { YIELD } \\
\text { (in Million } \\
\text { Bushels) }\end{array}$ & $\begin{array}{c}\text { YIELD PER } \\
\text { ACRE } \\
\text { (in Bushels) }\end{array}$ \\
\hline New South Wa & & & $3 \cdot 5$ & $36 \cdot 7$ & $10 \cdot 4$ \\
\hline Victoria & $\ldots$ & $\ldots$ & $3 \cdot 1$ & $51 \cdot 1$ & $16 \cdot 4$ \\
\hline Queensland & $\ldots$ & $\ldots$ & $\cdot 2$ & 2.5 & $10 \cdot 8$ \\
\hline South Australis & $\ldots$ & ... & $2 \cdot \overline{8}$ & $43 \cdot 8$ & $15 \cdot 8$ \\
\hline West Australia & $\ldots$ & $\ldots$ & 1.6 & $16 \cdot 1$ & $10 \cdot 3$ \\
\hline Tasmania .. & $\ldots$ & $\ldots$ & .03 & .35 & $12 \cdot 6$ \\
\hline Total & $\ldots$ & $\ldots$ & $11 \cdot 23$ & 150.55 & 13.4 \\
\hline
\end{tabular}

(b) European Area.-This area, extending over the whole of Western and Central Europe, comprises almost all the importing countries, while Roumania is the only exporting country of any importance. The whole of the area has been cultivated for the production of wheat for several centuries, and consequently cultivation assumes the mark of intensity in opposition to the extensive methods prevalent in the other countries which we have been considering. The law of diminishing returns has for some time been in operation, but owing to the greatly increased demand which has pressed down the margin, wheat growing is still a highly remunerative pursuit, and the area produces more than half the world's supply.

The conditions under which the cereal is produced are much the same over the whole area. A favourable rainfall in the growing season with a hot sun in the ripening period goes far to counterbalance any disadvantages which are experienced on account of soil exhaustion. Moreover, this latter difficulty is overcome to a considerable extent by artificial manuring, a skilful rotation 
of crops, and a careful method of cultivation. The prevalence of small holdings on the Continent adds greatly to the efficiency of methods of cultivating the soil. In many places-notably in France and Germany - high farming, par excellence, is practised, and much of the modern farming machinery has been adopted. As we move further south to Austria and the Balkan States, the adoption of modern facilities for wheat production is not so marked, but still the same intensive cultivation is practised.

In England the farms are somewhat larger than those on the Continent, but the methods of producing wheat differ very little, as each farm in England employs sufficient men to produce on an intensive scale.

(c) Yield per Acre in the Chief Producing Areas.The yield per acre throughout the area is relatively high, but there is scope for improvement in some parts. Belgium has the highest yield, with an average of 35.9 bushels for the period (1901-11), and the United Kingdom third ' with $31 \cdot 6$. The following table shows the average yield per acre for the ten years (1902-11) of the chief wheat producing countries of the world.

\section{TABLE VII.}

Average Yield per Acre for Perlod 1902-11 in Leading Countrles.

Country.

Belgium

Netherlands

United Kingdom

New Zealand

Germany . .

France

Hungary

Austria

Canada

Roumania

United States

India

Australia

Argentina

Siberia

Russia

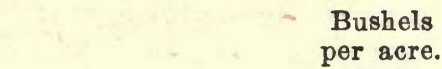

per acre.

$35 \cdot 9$

$33 \cdot 4$

$32 \cdot 0$

$31 \cdot 6$

$29 \cdot 7$

$19 \cdot 7$

$19 \cdot 2$

$18 \cdot 9$

$18 \cdot 2$

$17 \cdot 0$

$13 \cdot 6$

$11 \cdot 4$

$11 \cdot 2$

$10 \cdot 8$

$10 \cdot 4$

$9 \cdot 5$ 
The table has been compiled from Annual Statistics given in the Year Book for the Commonwealth of Australia, and illustrates well the different methods of cultivation which are adopted in the different countries. With the exception of New Zealand no new country has a high yield, while the yields of most of the European countries are relatively high, showing that wheat is produced on an intensive scale. The great exception is Russia, and so low is the yield here that it is obvious that with the dawn of higher civilisation this country will produce enormous quantities.

\section{Conditions Necessary for Profitable Production.}

In seeking to investigate the present situation of the wheat industry, it is necessary to take a survey of the conditions under which the most efficient production can be engendered. The belief that haphazard and careless methods of production will afford sufficient yields to make the pursuit lucrative is far too prevalent, and although New Zealand farmers have departed very far from primitive methods, no more effective answer: can be given to their cry of inability to profit by wheat growing, than that they do not realise sufficiently the advantages of superior cultivation which their education and environment in a democracy warrant. A brief consideration of these conditions shows them to be as follows :-

(a) Soil and its Amendments.-(i) Choice of soil.The character of the soil affects the yield and quality in varying degrees. Wheat soils may be divided into three main classes:-

(1) Heavy black soil.

(2) Clay soils usually light in colour; tenacious in texture, and requiring careful cultivation.

(3) Loamy organic soils.

Russia abounds in the first type, and the last two are found in plenty in the United States. All these can be found in New Zealand, at North Otago, South Canterbury, and North Canterbury, in the order named, 
though the variations are not distinct. Consequently we should expect to find different methods of cultivation and different kinds of seed sown, but such is by no means the case, and here then is one reason for a declining industry.

(ii) Use of Fertilisers.-No greater evidence of the operation of the law of diminishing returns can be found than that the problems of artificially fertilizing the land are claiming attention in many countries of the World. It is not within my purpose in this paper to indulge in the technicalities arising from the more detailed aspect of the subject. To the chemist and agriculturalist will be left the consideration of the compositions of various manures; but for the purposes of considering the whole economic view it is often incumbent upon the economist to enter the domains of the physical and natural sciences. Hence the few speculations made upon the advantages of fertilisers must not be looked upon as a treatment of the chemistry of the subject.

Two methods of adding plant food to the soil are at once apparent.-(1) Direct: (2) Indirect.

(1) Direct.-The greatest problem with which the farmer has to contend in this respect is the provision of suitable quantities of nitrogen in the soil. It is the superiority in this respect which the Russian black soils and the virgin soils of Canada and the United States enjoy that makes them the home of wheat growing. Zealand soils generally are not of a black free nature, but contain comparatively low proportions of nitrogen, and when farmers realise this, better prospects will be in view. For the production of wheat on the most efficient basis, the soil requires now in most countries, in addition to nitrogen, complete mineral manures containing phosphorus, calcium, and potassium.

Naturally, manuring for wheat was for many years thought to be quite unnecessary in New Zealand, because of the residual fertility of the soil. When, afterwards, manuring was commenced, the English practice in the application of nitrogenous manures was copied, and was found to be non-effectual, or at least uneconomical. 
Manuring cereals then ceased, until it was found that the warmer and drier summers experienced here allow of the nitrification of the waste organic matters in the soil to such an extent as to provide a sufficient supply of nitrates for satisfactory plant growth.

In the search for the element necessary for plants and least plentiful in the soil, phosphorus was some ten years ago found to be of great advantage, and phosphates are now being used to an increasing extent to counterbalance the exhaustion of the soil due to eropping.

(2) Indirect.-The indirect method is of special importance to New Zealand conditions; for the Dominion is very well adapted to mixed farming. Two ways of employing this method may be used, by a system of crop rotation or by the grazing of animals on wheat lands. In practice they are employed together when opportunity offers. There are various systems of crop rotation, but it will suffice to describe one and point out its advantages. A rotation may begin with a root crop, usually turnips, manured with phosphates. This crop not only gives an opportunity for cleaning the land but it provides excellent winter feed when supplemented by hay or, more commonly, wheat straw. The residue left then provides an excellent manure. After the turnips are eaten off the farmer prepares the soil for a crop of barley or oats, as it is now too late to sow wheat. The land is ploughed, but the ploughing is only a shallow one, so that the water stored in the deeper layers of the soil which have been solidified by the trampling of the sheep may not be disturbed. Clover and grasses are sown among the barley or oats so that they may take firm root whilst the latter is growing and ripening. The crop is harvested in the autumn, and the young clover and grasses establish themselves during the autumn or winter, and produce a crop of hay the following year. This is harvested in midsummer, and the aftermath forms an excellent autumn grazing for the sheep and cattle which are to be fed the next winter.

In the autumn the ground is ploughed again, and 
cultivated ready for wheat, which should be sown before winter sets in, so that the young plant may come up and establish itself before the cold frosts commence. The wheat spends the winter in root development, and does not make much show above the ground until the spring. After harvesting the crop in the autumn the farmer again ploughs the land, after which it is left until the spring. It is ploughed again then, and between this ploughing and the sowing of a root crop, it undergoes a thorough cleaning.

Such, then, is the complete rotation, and it is obvious that it is adapted only to countries where intensive methods of cultivation are in operation. Among its numerous advantages we may note that the system provides excellent conditions for growing both wheat and barley or oats in districts where the rainfall is inclined to be deficient. Not only is an abundant supply of nitrogen provided for these crops through the medium of the cake purchased for the stock, but the solidification of the deeper layers of the soil ensures the retention of the winter's rain for the use of the crop during the dry summer. Then, again, the residue of the phosphates and potash applied to the root crop and left in the soil when that crop is removed, provides for the mineral requirements of the cereal crop. Furthermore, rotation husbandry also distributes the labour of the farm over the year.

A modified form of this type of rotation is easily applicable to New Zealand conditions, but would require more labour than is obtainable at present. The home of this rotation system is in England, and some of the thickly populated countries of the Continent, and with what results can readily be comprehended by a glance at the table of yields for the different countries; for several of these countries produce over thirty bushels per acre. If New Zealand can produce a yield of over thirty bushels per acre on a system bordering between intensive and extensive cultivation, how much greater would be her yield if the above rotation were adopted?

(b) Climate.-Wheat has a very wide climatic range, 
its range of successful cultivation extending from regions bordering on the tropics-such as California and India, almost to the Arctic circle, as in Siberia and Northern Canada. Most countries in which its growth is practised have cold winters and moderate summers. The most noteworthy fact about this aspect of the subject is that the range of successful culture is gradually extending into colder regions, which shows that wheat possesses a certain power of adaptation to its environment.

A cool, prolonged, but not too wet spring, followed by moderately dry, sunny weather, during ripening, is most favourable to the largest yield of best quality. The most favourable ripening requires a mild temperature with a slightly clouded sky. All these attributes New Zealand possesses in a remarkable degree, and the relation of yield to them will be considered later.

The rainfall is an important matter-wheat being very sensitive to extremes of drought or moisture. The most suitable rainfall ranges between 20 and 30 inches, but good quality wheat can be grown with from 15 to 20 inches in quantities up to 20 bushels per acre. These conditions prevail in Australia, but New Zealand here again possesses the necessary attributes almost perfectly.

(c) Cultural Methods. - Too much stress cannot be laid upon the importance of a careful cultivation. Not only does tillage render the seed-bed specially adapted to growth, but by cultivating in the right way at the right time moisture is conserved in the soil and the growth of weeds discouraged. A fine but firm seed-bed is necessary for efficient production. For the methods of cultivation ploughing, discing, harrowing, etc., a great deal depends upon the character of the crop which the land has just produced. For instance, after grass or clover the land should be skim ploughed in early March, and left for six or eight weeks. Then cultivation should proceed with a firm discing and then deep ploughing, etc. No attempt is going to be made here to treat this part of the subject in elaborate detail ; but from the few facts noted it is hoped that sufficient weight has been given to the necessity for careful and continuous cultivation. 
(d) Harvesting.-Here, again, it is of the utmost importance that the farmer pay attention to the methods he employs, and the time at which he performs the different operations. Harvesting operations commence in New Zealand from January onwards, and many considerations influence methods adopted. For instance, the prevalence of hot winds in Canterbury, very often assuming the character of gales, necessitates a somewhat premature cutting, which places the farmer in rather a precarious situation should a heavy fall of rain occur. The cheapest method of harvesting is the use of the combined harvester and thresher, a large ungainly machine, drawn by 18 horses, and requiring 5 men to work it. It possesses the advantage of cutting and threshing all in one operation, and consequently can be used only where the climate permits the wheat to become very ripe without fear of losing it by shelling out on the ground. It is commonly employed in the Western United States and Australia.

Harvesting operations in New Zealand are somewhat more expensive than elsewhere, as we shall see when considering the cast of production. It will suffice here to point out the method used. English methods pre. dominate, the crop being cut by a reaper and binder and then stooked. After two or three weeks it may be stacked and then threshed, but very often "threshing out of stook," where the drays cart it straight to the mill, is the method used. Given favourable weather, the method is very efficient in producing good quality, but not infrequently autumnal rains prolong the period of harvesting so long as to curtail profits very considerably.

(e) Marketing. - In Chapter I. we discussed the question of marketing. There remains little further to say on the subject save again to stress the important place which marketing holds in the efficient production of wheat. The most suitable method for large scale production is the use of elevators, but in a country like New Zealand where comparatively small quantities are produced, their use is impracticable, and all wheat 
has to be handled in sacks. But where good roads are formed and efficient railway facilities are provided, the method is followed with success. Under this head, too, it is necessary to note that firsthand knowledge of market prices in various centres is more than important. This can be secured through the public press, provided that the information is supplied from official sources, and it certainly ranks as a factor in the efficient production of wheat.

In conclusion, certain factors require passing notice. While the prevention of certain pests should excite the farmer's attention, the choice of varieties of wheat is a matter of no less importance. New Zealand produces the Tuscan varieties best, while Hunter's is a very good all round wheat. Velvet and Pearl require good soils and are liable to be threshed out with the wind.*

The establishment of agricultural colleges and experimental farms by the Government is prevalent in most wheatgrowing countries. These are benefiting producers very considerably, not only from the point of view of the advice they give as to methods of cultivation and scientific farming generally, but also in fostering the growth of varieties specially adapted to the particular environment. 


\section{Chapter III.}

\section{GENERAL CONDITIONS IN NEW ZEALAND.}

Throughout the preceding chapters of this work great prominence has been given to the fact that various parts of New Zealand are specially adapted for the production of wheat. We shall here consider these qualifications in comparison with those of other producing countries.

\section{Suitability for Wheat Production.}

"The Dominion of New Zealand is a country specially favoured for primary production. The soil covering is varied in character, a considerable portion of it being of exceptional fertility, and even the poorer soils are often capable of profitable utilization by reason of the comparatively mild and equable weather conditions."

(a) The North Island.-This Island is remarkable for the congenial environment it furmishes for many phases of production. The fertile province of Hawke's Bay provides, perhaps, the best sheep grazing country in the world, while many parts of the West Coast furnish ideal pastures for dairy cattle. Although the Island possesses many natural qualifications for wheat production, as we shall see when considering soil and climatic conditions, attention has been diverted into the more profitable pursuits of dairying and sheep farming, furnishing a remarkable example of the tendency, established by the theory of International Trade, of countries to specialise in that for which they are most advantageously adapted.

(b) South Island.-The South Island was the portion of New Zealand where agriculture was first established to any considerable extent, settlement here being greatly facilitated by the presence of large fertile plains, and rolling downs and hills devoid of forests and other

${ }^{*}$ New Zealand Official Year Book (1914) p. 569. 
natural encumbrances. Except for certain portions of the Southern part of the Island the climate enjoyed is second to none in the temperate zone, mild winters and warm summers being the chief characteristics. While stock raising is the main rural industry, grain growing is pursued on a considerable scale. The chief grain growing areas are Marlborough in the North, Otago in the South, while the Canterbury Plains, extending over an area of 3,000,000 acres, produce large quantities of wheat annually. Such is the character of this area for wheat production that yields often average 35 bushels per acre, while between 80 and 90 bushels per acre have been registered on individual fields at times. From such a general survey it is at once obvious that our Dominion possesses qualifications for agriculture of no mean importance.

(c) The Producing Area.-In considering in detail the general conditions under which wheat is produced in New Zealand attention for the most part will be confined to Canterbury and North Otago. I have chosen this area for the centre of my investigation because, in reference to wheat production, no other area in New Zealand is of immediate importance, though there is no doubt that were wheat growing to become relatively more lucrative than pastoral farming, in many parts of the Dominion there would be found conditions very well suited for profitable production. This area, composed of the Canterbury Plains, the Downs of South Canterbury, and those of North Otago, is our present wheat producing area, and I propose to confine my attention mainly to these districts.

In order to illustrate the relative importance of this area, I have prepared a graph comparing the sum of the areas in cultivation for Canterbury and Otago with the total area for New Zealand, and the result is both remarkable and illustrative. It is remarkable in that it shows to full advantage the predominance of this area in the total area for New Zealand, and illustrative because of the advantage to be obtained from the graph 
$z^{0}$

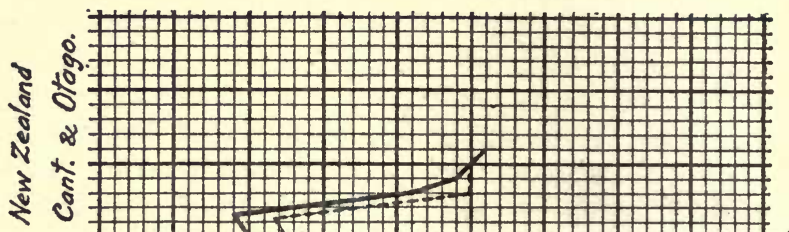

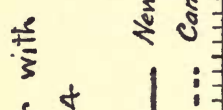

क

$\begin{array}{ll:l:l} & 1 & 0 & =\end{array}$

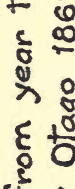

$\leftarrow \infty$

a $x$

\& 5

वे की

$\frac{0}{0} \frac{\pi}{5}$

$\frac{\sigma}{8}$

ले

\begin{tabular}{ll}
3 & 0 \\
2 & 0 \\
\hline & 1
\end{tabular}

84

54

ถิ ह

ธิ ป็

a. $)$

@

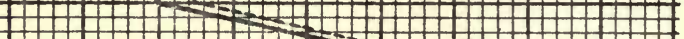

HH

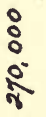

0
0
0
0

: 
in common with most graphs but outstanding in this one, in that it shows at a glance the position which could have been obtained from two columns only after a close scrutiny and then but in part. The greatest area in production outside of Canterbury and Otago was about 45,000 acres in 1899, while in many later years the difference is negligible, an average of about 5 per cent. only of the total area not being situated in these two provinces since 1900 .

But a precaution must be observed in interpreting the result as it is depicted by the graph, for it tends to exaggerate the position. If we observe the lines only the perpendicular distance between them is very small. But this does not measure the real result; for this we have to look to the vertical distance between the peaks of each graph. Were this precaution not observed, it would appear that the percentage area in production outside of Canterbury and Otago is less than half of what it really is.

Having now given reasons for choosing a particular area for investigation, we can now proceed with a consideration of conditions in detail as they are found there.

\section{Soils.}

(a) Soil Qualifications.-Mr. B. C. Aston, Agricultural Chemist to the New Zealand Government, after a comprehensive analysis of New Zealand soils, concludes that "New Zealand is a country remarkable for containing within a comparatively small land area such a number of different types of soils that a Continent would require to be ransacked to discover elsewhere a similar variety." The district of Central Otago contains the richest soils of the Dominion, but lack of water prevents these being fully utilised. The fertile Canterbury Plains supply excellent examples of gravel fans covered with soils of varying depths and fineness. This area together with North Otago comprises the greater part of the wheat producing area of New Zealand, and furnishes an excellent proof of the fact that wheat has a wide range 
of productive soil. In North Otago there is rich black soil the fertility of which almost surpasses that of the great wheat belts in Russia and the United States of America. Coming further north a large area in South Canterbury can be distinguished stretching from the Waitaki River to the Rangitata River. The soil in this area is of a heavy clay type for the most part, being very suitable for intensive methods of cultivation. From this area another one can be distinguished stretching from the Rangitata River to the Waimakariri River, the soil of which is somewhat lighter, being of a loamy character. Wheat production here resembles that in Australia to a considerable degree, though on account of the differing climatic conditions, harvesting operations are quite dissimilar. Finally, there is the area north of the Waimakariri River and stretching as far north as the Nelson Province. This area is somewhat similar to that of North Otago, though probably not so rich in nitrogenous matter, which is a very important factor in wheat production. But on account of the looseness of its structure, cultural methods are much easier here, and consequently more attention is devoted to wheat growing. Considering the results of the Government Chemist's analysis, we find the following instructive conclusion.*

TABLE VIII.

AVAILABLE PLANT FOOD IN NEW ZEALAND SOILS

\begin{tabular}{|c|c|c|c|c|c|}
\hline \multirow{2}{*}{ DISTRICT } & $\begin{array}{l}\text { Number } \\
\text { of Samples }\end{array}$ & Potash & $\begin{array}{c}\text { Phosphoric } \\
\text { Acid }\end{array}$ & Nitrogen & \multirow{2}{*}{ Rating } \\
\hline & analysed & $\begin{array}{c}\text { Number } \\
\text { of Samples }\end{array}$ & $\begin{array}{c}\text { No. of } \\
\text { Samples }\end{array}$ & $\begin{array}{l}\text { No. of } \\
\text { Samples }\end{array}$ & \\
\hline$\overline{\text { Otago }} \ldots$ & 95 & $\begin{array}{r}1 \\
18 \\
76\end{array}$ & $\begin{array}{r}3 \\
21 \\
71\end{array}$ & $\begin{array}{r}3 \\
14 \\
78\end{array}$ & $\begin{array}{l}\text { Deficient } \\
\text { Normal } \\
\text { Good }\end{array}$ \\
\hline $\begin{array}{l}\text { Percentage } \\
\text { Deficient }\end{array}$ & f & 1 & 3 & 3 & \\
\hline Canterbury & 41 & $\begin{array}{r}4 \\
37\end{array}$ & $\begin{array}{r}3 \\
8 \\
30\end{array}$ & $\begin{array}{r}3 \\
5 \\
33\end{array}$ & $\begin{array}{l}\text { Deficient } \\
\text { Normal } \\
\text { Good }\end{array}$ \\
\hline $\begin{array}{l}\text { Percentage } \\
\text { Deficient }\end{array}$ & \} $\mid$ & Nil & 7 & 7 & \\
\hline
\end{tabular}

"New Zealand Official Year Book (1914), p. 576. 
This table clearly shows that the soils of the wheat producing areas of New Zealand contain the ingredients necessary for the economical and efficient growth of wheat to a remarkable degree. Few other countries can compare with New Zealand in this respect. Russian soil is perhaps richer, while the United States of America wheat belt possesses many similar qualities. European areas do not surpass the Dominion in natural fertility, while Australia and Argentina are on the whole outclassed by her.

Thus the conclusion is forced upon us that New Zealand possesses a differential advantage from the fine qualities and equal distribution of her soil ingredients. After considering the advisability of making a systematic soil survey of the soils of the Dominion, we shall turn our attention to an investigation into the possibilities of improving the natural fertility of the soil by the use of fertilisers, both direct and indirect.

(b) A Soil Survey.-In every country water supply is the most important factor governing the productivity of the soil. Given a sufficiency of water, the chemical constitution of a soil is usually of secondary importance. The textural classification of soils into sands, loams, clays, etc., is essential in defining their cultural character, and, if this classification is accompanied by the water requirements of the soil, we gain some idea of the agricultural value of the land.

The factors controlling productivity are of two groups -water supply, and chemical constitution of the soiland if it is necessary to assess the agricultural value of the land, we must classify the soils according as they conform to or differ from types, and group the types according to their water requirements. This latter requirement is necessary because of the fact that in any locality with land of a uniform chemical composition and with a uniform rainfall, the supply of water may be excessive in one part and defective in another. The 
reason for this is that the texture of the soil varies, the first part being too dense, and the second part too porous.

In the settlement of new countries those portions which, by their sufficiency of water supply and their suitability of soil conditions, lend themselves readily to agriculture are first settled. This is well illustrated by the early settlement of Canterbury. When population increases and new lands must be settled, steps are taken by individuals for the provision of water supply; but in the absence of reliable information on the quality and texture of the soil, much of this work is in vain. What is necessary is a central institution to collect information on these matters before any further work is done. The Department required may be designated the Bureau of Soils Department, and could very well be a branch of the Department of Agriculture, which in many countries has hitherto been content to deal mainly with farm produce.

"Where soil surveys have been made they have proved of immense value. The individual farmer can learn the relationship of the soils upon his own farm to soils of the same charicter in other parts of the country. He can observe and study more closely the methods and results that have been obtained by successful farmers upon such soils; he can apply the experience and observations of others to his own particular needs and conditions, determine the crop or crops to which his particular soils are best adapted, and ascertain the systems of crop rotation, tillage, and fertilisation calculated to produce the maximum crops from these soils without impoverishing his farm." **

In his 1907 Report the New Zealand Government Analyst outlined a plan for conducting a soil survey, of which I shall give a brief summary.

The essence of the plan is the personal investigation of a soil survey party who shall furnish a report on each

*Mr. Edwin Hall, in a paper read before the $A$. and $P$. Societies' Conference. 
tract of land visited, with reference to six questions:-

1. Climatic conditions;

2. Conditions of surface;

3. Geological origin;

4. Physical and chemical characters;

5. Flora, native and introduced;

6. Recognised economic adaptation.

With such information relating to every district in the Dominion, a systematic report could be furnished which would give a full description and explanation of all important matters - such as meteorology, chemical contents of soil, vegetation, etc., relating to the agri. cultural value of the land, and from which could be readily inferred the special pursuit for which the particular lands were best suited. That such information would be of distinct economic value is unquestionable, and it is discussed here at such length because of its importance. The question opens up an interesting investigation of which only the outline has been given here, with the hope that what has been said will in some way add further to the already realised value of agro-geological surveys.

\section{Use of Fertilisers.}

It must not be concluded that because artificial manures are in use in many parts of the country that the virgin character of our soil is totally impaired by cropping. Nevertheless, owing to the system of cropping prevalent in the two closing decades of last century, we are faced with the fact that existing methods of cultivation have brought us in many parts to a point of diminishing returns. This situation raises the whole question of artificial manures. We shall find that it is impossible to conclude with any exactitude what advantages can be realised from any one line of action, but the only method of discovering the adequacy of such, lies in an attempt to weigh the real net advantages of the different methods.

As indicated in the previous chapter, two methods of applying fertilisers in production are possible. 
(a) Indirect.-New Zealand farming is characterised by its peculiar suitability for mixed methods, and this is especially true of the wheat producing area under investigation. Experience has shown that in this area no one method of farming is sufficient. Sheep farming is very profitable for a few years; but the pastures sooner or later lose their vitality. The farmer is then faced with the difficulty of producing fresh grasses, which are found to thrive best after a short period of cropping. Moreover, in the provision of adequate winter forage a sheep farmer is often placed in difficulty. For instance, in a dry season farmers who have been relying solely on their pasture for winter feed, are sadly disappointed, and are compelled to sell considerable quantities of their stocks very often at a loss. On the other hand close adherence to agricultural pursuits is likely to prove no less a failure. Examples of failure in this method of farming are not wanting in New Zealand; and the farmer who is found after a comparatively short period of years with an outcropped farm is not altogether uncommon.

Experience thus shows that the mixed method of farming in Canterbury is the most profitable; not only this, but we are learning year by year that this region is specially adapted to mixed farming. Wheat production is fostered by an excellent soil, and by a good and systematic rotation of crops the whole area provides excellent grazing land for both eattle and sheep. Moreover, the growth of root crops for winter feed is beneficial to both agricultural and pastoral pursuits, in that it is an excellent preparation for soil for wheat and oats, and furnishes good fattening material, which, along with hard pastures is responsible for the world. wide famous "Prime Canterbury" mutton and lamb.

(b) Direct Fertilisers.-In many parts of the wheat producing area of New Zealand the virgin fertility of the soil has been somewhat impaired. But for the past decade continuous cropping has been by no means the universal practice of the New Zealand farmer, as it has been in other new countries, notably in the United 
States. Consequently when the application of certain manures to our soils is advocated, it must not be thought that this is solely on account of a diminished fertility. On the other hand, by the employment of incremental additions of capital, (manure in this specific case) the farmer will get higher proportional returns up to a certain point. Hence, in addition to manuring the root crops preceding wheat, it has become the practice in many parts to manure the wheat crop also. This practice, however, should not have a very detrimental effect on wheat growing in New Zealand, for, in the first place, "it is now certain that wheat nearly always responds to phosphatic manures," manures are easily obtainable in New Zealand on account of the freezing industry. We shall see later in analysing costs of production what proportion is attributable to manures.

\section{Climatic Conditions.}

A detailed analysis of climatic conditions is of paramount importance in any investigation relating to agriculture, for no one will dispute the fact that there is a connection between productivity and meteorological conditions, though the degree of this relationship is not yet exactly established. The climate of New Zealand has to be considered in relation to three main features:-

(1) Its pasition, stretching for nearly a thousand miles southward of latitude $34^{\circ}$ south.

(2) Its insular position, situated in the greatest ocean of the World, from which no part of the country is more than 75 miles distant.

(3) Its physical features, especially the mountain chains, running mostly north and south, and affording differential aspects.

From a survey of these it is obvious that New Zealand can rank with any of the great wheat producing countries of the World so far as favourable weather conditions are concerned.

*Dr. Hilgendorf, in "The New Zealand Journal of Agriculture," March, 1915. 
(a) Sunshine. - Two Government meteorological stations are situated in the producing area; but unfortunately they are very close together, so that observations from them cannot be considered to be general. Information from private sources will have to be considered. The wheat producing area is situated in a very favourable position for obtaining the maximum amount of sunshine. Over the years 1907-13, the average annual number of hours of sunshine was 2,064, showing a daily average of 5.65 hours, which is about 50 per cent of the possible amount.

(b) Temperature. - The oceanic influences are recognised as the dominant feature with regard to both summer heat and winter cold, upon both of which they exercise a moderating effect. No great extremes of heat or cold are found on this account, and, although the winter is sharp, it is characterised in Canterbury by clear frosty nights and bright sunny days. The excellent nature of the summer heat promotes the growth of cereals to a very high degree. The following table shows the temperature for the four seasons in the area of Canterbury and Otago.

\section{TABLE IX.}

TEMPERATURE IN CANTERBURY AND OTAGO.

OANTERBURY.

\begin{tabular}{lc|c|c|c|c|c}
\hline & & Spring & Summer & Autumn & Winter & Annual \\
\hline Mean $\ldots$ & $\ldots$ & 52.5 & 60.8 & 53.2 & 43.1 & 52.4 \\
Maximum & $\ldots$ & 61.9 & 70.9 & 62.3 & 48.6 & 61.6 \\
Minimum & $\ldots$ & 43.1 & 50.9 & 44.3 & 35.1 & 43.3 \\
& \multicolumn{5}{|c|}{ OTAGO } \\
Mean ... & $\ldots$ & 50.4 & 57.9 & 51.0 & 41.5 & 50.2 \\
Maximum & $\ldots .$. & 59.5 & 67.5 & 59.1 & 48.1 & 58.5 \\
Minimum &.. & 51.5 & 48.2 & 43.0 & 35.0 & 41.9 \\
\hline
\end{tabular}

Hence it will be seen that the temperature is more even over the seasons than is common; moreover, that while the summers are cool for the most part, the winters are mild.

(c) Rainfall.-Throughout the country rainfall varies 
in the main from 20 to 100 inches, and in a few scattered localities lies outside these limits, being as low as 10 inches in Central Otago and as high as 120 inches on the West Coast. The most suitable rainfall for wheat production lies between the limits of 20 and 30 inches, though it will thrive on from 10 to 15 inches, as is shown by the ease of Australia. Throughout the wheat producing area the average annual rainfall for 36 years was about 25.5 inches as recorded by the meteorological stations.

How far these observations are representative is a matter open to question, as there is no station in South Canterbury. For the purpose of ascertaining the distribution of rainfall further enquiries were made, and private individuals, who had kept records, were asked to furnish reports of such. It was a matter of great surprise to find that these records were very few indeed. and that the farming community which is so vitally concerned with the amount and distribution of the rainfall, was almost totally ignorant on the whole question. But out of the few records obtainable a comprehensive one was forthcoming from the very centre of production in South Canterbury, and this shows for the years 1890-1914 variations in amount from $15 \cdot 1$ inches in 1890 to $37 \cdot 0$ inches in 1899 . But these are exceptional years, and the average for the 25 years was $22 \cdot 2$ inches, a figure almost ideally suitable for wheat production.

From these statistics we are able to state, with a high degree of confidence, that the rainfall is more or less evenly distributed over the wheat producing area. It is, nevertheless, a matter of great regret that there is no meteorological station in South Canterbury. There is no doubt as to the value of climatic observations, and steps should be taken to establish a station in the district immediately, and to collect what records of meteorology have been taken in the past.

(d) Observations on Connection Between Yields and Rainfall.-While discussing the question of rainfall, it will be expedient to consider the nature of the connection 
TABLE $X$.

CORRELATION BETWEEN YIELD AND "USEFUL" RAINFALL (MAY-NOVEMBER) FOR CANTERBURY, 1871 to 1913.

\begin{tabular}{|c|c|c|c|c|c|c|c|}
\hline \multirow{2}{*}{ YEAR } & \multicolumn{3}{|c|}{ RAINFALL } & \multicolumn{3}{|c|}{ YIELD } & \multirow{2}{*}{$\begin{array}{l}\text { Product } \\
\text { of Devi- } \\
\text { ations }\end{array}$} \\
\hline & $\begin{array}{c}\text { May-Nov. } \\
\text { Inches }\end{array}$ & $\begin{array}{c}\text { Devi- } \\
\text { ations }\end{array}$ & Squares & $\left|\begin{array}{c}\text { Per Ac. } \\
\text { Bush. }\end{array}\right|$ & $\begin{array}{c}\text { Devi- } \\
\text { ations }\end{array}$ & Squares & \\
\hline 1871 & 15.7 & +.5 & .25 & 21.5 & -3.5 & 12.25 & -1.75 \\
\hline 2 & 9.8 & -5.4 & 29.16 & 21.8 & -3.2 & 10.24 & +17.28 \\
\hline 3 & 16.8 & +1.4 & 1.96 & 23.8 & -1.2 & 1.44 & -1.68 \\
\hline 4 & 14.6 & -0.6 & .36 & 26.0 & +1.0 & 1.00 & .60 \\
\hline 5 & 25.6 & +10.4 & 106.16 & 30.8 & +5.8 & 33.64 & +60.32 \\
\hline 6 & 12.2 & -3.0 & 9.00 & 28.3 & +3.3 & 10.89 & -9.90 \\
\hline 7 & 11.1 & -4.1 & 16.81 & 32.0 & +7.0 & 49.00 & -28.70 \\
\hline 8 & 8.8 & -6.4 & 40.96 & 21.0 & -4.0 & 16.00 & +25.60 \\
\hline 9 & 16.0 & +0.8 & .64 & 28.0 & +3.0 & 9.00 & +2.40 \\
\hline 1880 & 11.4 & -3.8 & 14.44 & 23.8 & -1.2 & 1.44 & +4.56 \\
\hline 1 & 23.4 & +8.2 & 67.24 & 21.3 & -3.7 & 13.69 & -30.34 \\
\hline 2 & 14.9 & -0.3 & .09 & 25.5 & +0.5 & 0.25 & -0.15 \\
\hline 3 & 18.2 & +3.0 & 9.00 & 25.6 & +0.6 & 0.36 & +1.80 \\
\hline 4 & 16.1 & +0.9 & .81 & 24.4 & -0.6 & 0.36 & -0.45 \\
\hline 5 & 12.8 & -2.4 & 5.76 & 24.0 & -1.0 & 1.00 & +2.40 \\
\hline 6 & 24.8 & +9.6 & 92.16 & 23.7 & -1.3 & 1.69 & -12.48 \\
\hline 7 & 25.9 & +10.7 & 114.49 & 25.0 & - & - & - \\
\hline 8 & 18.6 & +3.4 & 11.56 & 22.9 & -2.1 & 4.41 & -7.14 \\
\hline 9 & 12.7 & -2.5 & 6.25 & 24.3 & -0.7 & 0.49 & +1.75 \\
\hline 1890 & 10.7 & -4.5 & 20.25 & 17.9 & -7.1 & 50.41 & +31.95 \\
\hline 1 & 10.2 & -5.0 & 25.00 & 24.9 & -0.1 & .01 & +0.50 \\
\hline 2 & 16.7 & +1.5 & 2.25 & 21.0 & -4.0 & 16.00 & -6.00 \\
\hline 3 & 11.3 & -3.9 & 15.21 & 19.6 & -5.4 & 29.16 & +21.06 \\
\hline 4 & 17.5 & +2.3 & 5.29 & 23.7 & -1.3 & 1.69 & -2.99 \\
\hline 5 & 19.9 & +4.7 & 22.09 & 27.0 & +2.0 & $4 \cdot 00$ & +9.40 \\
\hline 6 & 16.2 & +1.0 & 1.00 & 21.0 & -4.0 & 16.00 & -4.00 \\
\hline 7 & 8.0 & -7.2 & 51.84 & 15.1 & -9.9 & 98.01 & +71.28 \\
\hline $\begin{array}{l}8 \\
9\end{array}$ & 12.6 & -2.6 & 6.76 & 33.7 & +8.7 & 75.69 & -22.62 \\
\hline 1900 & & & & & & & \\
\hline $\begin{array}{l}1 \\
2\end{array}$ & 11.0 & -4.2 & 17.64 & 23.7 & -1.3 & 1.69 & +5.46 \\
\hline 3 & 12.2 & -3.0 & 9.00 & 34.2 & +9.2 & 84.64 & -27.60 \\
\hline 4 & 18.0 & +2.8 & 7.84 & 35.0 & +10.0 & 100.00 & +28.00 \\
\hline 5 & 20.5 & +5.3 & 28.09 & 30.4 & +5.4 & 29.16 & +28.72 \\
\hline 6 & 15.0 & -0.2 & .04 & 28.1 & +3.1 & 9.61 & -0.62 \\
\hline 7 & 12.3 & -2.9 & 8.41 & 28.2 & +3.2 & 10.24 & -9.28 \\
\hline 8 & 15.2 & +0.0 & - & 35.6 & +10.6 & 112.36 & - \\
\hline 9 & 15.5 & +0.3 & .09 & 27.8 & +2.8 & 7.84 & +0.84 \\
\hline 1910 & 13.3 & -1.9 & 3.61 & 26.0 & +1.0 & 1.00 & -1.90 \\
\hline 11 & 19.9 & +4.7 & 22.09 & 34.3 & +9.3 & 86.49 & +43.71 \\
\hline 12 & 17.3 & +2.1 & 4.41 & 26.6 & +1.6 & 2.56 & +3.36 \\
\hline \multirow[t]{2}{*}{13} & 16.9 & +1.7 & 2.89 & 31.6 & +6.6 & 43.56 & +11.22 \\
\hline & \multicolumn{2}{|c|}{ Sum of Squares } & 780.90 & \multicolumn{3}{|c|}{ Sum of Squares 867.27} & +203.41 \\
\hline
\end{tabular}


STANDARD DEVIATION OF RAINFALL $=\sqrt{\frac{780.90}{40}}$

$$
\begin{aligned}
& =\sqrt{19.02} \\
& =\sqrt{\frac{4.36}{867.27}} \\
& =\sqrt{\frac{40}{21.68}} \\
& =\frac{4.65}{+203.41} \\
& =\frac{+40 \times 4.36 \times 4.65}{}
\end{aligned}
$$

STANDARD DEVIATION OF YIELD

CO-EFFICIENT OF CORRELATION$$
=+.250
$$

PROBABLE ERROR

$$
\begin{aligned}
& =\frac{1-(.250)^{2} \times 6745}{\sqrt{40}} \\
& =\frac{.1}{}
\end{aligned}
$$

between rainfall and yields in New Zealand as far as it is possible with the information I have been able to collect.

The method adopted has been to ascertain the coefficient of correlation between yields and rainfall over a series of years. Rainfall records at Lincoln meteorological station were used, and the rainfall for the seven months (May to November) was taken as the most important. But it is doubtful whether it would not have been more appropriate to have taken the rainfall from August to December, as it is during these months that the crop is really growing and ripening. In the opinion of many persons who are interested in agriculture, the rainfall for May and June is not of great importance; for the ground is regarded as being moist enough during those months whatever rainfall is experienced, and provided a good spring rainfall is forthcoming, a good yield should follow in any case. But this opens up a further line of investigation, for which time is not available at present. The principle is the same, and the only difference would be to take rainfall statistics for the months August to December, and then proceed along the same lines as are here indicated. 


\section{Yield in Bushels per Acro.}

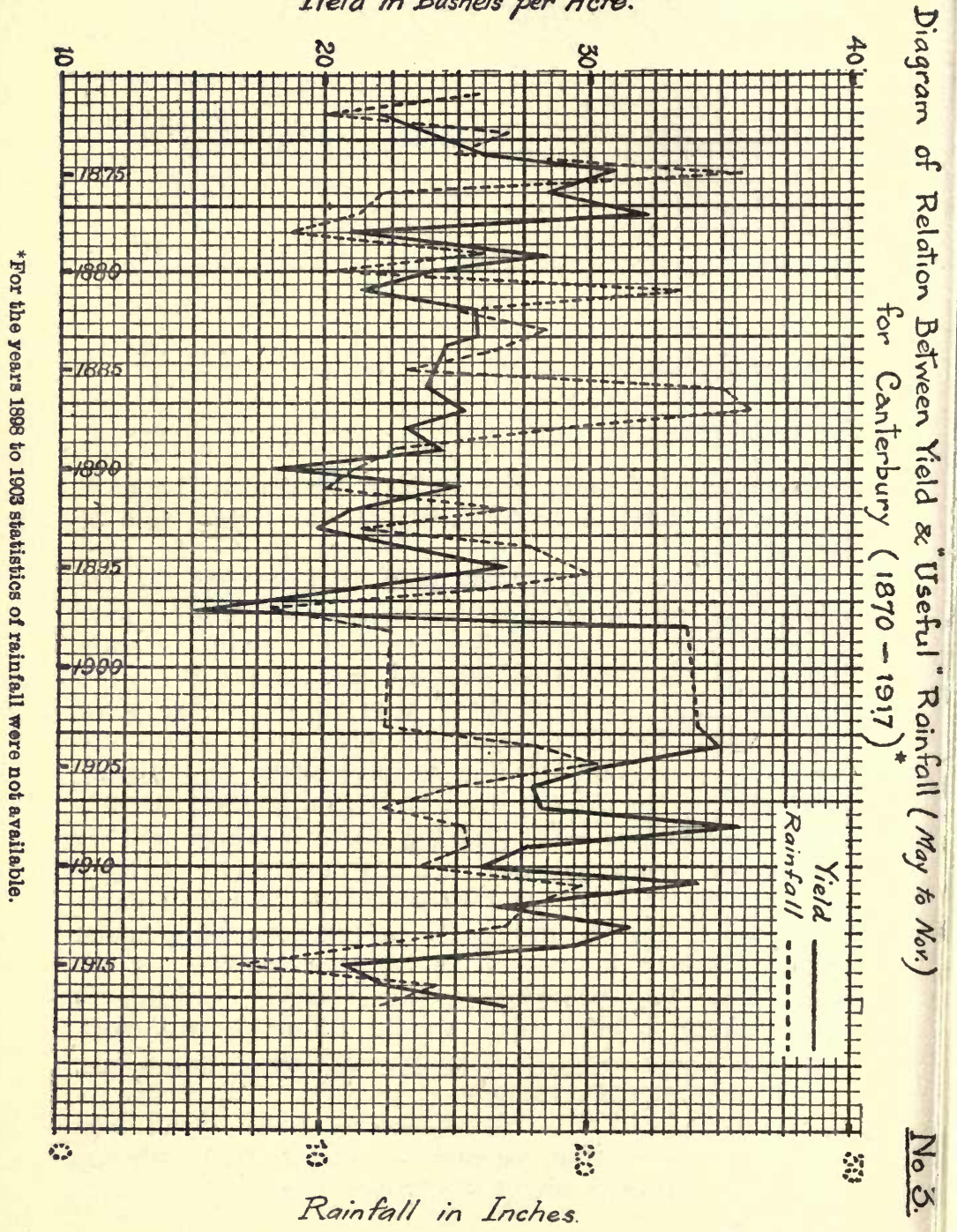


Yield in Bushels per Acre.

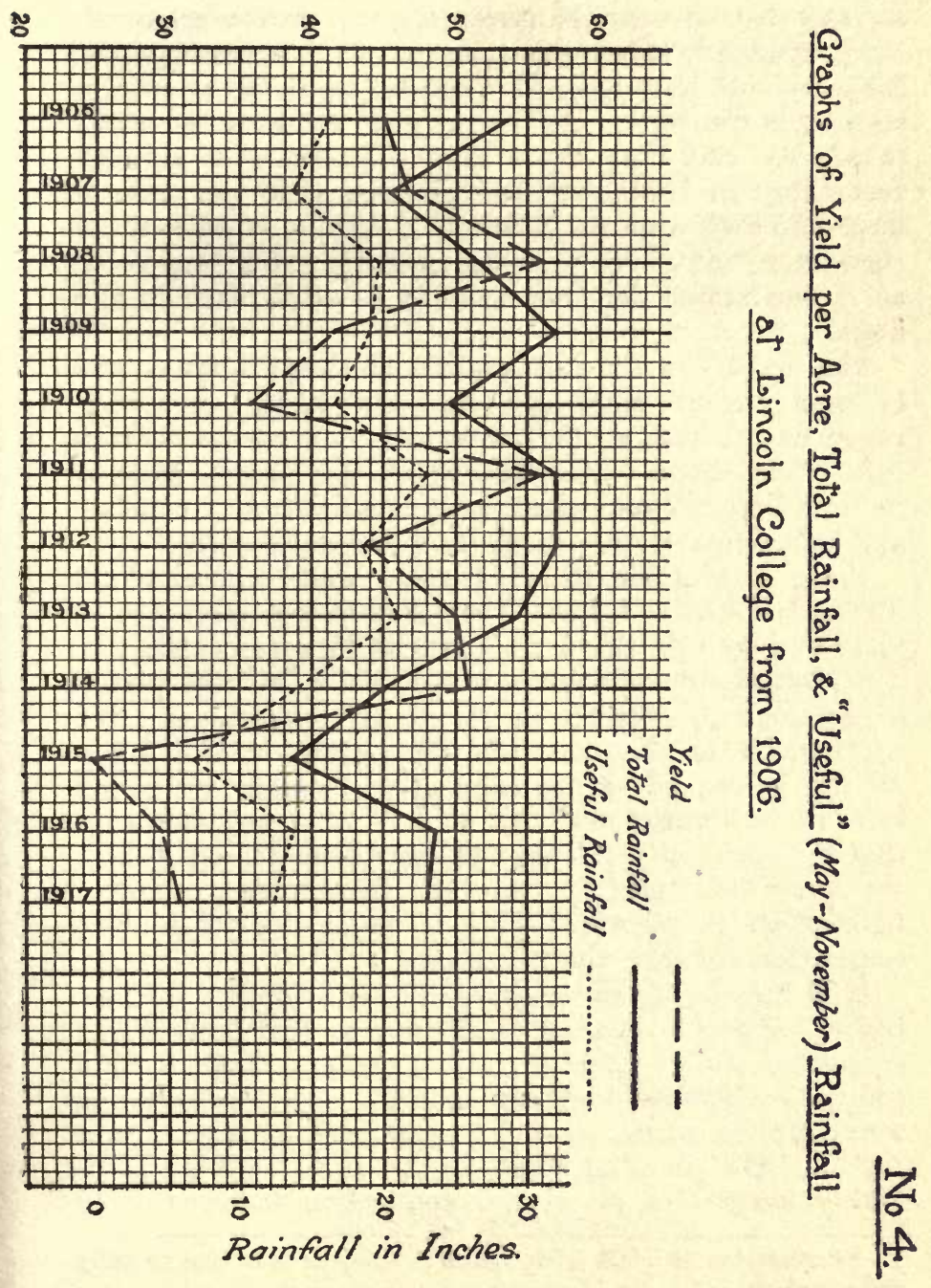


The yield per acre for the whole province of Canterbury had to be taken because no separate continuous statistics for any district near the meteorological station are available. Probably this is the weak spot in the investigation: for we should have composite rainfall statistics at several stations in Canterbury, when the yield refers to the whole province. But with the available statisties of rainfall from May to November and average yield per acre, I have obtained over the years 1871-1913 a co-efficient of correlation* of $+\cdot 251$. As the probable error is as much as 1 correlation does not seem to be established in any degree.

The defects in the information as shown above, must be kept in mind, as also the fact that wheat has a wide range of rainfall, so that a country where the average rainfall is about in the middle of this range, as it is in New Zealand, may show wide fluctuations in rainfall, and get comparatively small fluctuations in yield.

From the Agricultural College and Experimental Farm at Lincoln I have been able to get statistics of yield and rainfall there, for the past 12 years (1906-17). The statistics are shown in graph No. 4 , but the period is too short to afford a conclusion of importance. The continuance of these records will provide useful information in regard to the connection between yield and rainfall in Canterbury. It may be observed, however, that the curve of yield per acre moves in sympathy with the curve of "useful" rainfall, though the range of fluctuation is greater. This is suggestive of a close connection between the two series.

It is interesting to compare similar statistics in Australia. A graph showing yield per acre for Victoria and composite winter rainfall (May-October) shows a vita] connection between yield and rainfall. This information was supplied to me by the Department of Agriculture for Victoria, and the result in the form of a graph is highly suggestive of a vital connection between yield

*Correlation is dealt with again in Chapter VI., and is fully explained in Appendix II. 


\section{Rainfall in Inches}

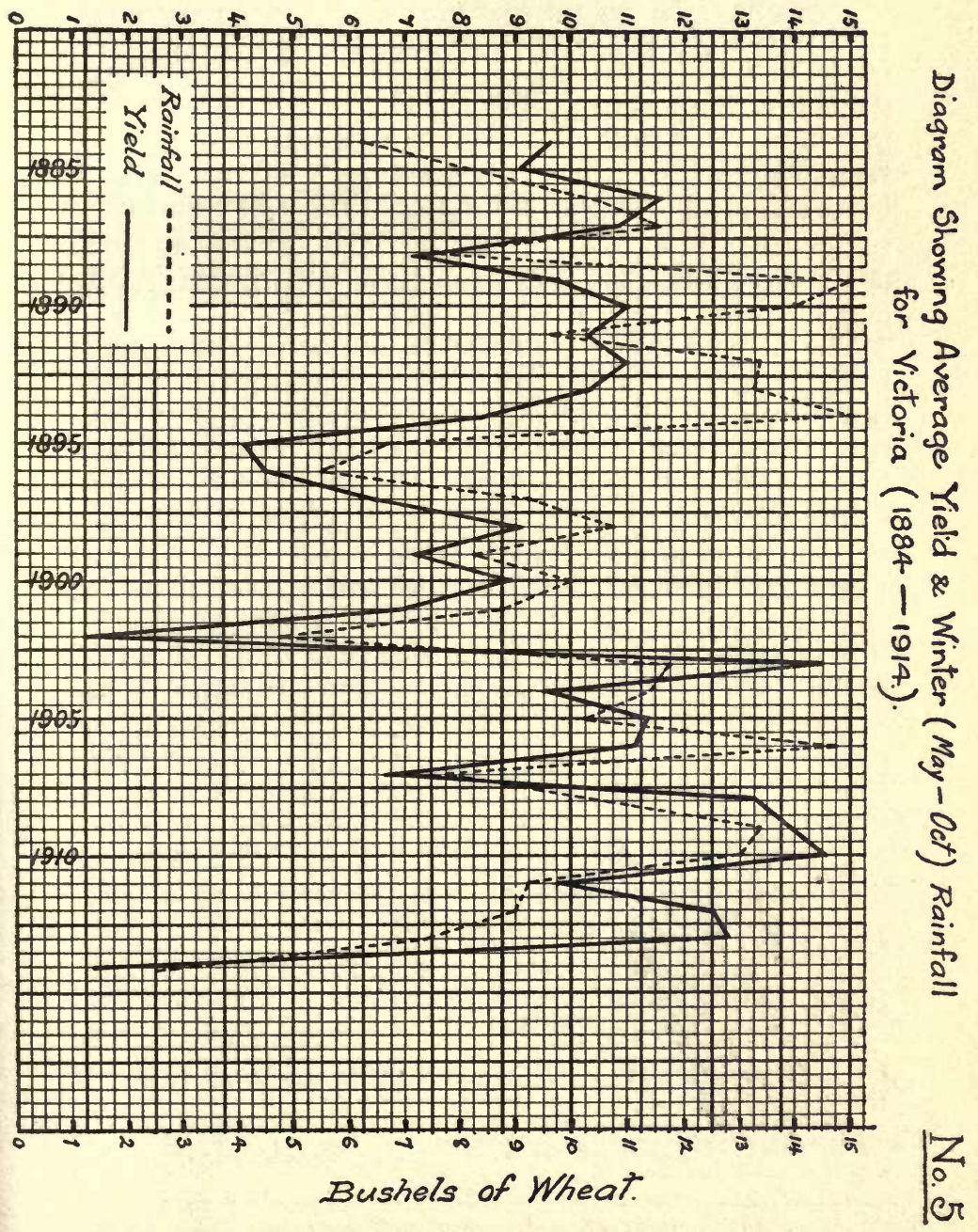


TABLE XI.

WHEAT YIELD AND RAINFALL. CORRELATION BETWEEN YIELD AND COMPOSITE WINTER RAINFALL (MAY-OCTOBER) FOR VICTORIA,

1884-1913

\begin{tabular}{|c|c|c|c|c|c|c|c|}
\hline \multirow[b]{2}{*}{ Year } & \multicolumn{3}{|c|}{ YIELD } & \multicolumn{3}{|c|}{ RAINFALL } & \multirow{2}{*}{$\begin{array}{l}\text { Products } \\
\text { of Devia- } \\
\text { tions }\end{array}$} \\
\hline & $\begin{array}{l}\text { Yield in } \\
\text { Bushels } \\
\text { per Acre }\end{array}$ & Deviation & Squares & $\begin{array}{c}\text { Rainfall } \\
\text { May-Oct. } \\
\text { inches }\end{array}$ & $\begin{array}{c}\text { Devis } \\
\text { tion }\end{array}$ & Squares & \\
\hline 1884 & 9.5 & -0.1 & 0.01 & 6.3 & -3.9 & 15.21 & +0.39 \\
\hline 5 & 9.1 & -0.5 & 0.25 & 8.7 & -1.5 & 2.25 & +0.75 \\
\hline 6 & 11.5 & +1.9 & 3.61 & 10.5 & +0.3 & 0.09 & +0.57 \\
\hline 7 & 10.8 & +1.2 & 1.44 & 11.6 & +1.4 & 1.96 & +1.68 \\
\hline 8 & 7.2 & -2.5 & 6.25 & 6.9 & -3.3 & 10.89 & +8.25 \\
\hline 9 & 9.7 & +0.1 & 0.01 & 15.1 & +4.9 & 24.01 & +0.49 \\
\hline 1890 & 11.2 & +1.6 & 2.56 & 13.8 & +3.6 & 12.96 & +5.76 \\
\hline 1 & 10.3 & +0.7 & 0.49 & 9.5 & -0.7 & 0.49 & -0.49 \\
\hline 2 & 10.9 & +1.3 & 1.69 & 13.3 & +3.1 & 9.61 & +4.03 \\
\hline 3 & 10.3 & +0.7 & 0.49 & 13.2 & +3.0 & 9.00 & +2.10 \\
\hline 4 & 8.3 & -1.3 & 1.69 & 15.1 & +4.9 & 24.01 & -6.37 \\
\hline 5 & 4.0 & -5.6 & 31.36 & 6.6 & -3.6 & 12.96 & +20.16 \\
\hline 6 & 4.5 & -5.1 & 26.01 & 5.5 & -4.7 & 22.07 & +23.97 \\
\hline 7 & 6.4 & -3.2 & 10.24 & 9.2 & -1.0 & 1.00 & $\begin{array}{r}3.20 \\
+\quad 3.2\end{array}$ \\
\hline 8 & 9.1 & -0.5 & 0.25 & 10.8 & +0.6 & 0.36 & -0.30 \\
\hline 9 & 7.2 & -2.4 & 5.76 & 8.2 & -2.0 & 4.00 & -4.80 \\
\hline 1900 & 8.8 & -0.8 & 0.64 & 9.9 & -0.3 & 0.09 & +0.24 \\
\hline 1 & 6.9 & -2.7 & 7.29 & 8.8 & -1.5 & 2.25 & +4.05 \\
\hline 2 & 1.3 & -8.3 & 68.89 & 4.6 & -5.6 & 31.36 & +46.58 \\
\hline 9 & 14.5 & +4.9 & 24.01 & 11.8 & +1.6 & 2.56 & +7.84 \\
\hline 4 & 9.5 & -0.1 & .01 & 11.4 & +1.2 & 1.44 & -0.12 \\
\hline 5 & 11.3 & +1.7 & 2.89 & 10.2 & 0.0 & $\cdots$ & ... \\
\hline 6 & 11.2 & +1.6 & 2.56 & 14.8 & +4.6 & 21.16 & +7.36 \\
\hline 7 & 6.6 & -3.0 & 9.00 & 7.8 & -2.4 & 5.72 & $\begin{array}{r}7.20 \\
+70\end{array}$ \\
\hline 8 & 13.2 & +3.6 & 12.96 & 10.6 & +0.4 & 0.16 & +1.44 \\
\hline & 13.8 & +4.2 & 17.64 & 13.5 & +3.3 & 10.89 & +13.86 \\
\hline 1910 & 14.5 & +4.9 & 24.01 & 13.1 & +2.9 & 8.41 & +14.21 \\
\hline 1 & 9.8 & +0.2 & 0.04 & 9.1 & -1.1 & 1.21 & -0.22 \\
\hline 2 & 12.6 & +3.0 & 9.00 & 8.9 & -1.3 & 1.69 & -0.39 \\
\hline \multirow[t]{2}{*}{3} & 12.8 & $\begin{array}{r}+3.2 \\
\end{array}$ & 10.24 & 7.4 & -2.8 & 7.84 & -8.46 \\
\hline & \multicolumn{3}{|c|}{ Sum of Squares $=281.29$} & \multicolumn{3}{|c|}{ Sum of Squares 245.65} & +158.2 \\
\hline
\end{tabular}

STANDARD DEVIATION OF YIELD

$$
\begin{aligned}
& =\sqrt{\frac{281.29}{30}} \\
& =\sqrt{\frac{9.30}{3.06}}
\end{aligned}
$$




\begin{aligned} & STANDARD DEVIATION OF RAINFALI $=\sqrt{\frac{245.65}{30}} \\ &=\sqrt{8.19} \\ &=\frac{2.85}{30 \times 3.06 \times 2.85} \\ &$ CO-EFFICIENT OF CORRELATION $=\frac{+158.20}{1-(.602)^{2} \times .6745} \\ &$ PROBABLE ERROR $=\frac{1.0786}{\sqrt{30}} \\ &$\hline\end{aligned}

and rainfall for that state, and $a$ priori for the whole of Australia. Fluctuations in rainfall are invariably followed by fluctuations of a similar nature in yield.

The co-efficient of correlation between these two series is +.602 and the probable error only .08 , so that correlation may be regarded as a practical certainty, according to Professor Bowley, who takes as one test of correlation a probable error of less than one sixth of the co-efficient of correlation.

From the graphs for New Zealand and Australia given here many interesting conclusions could be drawn, but we must content ourselves with a brief summary of results.*

The correlation between yield and rainfall in Australia is more vital than it is in New Zealand, because Australian rainfall is so small that fluctuations either way greatly affect the productivity of the soil. In New Zealand, on the contrary, it is only in very exceptional circumstances that rainfall is so low as to interfere greatly with productivity, while it is generally of such an amount that an increase does not add much to the yield of produce.

This conclusion adds further to the contention that from the point of view of rainfall, New Zealand enjoys a differential advantage in wheat production.

* Statistics from Lincoln College, Canterbury, and Roseworthy College, South Australia, are given in Table XII., and they support the general conclusions arrived at here. 
TABLE XII. WHEAT YIELD AND RAINFALL.

Relation between Yield and "Useful" Rainfall in Canterbury, 1871-1913; Victoria, 1884-1913 ; Lincoln College, 1906-1914: and Roseworthy College, 1904-1914.

\begin{tabular}{|c|c|c|c|c|c|c|c|c|}
\hline \multirow{3}{*}{ YEAR } & \multicolumn{2}{|c|}{ Canterbury } & \multicolumn{2}{|c|}{ Victoria } & \multicolumn{2}{|c|}{$\begin{array}{l}\text { Lincoln } \\
\text { College } \\
\end{array}$} & \multicolumn{2}{|c|}{$\begin{array}{c}\text { Roseworthy } \\
\text { College }\end{array}$} \\
\hline & * Yield & $\begin{array}{l}\text { Usoful } \\
\text { Rainf' }\end{array}$ & Yield & $\begin{array}{l}\text { Useful } \\
\text { Rainf'1 } \\
\end{array}$ & *Yield & $\begin{array}{l}\text { Useful } \\
\text { Rainf'l }\end{array}$ & Yield & $\begin{array}{l}\text { Useful } \\
\text { Rainf'l }\end{array}$ \\
\hline & Bus. & inches & Bus. & inches & Bus. & inches & Bus. & inches \\
\hline 1871 & 21.5 & 15.7 & & & & & & \\
\hline 72 & 21.8 & 9.8 & & & & & & \\
\hline 73 & 23.8 & 16.8 & & & & & & \\
\hline 74 & 26.0 & 14.6 & & & & & & \\
\hline 75 & 30.8 & 25.6 & & & & & & \\
\hline 76 & 28.3 & 12.2 & & & & & & \\
\hline 77 & 32.0 & 11.1 & & & & & & \\
\hline 78 & 21.0 & 8.8 & & & & & & \\
\hline 79 & 28.0 & 16.0 & & & & & & \\
\hline 1880 & 23.8 & 11.4 & & & & & & \\
\hline 81 & 21.3 & 23.4 & & & & & & \\
\hline 82 & 25.5 & 14.9 & & & & & & \\
\hline 83 & 25.6 & 18.2 & & & & & & \\
\hline 84 & 24.4 & 16.1 & 9.5 & 6.3 & & & & \\
\hline 85 & 24.0 & 12.8 & 9.1 & 8.7 & & & & \\
\hline 86 & 23.7 & 24.8 & 11.5 & 10.5 & & & & \\
\hline 87 & 25.0 & 25.9 & 10.8 & 11.6 & & & & \\
\hline 88 & 22.9 & 18.6 & 7.21 & 6.9 & & & & \\
\hline 89 & 24.3 & 12.7 & 9.7 & 15.1 & & & & \\
\hline 1890 & 17.9 & 10.7 & 11.2 & 13.8 & & & & \\
\hline 91 & 24.9 & 10.2 & 10.3 & 9.5 & & & & \\
\hline 92 & 21.0 & 16.7 & 10.9 & 13.3 & & & & \\
\hline 93 & 19.6 & 11.3 & 10.3 & 13.2 & & & & \\
\hline 94 & 23.7 & 17.5 & 8.3 & 15.1 & & & & \\
\hline 95 & 27.0 & 19.9 & 4.0 & 6.6 & & & & \\
\hline 96 & 21.0 & 16.2 & 4.5 & 5.5 & & & & \\
\hline 97 & 15.1 & 8.0 & 6.4 & 9.2 & & & & \\
\hline 98 & 33.7 & 12.6 & 9.1 & 10.8 & & & & \\
\hline 99 & & & 7.2 & 8.2 & & & & \\
\hline 1900 & & & 8.8 & 9.9 & & & & \\
\hline 01 & 23.7 & 11.0 & 6.9 & 8.8 & & & & \\
\hline 02 & & & 1.3 & 4.6 & & & & \\
\hline 03 & 34.2 & 12.2 & 14.5 & 11.8 & & & & \\
\hline 04 & 35.0 & 18.0 & 9.5 & 11.4 & & & 18.0 & 11.60 \\
\hline 05 & 30.4 & 20.5 & 11.3 & 10.2 & & & 24.2 & 14.23 \\
\hline 06 & 28.1 & 15.0 & 11.2 & 14.8 & 49 & 16.02 & 14.5 & 16.30 \\
\hline 07 & 28.2 & 12.3 & 6.6 & 7.8 & 45 & 13.17 & 13.3 & 13.81 \\
\hline 08 & 35.6 & 15.2 & 13.2 & 10.6 & 46 & 19.17 & 22.2 & 15.53 \\
\hline 09 & 27.8 & 15.5 & 13.8 & 13.5 & 56 & 18.61 & 25.1 & 21.15 \\
\hline 1910 & 26.0 & 13.3 & 14.5 & 13.1 & 41 & 16.19 & 16.6 & 16.79 \\
\hline 11 & 34.3 & 19.9 & 9.8 & 9.1 & 36 & 25.60 & 14.3 & 9.46 \\
\hline 12 & 26.6 & 17.8 & 12.6 & 8.9 & 56 & 18.80 & 19.6 & 13.05 \\
\hline 13 & 31.6 & 16.9 & 12.8 & 7.4 & 44 & 20.90 & 6.5 & 10.82 \\
\hline 14 & 29.6 & 11.3 & & & 50 & 13.42 & 11.5 & 6.12 \\
\hline 15 & 20.8 & 6.8 & & & 24 & 6.75 & 21.22 & 18.33 \\
\hline 16 & 22.3 & 14.4 & & & 30 & 14.42 & 24.73 & 20.25 \\
\hline 17 & 27.0 & 12.3 & & & 30 & 12.28 & 17.53 & 17.25 \\
\hline
\end{tabular}


(e) Winds.-The greatest disadvantage which our wheat producing area suffers in respect of climatic conditions is the prevalence of very strong winds coming from the West Coast. They bring plentiful supplies of moisture; but this is deposited before they cross the Mountain Ranges, after which they blow with the strength of a gale, at times, across the Canterbury Plains as hot dry winds commonly known as the "Nor' Westers." Their strength, however, is now much abated by the growth of plantations over the country. and it is only occasionally that they do any very serious damage to the crops. At Lincoln, which occupies a fairly central position in the area of these winds, the average velocity of the wind per day, over 13 years, was 135 miles, while the maximum velocity registered in any one day was 693 miles.

But the very causes which are responsible for these winds are themselves highly beneficial to the agricultural community of the area over which the winds blow. The nor' wester of Canterbury is a continuation of a wind which blows across the Tasman Sea, and reaches the West Coast of New Zealand laden with moisture. Fortunately for Canterbury the Southern Alps intervene and cause the wind to deposit its moisture on the slopes of the mountains, after which it comes across the plains as a hot dry wind. Were it not for these intervening mountains wheat production in Canterbury and Otago would be almost non-existent, on account of the increased rainfall which would result.

The nor' wester is further benefieial to wheat production on account of the influence it exerts during the ripening period, because it is then that it is at its maximum frequency and velocity. It is doubtful, however, whether this beneficial influence is not off set by the detrimental effects that wind has in "shaking out" the crops.*

*This wind is also of extreme importance in the pastoral industry, as it largely accounts for the character of the dry pasture which produces a high quality mutton. 
( $f$ ) Summary and Conclusion.-On the whole, the New Zealand climate is very beneficial to the growth of a vigorous and healthy population. No greater tribute can be paid to the climate of the Dominion than the fact that the Maori race, which the Europeans found here on their arrival, was characterised by a vigour and determination rare among uncivilised races. Undoubtedly, natural environment contributed considerably to its fine physique, intelligence, and character.

Further, the fertility of the soil gives remarkable testimony to the genial climate of New Zealand; for in agricultural yields the Dominion can compare with any other country in the world.

Lastly, the vital statisties show the lowest death rate in the world, and this is undoubtedly due largely to the salubrity of its climate.

\section{Cultural Methods.}

The necessity of paying close attention to the cultivation of the soil is a matter the importance of which has been emphasised already in the previous chapter. Two main objects should be kept in view when any method of cultivation is adopted:-

(1) Conservation of moisture in the soil ; and

(2) Conservation of fertility.

Methods which ignore the importance of either of these are not likely to afford the best results, but will ultimately prove disastrous, both to the farmer and to the community.

For the first of these objects attention must be directed to the necessity of fallowing the land, while for soil fertility a consideration of crop rotation and artificial fertilisation of the soil is necessary. The latter has already received due attention under another heading. It remains to consider the importance of fallowing.

The greatest advantage of bare fallowing is that it permits the farmer to obtain the maximum benefit from the rainfall, for fallowed land will preserve tho 
moisture in it from the previous season. Proof of this is not wanting; for experiments tried in Australia, at Rutherglen Viticultural College in Victoria afford the following interesting results:-

\section{TABLE XIII.}

Percentage of moisture on fallowed and non-fallowed land prior to seeding, 1st May, 1912. Rutherglen Viticultural College, Victoria :-

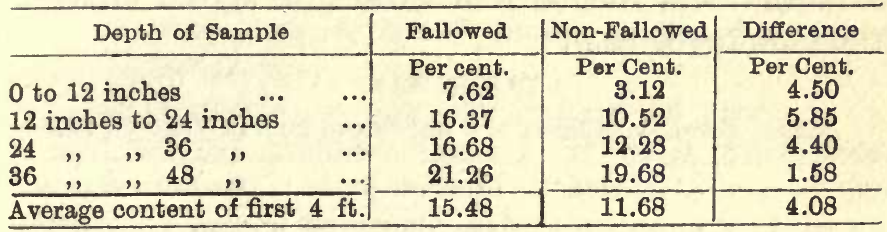

Hence assuming the weight of 1 acre of dry soil to be approximately 3,500,000 lbs., it follows that in the first 4 feet of the Rutherglen fallow there were 571,200 lbs. more water per acre than in the non-fallowed land; i.e., an amount equal to approximately $2 \frac{1}{2}$ inches of rainfall.

A second great advantage from fallowing arises from the fact that it increases the supply of available plant food. While the land is lying in fallow during the summer months, many chemical and biological changes take place within the body of the soil, and result in the liberation of plant food. Experience proves that there is a substantial increase in nitrates, ${ }^{*}$ and there can be little doubt that other important plant foods, particularly potash and phosphoric acid, are converted from unavailable to available forms.

Thirdly, fallowing distributes the work on the farm evenly throughout the year; for it enables the wheat

*For example, at Longernong in Victoria, on fallowed land, on 7 th December, 1911, there was found to be $57 \cdot 75 \mathrm{lbs}$. of nitrogen per acre present as nitrate in the first 5 feet. On 1st April, 1912, this amount had increased to $105 \mathrm{lbs}$. in the same volume of soil. 
grower to have ready in autumn large areas in the best state of tilth to receive the seed as soon as weather conditions are favourable to sowing.

Finally, many subsidiary advantages accrue from fallowing. The land is cleaned of weeds, and a consolidated seed bed is the more easily made.*

The following table will sum up effectively what has been said with reference to wheat growing on fallowed and unfallowed land.

TABLE XIV.

Wheat grown on fallowed and unfallowed land in Victoria, 1908.

\begin{tabular}{llll|r|r|r|r}
\hline & & & \multicolumn{2}{|c|}{ Fallowed Land } & \multicolumn{2}{c}{ Non-Fallowed Land } \\
\cline { 5 - 7 } & & & & Area & $\begin{array}{c}\text { Average } \\
\text { Yield }\end{array}$ & Area & $\begin{array}{c}\text { Average } \\
\text { Yield }\end{array}$ \\
\hline Wimmera & $\ldots$ & $\ldots$ & $\ldots$ & 69,834 & $\mathbf{1 1 . 8 2}$ & 27,520 & 5.75 \\
Mallee & $\ldots$ & $\ldots$ & $\ldots$ & 31,963 & 5.75 & 20,908 & 2.62 \\
Northern & $\ldots$ & $\ldots$ & $\ldots$ & 41,110 & 9.50 & 28,946 & 4.06 \\
Western & $\ldots$ & $\ldots$ & $\ldots$ & 4,821 & 17.93 & 5,993 & 13.47 \\
\hline
\end{tabular}

\section{Harvesting.}

The differential advantages which New Zealand enjoys on account of the fertility of her soil and the salubrity of her climate, are somewhat counteracted by her methods of harvesting. Not that these methods are inefficient; but as the area is not very large the application of very expensive machinery is not practicable, and, moreover, the fear of adverse weather conditions, mainly strong winds during the harvest, renders the use of such machines as the combined harvester, rather a precarious operation; for the wheat must be very ripe for the efficient employment of this machine, and when in this

*It must be noted that this discussion is not relevant to conditions in many parts of New Zealand where the rainfall is abundant. But where, as is often the case in Canterbury, the months October to January are dry, the question of fallowing is an important consideration. 
condition it is very easily "shaken." But, though our methods are costly they are none the less efficient, and the quality of wheat turned out under their operation is as good as general conditions allow. For the most part harvesting operations are divided into three steps:-

(1) Cutting with the reaper and binder and stooking by hand.

(2) Stacking after the crop has been in stook for some two or three weeks and is thoroughly hardened.

(3) Threshing at any time during the year.

The last two operations are, as far as is practicable, done in one by the system of "threshing out of the stook." There is a considerable advantage in this, on account of the quantities which can be threshed in a day with a few labourers; but weather conditions must be suitable and, further, the paucity of threshing plants limits the method very considerably, for farmers cannot wait when the weather is fine enough for stacking. Harvesting extends over a period of some 5 weeks on most farms under normal conditions, but adverse weather conditions, which of late have been rare, may extend the period considerably.

The specific cost of harvesting will be treated later. Enough has been said here to show that we have a rather cumbersome method. Circumstances, however, are responsible for this, and it will be shown later that the farmer possessed of good managing capabilities who is far-seeing enough can turn it to advantage, and find it a highly lucrative method.

\section{Note on the Harvester.}

The combined harvesters include all combinations of machines designed to leave both straw and chaff in the field and to deliver the wheat cleaned ready for market. The machine is the culmination of modern invention in harvesting machinery; for with it the wheat is cut, gathered, threshed, cleaned, and even sacked without a single touch from the human hand. Every operation 
except sewing up the sacks is mechanically and automatically performed by the application of horse or steam power. In economy, in capacity and thoroughness of work, in perfection of mechanical construction and in ease of operation, there is apparently little more to be attained. The machine is used only in dry climates where there is little fear of rain and no heavy dews.

The machine commences by heading the crop, after which the grain is threshed out in a type of drum not unlike that used in a threshing mill. The wheat is then cleaned and sacked, all these operations being performed by machinery.

There are two types of harvesters; one driven by horse power and the other by steam. The former requires from 24 to 40 horses with 4 men to operate it. It cuts a swath of from 16 to 20 feet wide, and harvests from 25 to 45 acres per day.

The steam harvester cuts a swath of from 24 to 42 feet wide, reqquires 8 men to work it, and cuts from 75 to 125 acres per day. This machine is much more complicated than the horse power one. It has an engine to drive the machinery of the harvester independent of the traction engine or motive power. The manufacturers of the machine claim for it that "the steam harvester can handle grain in almost any condition, whether it is standing, lodged, tangled or overgrown with weeds."

\section{Marketing.}

Here, again, New Zealand is wanting in organisation. What place the market for wheat in this country has in the evolution of markets it is hard to imagine. In the modern view as prevalent in most advanced countries, we in New Zealand have no systematised wheat market. Bargaining between isolated individuals functions in its place. A farmer, with no accurate knowledge of wheat prices, probably wholly ignorant of prices in the great wheat markets-arrives at a commercial centre with samples of his wheat. The only method open to him is to proceed to different millers or grain merchants in the town and endeavour to drive a bargain.

It is a very easy matter for the merchants to fix prices which they will give throughout the day for different kinds of wheat, and unless something unprecedented happens, that is the beginning and end of competition. Of course the farmer who is financially secure can wait 
for his own price, but the financial position of many of our farmers necessitates an immediate sale. Consequently they are at the mercy of circumstances which may be favourable or otherwise.

In forwarding our wheat to the market we experience a serious disadvantage, when compared with other countries, on account of the method of handling the grain. Our output is not large enough to warrant any system but that of handling in the sack. This consequently involves a great amount of labour which is not required in some other producing areas.

New Zealand railway facilities are somewhat inadequate for the traffic in the very busy season of the year. Small country stations experience considerable difficulty in getting the required number of trucks; and often the grain must be stacked at the station, sometimes outside the shed, which is a risky procedure, for an autumn rain would damage large quantities. Farmers throughout the country, however, recognise that the railway authorities meet them as far as is possible, but the lack of sufficient rolling stock is responsible for the delay in transportation.

The export of wheat varies from year to year, as reference to the graph of exportation will show.* It will be shown in Chapter VI. that the yearly exportation is a tolerably good index of the productivity of the industry in any year. What we are concerned with here is whether our methods of exporting are efficient. Details have already been given of the almost perfect system of marketing and exporting in the United States of America, and even if we remember that the widely differing circumstances of production and output somewhat nullify an attempt to compare New Zealand with that country, still such a comparison would not only show how much inferior are methods in New Zealand but would also open the way for reform. Mention has been

\footnotetext{
*See Graph VIII., page 101.
} 
made several times of the cumbersome method of handling wheat. This is, of course, necessitated by the smallness of the output and is unavoidable, for the more efficient method suitable only for large quantities would not be profitable for such a small output. Our grading system, however, is very inefficient, and might easily be improved with advantage to buyer and seller, especially the latter. The wheat is graded by the Secretary to the Chamber of Commerce, into three different classes. A standard sample of each class is picked, which is called the F.A.Q. (Fair Average Quality) sample. The wheat for each group is then sold at a price according as it is thought to be above or below the F.A.Q. sample for that group. The three groups are obtained from the three main kinds of wheat grown:-

(1) Pearl ;
(2) Tuscan;
(3) Hunter's.

These three varieties are by no means representative of the many varieties grown in New Zealand. Thus for Canterbury six classes are clearly distinguishable:Hunter's, White Straw Tuscan, Velvet Chaff Pearl, Smooth Chaff Pearl, Bordier, Federation, and under each of these several varieties are noticeable. For instance, in the class White Straw Tuscan we have Talavera; Marshall's White; Red Tuscan; Solid Straw Tuscan. The relative merits of these varieties will be considered in the next chapter. They are mentioned here to illustrate the inadequacy of our grading system, for all these varieties have to be grouped under the three heads given above. Consequently the real quality of New Zealand wheats is not known in foreign countries, which is to the disadvantage of the New Zealand producer. 


\section{Labour Conditions.}

The general efficiency of the New Zealand labourer is of a high order surpassed only by that of American workers. A generous and beneficial education system together with a congenial home and social environment, promotes the growth of those faculties of judgment, promptness, resource, carefulness and steadfastness of purpose which characterise the efficient worker. In short, the New Zealand labourer possesses in a remarkable degree that nervous strength which Dr. Marshall in his exposition* lays down as a necessary qualification for industrial efficiency.

(a) Necessity for Skilled Labour.-So much for the efficiency of labour generally. Let us pass to general labouring conditions in the wheat industry. At first sight the qualifications which the worker requires here do not appear to be of a high character. But when we look more closely we shall see that the farm labourer requires ability of no common nature, if he is going to be a success to himself and his employer. It is difficult to designate this labour as skilled or unskilled. Many of the operations involve mere routine, but the worker must be able to go beyond this to more complex tasks. Can we say that the ploughman who handles his plough and drives six horses to the fullest advantage is performing an unskilled operation? In the first place simple as the plough may appear to the casual observer, the technique of caring for it so as to prevent undue depreciation and of "setting" it to different kinds of ploughing requires more skill and knowledge than is apparent; and secondly, it is only a few who possess the special capabilities of caring for their horses and driving them efficiently.

Furthermore, the ploughman's tasks do not end at ploughing. He must possess a knowledge of the working

*"Principles of Economics." Book IV., Chaps. IV.-to VII. 
of all other farm implements including the drill, by which wheat, often along with manure, is sown.

When the harvest comes he is expected to be able to drive the reaper and binder, and very often to stack later. Our conclusion then must be, that the general farm labourer should possess sufficient skill to be classed among skilled labourers. Unfortunately the view ex pressed above is not held universally by our democracy. On the other hand, there is a great tendency to class farm labour as wholly unskilled. The routine work of the office is exalted above the manual labour of the farm, and there is a constant flow of our most capable country workers into the towns, where very often their capabilities are wasted in some routine task, solely for the purpose of enjoying the cheap pleasures and amusements of town life.

(b) Characteristics of Farm Labour.-The evil which is brought about by the current view of farm labour is that very often it is the workers who have been unsuccessful in town, whether through their incapability or their methods of living, who migrate to the country and take up employment there. While the farmer is able to obtain a certain supply of his labour from the vigorous country population, he has to be content in many cases to fill up the gap by the residue of town labourers. These labourers get through their task in a more or less efficient manner, but only under the very close supervision and constant attention of the farmer. Moreover, considerable losses from depreciation of plant and careless attention to horses are experienced, so that the farmer is paying a very high price for this kind of labour. Further, very many find their tasks a continual burden to them and take no pride in labour for its own sake. On the other hand, however, those labourers who are brought up on the farm develop an efficiency of a very rare kind. Most of them are interested in the 
administration and management of the whole farm and take a great pride in their daily tasks. Unfortunately, the supply of these men is not adequate to the amount of labour required, and so the farmer is very often harassed with poor labour.

On the whole the farm labourers are the most unorganised body of workers in New Zealand, perhaps the only large group which still remains unorganised. This is due to the heterogeneous collection of which the group is composed, and the large area over which they are scattered. Thus the beneficial effects of trades unionism in stimulating efficiency in particular trades is lost to this industry. On the other hand, however, the worker generally gets fair treatment, though he has to rely on his individual resources. This is due mainly to the fact that the farmers themselves have risen from the ranks of labour and still undertake many tasks, being on the whole a very hard-working community.

(c) Farm Labour and Trades Unionism.-Attempts have been made to get a farm labourers' award under the Arbitration Act. In 1908, some ardent trades unionists attempted this for the Canterbury Province. The farmers and sheepowners objected, and a very long and interesting case followed, at which evidence from the whole Province was taken on behalf of the three parties involved. Higher wages and regulated hours, better housing, and more recreation were aimed at by the workers' representative. The evidence went to show that efficient men were quite satisfied with their wages and hours as were the farmers. But the latter class objected strongly on account of the inefficiency of farm labourers. Some went so far as to say that 50 per cent of farm workers were incompetent, and under the Award these would be paid as highly as the competent men. The Court upheld their objection and the award was refused. The case though lost to the labourers, had the effect of 
procuring for them in some cases better conditions, while they began to realise that they were receiving fair terms at the hands of the farmers.*

(d) Labour Bureaux.-Another difficulty in the labour problem arises from the administration of labour bureaux where labourers offer their services and farmers engage them. The real difficulty is that efficiency is not given adequate consideration, and often labourers who are wholly incompetent are given employment under a misapprehension. On the other hand, the disadvantage is not all on the side of the farmer; for often the positions offered at the time do not come up to the expectations of the labourer. Great improvements, therefore, are possible in this department, which really lies at the foundation of the labour problem.

Here, then, we find an additional disadvantage under which New Zealand farming operations are conducteda disadvantage which is of paramount importance, for not infrequently do we find farmers giving as one of their reasons for partially abandoning wheat growing, the fact that the inefficiency of labour causes them trouble and expense which they have no desire to undertake.

(e) Seasonal Labour. - A further difficulty arising from the question of labour is experienced by our farmers. Much of the work is done at certain seasons

*The Labour Question is again discussed in Chapter IX. The case for Unionism in agricultural occupations has many peculiarities, but those conversant with recent tendencies in industrial evolution will readily realise that the problem of combination of Labour on the one hand and Capital on the other has risen above the clamour of party politics or the class war. This is evident in recent developments in England and elsewhere, where industrial reconstruction is under consideration. The discussions on this topic should be elearly grasped in New Zealand, and those interested would do well to study "The Whitley Report." Such a suggestion does not signify the present writer's adherence to the principles involved in that report. 
of the year, and at these times it is necessary for the farmer to increase his hands for a period. Thus in the winter and early spring the work of preparing the soil and sowing the seed requires many more farm labourers than are necessary during the summer. Then again at harvesting there is a keen demand for farm labour, for the satisfaction of which a large number of casual work. ers is necessary. But of recent years all the industries of New Zealand which employ such casual labour are in full operation at this period of the year. Thus freezing works are working up to their maximum efficiency as are consequently the transportation industries, which absorb much casual labour. The supply of such seasonal labour, as is necessary in the case of the wheat industry, is always a matter of difficulty, but in New Zealand this difficulty is exaggerated by the absorption of much casual labour by other more or less "seasonal" industries.

\section{Government Encouragement.*}

Directly and indirectly the State has assisted agriculture in New Zealand. The land legislation of the Dominion has undoubtedly contributed largely to the development of mixed farming, which is probably the most potent factor tending to advancement in the rural industries and to progress generally. The wheat industry in particular has received a measure of encouragement from the Government.

(a) Experimental Farms. - In the first place not a little advantage accrues from the growth of experimental farms and agricultural colleges, some of which are under the direct supervision of the Government, while others receive distinct advantages from the State though not under direct State control. There are six experimental farms in the Dominion, which carry out experiments and

*See Chapter X. 
demonstrations of national as well as of local importance. All forms of agricultural work are conducted at these farms, including dairying, sheepfarming, fruit growing, and wheat growing. Attached to three of the farms are a number of students who are being instructed in the most up-to-date methods of agriculture.

The instructional work covers a comprehensive area, all classes of farmers being assisted by advice. Agricultural literature, mostly in the form of quarterly journals, is issued, dealing with the latest investigations made, and instructing farmers as to the most efficient methods of farming. Our farmer may have his soil tested, his seed examined for germination capacity, his plants identified, and diseases of plants or animals investigated and a remedy suggested-all these services being free of charge.

A State endowed Agricultural College with an Experimental Farm attached is situated at Lincoln in the main wheat growing area, occupying a fairly central position. The main investigations here are concerned with wheat growing and wool raising. All modern methods of farming are adopted, and close records of all results are now being kept over the whole farm. The area of the farm is some 2,200 acres, and wheat is grown yearly on about 200 acres. The results of this for the last few years will be shown in statistical form in subsequent chapters.

Much research work is done by the Director and his assistants in discovering the relative merits of different varieties of wheat for growth in New Zealand climate and soil, in testing the efficacy of various fertilisers, in considering the best methods for cultivation, and in other kindred matters. The results of this work are placed at the disposal of the farmers throughout the country, and much good has been derived from this, especially in educating farmers to endeavour to realise their full opportunities. At the College in connection with the farm the technicalities of the various subjects connected 
with wheat growing are studied, and all students pass through a theoretical course along with their practical farming instructions. Quite recently the course for the degree of Bachelor of Agriculture has been instituted in the University of New Zealand, the technical part of which must be taken at the Agricultural College.

(b) Board of Agriculture. - In another respect the Government encourages agriculture by means of the establishment of a Department of Agriculture, Industries, and Commerce, under the direct Control of the Minister of Agriculture. Under the Act of 1913 this has been supplemented by the establishment of a Board of Agriculture, composed of twelve members whose functions are to advise the Minister of Agriculture on matters relating to the development of agricultural and other rural industries in New Zealand. In particular the functions of the Board relate to the following matters:-

(a) The aiding, improving and developing of agriculture and all rural industries;

(b) The prevention and control of disease in stock and poultry, and the control of noxious weeds;

(c) The establishment of agricultural colleges and agricultural education generally;

(d) The aiding or facilitating of the carriage and distribution of produce.

The official publication of the Department of Agriculture is The Journal of Agriculture, which resembles similar publications of other countries. The results of all research work carried on at any experimental farms, as well as private work are published, and the farmer is kept in touch with modern developments and tendencies in his own particular branch.*

Hence we see that the Government has the interests of the agricultural community at heart. The educative

*The reconstruction of the Department of Agriculture is at present under consideration, and the functions of the Department may be considerably extended at an early date. 
influence from the work of its various experimental farms and individual investigators cannot but show itself in improved methods of farming generally.

\section{Survey and Conclusion.}

It would appear that my contention that New Zealand is specially adapted to the cultivation of wheat is adequately borme out by a survey of the relevant conditions. We have seen that the fertility of her soils is quite remarkable; that her climatic conditions are unsurpassed in any other wheat growing country of the world; and that the character of the land from both a structural and general surface point of view is specially favourable to intensive methods of cultivation which are essential to New Zealand conditions of farming. In short, in her natural capabilities New Zealand possesses advantages which rank with the best among the leading wheat growing countries of the world.

But her isolation from the rest of the world, the conditions of harvesting, the difficulties experienced with labour, and the smallness of the output, which renders large scale operations impracticable, counteract to a considerable extent differential advantages which are derived from the bounty of Nature. On the whole, however, the balance of favour rests on the side of these differential advantages, and we have yet to see why these do not foster the industry in New Zealand, and why other industries have largely supplanted wheat production. 


\section{Chapter IV.}

\section{THE QUALITY OF WHEAT.}

\section{Introductory.}

The quality of wheat must be viewed from the standpoints of the farmer and the miller. While the latter's point of view is essentially the more important, it does not always coincide with the former's, and hence allowance must be made for this.

From the farmer's side of the question a good wheat is one that will give him, year by year, a good monetary return per acre. The monetary return obviously depends upon two factors; the yield per acre, and the value per bushel. While these two factors are quite independent for any given variety in a normal year, the farmer must so relate them that he obtains the maximum profit from the conditions under which he is producing.

It is not necessary here to discuss the causes which are responsible for different values per bushel of different wheats, but only to point out that the value for the most part is dependent, on the demand side, on the milling qualifications of the wheat. Nevertheless, the consideration is one of vital importance to the farmer; for it may be very profitable to sacrifice extra yield to higher value per bushel, while on the other hand a wheat of very high quality may yield so poorly, that it will not pay the farmers to produce it. Thus it was found that the variety Red Fife would produce a strong wheat in England, with milling qualifications as good as those of 
Canadian wheats. But when the Home grown Wheat Committee distributed the seed, the yield was found to be inferior, by about 50 per cent., to ordinary Home grown varieties. A yield of 24 bushels per acre of this wheat at 40 s. per quarter will give a return of only $£ 6$ per acre as compared with a return of nearly $£ 8$ from 36 bushels of "weak" wheat at 35s. per quarter. Moreover, in fostering higher "strength" in the "strong" wheat greater attention would be necessary in cultivation and harvesting than in the case of the ordinary Home grown varieties. Hence the cost of production of the former is likely to be higher than that of the latter.

New Zealand conditions offer a good example of this. Two of the most common varieties are Pearl and Tuscan, the former being slightly better in "strength" and general quality, though both in reality are "weak" wheats. On account of its higher milling qualifications Pearl brings up to $3 \mathrm{~d}$. per bushel higher than Tuscan. The yield of Pearl, however, falls short of the yield of Tuscan by some 10 bushels per acre. If then, the average yield of Tuscan on good land be taken as 40 bushels per acre and the average price $40 \mathrm{~d}$. per bushel, the total return per acre will be $£ 613 \mathrm{~s}$. $4 \mathrm{~d}$. But with regard to Pearl grown on the same ground assuming that the yield is 30 bushels per acre and the price $43 \mathrm{~d}$. per bushel, the total return per acre is only $£ 57 \mathrm{~s}$. $6 \mathrm{~d}$. It is generally understood that Tuscan requires less trouble in cultivation, though it may be more difficult to harvest than Pearl. Hence the difference in return of some $£ 15 \mathrm{~s}$. has led largely to the substitution of Tuscan varieties where conditions are at all favourable.

\section{The Miller's Conception of Quality.}

Of more importance in the world's markets is the quality viewed from the miller's standpoint. To the miller the quality of wheat depends on three chief 
factors; first, the percentage of dirt, weed seeds, and other impurities; secondly, the percentage of water in the sample; and, thirdly, a complex and somewhat ill-defined character, commonly called "strength."

(a) Impurities.-The first factor is not very important in New Zealand, for under the methods of growing, cleaning, and threshing practised here, a practically clean sample is produced. The threshing machine used generally throughout the country separates the sheaf into six parts, straw, short straw, chaff, dust and small weeds, "seconds" or shrivelled and broken grain, and finally "firsts" or clean wheat fit for milling. It will be easily seen that this classification gives a good, clean sample. In some foreign countries, however, this is far from the actual state of affairs. Indian and Russian wheats contain a great percentage of impurities, which render them in this respect relatively inefficient from the miller's point of view.

(b) Percentage of Moisture. - The percentage of moisture, the natural moisture as it is usually called, varies greatly in the different producing countries. English wheats contain about 16 per cent. of moisture, rising in wet seasons to 18 per cent. In Russia the per. centage is about 12, which is the average for Canada, United States, and Argentina; while in Australia and on the arid lands of the Pacific Coast of North America 10 per cent. is about the average. New Zealand wheats contain relatively high moisture percentages. Pearl in normal seasons has a moisture content of from 15 to $\mathbf{1 6}$ per cent., according to the tests made over a series of years by a local miller; while Tuscan and Hunter's go as high as 16 to 17 per cent. In wet seasons these percentages may be increased to 17 for Pearl, and 18 for Tuscan and Hunter's, which is considerably higher than the percentage for most of the exporting countries.

The importance of the percentage of water arises from 
the fact that the more water a wheat contains, the less flour it will yield in the mill. Consequently, the less value it has to the miller. A difference of 5 per cent. of natural moisture means a difference of from 1s. $6 \mathrm{~d}$. to 2s. 0d. per quarter in favour of the drier wheats. This is one of the reasons why New Zealand millers prefer Australian wheats, and the New Zealand farmers clamour for protection.

(c) Strength. - Of vastly greater importance is the third factor from the miller's point of view. We may provisionally define "strength" as the capacity for making bread which suits the public taste of the day. The generally accepted method of determining the "strength" of a sample of wheat is to mill it, and make it usually into cottage loaves. The strength of the wheat is then determined from their size, shape, condition, and general appearance. A "strong" wheat makes a large well risen loaf of uniformly porous texture. The principle of greatest importance is the capacity of the bread to absorb water, that is, the production of a porous loaf is the most desirable end.

(d) Importance of Gluten Content. - The degree to which this end is attained is dependent on the amount and character of the gluten of the flour produced from the special variety of wheat. The technical processes of baking do not concern us here, but in order to comprehend the importance of gluten a passing comment on the technicalities of baking will not be inappropriate.

"In making bread flour is mixed with water and yeast. The yeast feeds on the small quantity of sugar contained in the flour, fermenting it, and forming from it, alcohol and carbon dioxide gas. The gluten being coherent and tough is blown into numberless small bubbles by the gas which is thus retained inside the bread. On baking, the high temperature of the oven fixes these bubbles by drying and hardening their walls, and the bread is thus 
endowed with its characteristic porous structure. If a cereal meal devoid of gluten is mixed with water and yeast, fermentation will take place with formation of gas, but the gas will escape at once and the product will be solid and not porous.'

The above quotation is sufficient to show that gluten is of the greatest importance from the milling point of view. It is to this gluten content that the "strength" of wheat refers. Gluten is a mixture of two substances -gliadin and glutenin-and may be obtained in a crude state from wheat meal or flour, by washing the dough, made by kneading the meal with water, which removes starch and other non-gluten compounds. Not only is the amount of gluten important, but its quality is a very potent factor in giving flour its baking qualities. This quality is dependent upon the ratio of the amount of gliadin to the amount of glutenin in the flour. The most favourable ratio seems to be one of the former to three of the latter, and, for the purpose of obtaining this ratio, flours are mixed after milling, or more commonly in some countries wheats are mixed before milling. A good gluten has a light yellow colour, is sticky, but not elastic. This difference is at once apparent if a small quantity of "strong" Canadian wheat is masticated after one of the "soft" New Zealand wheats.

\section{3. "Strong" and "Weak" Wheats.}

From the point of view of the gluten content wheats are divided into two main classes, "strong" and "weak," each marked by certain external characters, which can readily be judged by the eye of the practised wheat buyer.

"Strong" wheats are usually red in colour, their skin is thin and brittle and the grain is usually rather small. Page 36. 
The grains are absolutely hard and brittle, and when broken the inside looks flinty. On chewing a few grains, the starch is removed and there remains in the mouth a small pellet of gluten which is tough and elastic, like rubber, but not sticky. The Canadian wheat imported by the New Zealand Government at the end of 1914 almost corresponded exactly with the above description, but to one inexperienced in grain dealing it would appear a very poor sample.

"Weak" wheats present a contrast. Their colour may be red or white, their skin is usually thick and tough, the grain is usually large and plump and often has an opaque appearance. It breaks easily, and inside is white, soft and mealy. Very little gluten can be separated in the process of mastication, and that little is much less tough and elastic than the gluten of "strong" wheat. On the whole, New Zealand and English wheats are "soft," and from outside appearances are specially good samples.

\section{Factors Fostering "'Strength."}

(a) Soil. - The principal factors in promoting high "strength" in wheat are soil and climatic conditions. Rich black soils, high in organic matter, are most favourable to the production of "strong" wheats. William E. Edgar says, "Gradually as the North Western States have become cultivated the original hard wheat has grown scarcer. Wheat raised on virgin lands has a peculiar strength lacking in that produced in other fields." *

(b) Climatic Conditions.-But of more importance in determining the "strength" are climatic conditions. For some time it was thought that sunshine during the later stages of growth resulted in "strength," but many 
foreign wheats, notably Californian, which have their last three months of growth in cloudless weather, yet remain weak. The best climate appears to be one which Schimper calls a "steppe" climate. The winter is very severe, too cold in fact for the wheat plant to survive. During the spring, showery weather prevails, while the temperature rises rapidly, and as the season advances both the heat and the dryness become extreme. Thus the "strong" wheats are essentially spring wheats. Their period of growth is necessarily short, not exceeding five months, and sometimes less. It will be seen how admirably Canada is suited for the growth of "strong" wheat on account of both her "steppe" climate and her rich native soil.

(c) These Factors in New Zealand.-The wheat producing area in New Zealand possesses neither a rich black soil nor a "steppe" climate. Hence, it may at once be assumed that on the whole the varieties of wheat grown are "soft." That this assumption is warranted in practice will be seen from the table appended* showing the "strength" and milling products of the main varieties produced in the Dominion.

\section{New Zealand Varieties.}

The varieties of wheat most commonly grown in Canterbury may be divided into three main classes, Hunter's, Tuscan, and Pearl. But there are several others grown in scattered localities, such as Red King, Bordier, and New Era.

(a) Tuscan.-The introduction of the Tuscan varieties, as was pointed out above, caused something in the nature of a revolution in wheat production in New Zealand. Pearl and Hunter's were the varieties most commonly

${ }^{*}$ See page 77. 
grown before Tusean was introduced, and, although the production of this variety has progressed rapidly, Hunter's and Pearl, on account of their relatively high "strength," are still produced in large quantities. Tuscan wheats are the most prolific yielders of the wheats of New Zealand and, as their milling qualities are fairly high, farmers are favouring their production in ever increasing quantities, where conditions are conducive to profitable production. To such an extent has this course been pursued, that it is stated that the introduction of Tuscan into South Canterbury and the lighter soils of Mid and North Canterbury enhances the value of land on which it is grown by $£ 1$ per acre.

In contradistinction to most New Zealand varieties Tuscan can be used as a spring wheat, producing a good crop if sown even as late as August. The common practice, however, is to sow in May, or as soon after as possible. Other varieties yield satisfactorily only when sown in the late autumn, and are likely to have their grain threshed out when nearly ripe by violent hot northwest winds, while Tuscan resists the threshing action of the wind to a much greater degree. In fact, this particular qualification is a very potent factor in rendering this variety favourable from the farmer's point of view.

The general characteristics of Tuscan are a very large and long grain, with a distinctive ridge on the back. It is quoted in Mark Lane as "New Zealand Long Berried Wheat."

(b) Pearl.-The variety of wheat which has the highest value from the miller's point of view is Pearl, known in some parts as Velvet. In normal seasons the yield is good and the sample is very clean and free from smut and other pests. The grain is small, round, plump, yellowish white, with a thin skin, a narrow and deep sided groove, and generally a most attractive appearance. As it hardens quickly and readily in the field, it is 
specially adapted to stook threshing, and is ready for the miller at once. Its price is quoted $2 \mathrm{~d}$. and $3 \mathrm{~d}$. per bushel higher than that of other varieties, chiefly on account of its high milling qualities, which in good seasons approach those of good Australian varieties.

(c) Hunter's. - Hunter's, or Hunter's White, is a variety grown mostly in North Canterbury, and is second in quality only to Pearl among the wheats of New Zealand. Some confusion of names has arisen among the English importers and distributors of this wheat, which does not correspond with the variety which in Britain bears the same name. The yield is good, and generally speaking the varied excellencies of this wheat make it one of the most suitable for general cultivation in Canterbury, as it thrives well in all the medium wheat growing soils. The grain is medium sized, plump, and either a deep reddish brown colour or a pale brown, almost white. Although it produces in milling 20 per cent. of bran, its flour absorbs 47 quarts per $200 \mathrm{lbs}$., so that its "strength" is equal to that of fair Australian wheat.

(d) Other Varieties.-Of the other varieties some disadvantages in yield, quality, or resistance to climatic conditions and pests render their production somewhat precarious. "Bordier" wheat for example, an impor. tation from France, proved to be a prolific yielder, while its yield of flour was fairly good and its "strength" a little below the average. It was found, however, to be subject to certain fungi, notably smut, while a strong wind during the ripening period had the effect of "shaking" a considerable portion of the grain. Another variety, Red King, was found to yield highly and gave $76 \cdot 1$ per cent. of flour in milling, but its very low "strength" caused millers to look upon it with disfavour, and hence its production is rapidly falling off. 
It will thus be seen that although New Zealand has been growing wheat for some forty years on a fairly large scale, she has not yet passed out of the experimental stage, and there is great lack of agreement among producers as to which wheat is the most profitable. Certain tendencies, however, are worthy of note.

(e) Comparative Production of these Varieties.-Until comparatively recently Pearl was by far the most common wheat grown over the whole of the producing area. It is still produced in large quantities, but has been superseded first by Hunter's, which is grown to a large extent in North Canterbury, and secondly, by Tuscan varieties, which enjoy the most general production.

South Canterbury is the home of this variety, while it is grown in large quantities in most other parts of the area. The steady increase in the production of Tuscan is likely to be maintained for some time yet, while, especially in South Canterbury, the other varieties Pearl and Hunter's - will be produced in slightly decreased quantities.

But the fine milling qualities of these, especially of the former, will be sufficient to cause them to be produced very largely, unless the future brings forth better varieties.

A great many experiments have been made, and continue to be made, not only on the Government Experi. mental Farms, but also on many private farms. A great many varieties have been tried, but, with the exception of the three above mentioned, none of these is produced on anything approaching a large scale. Among these a comparatively new variety, "Federation," grown on a considerable scale in North Canterbury, seems to be most promising, but it is not known yet whether it will yield sufficiently to make its production profitable. 
The following tables, compiled by the Agricultural Chemist of Queensland, show the milling products and "strength" of New Zealand wheats. These figures cannot be regarded as wholly reliable, because they refer only to an individual sample of each variety, and as different samples of the same variety differ, on account of the varying nature of the New Zealand soils and general climatic conditions, an average of several samples should have been taken in order to get fully reliable estimates. The figures, however, will serve as an indication useful for making comparisons.

TABLE XV.

MILLING PRODUCTS OF NEW ZEALAND WHEATS.

\begin{tabular}{|c|c|c|c|c|c|}
\hline \multicolumn{3}{|l|}{ VARIETY } & Flour & Pollard & Bran \\
\hline Red King & & & 76.1 & Percentages & 16.0 \\
\hline Hunter's White & ... & $\ldots$ & 75.3 & 8.2 & 16.5 \\
\hline Velvet Chaff ... & ... & $\ldots$ & $\mathbf{7 4 . 0}$ & 9.2 & 16.8 \\
\hline Bordier $\quad \ldots$ & $\ldots$ & $\ldots$ & 73.1 & 9.4 & 17.5 \\
\hline McCallum's Wheat. & ... & $\ldots$ & 71.8 & 9.4 & 18.8 \\
\hline Solid Straw Tuscan & $\ldots$ & ... & 71.4 & 11.5 & 17.1 \\
\hline Webb's Challenge & $\ldots$ & $\ldots$ & 71.4 & 12.4 & 16.2 \\
\hline Red Tuscan ... & $\ldots$ & $\ldots$ & 71.2 & 10.5 & 18.2 \\
\hline Hunter's White & $\ldots$ & $\ldots$ & 70.7 & 9.3 & 20.0 \\
\hline White Tuscan & $\ldots$ & $\ldots$ & 70.2 & 8.9 & 20.9 \\
\hline New Era & $\ldots$ & $\ldots$ & 68.1 & 10.1 & 21.8 \\
\hline
\end{tabular}

TABLE XVI.

STRENGTH OF FLOUR:

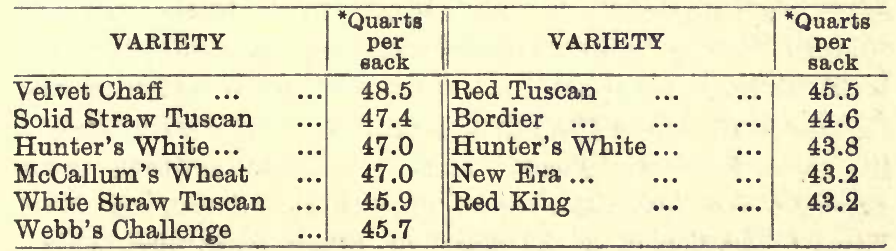

* Water absorption in dough-making. 
TABLE XVII.

THE NEW ZEALAND VARIETIES JUDGED BY POINTS.

\begin{tabular}{|c|c|c|c|c|c|c|c|c|c|c|}
\hline & & & 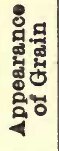 & 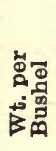 & 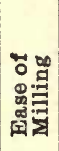 & 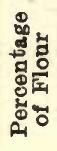 & $\frac{3}{3}$ & 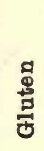 & 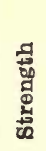 & 是 \\
\hline MAXIMUM & $\cdots$ & $\cdots$ & 10 & 15 & 10 & 10 & 15 & 20 & 20 & 100 \\
\hline Velvet or Pearl ... & . & $\ldots$ & 9 & 13 & 9 & 9 & 14 & 17 & 17 & 88 \\
\hline Hunter's & $\ldots$ & $\ldots$ & 9 & 13 & 9 & 10 & 14 & 17 & 13 & 85 \\
\hline Solid Straw Tuscan & .. & ... & 9 & 12 & 9 & 6 & 14 & 18 & 16 & 84 \\
\hline McCallum's Wheat & & ... & 9 & 12 & 9 & 7 & 14 & 16 & 16 & 83 \\
\hline Red Tuscan & . & ... & 9 & 14 & 9 & 6 & 13 & 17 & 14 & 82 \\
\hline Bordier ... & .. & ... & 10 & 13 & 9 & 8 & 13 & 16 & 13 & 82 \\
\hline Hunter's White & .. & ... & 7 & 11 & 9 & 6 & 14 & 17 & 16 & 80 \\
\hline White Straw Tuscan & & ... & 9 & 12 & 9 & 6 & 13 & 15 & 15 & 79 \\
\hline Rod King & ... & ... & 10 & 11 & 9 & 10 & 13 & 14 & 12 & 79 \\
\hline Webb's Challenge & ... & ... & 9 & 12 & 9 & 6 & 13 & 15 & 14 & 78 \\
\hline New Era & & $\ldots$ & 6 & 11 & 9 & 5 & 14 & 19 & 12 & 76 \\
\hline
\end{tabular}

\section{Survey.}

It has been shown above that the quality of wheat is the resultant of a variety of causes, among which climatic conditions and the fertility of the soil predominate. Further, it was indicated that the relative importance of the influence of climatic conditions was very much greater than that of soil fertility; for, in many countries a rich black soil does not produce wheats of very high "strength." Heredity, too, was shown to exert an influence on "strength," for certain varieties remain "weak" wherever grown, while one variety, Red Fife, at least retained its "strength" even when grown in England, where the climate and soil essentially favour the growth of a "weak" variety. How far these conclusions are correct will be shown by comparing New Zealand varieties with those of other countries which are competitors in the same market. 


\section{Chapter V.}

\section{IMPROVEMENT OF WHEAT BY SELECTION IN NEW ZEALAND.}

(By Dr. F. W. Hilgendorf).

\section{Historical.}

Wheat has been a cultivated plant since the dawn of human history, and there is no doubt that at various periods efforts must have been made to improve its qualities. Darwin quotes Virgil - "I have seen the largest grains, though viewed with care, degenerate, unless an industrious hand did yearly cull the largest." Coming to our own times the record of selection of wheat for improvement in quality starts with the work of Le Couteur, who lived in the Island of Jersey, and who, in 1815, made his famous selection "Bellevue de Talavera," which under the name of "Talavera" is still grown in France, Britain, and New Zealand. Shireff, of Haddingtonshire, Scotland, made some famous selections between the years 1819 and 1872. In 1886 there was established at Svalof, Sweden, the Swedish Seed Association, a private venture for the improvement of cereal seeds. Under the direction of Dr. H. Nilsson, very many selections of the highest value have been made, and the institution has become world-famous. The three wheat breeders mentioned all worked separately, and probably in ignorance of the methods employed by the others. But all of them hit on the same plan of taking a single wheat ear of apparently outstanding merit and multiplying the offspring of that ear without further selection. This is called "Single Ear Selection." As the true quality of an ear is not discernible from 
inspection but only from a study of its offspring, all these workers grew the offspring in plots in comparative trials with other varieties, and based their conclusions as to the value of a selection on its performances during the few succeeding generations. Hays, of Minnesota, United States of America, and von Lochow, of Petkus, Germany, separately hit upon the plan of growing 100 seeds of very numerous single ear selections, and comparing the offspring of the plots; and to this method of comparing the yield of selections the name of the " centgener power" was given. Mr. Green, of Ruakura, New Zealand, tells me that he also found the idea of single ear selection independently, and, indeed, it could hardly be otherwise since no information on the subject was available to the English speaking world prior to the publication in 1907 of De Vries' Plant Breeding.* Other workers apparently hit on the same plan, but did not follow it up to success. $\dagger$

During the development of the single ear method other plans for the improvement of wheat were occupying the attention of breeders. A special plan was adopted and elaborated by F. F. Hallett, who commenced work at Brighton, England, in 1857. From the best head he could find he picked the best single grain, and grew that under the most favourable conditions he could secure in a garden. He gave the resulting plant the best of soil, manure, moisture, and space. From the best head produced he again selected the best grain, and so on, growing the plants for many generations under ideal conditions. Great improvements were of course secured, and some stir was raised among those who saw his work. But the improvements were mainly the result of environment, and as soon as the plants were put back under

*"Plant Breeding." De Vries. Kegan Paul and Co.

†Rust in Wheat Conference. Parliament of South Australia. Paper XXIV., 1892, pages 56-7. 
field conditions their yield fell to that of the original ancestors, and it was seen that the scheme was a failure. Hallett's work was of high importance, and the publicity it received was of the greatest value, for it proved to all plant breeders that environmental improvement is not hereditary.

During the whole of the 19th century wheat selection was ardently pursued in Germany by a group of breeders usually associated with the name of Rimpau, one of their leaders. Their plan was almost exactly that followed by breeders of cattle and sheep. They went into the fields and gathered a number of the best heads of any variety. These heads they threshed, and then they sowed the resulting grain in a single plot. Through this plot they went again at harvest time and picked out the best heads once more, and continued to do so, in many cases for a score of years on end. But they always mixed the seed from all their best heads and sowed the product together. Some improvements were made by this process of "mass selection," which indeed became the starting point of the work at Svalof in 1886.

Wheats are normally self-fertilized, so that a pure strain tends to remain pure for long periods. They can, however, be artificially cross-fertilized, and this plan has been adopted to produce new varieties combining the outstanding good qualities of different parents. One of the most famous cross breeders of wheat was William Ferrar who, working in New South Wales from 1906 onwards, produced Bobs, Federation, and other crosses which have revolutionized wheat growing in Australia. On the re-discovery of Mendel's law of Inheritance, in 1899, great hopes were entertained that a new era had dawned and that practically any number of excellent characters would be able to be combined in a single wheat.

Biffen, of Cambridge, England, has worked most 
consistently on Mendelian lines, but it must be confessed that so far the intricacies of the problem have prevented the attainment of very notable results.

A summary of the wheat selection work within the last century is, therefore, as follows:-

1. Single ear selection. Le Couteur (1815). Svalof (1893).*

a. Centgener power. Hay and von Lochow.

2. Influence of Environment. Hallett (1857).

3. Mass Selection. Rimpau and others (whole of 19th Century).

4. Cross Breeding. Ferrar (1896).

a. Mendelian Crossing. Biffen (1903-).

\section{The Choice of a System for New Zealand.}

In 1909 the writer was instructed by Mr. R. E. Alexander, Director of Canterbury Agricultural College, to undertake experimental work in the improvement of wheat for growing in Canterbury. The scanty literature on the subject was examined in order to see what method would be likely to lead to results satisfactory both as to magnitude and early maturity. Some whisperings of the work done at Svalof had by this time reached New Zealand, and such information as we had of their methods backed by the common knowledge of inheritance in plants seemed to indicate single ear selection as the best plan of action to adopt. Later information as to the Swedish methods and results has fully confirmed this view. As mentioned above, the Swedish Seed Association was founded in 1886. It was a private venture, but its development is closely bound up with the economic and social progress of the country. It now owns thousands of acres of land and palatial laboratories manned by a staff

* 1893 was the year in which single ear selection started. Previous to that mass selection had been used. About 1904 crossbreeding was added to single ear selection. 
of highly trained men of science. Wheat, oats, and barley are now grown in Sweden on lands previously considered as mere waste, and the yield of previously cultivated districts has been materially increased. The Government of Sweden recognizes the work of the Association by an annual grant of $£ 2,000$, the other $£ 2,000$ of its yearly income being provided partly by the profits of the venture, but chiefly by the Agricultural Societies of the country at large. (These figures are for the year 1909).* Some of the results achieved by the Association are appended.

AUTUMN WHEATS.

\begin{tabular}{c|c|c}
\hline STRAIN & $\begin{array}{c}\text { Number of Years } \\
\text { Tested }\end{array}$ & $\begin{array}{c}\text { Yield -The Common Variety } \\
\text { of the Country }=100\end{array}$ \\
\hline 0290 & 4 & 135.6 \\
0501 & 13 & 128.5 \\
0406 & 13 & 122.5 \\
0200 & 13 & 121.5 \\
0315 & 9 & 115.9 \\
\hline
\end{tabular}

These figures were published in 1912, $\uparrow$ and are sufficient to show that the methods used at Svalof are an unqualified success. Had the information given above been at our disposal in 1909, we could have started work on the improvement of the wheats of Canterbury with some confidence, but all we knew was that Sweden was using single ear selection with good results, and that the method had been followed by workers in other countries -notably by Hunter, in Ireland. $\ddagger$ A plan of work was therefore evolved which has proved in the main similar to that used in other lands where the single ear is the basis of the selection.

"Sixth Annual Report Canadian Seed Growers' Association. †Newman, "Plant Breeding in Scandinavia." Canadian Seed Growers' Association, Ottawa.

†. Hunter, "Experiments in Barley Growing." Journal of the Department of Agricultural and Technical Instruction for Ireland. Vol. XIII., No. I. 


\section{Scheme of Work.}

Since wheat is normally self-fertilized, different races can grow together in the same crop and yet preserve during an indefinite number of generations their individual characteristics. Chance variations induced by accidental crossing or by unknown eauses do, however, occur, and so a field of ordinary wheat, even though pure as to variety, contains a large number of strains, the differences between which are easily discernible to the practised eye, just as in the show ring judges are able to discern different strains in a pure breed of sheep, and are able to name the breed of many a sheep merely from the appearance of the wool or from the configuration of the limbs or body. Now, some sheep have the characteristic of fattening more quickly than others on the same feed, and this is naturally a quality highly valued. If a hundred sheep are running in the same field and they all have the same feed the fattest are congenitally early fattening, and can therefore be bred from with confidence that they will transmit this character. But if one were given a large flock of sheep that had been fed under different but unknown conditions, then some would be congenitally fat, but others only accidentally so, that is fat because they had received better or more plentiful feed. These latter, if used for breeding, would not produce early fattening lambs. What could the breeder do? He could only pick out the fattest sheep and breed from them, because he could not distinguish the congenitally fat from the accidentally fat. He would probably mix all the breeding sheep together and note the fatness of the resulting flock, when all fed under the same conditions. This would be mass selection. The average of the offspring would be fatter than the average of the flock from which their parents were selected, but there would be fat lambs and lean ones, because some would be descended from congenitally 
fat parents, and some from parents only accidentally fat. This is the general fate of mass selection. Some improvement is made, but it is an improvement of the average not of the whole, and progress towards improvement is slow and tedious. Now, suppose the sheep breeder recognized the difficulties of his task, and instead of mixing up all the selected breeding sheep and looking at the average of the resultant lambs, that he mated the sheep separately and kept their offspring separately under observation while giving them the same feed. He would still get fat lambs and lean ones, but he would be able to pick the parents that had produced the fattest lambs, and know that these parents were congenitally fat because they had transmitted the character. Thus he would be able to pick out an early fattening strain in a single generation, and would have only to multiply that strain. The whole of the resulting flock would then be early fatteners. This is the homologue of "single ear selection." The problem above supposed confronts the animal breeder only when he is buying breeding stock and does not know how the animals have been fed, never when he is selecting from his own stock for breeding. But the problem confronts the plant breeder in every first selection he makes. He can never know if the apparent excellence of a head of wheat is an inherent character or due only to an extra favourable position in the soil, relative to manure, moisture, space, etc. If all the heads are threshed together the resultant offspring is a mixture of good and bad as the parents were, and although repeated re-selection is bound to produce improvement, the process is tedious and slow. If, however, each head is threshed separately, and its seed sown separately under similar conditions under strict control, then the head whose progeny yields well will be a congenitally good head, and that whose progeny is indifferent will be an indifferent head, and look good only 
owing to some adventitious aid. Thus the best heads are picked out of the mixed population in a single year, and nothing remains but to multiply the progeny of that head until enough seed is procured for commercial purposes.

In practice the process is not quite so simple as the above description would suggest, but the lack of simplicity is due to that bane of all agricultural trials-the experimental error.

\section{Experimental Error.*}

The "Probable Error" and the "Theory of Chances" are branches of mathematics with a very practical bear. ing. Unless it is constantly recognised that there is a probable error, all experimental work is reduced in value. In agricultural experiments the probable error is very large and very elusive. If two plots of wheat are grown side by side in a paddock the soil of which is apparently very even; if the seed of the two plots is out of the same bag; if the cultivation, manuring, and harvesting are the same in all respects, it might be anticipated that the yields would be the same within a very slight margin. As a matter of fact the yields often differ by quantities that are of the greatest importance. For instance, the land occupied by one plot may be three inches lower than the land occupied by its neighbour. Such a difference could never be detected, but if heavy rain comes while the seed is germinating the seed on the lower plot may be drowned out, or so checked in its development as to yield much less than the plot on higher ground. Or a colder piece of soil may delay ripening and render its crop liable to rust, or the warmer soil may ripen its crop earlier so that it is attacked by birds, and the final

\footnotetext{
*See supplement No. 7 to "Journal of Board of Agriculture." London, 1911.
} 
result shows that not the slightest trust can be placed in a competitive trial of two wheats, if the trial is made only once over. In the season 1913-14 the writer grew nine plots of Hunter's wheat side by side in a very even paddock. The plots were about half-an-acre each in area. The seed and the treatment in every respect were the same. The following were the yields :-

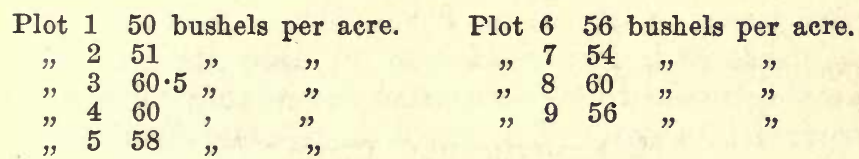

Now, differences approaching 10 bushels per acre are of the greatest significance in wheat growing : indeed, it will be shown later that an increased yield of 4 bushels per acre is sufficient profoundly to affect the industry. If, then, one not alive to the importance of the experimental error had grown one kind of wheat on plot 2, and another kind on plot 3 , he would at once have declared the latter infinitely the better wheat. Or if he had gone to more trouble and grown a new wheat on plot 8 , and his old standard wheat on each side of it, on plots 7 and 9 , he (and 99 per cent. of observers) would unhesitatingly have declared the new wheat an improvement of the highest value, whereas we know from the above trial that it would not necessarily be a scrap the better. Practically every agricultural experiment made in this country has been a trial of plot, against plot, and the results are worse than worthless.

To be able to arrive at any reliable result, plots must be replicated sufficiently frequently to allow all inequalities of soil to be smoothed out in taking the average, and the greater the accuracy of result aimed at the more frequent must be the replication. Mathematical calculation shows that in experiments of this kind 10 to 15 trials are necessary before the probable error of the average is reduced so low as to be negligible. 
But, besides the error ascribable to variation in soil in a single season, there is a still larger probability of error due to variations between season and season. This fact is, however, so generally recognised that to enlarge upon it is unnecessary, except to point out that compara. tive trials carried out during successive seasons must be carried out on the same class of land if any conclusion is to be arrived at. It is obvious that a trial made on heavy soil in a dry season and on light soil in a wet season will tend to give the same result, and the experimenter might say, "The result is reliable, for I have proved it on two different classes of land during two different seasons." In reality, the result might be misleading as regards both heavy and light land in a normal season and certainly is inconclusive for heavy land in wet seasons, and light land in dry ones. The prime necessity of carrying out a series of experiments during successive seasons only on lands of the same type seems to be the weightiest argument in favour of a soil survey.

\section{Details of Experimental Work.}

Having described the principles of single ear selection, and the necessity of replication of experiments in order to arrive at reliable results, the details of the method of experiment may now be described. It was decided to commence work on the varieties commonly grown in the country, on the assumption that these were best suited to it, as having stood the test of half a century of cultivation here while other varieties had been tried and rejected. The varieties dealt with, were, therefore, Hunter's or Red Chaff, White Straw Tuscan, Solid Straw Tuscan, Velvet, and Pearl. The experience with Hun. ter's will be described, as it has produced the most noticeable results.

Some hundreds of heads differing in appearance were selected from a normal crop, and these were reduced by 
comparison in the laboratory to 100. Each of these 100 heads was threshed separately and their seed sown in small plots close together on land as even as possible. Among the 100 plots there were placed at frequent intervals plots of the ordinary Hunter's of commerce to serve as a eheck upon the selections. As soon as the plants had started to grow many differences in habit of growth became apparent. Some were more vigorous, some taller, some more spreading, some darker green than the others. As growth progressed, further variations were seen and noted, and finally the 100 plots were cut and threshed separately. Of these rows the best 11 were selected and their seed sown next year again in long plots beside each other so as to avoid as much as possible the variations in soil. The growth characters in this year proved to be in the main the same as those noted in the preceding year, though in some cases the features were more marked and in some cases less marked. This was doubtless due to the difference in the season. The yields of these 11 rows after threshing were as follows :-

Average of Commercial Plots 100.

$\begin{array}{cccccc}\text { Plot. } & \text { named. } & \text { bush. p. ac. } & \text { Plot. } & \text { named. } & \text { bush. p. ac. } \\ \text { 1. } & \text { A1 } & 118: 1 & 7 . & \text { A7 } & 106 \cdot 7 \\ 2 . & \text { A2 } & 82 \cdot 6 & 8 . & \text { A8 } & 143 \cdot 4 \\ \text { 3. } & \text { A3 } & 103 \cdot 4 & 9 . & \text { A9 } & 96 \cdot 4 \\ \text { 4. } & \text { A4 } & 116 \cdot 3 & 10 . & \text { A10 } & 112 \cdot 6 \\ 5 . & \text { A5 } & 77.9 & 11 . & \text { A11 } & 121 \cdot 2 \\ 6 . & \text { A6 } & 114 \cdot 3 & & & \end{array}$

Plots $1,4,6,8,10,11$, were kept for further trial. Plot 8 had proved to be a natural hybrid-one of the three that have been observed among the thousands of single ear selections that have since been grown. Its hybrid nature explains its great productivity, but this gradually lessened in succeeding years, and since there were qualities of grain and straw that made it undesirable it was finally discarded. It will not be referred to again. The seed from the remaining rows were sown in 
separate plots, again with several plots of commercial seed for comparison. The yields in the harvest of 1912 were as follows:-

Average of Commercial Seed Plots 100.

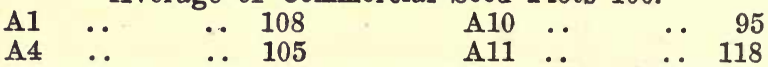

$$
\begin{aligned}
& \begin{array}{llllll}
\text { A6 } & \ldots & \ldots & 114 & & \\
& . . & 118
\end{array}
\end{aligned}
$$

Of these, A1, A6, and A11 were kept for further trial, and their seed was sown in 1912, in large duplicated plots each about an acre in extent. The arrangement of the plots was as follows :-

$$
\begin{aligned}
& \text { Plot } 1 \text { Commercial sample. }
\end{aligned}
$$

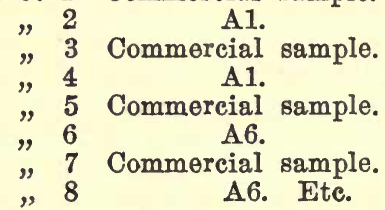

It is now perhaps time to refer to the "commercial sample" used as the basis of comparison.

Five or six of the leading grain merchants in Christchurch were each asked for a bushel of the best Hunter's seed they had in stock. The grain received was all mixed together and the resultant sample was considered as an average of the best seed of the variety a farmer could procure under the conditions then obtaining. The progeny of this seed has been used as the standard in the subsequent trials.

The harvest of 1913 showed the following results :-

$\begin{array}{cccccc}\text { Plot. } & \text { named. } & \text { bush. p. ac. } & \text { Plot. } & \text { named. } & \text { bush. p. ac. } \\ \text { 1. } & \text { C1 } & 50 & 8 . & \text { A6 } & 57 \cdot 5 \\ 2 . & \text { A1 } & 62.5 & 9 . & \text { C5 } & 58 \\ 3 . & \text { C2 } & 51 & 10 . & \text { A11 } & 54 \\ 4 . & \text { A1 } & 64 . & 11 . & \text { C6 } & 56 \\ 5 . & \text { C3 } & 60 \cdot 4 & 12 . & \text { A11 } & 53 \cdot 5 \\ 6 . & \text { A6 } & 60 \cdot 2 & 13 . & \text { C7 } & 54 \\ 7 . & \text { C4 } & 60 & & & \end{array}$

These results are displayed in graphic form opposite. The graph shows the plots in the same order as they occurred in the field. 
Bustiels per Acre.

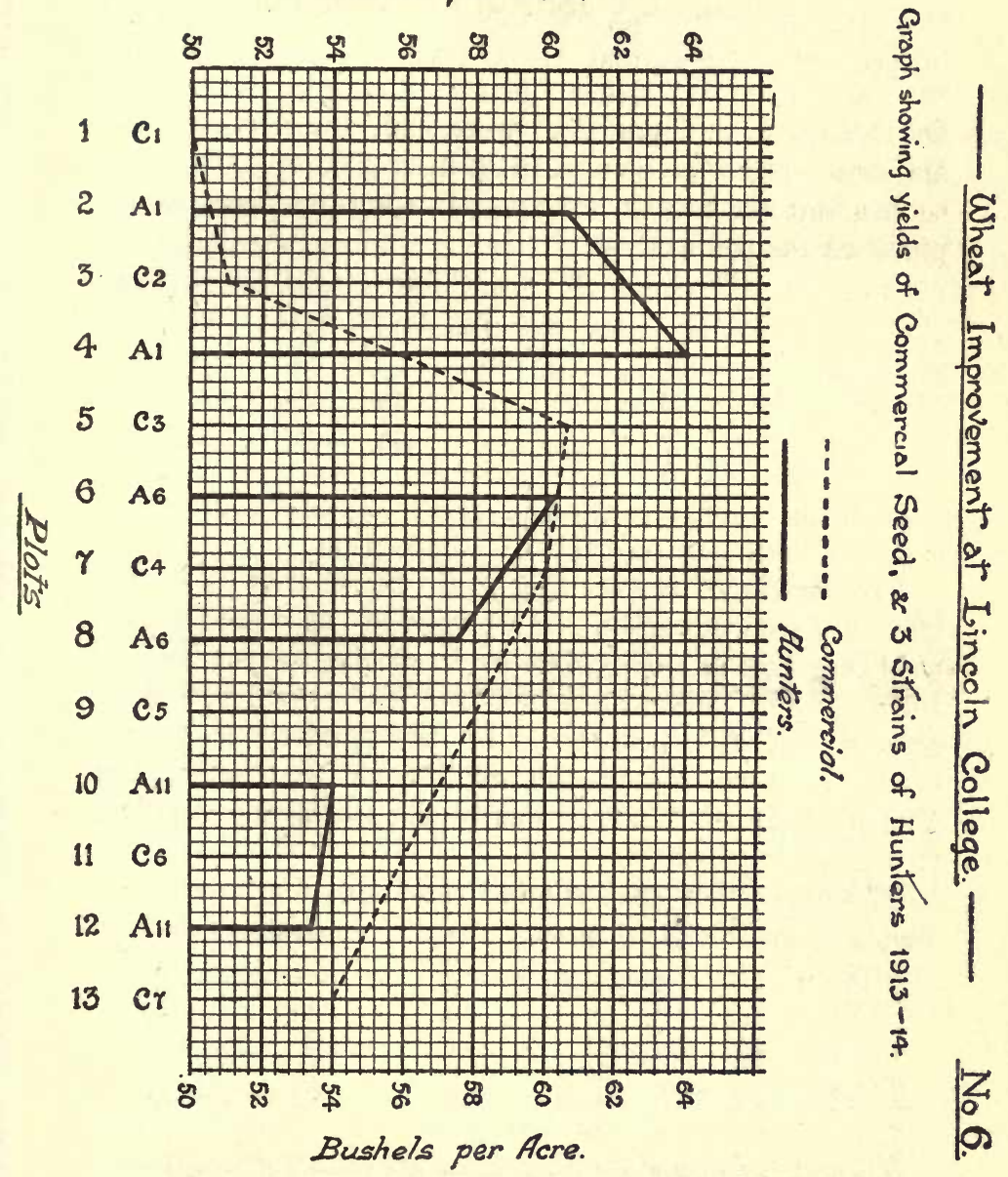


The high yield of the strain A1 in this its fourth year of trial, together with its excellent quality, justified an extended trial of the strain. In 1914, therefore, a field of about 25 acres was sown partly with the strain and partly with commercial seed. Small lots of seed were sent out to two reliable farmers, and the usual halfacre plots were sown in the experimental field. The following were the results in bushels per acre, the order of the figures in each horizontal row representing the order of the plots in the fields.

\begin{tabular}{l|c|c|c|c|c}
\hline & $\begin{array}{c}\text { Com- } \\
\text { mer- } \\
\text { cial }\end{array}$ & Strain & $\begin{array}{c}\text { Com- } \\
\text { mer- } \\
\text { cial }\end{array}$ & Strain & $\begin{array}{c}\text { Com- } \\
\text { mer- } \\
\text { cial }\end{array}$ \\
\cline { 2 - 6 } Experimental field, half-acre plots & 50 & $\mathbf{6 3}$ & 51 & 64 & 60 \\
Field xv., College, plots 6 acres ... & & 38 & 29 & 43 & \\
T. Blackley, Rakaia, plots 8 acres & & 27 & 25.6 & & \\
A. L. Joseph, Kirwee, plots 8 acres & & $\mathbf{2 6}$ & 20 & & \\
\hline
\end{tabular}

\section{Results.}

This ended the preliminary trials of the strain. It had now been grown and tested against commercial seed during 5 seasons, on moderate wheat growing land. It had been tested in 11 different plots in 7 different fields and on 3 separate farms. The conditions of trial have been detailed above, and the results may be tabulated as follows, percentages in the earlier trials being translated into bushels per acre on the yields of the other parts of the field in which the small plots were grown.

\begin{tabular}{|c|c|c|c|c|c|c|}
\hline Harvest of & \multicolumn{3}{|c|}{ PURE STRAIN } & \multicolumn{3}{|c|}{ COMMERCIAL } \\
\hline 1911 & \multicolumn{3}{|c|}{44 bushels per acre } & \multicolumn{3}{|c|}{40 bushels per acre } \\
\hline 1912 & 59 & , &, & \multicolumn{3}{|c|}{50} \\
\hline 1913 & 54 & , & , & 52 & ", &, \\
\hline 1914 & 63 & , &, & 54 &, &, \\
\hline 1915 & 44 &, &, & 41 &, &, \\
\hline Average & \multicolumn{3}{|c|}{53 bushels per acre } & \multicolumn{3}{|c|}{47 bushels per acre } \\
\hline
\end{tabular}

This increased yield, together with obvious superiority in milling quality, appeared to warrant the College authorities in putting the seed of the strain upon the 
market, and early in 1915 it was offered for sale under the name of "College Hunter's," at a price of about $6 \mathrm{~d}$. per bushel above rates for ordinary seed. The slight increase of price was decided on so as to ensure that only those farmers who realized the value of the seed should apply for it, and yet the price was kept low because (1) the object of the work that resulted in the production of the seed was to improve the wheat yield of Canterbury and not to enrich the College: and (2) it would encourage farmers to buy in larger quantities and so diminish the proportions of impurities that would inevitably creep in during threshing operations.

Seed was sold to 32 farmers, and of these 28 reported their experience of the wheat. The reports may be classified as follows :-

Two had worse results than with other seed.

Six could make no report owing to losing their crops by frost or drought. (Harvest of 1916).

Twenty were quite satisfied with the strain. The following are some extracts from reports.

"My seed 35 bushels. Yours 45 bushels." Pinkington, Fairlie.

"Threshed much better than other wheat under similar conditions." LeadLex, Ashburton.

"Well satisfied: beat Solid Straw Tuscan." IRwIN, Rakaia.

"One bushel more than my own seed. Last year sowed 8 acres, this year will sow 75 acres." JoHnson, Kirwee.

"Four bushels more than our own seed." SмiтH, Ladbrooks.

"No doubt ass to superiority," TOBEE, Tai Tapu.

"Quite satisfied; several bushels per acre better than our own seed." HAY, Morven.

"In every way satisfactory; 10 to 14 bushels more than Tuscan or Velvet." HoLmes, Rakaia.

"The best sample of Hunter's I have ever seen." R. Allan, (Miller) Christchurch. 
No reports were asked from growers after the harvest of 1917, as the majority of them had obtained their seed from other farmers and so were not in direct correspondence with the College, but general remarks, and the experiments in our own plots show that the strain exhibits no sign of deterioration.

It is estimated that the result of the whole of the trials shows that College Hunter's is 4 bushels per acre better than the commercial sample. Such a degree of superiority is of great importance as the following consideration shows:- The average area under wheat during the 10 years before the war was 233,000 acres. and the average price was 3s. 4d. per bushel. Four bushels per acre additional on that area and at that price comes to $£ 150,000$. This will be the annual gain to the country if, other things being equal, a similar improvement to that achieved in Hunter's is extended to the other commonly grown varieties. Again, on the farm at Lincoln College the yield during the past 10 years has been 45 bushels per acre, and in normal times the cost of production is covered by a return of 36 bushels per acre, leaving 9 bushels per acre as profit. An increase of 4 bushels per acre through using better seed represents an increase of only nine per cent. in the yield but an increase of over 44 per cent. in the profits. Small increases in yield are therefore of great importance, and it is to discover and verify even small increases that the elaborate experimental work above detailed becomes necessary.

\section{Further Work in Hand.}

The original selection of the heads of Hunter's in 1910, and the further trials of those selections did not of course complete the work with that variety. It was not considered as proved that a favourable selection had been made until after 5 years of trial, and in the meantime 50 new selections were made each year, in case the earliest 
ones failed. Even after a success was assured the annual selections were continued to see if a strain superior to what was originally called Hunter's A1 would be obtained. Thus from 1910 till the present time about 65 pure strains of Hunter's have been under trial each year, but none of these has so far proved better than A1. Ten other strains are still under trial.

In Velvet the same work has been done as in Hunter's. Some 400 selections have been made, but none has proved of sufficient merit to warrant its distribution. Several times over strains of high yield have been secured, but these had to be rejected owing to thickness of husk or to poor quality of flour, or liability to "shake" in the wind. On the other hand, strains of good quality have been isolated, but their yield was not constantly above that of the commercial sample.

In Pearl, also, 400 selections have been made, and one of these has successfully passed its fourth year of trial. It is of high quality and has averaged 4 bushels per acre more than the commercial seed. This year (1917) it will be tried by a few selected farmers as well as in the plots at the College.

In White Straw Tuscan again out of about 500 selections two give considerable promise, and are in their fourth year of trial. Of these also some seed will be given to a few farmers for trial before a pronouncement is made.

Solid Straw Tuscan is a variety that shows great evenness of growth and few variations, and the earlier selections proved worthless. One of the 50 selections made in 1913, however, when it was harvested in 1914 gave evidence of good quality combined with high productivity. Successive trials have caused it to keep its position in the breeding plots, and it is now entering on its final year before an opinion is finally expressed as to its superiority. 
Thus the work of single ear selection in New Zealand may be said to be fairly launched, though the improvements, ranging in the neighbourhood of 8 per cent. are not to be compared with the improvements of 16 to 35 per cent. realized in Sweden.

The growing of many hundreds of pure strains at the same time and the harvesting of these separately so that no grain of one plot becomes mixed with others, involves a great amount of work, both manual and supervisory. Much special machinery has to be procured for drilling, harvesting, and threshing. It is the pleasure of the writer to have to acknowledge the initiative of the Director and the broad mindedness of the Board of Governors of Lincoln College in starting and maintaining this laborious, time-absorbing, and expensive undertaking.

March, 1919. - In the harvest just concluded good evidence of the value of some of these selections has been obtained. Many crops of Hunter's A1 have produced over 70 bushels per acre, and in two noted examples have yielded 88 and 89.5 bushels. The popularity of the strain is proved by the fact that a survey of the fields in Canterbury showed that out of every 5 crops of Hunter's, 4 were of the pure strain. The strains of other varieties have now been distributed and grown for two seasons by a number of farmers. They are generally satisfactory, but not so markedly superior as in the case of Hunter's. A purple straw Tuscan is next to Hunter's $\mathrm{A} 1$ the best selection so far made. 


\section{Chapter VI.}

\section{HISTORY OF WHEAT PRODUCTION IN NEW ZEALAND.}

\section{Early History.}

The story of the early history of the colonisation of New Zealand is familiar in these days, but of the habits and activities of the early colonists a great deal has yet to be written. Although there are many pioneers who can relate experiences which throw much light on these there is still wanting a reliable description of the economic life of the Dominion during the first half century of its settlement. Necessarily such an account would give prominence to agriculture, for industries such as whaling and sealing, the first to attract visitors to these shores, were for the most part transient. It was indeed during the rise and fall of these industries that the pursuits-agricultural and pastoral-which were to make New Zealand so prosperous, and become so largely responsible for the progress of the last four decades were being slowly but surely established.

During the decade ending in 1850, the conception of New Zealand as an agricultural community rested on the prosperity of a few settlements in the North Island and the progress that had been made in the Nelson district. Few, if any, had realised that Canterbury and Otago, because of their superiority in ease of 
cultivation, and suitability for pure agriculture, were destined to form the main centres of rural life for the next three decades. In 1853 Canterbury (founded in 1849 by the Canterbury Association) was made a province under the new constitution. That Canterbury would soon be the leading agricultural community was realised almost immediately, and a writer of that time states, "The pastoral merits of Canterbury have somewhat obscured her agricultural capabilities. The heaviest crops I have ever seen in New Zealand or in any part of the world, I saw on the Canterbury Plains, and should wheat ever pay better than wool in New Zealand and become the leading export no two other Provinces will, I think, produce more of such export than Canterbury and Otago."

At first pastoral pursuits flourished at the expense of wheat production, and then came the "gold rushes" of the early sixties as counteracting forces. But immigration proceeded rapidly and the great influx of population during the sixties created something of a social revolution in the Colony. In 1861 the total estimated population was 89,323 , three years later it had almost doubled, while in 1870 the numbers had reached 248,000. Contemporaneously with this the export of food stuffs dwindled, while prices of farm products rose considerably, consequent on the increased demand and the plentiful supply of the circulating medium. The allurement of the gold discoveries had turned the attention of the colonists from the monotonous pursuits of farming to such an extent that the area in wheat, estimated at 29,547 acres in 1861, had decreased to 25,607 acres in 1864. Meanwhile prices had been rising steadily, and Dr. McIlraith's History of Prices in New Zealand shows that the price of farm products rose in the period 1862 to 1866 , the index number being 186 in 1862 and 224 in 1866, where 
100 represents the average annual price for the years 1890-9.

But the period of stagnation was only temporary, for those very forces which were responsible for the abandonment of agriculture laid the foundations for the decided step forward which the Colony took in the ten years following. With prices already high and the prospect of the maintenance of the high level, with the constantly growing attention which New Zealand was attracting in the Motherland on account of the gold discoveries and her natural qualifications for agriculture and the development of regular communication with foreign countries, and access to their markets, agriculture especially wheat growing, received an impetus at what may be called the strategic time.

\section{Period of Expansion.}

Wheat growing now proceeded apace, and during the "seventies" great progress was made. In the period $1860-9$, the average annual area under wheat in New Zealand was 47,000 acres, and in the following decade it was 159,000 acres, while prices maintained a satisfactory level, being at an average of $4 \mathrm{~s}$. $7 d$. for the decade 1871-80.

The early "seventies" marked a period of great prosperity throughout the whole world, which was reflected in New Zealand in the optimistic attitude of the Government and in the readiness of the colonists to launch out on new enterprises. It was in these circumstances that Sir Julius Vogel brought forward his Public Works Policy. Vogel's cheery optimism soon convinced the colonists of the benefits of his scheme, and he set out on his ambitious borrowing policy in order to open up the country by roads and railways and introduce improved facilities for communication. A substantial National 


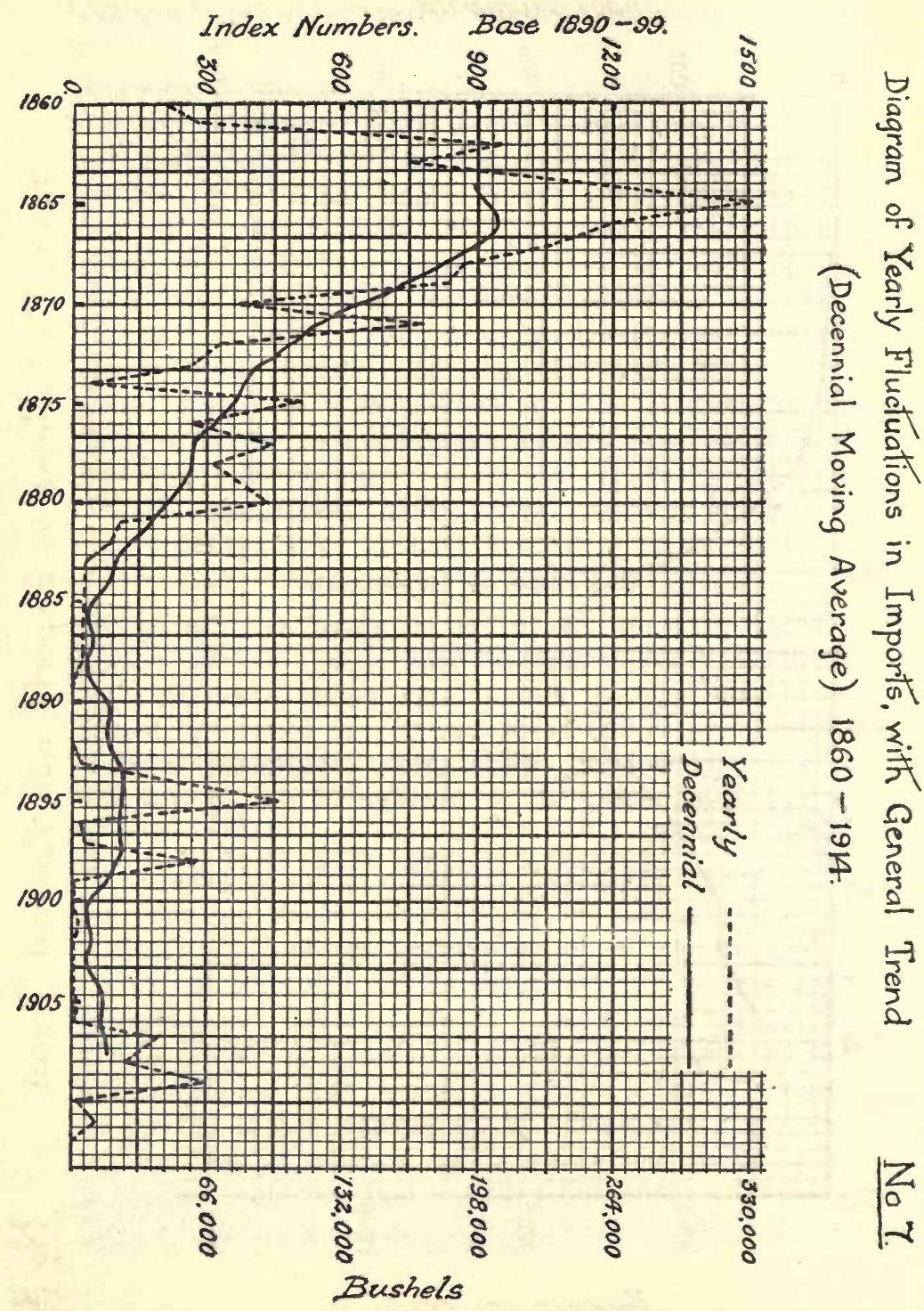


Debt was soon contracted, and it is necessary to bear this in mind when considering the events of the eighties.

A fresh development had commenced in the late "seventies" when the large estates, which had been procured in the early days by the squatters, were devoted to cereal growing. These large estates, formerly used for grazing sheep, were broken up and thousands of acres were sown in wheat. Many attempts were thus made to commence wheat production on a large scale, but it was attended by certain disadvantages, and when prices began to fall, these "bonanza" farms ( the term applied to the large wheat farms of America) offered very small, if any, profits. The exact nature of these disadvan. tages will be indicated later, but it is sufficient to note here that the large estate was the outstanding feature of wheat production for the twenty years succeeding the middle "seventies." "*

The forces, then, which led to the great progress in wheat production after 1870 were mainly the decline in the gold production leaving a surplus of labour and capital for other industries, the high prices of wheat, the disadvantages of sheep farming due to the low prices of mutton and the total lack of demand for such, the suitability of the Canterbury Plains for rapidity and ease of cultivation, and lastly the ambitious borrowing policy of Sir Julius Vogel by which railways were opened up, roads and bridges constructed, and the rate of the general development of the country greatly accelerated.

*The nature of this expansion is reflected in the movements in the price of agricultural land in Canterbury. For the graph of this given on page $104 \mathrm{I}$ am indebted to Mr. F. R. Callaghan, who recently made an investigation into "The History of Land Values in Canterbury.' The outstanding feature of the graph is the rapid rise in the "seventies"' culminating in the land boom of 1878 . The rise since 1895 must be attributed to the successful introduction of sheep farming, the improved methods of cultivation, the development of mixed farming, and most important of all, the rapid rise in the prices of farm products. 
HISTORY OF WHEAT PRODUCTION, IN WEW ZALA LAND:103
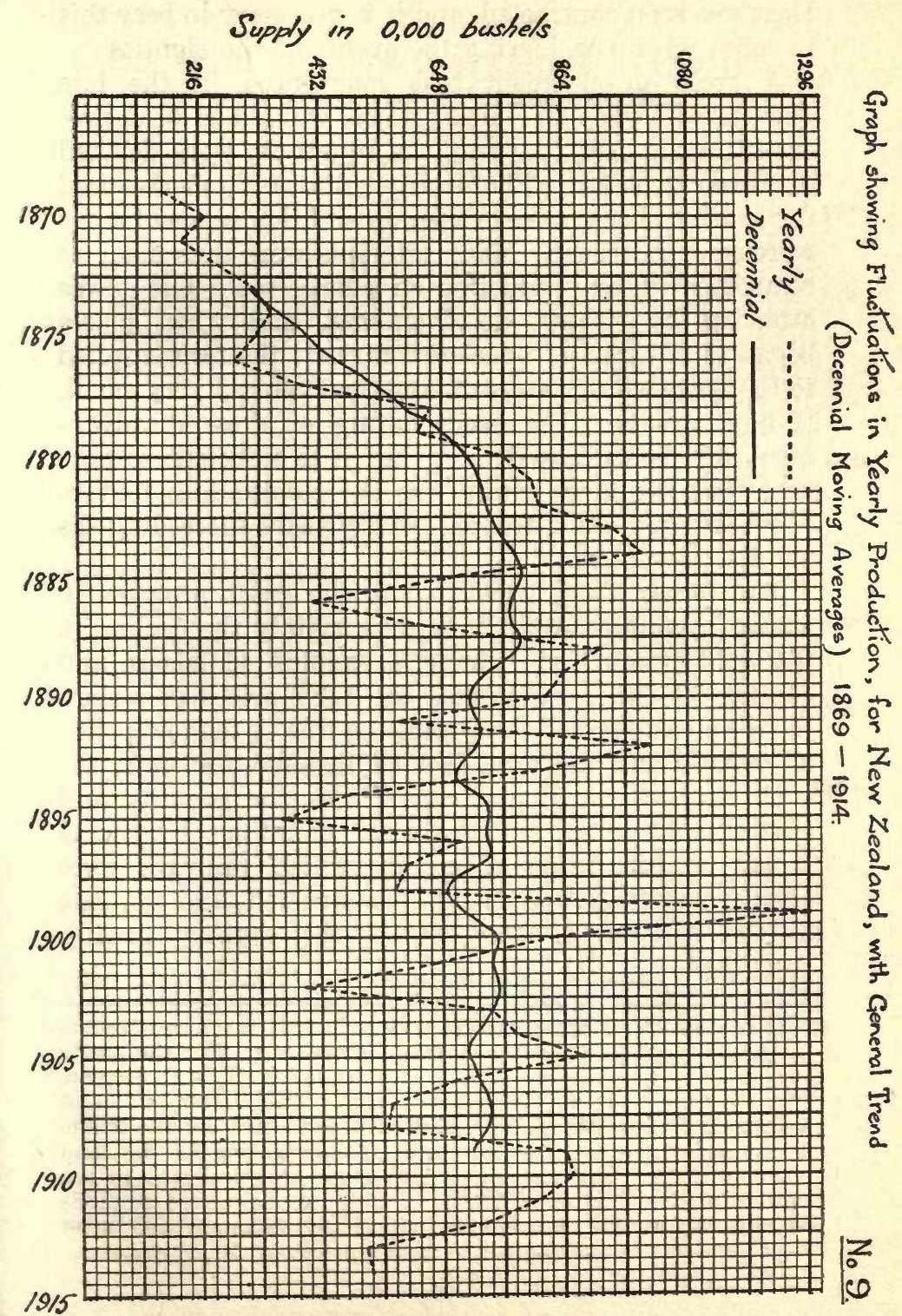
Index Numbers Base 1890-99.

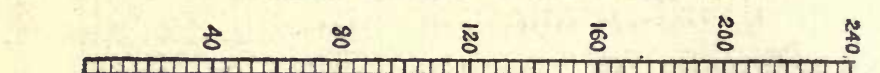

\section{蛋}

1870

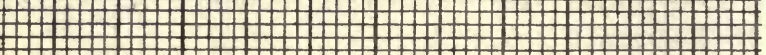

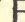

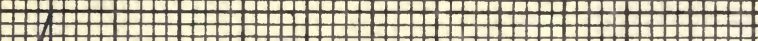

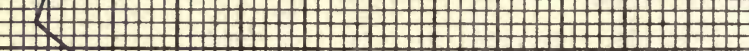
1873 F $1+\mathrm{H}+\mathrm{n}+\mathrm{H}$ H 1880

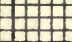
11 H 1 H

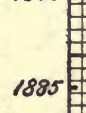

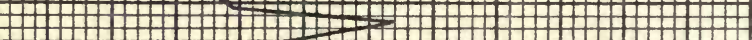

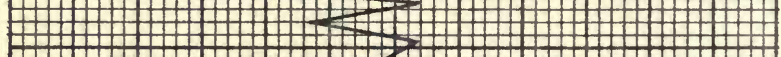
1885

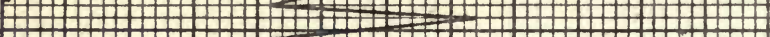
1890

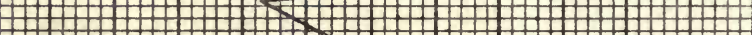

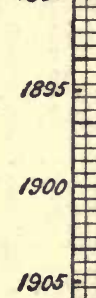

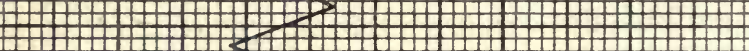

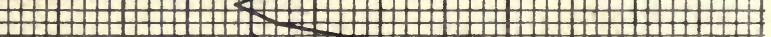

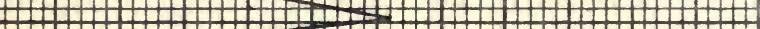

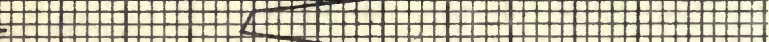

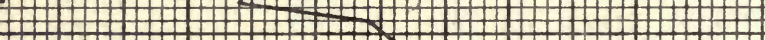

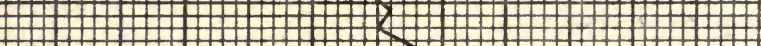

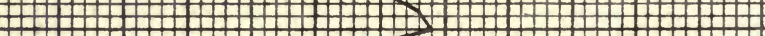

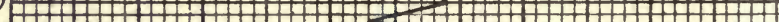
10 H 14n

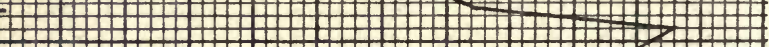

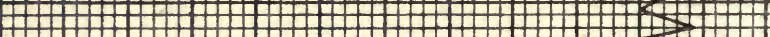

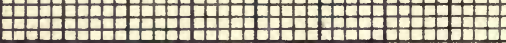

1910 \begin{tabular}{|c|c|c|c|c|c|c|}
\hline \\
\hline
\end{tabular} Price per Acre 


\section{Depression.}

But the decade 1881-90 witnessed a great change, and was probably the gloomiest in the history of New Zealand. A general world-wide depression had been experienced in the late "seventies," and this was reflected in New Zealand by falling prices of the staple exports -wool and grain. The average annual price of wheat per bushel for the decade was 3s. 8d., while in 1885 it had fallen to 2s. 11d. But the production of gold had declined, and in 1887 was only 50 per cent. of what it had been in 1877. Vogel's policy had been carried far beyond expectation, and nearly twenty millions of debt had been contracted in the previous decade. The country was now as pessimistic as it had been optimistic, and Vogel's policy was bitterly resented, though it merely had the effect of accentuating a depression caused by the fall in prices of the staple exports. It was not in itself the cause of the depression as many will endeavour to prove, but there is no doubt that it greatly increased the force of the depression, which was the result of falling prices of the staple exports-wool and wheat. And for the realisation of the extent and nature of this economic gloom of the "eighties" a slight digression will be of interest. General prices were falling throughout the world from 1875-1895, and the great increases in the world's production of wheat had caused a general world-wide reduction in price. Now the depression was accentuated in New Zealand because of the operation of two forces. Our imports are mainly manufactured goods and our exports products of the soil. The general tendency, in a time of falling prices is for the prices of the former to fall less than the fall in the general level of prices, while the prices of the latter fall to a greater extent. That is, while the general level of prices was falling the prices of the exports of New Zealand were falling to a greater extent than the prices of imports. 
Thus, if the general level fell 10 per cent., exports would fall, say, 13 per cent., and imports fall only 7 per cent. We see, therefore, that imports into New Zealand were increasing in value relative to exports, that is, that it required a greater quantity of exports to pay for imports than was the case formerly - or otherwise, the purchasing power of our exports had decreased.

But New Zealand was under a further disadvantage; for, being a debtor country, falling prices were unfavourable to her. Since the value of money had risen the interest paid represented a greater sum than previously. Thus the Colony was doubly hit by the falling prices of the eighties, and we are better able to understand why the depression experienced here was so great. Of course, in a time of rising prices like the present the circumstances are completely changed, and we, as producers, experience a double benefit because our interest payments are in reality lessened, while exports rise in value relatively to imports.

But despite this general depression it was not until the middle "eighties" that wheat production began to decline, and even then the decline was comparatively slight. The very fact that progress in wheat production was retarded is sufficient evidence of the attitude of the farmers toward the industry. And just at a time when a fate tantamount to bankruptcy was facing our Dominion there occurred an event which has rightly been called the country's salvation. In 1882 the experiment of freezing meat for export to England was successful, and the first shipment made. Prior to this, sheep were useful only for the wool they would produce. Their value was extremely low, and in many cases they could be obtained for the trouble of taking them away. But by the refrigerating process sheep proved to have value beyond that of mere wool and possible manure, and the attention of farmers began to be drawn to 
pastoral pursuits. It is unnecessary to dwell on the important progress made in the sheep freezing industry, but it must be noted that there is a vital connection between this industry and the wheat industry; also that it was the former that enabled us to withstand the forces of such a severe depression, and is very largely responsible for our present prosperity. Thus in the middle nineties when the frozen meat industry was well established the second great period in wheat production in New Zealand ended. Expansion had ceased and decline had set in.

\section{The Rise of "High" Farming.}

The year 1895 may be considered as the commencement of the last well defined period in the organisation of wheat production in New Zealand, and indeed of the rural industries generally. The years 1890-9 marked a transition from what may be called "predatory" cultivation (an American term used in connection with that form of cultivation which exploits the soil) to the more enlightened "high" farming characteristic of New Zealand agriculture at present. Wheat production from 1875-98 on a large scale was carried on by cropping merely and not by farming. This contention is well supported by the fact that the general trend of the average yield per acre from 1880-90 was downwards, while from 1890-1910 it rose as much as 10 bushels. But the difficulties of wheat production on a large seale were great. The labour problem is perhaps the most important. Two obstacles present themselves at once. There is the difficulty of obtaining casual labour, and the problems of finding employment for those engaged between sowing and reaping, and also at times when the weather forbids cultivating or harvesting operations. In the management of the estate there arises an obstacle of no mean importance, while production 
scattered over so wide a field was a difficulty in itself. A further difficulty arose from the fact that much capital was necessary, a great quantity of which was left lying idle during the greater part of the year on a purely agricultural estate. Where intensive cultivation is practised, and the system of mixed farming (the chief characteristic of rural life in Canterbury during the last twenty years) is in operation, this difficulty is not present.

These disadvantages rendered the production of wheat on a large scale a precarious pursuit, and when prices began to fall and yield per acre decreased owing to the predatory and unscientific methods of cultivation in operation, wheat growing on such an extensive plan was found to be of little or no profit in the long run. The final blow to the large agricultural estate was struck in the early "nineties" when the Graduated Land Tax came into operation. But the development of the freezing industry was equally important in bringing about the transition from the large to the small estate in the wheat producing area.

The outstanding features of rural life in the wheat producing area during the past twenty years is the small holding on which mixed farming is in operation, and intensive methods of cultivation are practised. Wheat is no longer produced on large tracts of land used exclusively for wheat production, but pastoral pursuits are carried on in conjunction with cereal growing. This is the system of mixed farming-where the main products are wool, frozen mutton, and wheat; and there is no doubt that the successful co-ordination of these pursuits is the most profitable system of farming for Canterbury, in the wheat producing area. A suitable system of crop rotation is necessary for the successful culture of wheat, while in Canterbury and North Otago, the pastures which are required for sheep farming necessitate careful culti- 
vation of the soil. And this point is of paramount importance if we are to comprehend clearly the relation of wheat growing to sheep farming. The interaction of sheep farming on wheat growing has undoubtedly operated to increase the yield of wheat, while the cultivation of the soil for wheat has produced the excellent pastures on which "Prime Canterbury" is fattened.

\section{Cultivation and the Yield.}

So important is the operation of mixed farming in the wheat producing world that it is necessary to consider the subject in further detail. During the "eighties" large scale production was the characteristic feature of wheat growing. Twenty years later our most important producers are comparatively small farmers whose activities are spread over both agricultural and pastoral pursuits. What factors have been responsible for this change, and why does the latter type afford the greatest advantage to the producer? Some of these factors have been mentioned above. The disadvantages of production on a large scale in agriculture, the economic depression of the "eighties," and the operation of the Graduated Land Tax were the predominant causes of the change. But the methods of farming the land under the system of large scale production were also greatly responsible for the decline of that system. While there was little change in the amount of land used for growing wheat during the decade 1881-90, both the technique and structure of agriculture were changing considerably. This is discernible in the movement in yield per acre throughout the period, and a study of graphs showing yield per acre and acreage in wheat is fruitful on the point. The general trend of yield per acre was upward at first, and then for two decades after 1873 it fell steadily until 1895 when it again began to rise, and it has shown a rising tendency since that date. Movements in the 


\section{Busthels per Acre}

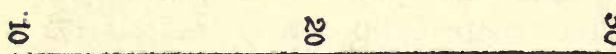

\&ั

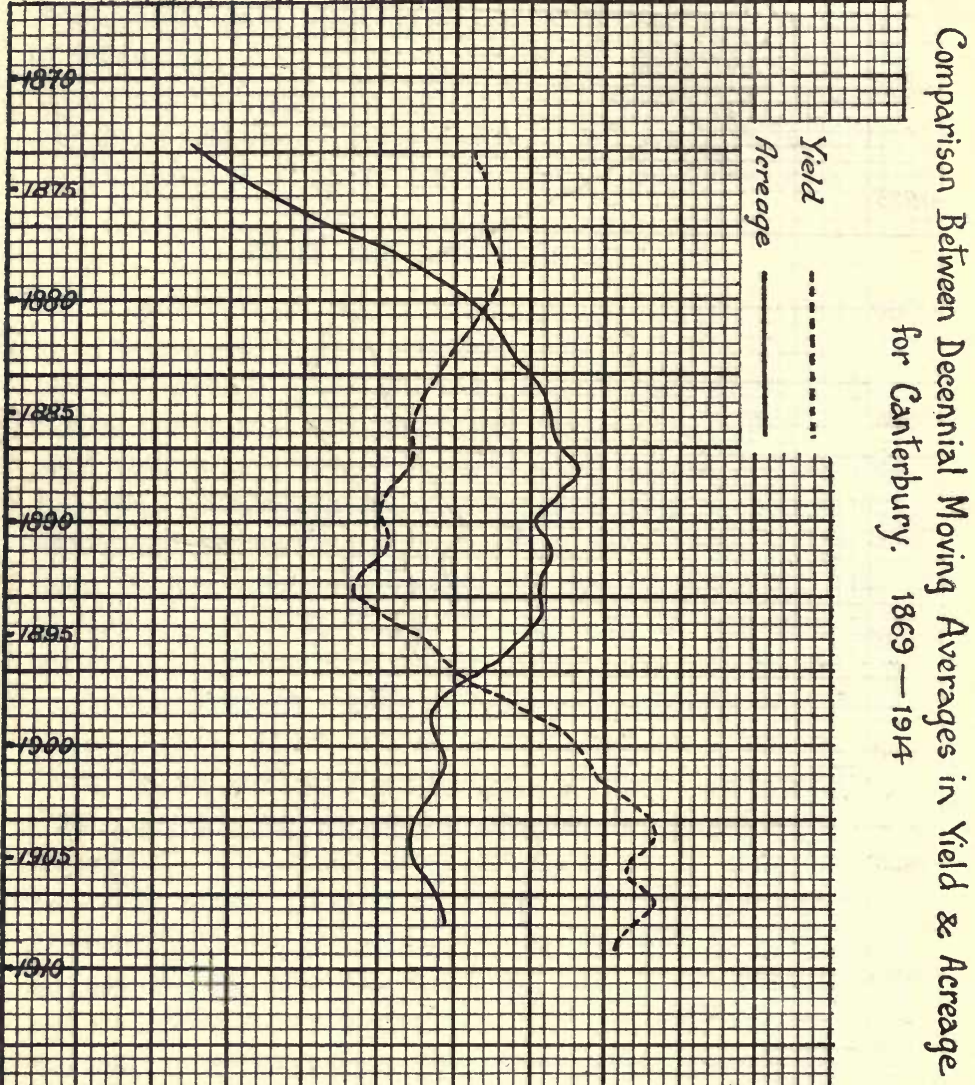

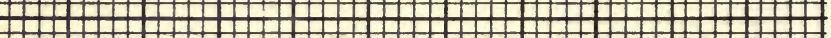

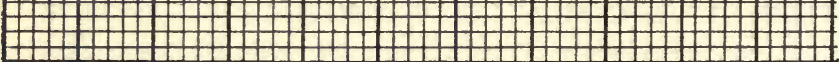

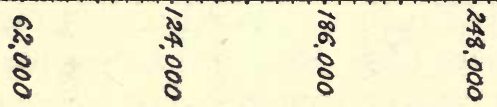

Area in Acres 
HTSTORY OF WHEAT PRODUCTION IN NEW ZEALAND 111

\section{Bushels per Acre}

ठै

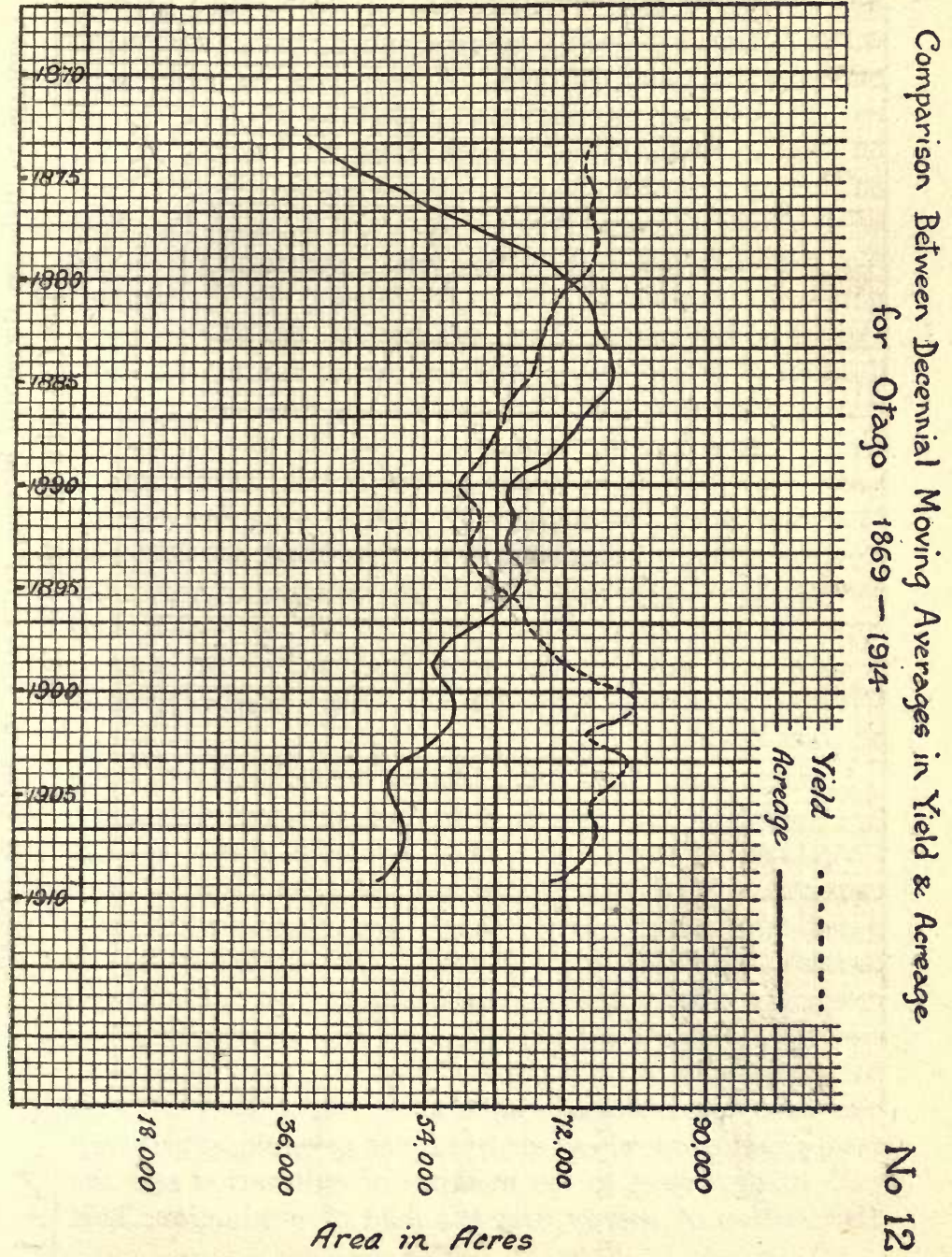


general trend of the average are exactly the opposite to these movements in yield per acre. This confirms the law of diminishing returns, which states that after a certain stage has been reached fresh additions of capital and labour to land do not yield corresponding returns. A modification of the law states that as the margin of cultivation extends and more land is brought under cultivation, the return per unit decreases. But the law of diminishing returns does not fully account for these movements in yield per acre. For, in the first place, the persistent decline of the yield during the "eighties" cannot be the result of soil exhaustion, nor of the introduction of inferior soils, since, as far as can be gathered, wheat production did not extend to these on a large scale. Secondly, the remarkable rise of 10 bushels per acre in the yield in the decade after 1895 at once suggests that more scientific methods of culture were introduced. These graphs showing comparisons in yield per acre and acreage for Canterbury and Otago individually, and for New Zealand as a whole, are full of suggestion and conclusively support the view that mixed farming is the most successful type for the wheat producing area of New Zealand.

I have said that the change in agriculture since the "eighties" has been in both structure and technique. Structural changes have been brought about by the conversion of the large agricultural estate into a comparatively small farm where both agriculture and pastoral pursuits are followed. The introduction of intensive cultivation in contrast to the unscientific methods of cropping practised on the large estate has fundamentally altered the technique of agriculture. It has been demonstrated that during the period of large scale production wheat growing was pursued extensively with little respect to the methods of cultivation and the distribution of energy over the field of production. This 


\section{Bushels per Acre}

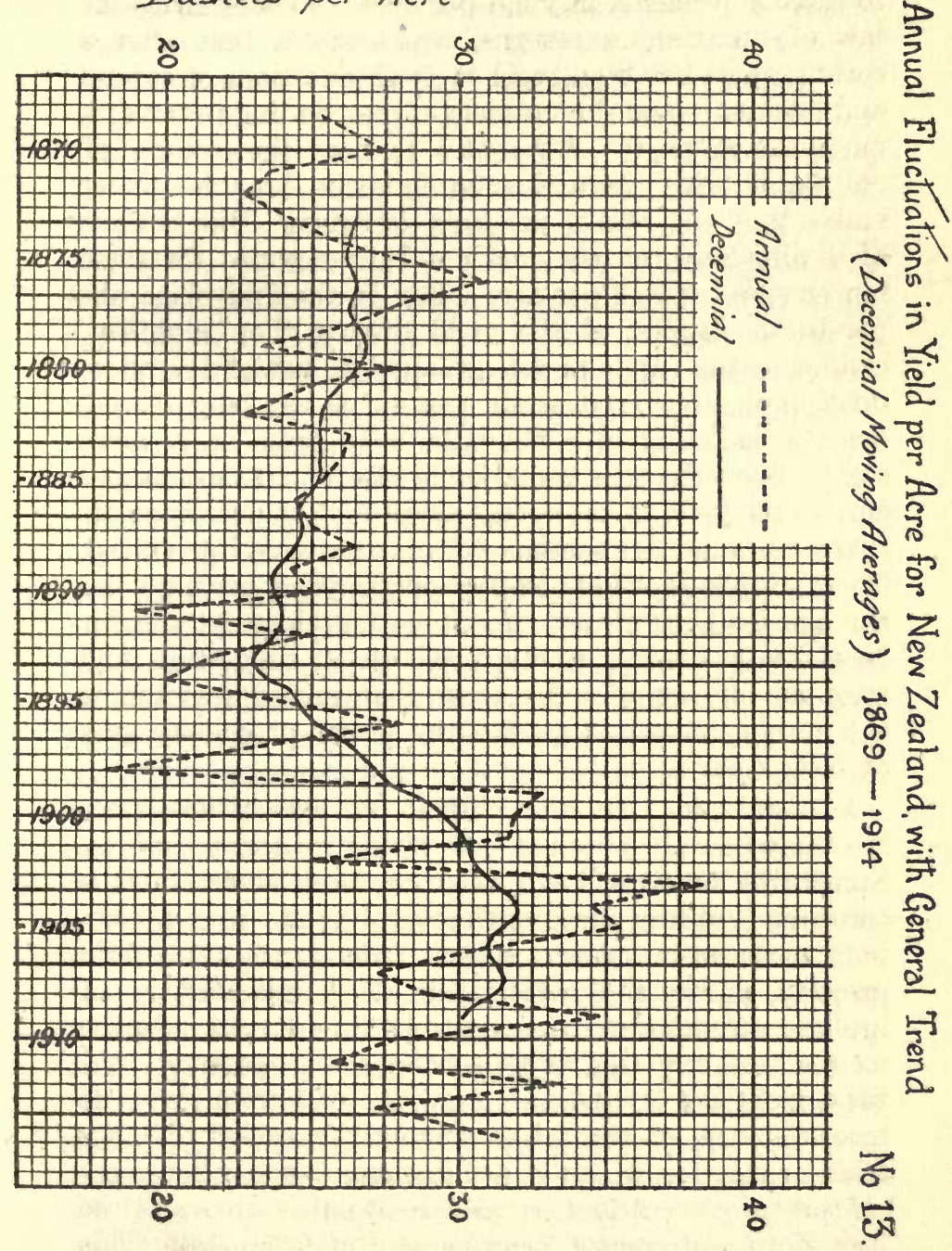


exploitation of the resources of a country in the early stages of its industrial development is common indeed; it marks a certain stage in the industrial history of every new country. "When new land is first taken into cultivation, the necessity of restoration is not felt. The store of elements of fertility is then large and may maintain itself, notwithstanding continuous drains for years and even for a generation. If there is plenty of new land another parcel can be taken under cultivation when signs of exhaustion appear in that first used, and so on, as long as new land is available. This is what the Germans call 'Raub-bau'-predatory cultivation." * This predatory cultivation was the outstanding feature of the organisation of wheat production during the "eighties." The land was not "farmed"' as we understand the word in these days, but was "cropped" ruthlessly with little or no thought for the future of agriculture in the country. The system of contracting which was in operation to a large extent encouraged this, for an individual who leased land for short periods was not greatly concerned with the future productivity of that land. The operation of these forces then-the system of large estates, extensive farming, and successive cropping, -brought about the result which was inevitable in such circumstances. The natural fertility of the soil was quickly diminished, and the low returns from wheat growing began to attract attention. At the same time, as will be shown in the next chapter, wheat prices had fallen greatly, and by the early "nineties" it was evident that greater attention to the culture of the soil was necessary if the industry was to be continued successfully. The decade $1890-9$ is, then, a transition period in which the breaking up of the large estates introduced a change from extensive to intensive farming, while the system of predatory cultivation was gradually superseded by the more enlightened practice of "high farming" now

"Taussic, "Principles of Economics." Vol. II., page 66. 
becoming characteristic of successful wheat production. The degree of success of this change is sufficiently well demonstrated by the graphs showing the yield per acre of wheat in Canterbury and Otago, both of which record a rise of as much as 10 bushels in the decade following 1893. In Chapter VIII we return to a discussion of the organisation of wheat production since 1895, when further consideration will be given to the system of mixed farming. It is now established that the factor of primary consideration responsible for the low yield of the "eighties" was extensive farming with its predatory methods of cultivation.

\section{Cyclical Changes in Production.}

The evidence of a cycle of production of wheat in New Zealand is more marked in the early periods of the industry than in the later. Commencing with the year 1869 there are four well defined cycles over a period of 34 years. These cycles are as follows:-

1. 1869-1876. - An eight-year period in which area under wheat and total crop gradually rise to a culminating point in 1873-4 and then fall away. No doubt the fact that there was a rush to wheat production after the stimulus given by rising prices, and other conditions already noticed, was responsible, in a large measure, for a rapid increase in production and a consequent falling off after the first rush had worked into normal conditions again.

2. 1877-1886. - This period of ten years shows a typical Jevonian cycle* in wheat production in New

"See H. S. Jevons on "Unemployment" in the Contem. porary Review," August, 1909.

The late Professor W. S. Jevons endeavoured to explain the regularly recurring fluctuation of industry over periods of ten to eleven years by connecting it with the size of the yearly harvests, and this in turn with the well-known variations-over 
Zealand. A gradual rise in total production took place until 1883-4 when a maximum was reached, after which in the succeeding two years production falls away rapidly. These are the circumstances of a typical credit cycle. At first, trade is depressed and progress is slow. Then comes a period of rapid expansion followed by sudden collapse, and trade once more becomes depressed. So our cycle from 1877-1886 may be divided into three periods:- the first, 1877-80, when progress was slow but sure; then a period of rapid expansion, 1881-4; followed thirdly, by a sudden collapse in 1885-6.

3. 1887-1895.-The third cycle, this time of nine years, is no less conformatory to Jevons's cyclical theory than the former period. Here, again, during the years 1887-91 production gradually increases until a culminating point is reached in 1892, after which there is a decline at first slow and then rapid until 1895.

4. 1896-1902.-A somewhat shorter cycle then follows, but nevertheless typical in its nature. A steady recovery from 1895 sets in, and in 1899 a maximum is reached, after which once more production declines.

5. 1902-1913.-Since 1902 cyclical changes are not so definite. The wheat industry, gradually losing its position as one of our principal industries, is consequently in a

ten or eleven year periods-of the sun spots, which were considered to reflect changes in the amount of heat given by the sun. His son, Prof. H. S. Jevons, continued the thesis by making extensive investigations into fluctuations in the agricultural produce of the United States of America, the results of which are set out in the article quoted above.

In this way he established a trade cycle of about $10 \frac{1}{2}$ years with three interacting cycles within the period of $3 \frac{1}{2}$ years. This is what is known as a typical Jevonian cycle. In order to test the validity of the theory in reference to New Zealand it would be necessary to consider the whole of the primary produce of the Dominion, which is rather beyond the scope of this investigation. 
somewhat transitional state, and the amount produced fluctuates considerably from year to year. Nevertheless, we can notice a more or less definite cycle over the period 1903-13. From statistics of the area in wheat the cycle is much more definite than from statistics of total crop. From the former we see that an upward tendency, with one exception of importance, that of the year 1908, was maintained until 1910, after which production fell off in the usual way. From the latter, however, a good harvest in 1905 breaks the gradual upward tendency; but otherwise the cycle is fairly typical reaching a maximum output in 1910-11 and afterwards declining.

In this connection the frequency and regularity with which a series of good harvests occurred is not unimportant. In the period 1869-1902 these were regular in their occurrence, being registered in 1873-4, 1883-4, 1892, and 1899. During the remaining period, as was noted, the graph representing the cyclical period 1903-13 has two crests, 1905 and 1909, while the harvest of 1915 gave an excellent yield, though the area sown was small.

Broadly speaking, then, we may trace out five cyclical periods between 1869 and 1913, the average length being about 9 years, which corresponds fairly closely with Jevons's period of a little over 10 years. It will be noticed also that good harvests occur up till 1905 at intervals of about nine years. The harvest for the present year has occurred with the same regularity and, with the exception of the year 1909, we have had good harvests at regular recurring intervals of about 9 years. New Zealand as yet affords no data for examining the validity of long period cycles, such for instance as Brückner's 34 year cycle and Wolf's cycle of 55 years. Moreover, it must be remembered that our enquiry into the causes of cyclical changes in production is made under rather exceptional circumstances, in that New 
Zealand is a young country with rapidly changing conditions; and there should be considered other conditions besides gross production, as for instance, rapidly changing population or the foundation of new industries. It will be only after an equilibrium has been established and the country passes out of its initial stages of development that the causes of cyclical changes will be open for study on a more certain foundation. The recent investigation by the Census and Statistics Office into the Cost of Living in New Zealand throws further light on the subject of cyclical fluctuations in agricultural produce in New Zealand. The graph of the combined index number of five home products (bread, flour, oatmeal, potatoes, and onions), shows a more or less regular period of fluctuation of about four years. This is very clearly shown in a graph which portrays deviations above and below the average of the series. The result is a regular succession of troughs and crests until recent years when conditions have been somewhat abnormal. "Roughly, these oscillations above and below the average represent variations in production from period to period, and the regularity with which periods of high and low prices alternate is so striking as to suggest some underlying cause or law, probably connected with production."

\section{Relation Between Supply and Price.}

If fluctuations in the annual supply of wheat produced in New Zealand are compared with the corresponding movements in New Zealand wheat prices during the last four decades, a tendency to inverse correlation is noticeable. Thus, a year of high prices is almost invariably followed by increased production at the following harvest. Such was the case after the relatively

*See "Report on the Cost of Living in New Zealand from 1891-1914." Pages 24-5. 
high prices of $1877-8,1880,1887,1903$, to pick out years at random. Similarly, we find years of relatively low prices followed by decreases in the total supply. Thus prices were comparatively low in $1885,1888,1893$, and 1900 , and in the following years there is a diminution in production. On the other hand, similar connections may be traced between supply and price, years of high total supplies being followed by years of low price, and vice versa. Typical examples of this are seen in the years 1892 , 1899, when production exceeded 10,000,000 bushels.

The connection is more evident from a graph of total supply and average annual price. Index numbers of supply and price with the base period of $1890-99$ have been taken, and from these graphs of the two periods have been drawn. Looking at this graph we notice the connection hinted at above even more marked, especially of recent years. With few exceptions a "crest" in the graph of prices corresponds with a "trough" in the graph of supply, and vice versa. It is remarkable how often a "trough" in supply just precedes a "crest" in price, while on the other hand price minima precede supply minima.

Such generalisations of course are open to exceptions, for supply is only one factor in the determination of price from year to year. In the following chapter price movements will be treated more fully, but this rough correspondence of supply and price movements may be noted here as an important influence determining the fluctuations in supply from year to year. Turning to graphs of supply and price where quinquennial averages are taken over the same period as previously, we notice that the curves frequently intersect and for the most part move in opposite directions. This suggests that there is correlation between supply and price. 


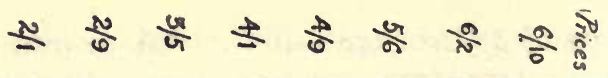

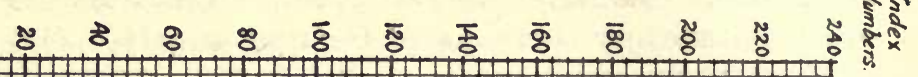
せ Z

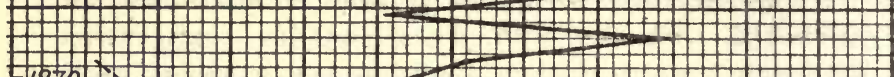

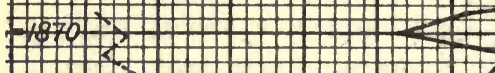

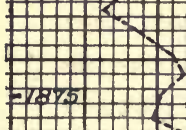

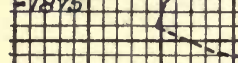

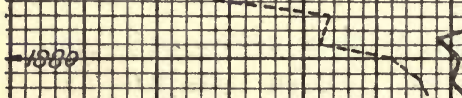

ஜ

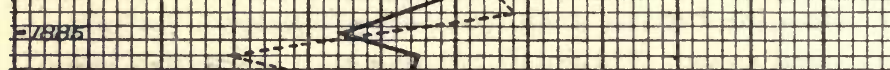
Z

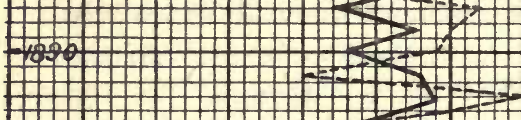
\begin{tabular}{|c|c|c|c|c|c}
\hline & & & \\
\hline
\end{tabular} 
Following out this suggestion the co-efficient of correlation* of the two series was calculated. Index numbers of supply and price were taken for the years 1869-1914, the base period being 1890-99. The annual average in each case during this period was equated to 100 and then corresponding numbers were taken out for each year. The next step was to find the mean for each series, and then the deviations from the mean in each case. By squaring these deviations and taking the square root of the mean of the squares in each case the standard deviation was found. The co-efficient of correlation was then taken from the following formula: $-\frac{\sum(x y)}{n z_{1} z_{2}}$, where $x$ and $y$ are the deviations of the two series from the mean with due regard to sign, $n$ is the number of terms and $z_{1}$ and $z_{2}$ the standard deviations. This gave a co-efficient of correlation of $\cdot 440$. The probable error

was then found by using the formula $\frac{1-r^{2}}{n}$ where $r$ is the co-efficient of correlation and $n$ is the number of terms. The probable error was $\cdot 079$.

Despite the fact that the co-efficient of correlation is not high, correlation may be regarded as a practical certainty, for the co-efficient is almost six times as great as the probable error, Dr. Bowley's criterion of correlation.

The correlation co-efficient is relatively high when all circumstances are considered. Many outside influences operate to interfere with the natural tendency of supply to act on price and vice versa. Thus our price is determined not so much by the local supply but largely by the English price. $t$ In the earlier years of the period the gold supplies played a large part in determination of II.

*The subject of correlation is explained briefly in Appendix VII.

†For a complete treatment of price determination see Chapter 
TABLE XVIII.

WHEAT IN NEW ZEALAND.

Correlation between Supply and Price in New Zealand, 1869 to 1914.

\begin{tabular}{|c|c|c|c|c|c|c|c|}
\hline \multirow[b]{2}{*}{ YEAR } & \multicolumn{3}{|c|}{ PRICE } & \multicolumn{3}{|c|}{ SUPPLY } & \multirow{2}{*}{$\begin{array}{c}\text { Products } \\
\text { of } \\
\text { Deviations } \\
(x y)\end{array}$} \\
\hline & $\begin{array}{c}\text { Index No. } \\
\text { Mean } \\
114=100\end{array}$ & $\begin{array}{l}\text { Devi- } \\
\text { ations }\end{array}$ & Squares & $\begin{array}{l}\text { Index No. } \\
720,000=100 \\
\end{array}$ & $\begin{array}{l}\text { Devi- } \\
\text { ations }\end{array}$ & Squares & \\
\hline 1869 & 124 & +10 & 100 & 22 & -66 & 4356 & -660 \\
\hline 1870 & 111 & -3 & 9 & 32 & -56 & 3136 & +168 \\
\hline 71 & 137 & +23 & 529 & 25 & -63 & 3969 & -1449 \\
\hline 72 & 129 & +15 & 226 & 35 & -53 & 2809 & -795 \\
\hline 73 & 140 & +26 & 676 & 44 & -44 & 1936 & -1144 \\
\hline 74 & 135 & +21 & 441 & 47 & -41 & 1681 & -861 \\
\hline 75 & 122 & +8 & 64 & 41 & -47 & 2209 & -296 \\
\hline 76 & 126 & +12 & 144 & 39 & -49 & 2401 & -588 \\
\hline 77 & 176 & $\begin{array}{r}+62 \\
\end{array}$ & 3844 & 56 & -32 & 1024 & -1934 \\
\hline 78 & 136 & +22 & 484 & 87 & -1 & 1 & $-\quad 22$ \\
\hline 79 & 116 & +2 & 4 & 84 & -4 & 16 & \\
\hline 1880 & 122 & +8 & 64 & 104 & +16 & 256 & +128 \\
\hline 81 & 120 & +6 & 36 & 112 & +24 & 576 & +144 \\
\hline 82 & 126 & +12 & 144 & 114 & $\begin{array}{r}+26 \\
\end{array}$ & 676 & +312 \\
\hline 83 & 124 & +10 & 100 & 131 & +43 & 1849 & +430 \\
\hline 84 & 106 & -8 & 64 & 136 & $\begin{array}{r}-48 \\
\end{array}$ & 2304 & -384 \\
\hline 85 & 87 & -27 & 729 & 94 & +6 & 36 & -162 \\
\hline 86 & 110 & -4 & 16 & 68 & -20 & 400 & +80 \\
\hline 87 & 109 & $-\overline{5}$ & 25 & 86 & -2 & 4 & $+\quad 10$ \\
\hline 88 & 88 & -26 & 676 & 129 & +41 & 1681 & -1066 \\
\hline 89 & 113 & -1 & 1 & 120 & $\begin{array}{r}32 \\
+32\end{array}$ & 1024 & $\begin{array}{r}-32 \\
-\quad 3\end{array}$ \\
\hline 1890 & 92 & -22 & 484 & 116 & +28 & 784 & -616 \\
\hline 91 & 113 & -1 & 1 & 79 & -9 & 81 & $\begin{array}{r}+9 \\
+\end{array}$ \\
\hline 92 & 117 & +3 & 9 & 141 & +53 & 2809 & +159 \\
\hline 93 & 81 & -33 & 1089 & 115 & +27 & 729 & -891 \\
\hline 94 & 73 & -41 & 1681 & 67 & -21 & 441 & +861 \\
\hline 95 & 86 & -28 & 784 & 50 & -38 & 1444 & +1064 \\
\hline 96 & 106 & -8 & 64 & 94 & +6 & 36 & $\begin{array}{r}-48 \\
-\quad 4\end{array}$ \\
\hline 97 & 125 & +11 & 121 & 81 & -7 & 49 & $-\quad 77$ \\
\hline 98 & 124 & +10 & 100 & 78 & -10 & 100 & -100 \\
\hline 99 & 75 & -39 & 1521 & 180 & +92 & 6724 & -3588 \\
\hline 1900 & 70 & -44 & 1936 & 118 & +30 & 900 & -1320 \\
\hline 01 & 71 & -43 & 1849 & 89 & +1 & 1 & $-\quad 43$ \\
\hline 02 & 103 & -11 & 121 & 56 & -32 & 1024 & $+\quad 1$ \\
\hline 03 & 122 & +8 & 64 & 102 & +14 & 196 & -112 \\
\hline 04 & 92 & -22 & 484 & 108 & +20 & 400 & -440 \\
\hline 05 & 92 & -22 & 484 & 125 & +37 & 1369 & -814 \\
\hline 06 & 91 & -20 & 400 & 93 & +5 & 25 & -100 \\
\hline 07 & 110 & -4 & 16 & 77 & -11 & 121 & $+\quad 44$ \\
\hline 08 & 135 & +21 & 441 & 76 & -12 & 144 & -252 \\
\hline 09 & 120 & +6 & 36 & 120 & +32 & 1024 & +192 \\
\hline 1910 & 107 & -7 & 49 & 121 & $\begin{array}{r}+31 \\
\end{array}$ & 961 & -217 \\
\hline 11 & 110 & -4 & 16 & 114 & +26 & 676 & -104 \\
\hline 12 & 107 & -7 & 49 & 100 & +12 & 144 & $-\quad 84$ \\
\hline 13 & 112 & -2 & 4 & 71 & -17 & 289 & $+\quad 34$ \\
\hline \multirow[t]{2}{*}{14} & 168 & +54 & 2916 & 72 & -16 & 256 & -864 \\
\hline & \multicolumn{3}{|c|}{ Sum of Squares 23.194} & \multicolumn{3}{|c|}{ Sum of Squares 53.066} & -15.151 \\
\hline
\end{tabular}




\begin{aligned} & STANDARD DEVIATION OF PRICES $=\sqrt{\frac{23.194}{46}} \\ &=\sqrt{\frac{504.21}{22.45}} \\ &=\sqrt{\frac{53.066}{46}} \\ &$ STANDARD DEVIATION OF SUPPLY $=\sqrt{1151} \\ &=\frac{33.93}{-15.151} \\ &$ CO-EFFICIENT OF CORRELATION $=\frac{-.440}{46 \times 22.45 \times 33.93} \\ &$ PROBABLE ERROR $=\frac{1-(.440)^{2} \times .6745}{\sqrt{46}} \\ &=\frac{.079}{} \\ &$\hline\end{aligned}

price. Such influences as the land boom of the "seventies," the depression of the "eighties," the South African War, also tended to disturb this natural tendency. The nature and extent of this influence is reserved for special study in the following chapter, but it is expedient here to point out that our co-efficient of correlation is not remarkably low relative to circumstances, and since the probable error is comparatively low we may regard the establishment of correlation as a practical certainty. The accompanying graph* showing the relation between price and area under wheat is interesting as illustrating the influence of price movements on the practice of our farmers in regard to wheat growing. Years of high prices are almost invariably followed by increases in the area sown, and low prices similarly exert an influence in reducing the area.

\section{Competition of other Industries for the Use of the Iand.}

1. Sheep Farming. - In dealing with the general history of wheat production references were made to 
various other industries as having an effect on the course of wheat production. First it was the tendency to sheep farming during early colonisation in the "fifties" and "sixties" which retarded progress in the cultivation of the cereal, though no doubt the position in many cases was that the land would have been idle if pasture had not been profitable. The prospects for this industry were good at the outset, especially from the point of view of the market, and as early as 1858 the export had reached 3,810,373 lbs. During the "sixties" rapid progress was made, and in 1870 the exports totalled $37,039,763$ lbs. Prices were exceedingly good until 1878, when a slight fall occurred, falling more rapidly in the "eighties," as did the prices of almost all commodities.

During the period $1870-90$ sheep farming did not have such a restrictive influence on wheat growing as previously, and during the "seventies" progress was relatively greater in the latter industry than in the former. This was largely due to the fact that, except for the supply of wool which sheep afforded, and their possible use as manure, they were of little value, and consequently of the two pursuits wheat growing was the more profitable and prosperous.

With the success of the refrigerating process in 1882 the situation became somewhat changed. Although the frozen meat industry was an established fact in the early "eighties," it is of course not surprising that for nearly a decade its influence was not marked. The new industry was of such a character that it required considerable capital, machinery, and skilled labour and managers. Moreover, sheep runs were already overstocked with sheep and there was an ample supply for the small demand from the industry. It is noteworthy that almost a decade passed before sufficient capital had been transferred to the industry to render its influence 

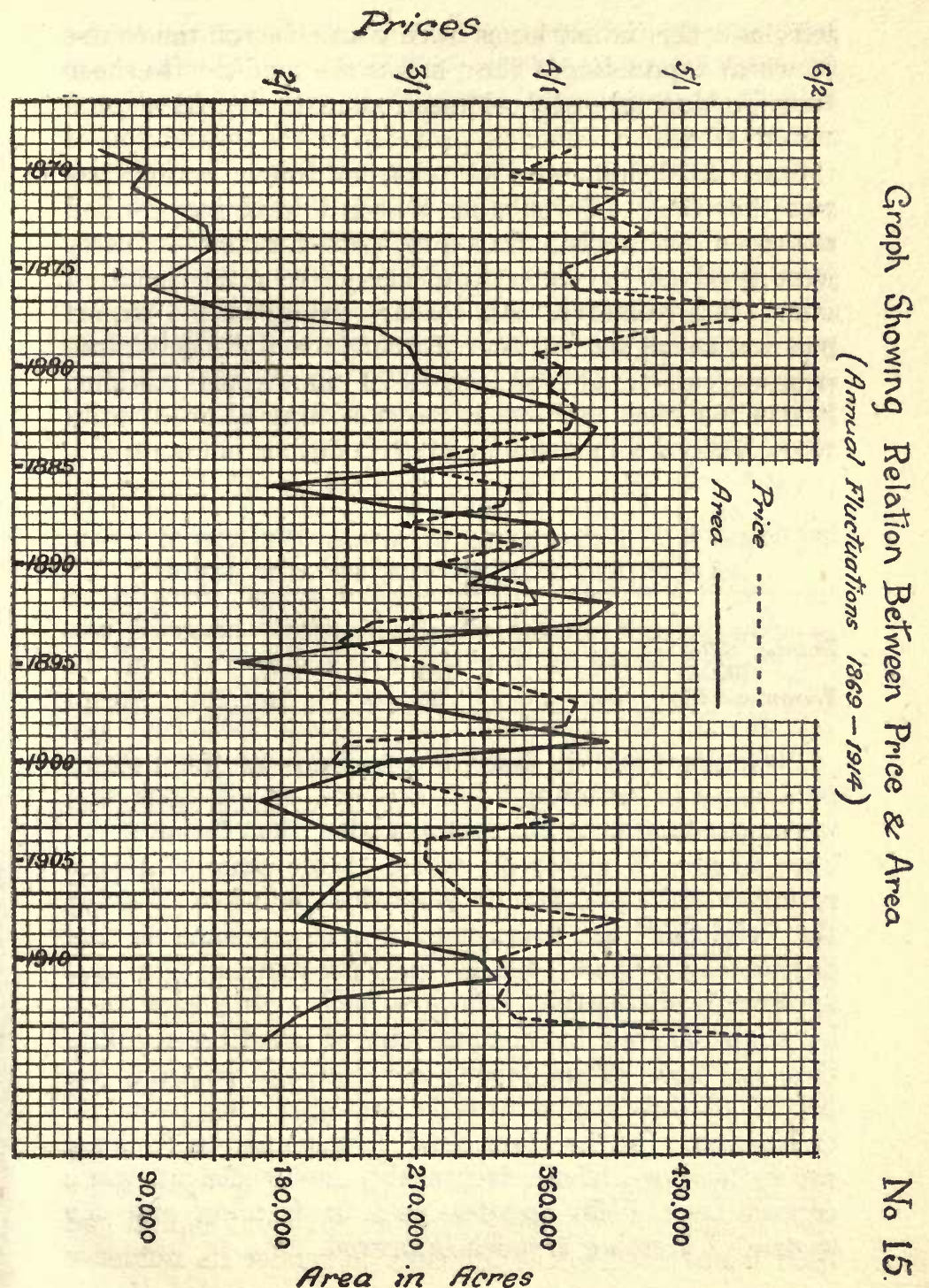
felt; and this is not surprising when we remember the financial depression of the "eighties," and the fact that New Zealand was still a young country in the experimental stage.

Since 1890, however, the trade in frozen mutton has gone ahead by "leaps and bounds," and has carried along with it the importance of woollen exports. These joint products of sheep farming, not to mention hides, skins, fat, manures, etc., easily occupy the premier position among our exports, in 1913 totalling $12 \frac{1}{2}$ millions sterling out of a total export of about $22 \frac{1}{2}$ millions. Prices for wool and frozen mutton have risen steadily since 1900, the increase in price being as follows:-

TABLE XIX.

INCREASES IN THE PRICES OF WOOL, FROZEN MUTTON, AND WHEAT DURING THE DECADE, 1900-9.

\begin{tabular}{ccc|c|c|c}
\hline & & & Wool & $\begin{array}{c}\text { Frozen } \\
\text { Mutton }\end{array}$ & Wheat \\
\hline Decade 1890-9 & $\ldots$ & $\ldots$ & 100 & 100 & 100 \\
, 1900-9 & $\ldots$ & $\ldots$ & 130 & 116 & 101 \\
Percentage rise & $\ldots$ & $\ldots$ & 30 & 16 & 1 \\
\hline
\end{tabular}

Statistics such as these throw light on the present tendencies in farming. We are told on all sides that wheat production is not remunerative, that farmers will have to give it up or be ruined if the scale of prices ruling over the past twenty years does not alter. During the "eighties" the average price was the same as that during the period 1901-10 and production then was apparently successful. Of course such a conclusion must be supplemented by comparisons of conditions ruling then and now. True, labour has risen and probably the law of diminishing returns is now operating in actual cultivation. On the other hand, transportation facilities are better now, labour is probably more efficient, while capital pays a far greater part in farming and the system of farming is much improved. 
It has already been pointed out that in many districts wheat growing is best carried on with sheep farming,in a word, that mixed farming is the most profitable method in New Zealand. For the frozen meat industry some form of cereal growing is almost necessary for the purpose of fattening sheep and lambs. Moreover, the best wheat crops are grown under a good and systematic crop rotation of which root crops, very useful for winter feed, form an essential part. Thus, although wheat growing has suffered at the expense of more extensive sheep farming, it is nevertheless very unlikely that, while in occasional years, such as 1914, there is a temporary tendency to abandon wheat production, agriculture will finally give way to pastoral pursuits. During the past two decades this tendency has been manifest, but how far it is likely to continue is a matter for speculation, of which more will be said in the concluding chapter.

2. Dairy Farming. - The second industry which is becoming a competitor of wheat growing for the use of the land is the dairying industry. This industry has long been established in the Dominion, the exports of butter and cheese in 1854 being 807 cwt. and 169 cwt. respectively. Up till the end of last century the industry, however, was not very important, but it then began to attract attention as a pursuit, for which the country had great advantages. Since then many factors have stimulated its progress. The establishment of "creameries" throughout many parts of the country, the development of the refrigerating process, and the success of home separators have been very active factors; of recent years prices have shown a rising tendency; lastly the Government has given much encouragement to the industry.

Under these stimuli the exports of butter and cheese each considerably over 100,000 ewt. in 1900 , have steadily risen, and in 1914 were 434,067 cwt. and 863,776 cwt. 
respectively, the values being $£ 2,338,576$ and $£ 2,564,125$. For the year 1916 the total value of these exports was

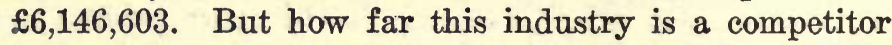
with wheat growing for the land, and how far each is encouraged by the other is a difficult matter to estimate.

In the first place much land, on which cultivation, if not impracticable, is extremely difficult, is devoted to pasture for stock. This is especially the case in the North Island, though there is no doubt that much land useful for wheat growing is also used for dairying. It is often convenient for a farmer to devote some attention to dairying in co-ordination with agricultural pursuits. Using a separator on a farm he can extract the cream himself and thus any inconvenience caused by carrying milk to a local creamery every morning is obviated, for one or two trips in the week to the local railway station with his cream is all that is necessary. So far dairying and wheat growing go hand in hand, but there are many points at which their paths diverge. Dairying has proved to be a highly remunerative pursuit, and much land now being opened up for settlement is being devoted to this industry, and progress is very rapid. In so far as land suitable for cereal growing is being absorbed for use as pasture for stock, thus far wheat production is being sacrificed to dairying.

On the whole, much less risk is attached to dairying than accompanies wheat growing. It is only the broad climatic changes which exert an influence on the former, while the latter is dependent in great measure on relatively small changes in climate. Further, much more manual labour and organising ability is necessary for growing wheat than for dairying.

In a word, wheat growing possesses fewer relative advantages than dairying, and as measured by quantities exported recently, the latter pursuit is proving a very serious competitor with the former for the use of the 
land, and is no doubt a factor of some importance in the determination of recent tendencies in the agricultural and pastoral industries of the Dominion.

\section{Competition of Other Countries.}

Considerable influence has been exerted on the normal growth of wheat production in New Zealand by the extension of wheat production on an almost unprecedented scale in other countries competing in the English market. During the "eighties" it was thought that New Zealand would have a permanent considerable export of wheat to England, but the hope has proved a vain one, and in some measure it is due to the action of other producing areas in pouring large supplies into the Home market.

- Thus from the following table it will be seen that there have been great increases in exports from various competing countries during the 30 years ending 1910 , while the export from New Zealand has decreased.

TABLE XX.

AVERAGE ANNUAL NET EXPORTS OF EXPORTING COUNTRIES FOR THE LAST THREE DECADES.

\begin{tabular}{lll|c|c|c}
\hline & & \multicolumn{3}{|c}{ Average Net Exports in Million Bushels. } \\
\cline { 3 - 6 } & & & $1881-90$ & $1891-00$ & $1901-10$ \\
\hline CANADA $\ldots$ & $\ldots$ & $\ldots$ & 2 & 13 & 42 \\
ARGENTINA & $\ldots$ & $\ldots$ & 4 & 37 & 68 \\
AUSTRALIA & $\ldots$ & $\ldots$ & 6 & 6 & 28 \\
NEW ZEALAND & $\ldots$ & $\ldots$ & 3 & 1 & 1 \\
\hline
\end{tabular}

From the above table it is at once obvious that the great increases in exports from Canada, Argentine, and Australia, contemporaneously with decreases in New Zealand, have affected the progress of wheat production here very considerably. The steady downward trend in English prices since the late "seventies" has been due to this great increase in supply, and it is in this reduced 
price that New Zealand has been affected. The price for New Zealand is determined, as we shall see in the following chapter, for the most part by English prices, and on account of the great distance at which New Zealand is situated from the market, price here, when there are considerable quantities for export, at times falls below the English level by the amount of the cost of carriage. Hence in times of low prices in England, when production in New Zealand is large, prices in the Dominion reach a very low level. It was this state of affairs which existed during the closing two decades of last century, and this accentuated the already existing tendency in favour of pastoral pursuits at the expense of wheat growing. As illustrative of this movement the following table showing average prices of English and New Zealand wheat for the years 1881-1900 is given :-

TABLE XXI.

NEW ZEALAND AND ENGLISH PRIOES.

1881-1900.

\begin{tabular}{r|c|c} 
Year & $\begin{array}{c}\text { "English } \\
\text { Prices"* }\end{array}$ & $\begin{array}{c}\text { New Zeeland } \\
\text { Prices"* }\end{array}$ \\
\hline 1881 & $5 / 8$ & $4 / 1$ \\
2 & $5 / 7$ & $4 / 3$ \\
9 & $5 / 2$ & $4 / 3$ \\
4 & $4 / 6$ & $3 / 7$ \\
1885 & $4 / 1$ & $3 /$. \\
6 & $3 / 10$ & $3 / 9$ \\
7 & $4 / 1$ & $3 / 9$ \\
8 & $4 /$. & $3 /$. \\
9 & $3 / 9$ & $3 / 11$ \\
1890 & $4 /-$ & $3 / 2$ \\
1 & $4 / 7$ & $3 / 10$ \\
2 & $3 / 10$ & $4 /$. \\
3 & $3 / 3$ & $2 / 9$ \\
4 & $2 / 10$ & $2 / 6$ \\
1895 & $2 / 10$ & $2 / 11$ \\
6 & $3 / 3$ & $3 / 7$ \\
7 & $3 / 9$ & $4 / 3$ \\
8 & $4 / 3$ & $4 / 3$ \\
9 & $3 / 2$ & $2 / 9$ \\
1900 & $3 / 5$ & $2 / 5$ \\
\hline
\end{tabular}

*To the nearest penny. 
It will be noticed that with one exception the English prices are considerably above the New Zealand prices in the "eighties." The exceptional year was 1889 when New Zealand prices exceeded English prices by 2 d., but the cause of this was that the New Zealand supply fell by nearly 700,000 bushels while the exports increased by 200,000 bushels, thus causing a net fall in home supply of some 900,000 bushels. We notice that in a year of abundant production in New Zealand when there is a large exportable surplus, the local price is very much lower than the English price. Such was the case in 1899,1888 , and 1883.

\section{Conclusion.}

The outstanding influences marring and moulding - the progress of wheat production in New Zealand have been considered at length for the purpose of obtaining suggestions as to the probable course in the future. The rise of the wheat industry has been traced from the "sixties" to its culminating point in the "eighties," when many and various factors came into operation tending to render the industry relatively less important. At one time it was thought that the cereal would ultimately form New Zealand's staple product, and circumstances were certainly favourable for this. The whole country waxed enthusiastic over the prospects of wheat growing, so much so that as a result of this, together with an ambitious borrowing policy, New Zealand experienced her first and most severe land boom.

But many factors have been found to come into -peration since 1880, and these were destined to cut away considerably the foundations upon which the production of wheat was resting. There was a period of great depression and a retrenchment policy on the part of the Government; prices fell to an exceedingly low level; several other producing areas, notably Canada, 
Argentine, and Australia, extended their production and their export to the English market; many pastoral pursuits were found to be more profitable in New Zealand, especially trade in frozen mutton and dairy produce. These factors came into operation all within one decade and, as events have proved, exerted a detrimental effect on the progress of wheat production.

During the "nineties" the industry wavered and showed a tendency to decline. In the first decade of the present century decline was marked, for then the full significance of the above factors was felt. How far the decline is to continue, and how far the industry is to be crippled by counteracting factors are subjects for study in a succeeding chapter. The history of the movement has been considered carefully in order that the lessons to be derived from experience in the past may furnish as much guidance as possible for forecasts of the future. 


\section{Chapter VII.}

\section{THE PRICE OF WHEAT.}

\section{General Remarks on Price Determination.}

It is a common-place that any investigation into the factors determining the price of any commodity should commence with an analytic survey of the conditions affecting the supply of and demand for that commodity. Wheat is no exception to this common rule. The price of wheat is normally determined by conditions of supply and demand in a market which is almost world-wide. The influence exerted by these conditions over price is of both immediate and ultimate importance. Direct variations in price result from variations in supply or demand, while fluctuations in price bring into operation forees which tend to adjust supply and demand to the changes in price. The former variations are immediate, and give rise to market price; the operation of the latter requires a long period, and they exert an ultimate influence, being fundamentally the cause of the transition from market, through sub-normal, to normal price.

The terms market price and normal price will receive consideration in the forthcoming exposition of the general factors determining the price of wheat. Before entering into this exposition it will be well to call attention to the importance of considering the problem in detail.

Produced in considerable quantities in almost every country, and consumed almost universally throughout the civilised world, wheat is subject to innumerable factors operating on supply and demand. No other commodity of the same class is produced over such a 
wide field, nor consumed so universally for such varying purposes as this cereal. On this account a study of the determination of the price of wheat is interesting to the economist, for the reason that it offers many illustrations of conclusions arrived at in abstract expositions of market and normal price. In the first place the influence of supply and demand as determining factors in market value is clearly illustrated. Then again, the study affords a typical example of the operation of the forces which affect the transition from market price to normal price. Further, a good illustration of price steadiness resulting from a wide range of production will be found in such a discussion. Finally, an excellent opportunity is given for a study of the operation of speculation; for on the market for wheat modern speculation is found in its most highly developed phase.

\section{The Wheat Market.}

Before commencing the main topic of our exposition, it is necessary to give a provisional account of markets, and discuss briefly the nature of the market for wheat. The question of the forces tending to bring about equilibrium between demand and supply is fundamentally concerned with the general question of markets.

If we suppose a community where each family or group is self-sufficing, little or no exchange takes place between the families, and there is no market. Such a state of affairs has probably never existed, for however primitive a community might be, some bartering is highly probable. As the division of labour begins to develop, as it did in the English manor in early medieval times, the volume of bartering increases. Progress in the economic world is ever in the nature of specialisation both by product and by process. Every step in specialisation by product increases the necessity of markets, while specialisation by process increases the need for the 
marketing of commodities previously not bought and sold. Now, if farmers consumed all their wheat on the farm, a market for wheat would not exist. When, however, division of labour springs up within the social unit, and the farmer confines himself to raising the food supplies from the soil, the smith to making the tools used in production, etc., a primitive stage in marketing is reached. But when wheat growing becomes confined to certain districts, that is, when in the social economy specialisation by product commences; and further, when the producer is distinct from the miller, the middleman, etc., that is, when specialisation by process arises, then a market is a necessity:

What, then, is the exact economic significance of the word "market"? Cournot says, "Economists understand by the term market not any particular market place in which things are bought and sold, but the whole of any region in which buyers and sellers are in such free intercourse with one another that the prices of the same goods tend to equality easily and quickly." "* The economic interpretation of the word "market" is that it refers not to any particular place, but to a commodity, or commodities and buyers and sellers of the same, who are in direct competition with one another. The primary elements of a market are:-A commodity, its owner and one or more persons who desire to become the owner of that commodity by exchanging for it a quantity of some other goods. It is important to notice that the buyers and sellers must be in direct competition with each other for the commodity. Around one commodity more than one market may exist. Thus we have the retail and wholesale markets for tea, or a great number of markets for cotton, commencing with that for the raw material and ending with the retail market for finished goods.

*Quoted Marshall's "Principles,' 6th Edition. Page 324. 
In the evolution of markets there are four important stages, and each of them may be observed in the development of wheat markets. The first step is the localising of markets where buyers and sellers may meet conveniently for the purpose of bargaining. Wheat was probably the first commodity to have localised markets, and now all important countries have their own. The next two steps in the evolution of marketing are the growth of the system of dealing in samples, and the transition from this to dealing in grades. Selling by sample has long since been in operation in wheat markets throughout the world, but the transition to selling by grade is far from complete, although in the United States and Canada this system has reached a high stage of perfection. The last step in the evolution of marketing is the differentiation of markets. One commodity only is sold in one market; thus we have the cattle market, the produce market, the cotton market, the textile market. The separate market for wheat has long since been evolved, and now on the great grain exchanges all classes and grades of wheat are bought and sold in a manner similar to operations on the stock exchange.

Before concluding our remarks on this subject it will be expedient to consider briefly how markets may be classified, and thus determine the nature of the wheat market. From the point of view of the extent of a market there are three classes. At the one extreme are world markets, in which competition acts directly from all parts of the globe; at the other those secluded markets in which all direct competition from afar is shut out, though indirect and transmitted competition may make itself felt even in these. About mid-way between these extremes lie the great majority of the markets with which the economist is concerned.

Next to the market for stock exchange securities the wheat market is the one that in its main features 
probably approximates most closely to the nature of a world market.

Then, again, markets vary with regard to the period of time which is allowed to the forces of demand and supply to bring themselves into equilibrium with each other as well as with regard to the area over which they extend. This element of time is really of more importance than that of space; for the nature of the equilibrium itself, and that of the causes by which it is determined, depend on the length of the period over which the market is taken to extend. Three groups are distinguishable here also, according to the length of this period. If the period is short the supply is limited to the stores which happen to be at hand, as in the case of perishable goods. If the period is longer, then supply will be influenced, more or less, by the cost of producing the commodity, as in the case of raw produce where machinery is not complex, for example, wheat in India. Lastly, if the period is very long the cost of production itself will be influenced by the cost of producing the labour and material required for producing the commodity, as in the case of goods where much machinery is used, for example, the precious metals.

These three classes merge into one another by imperceptible degrees, and we may class wheat as on the border between the second and third classes.

Having now fully determined the nature of the wheat market we are ready to study the factors which operate through this market to determine the price of wheat.

\section{Supply and Demand.}

The market price of wheat is the result of the tendency of supply and demand to reach a point of equilibrium. But modern factors operating to produce this equilibrium are so many and complex that the great underlying principle of the equilibrium of supply and 
demand as determining market price is often obscured. Isolated forces are regarded by the casual observer as being the sole determinants of price for short periods, whereas actually these forces are only a part of the system under which is worked out the tendency of demand and supply to come to equilibrium. Any factor operating to obstruct the natural course of this tendency has a corresponding effect on prices. On this account prices in a great market like the London market vary from day to day. Thus, if news is received that the monsoon in India is overdue; that the drought in Kansas has been broken; that the navigation on the Danube is unusually early; that an Australian drought is threatening the wheat crop there; that the Manitoban supply has been seriously impaired by a pest, or that bad roads in the Red River Valley are preventing delivery, prices rise or fall to a degree that corresponds to the importance attached to the news. But once the extent of this new factor is realised normal conditions once more operate to bring about a new equilibrium between demand and supply, thus determining market price. Any attempt to study the factors determining price must therefore commence with an analysis of the forces operating on demand and supply.

(a) Factors on the Supply Side.-By the supply of wheat is meant the amount of wheat which will be offered for sale at a given time. Factors operating on the supply side are many and various. Of these the most important are :-

(1) Changes in climatic conditions, including the abundance of rainfall, which exert a great influence on the yield of wheat.

(2) The opening up of new producing areas such as the recent extension of acreage in Australia.

(3) The decrease in acreage owing to the growth of more profitable crops in certain regions, e.g., fruit in California, or pastoral farming in New Zealand. 
(4) The degree of competition which may affect the supply at a given time or place.

(5) The establishment or abolition of trade restraints by commercial treaties. For example, consider the probable effect on Canada's wheat acreage if the United States tariff on wheat should be abolished.

(6) The facilities for or hindrances to transportation. This factor was well illustrated at the close of 1914 when the Russian supply was held up owing to the closing of the Dardanelles to trade.

(7) The variations in acreage resulting from variations in price.

(8) Improvements in methods of culture; e.g., a better rotation of crops.

(9) The degree of the fertility of the soil.

(10) New systems of agriculture extending the wheat regions; e.g., "dry-farming."

(b) Factors Operating on the Demand Side. - The demand for wheat at a given time is indicated by the amount of wheat which will be bought in a market. Causes effecting a variation in demand are:-

(1) A change of taste in rye-eating and rice-eating countries due to a rise in the standard of living.

(2) A diversion from the consumption of wheat to that of more flesh meat, owing to a rise in the standard of living in wheat-eating countries.

(3) A decrease in consumption caused by a decrease in population and other disturbances due to a war.

(4) The increase of population in such countries as Russia, where the taste for wheat bread has been acquired.

(c) The Equilibrium of Demand and Supply.-Under these two sets of influences prices fluctuate from day to 
day in any of the great world markets. Temporary disturbances are due for the most part to factors operating from the supply side, for the element of risk in the production of wheat is great, due chiefly to the large part which climatic conditions play in the yield and in a less degree to transportation difficulties. But the fact that the world supply of wheat comes from all quarters of the globe tends to prevent acute scarcity of the general supply, a temporary diminution in production in one area being counteracted by abundance from some other. Nevertheless, it must be observed that each of these factors will have a temporary effect on price.

On the demand side factors do not exert such an immediate influence. The condition that wheat is the staple food in the nations of the highest civilisation and of the greatest economic strength tends to keep the demand for wheat firm. In other words, the demand for wheat is characterised by its inelasticity.

This treatment so far offers an apparent contradiction to the principle, elaborated in most treatises on economies, that demand plays a predominating part in the determination of market price, while in normal price it is chiefly factors on the supply side which exert a decisive influence.* On the whole the contradiction is only apparent. The activity of buyers varies from day to day, and it is this activity which settles price from day to day. How then, as was stated above, can temporary fluctuations be due for the most part to factors operating from the supply side?

The demand for the products of wheat is so constant that buyers would make their purchases with a high degree of regularity were it not for temporary disturbances in supply. The activity of buyers on any one day is stimulated by news of the failure of certain

"Marshall's "Principles of Economics." Pages 372-8. 
crops or the breakdown of transportation facilities. The influence emanates from the supply side but operates through the demand side.

\section{Reaction of Price. Normal Price.}

The transition from the market price to the normal price of wheat is essentially the result of forces operating on the supply. In the determination of normal price supply is the predominating factor. The essence of the idea of normal price is that it is an approximation to the cost of production. If wheat prices fall so low that its production becomes unprofitable, there will be a tendency to withdraw eapital from the production of this cereal. The same capital and labour which before were engaged in producing wheat will ultimately be devoted to the production of other crops which yield a larger return. In the event of a rise in the price of wheat, capital and labour are attracted to the industry, and further supplies are put on the market until demand and supply reach a new equilibrium, at which the price is a fair remuneration for cost of production.

To go back again to market price we found that market values were governed by the relation of demand to stocks actually in the market, with more or less reference to future supplies, and not without some influence of trade combinations. Any increase in demand causes a temporary increase in price, the degree of the intensity of the demand and the probability of meeting the demand with existing appliances, settling the magnitude of the rise. In short periods the stock of appliances for production is practically fixed. Then, if demand changes, the supply of specialised skill and ability, of suitable machinery and other material capital, and of the appropriate industrial organisation has not time to be fully adapted to demand. The producers have to 
adjust their supply to the demand as best they can with the applianees already at their disposal.

In long periods, on the other hand, the flow of appliances for production is adjusted to the demand for the products of those appliances. All investments of capital and effort in providing the material plant and the organisation of a business, and in acquiring trade knowledge and specialized ability, have time to be adjusted to the conditions of demand. The length of this transitional period depends on the mobility of capital and labour, and the time required for the attainment of the necessary trade knowledge and skill in organisation. Those producers who were on the margin of profitable production will now, if market price rises, commence to produce. Their influence in bringing supplies on the market quickly may accelerate considerably the rate at which the transition is effected. The result of this adjustment is a new equilibrium between demand and supply at which a price approximating to cost of production will be determined. Of course the price will not be below the expenses of producing on the margin of production. If price were to fall to such a level then ultimately supply would be contracted until the production at the margin was profitable.

In the long period, then, the price tends to be equal to the marginal cost of production, that is, the cost of production per unit of output of the marginal firm, or also the marginal cost of production of each normal firm. The price thus arrived at is the normal or long period price, and the degree to which this price approximates to cost of production will depend upon the prevalence of "economic friction." If capital and labour are free to move from one industry to another, if every man is sufficiently well-informed as to the course of action most beneficial to him, if competition is free, then, ceteris paribus, normal price and 
cost of production (including rewards for managing capabilities) will approximate closely. The less the degree to which this freedom is realised, that is, the greater the economic friction, then the greater will be the diversity between cast of production and normal price.

Cost of production in the long run is the determinant of value, and over long periods the price of wheat cannot diverge widely from the expenses of producing it. Just as the minimum limit to price is the cast of production, so the maximum limit is fixed by the utility to the consumer. The tendency of economic forces, however, we have seen is to fix a price which is a close approximation to cost of production, including fair profits to the producers.

Under normal conditions, such are the factors which enter into the determination of the price of wheat. Certain other influences operating of recent years are of specific importance, and require passing reference.

\section{Speculation.}

The market for wheat affords, perhaps, the best example of the latest developments in the mechanism of speculation. The speculator undertakes an important function in the marketing of wheat, and in examining the factors under which wheat prices are fixed it is necessary to give an account of his work, and to estimate his influence on the market. This is the more imperative, in view of the fact that this matter is the object of much ill-informed criticism. But the complex nature of the problems connected with modern speculation necessitates careful treatment. At the outset we are confronted with a great divergence of views on the ethical side of the subject. Hostile criticism on this point arises from two rather conflicting points of view. In the first place, it is alleged that speculation is mere gambling, and has 
no reference to actual trade. Secondly, speculation is said to be so prevalent in exchange that it is now allpowerful in trade, "which has become demoralised by its subjection to fictitious trade conditions." The difference between speculation and gambling is not clearly defined, but it arises from the fact that the latter is artificial, and creates no new value (in fact, it destroys utility) while the former assumes real risks, and often does create value. The subsequent exposition will be an attempt to illustrate this function of speculation, and to estimate its importance in the wheat market.

(a) The Rise of the Speculative Market.-The initial feature in the economic organisation of modern society is the market. The exchange of commodities regulates their production and distribution. This is done through the medium of value. The producer pays attention to those goods, which, in his opinion, command a higher price, just as the merchant sells at the time and place of highest price. Now this adjustment of production and distribution is accurate only in proportion to the degree of success producer and consumer attain in ascertaining these values. Thus the test of the perfection of the organisation of trade is the promptness with which changes in value are learned, and the accuracy with which they are predicted. Where each individual produced for himself alone, no such element of risk entered into the producer's consideration. Later on, when the individual had a marketable surplus he, at first, combined the function of producer and trader. The next stage in the social economy marks the gradual evolution of the trader who assumed part of the risk. But with developments in transport and communication the market for all the great staples became a world market. Thus local fluctuations were lessened, for local scarcity or abundance might be offset by opposite conditions elsewhere. These distant fluctuations, however, began to influence price 
in a market which was world-wide, and consequently the risks which the trader assumed were no longer of local origin, but were caused by changes in world-wide conditions. The trader could not now undertake these risks under the new conditions. Just as the producer had handed over to him the assumption of trading risks, so the trader now delegates to a new class the assumption of these increasing risks. This class is composed of the speculators as distinct from producers and exchangers. Thus the development of world-wide markets gave rise to modern organised speculation, which is found only in commodities marketed under such conditions. Moreover, the machinery of speculation is limited to commodities of an uncertain production which are widely demanded and gradable. Absence of serious hindrances to free competition is a further requisite. Thus monopoly control of an article would prevent the operation of speculation in the market. Brief consideration will show that all these conditions are found in the market for wheat which is eminently favourable to the operation of speculation. Indeed, it is one of the markets where the machinery of speculation is most highly developed.

The practice of dealings in "futures" is the most important feature of modern organised speculation. In the market for wheat are found all the conditions necessary for the development of "future dealings." These conditions are:-

(1) The goods are sold by standard grades.

(2) Delivery of the goods is at stated and regularly recurring intervals.

(3) The speculative dealers are interested merely in the "differences." They do not generally buy the commodities for use themselves.

(4) There are clearing-houses in each market, and periodical settlements, and an association com. prised of operators on the market.

(5) The market is utilised for hedging transactions. 
(b) Speculative Transactions.-Technical terms used in the above will be explained as we proceed. These are the conditions necessary for the operation of future dealing, and a "future" may be defined as "a contract for the future delivery of some commodity, without reference to specific lots, made under the rules of some commercial body, by which the conditions as to the unit of amount, the quality, and the time of delivery are stereotyped, and only the determination of the total amount and the price is left open to the contracting parties." Another important class of transactions are "cash" or "spot" contracts which are merely the outright sale and purchase of goods for immediate delivery. These dealings may be purely speculative, as when a person makes cash purchases to settle future contracts previously made. Although they do not necessarily imply a cash payment, they do represent actual goods available in the market at the moment. A third important class of contracts are "privileges." By a "privilege" a person acquires the right to buy from or sell to another person a certain amount of a commodity at a price agreed on. But there is no obligation, and the person has the privilege or option of completing the contract. Privileges are either "puts" or "calls." The former is a contract made with a view to a fall in price, and the latter the reverse. In the case of the "put" by paying a fixed sum, a person acquires the right to deliver to a second person, the receiver of the fixed sum, or "put money," a certain quantity of a commodity at a price agreed upon on a certain date. If the price has fallen by that time the seller will then purchase the goods and make the delivery according to contract. If. however, price has risen he will relinquish the "put"

*Emery, "Speculation." Page 46. 
money and exercise his privilege of not delivering. The "call" is the exact reverse. By it a person acquires the right to receive from another individual a certain amount of a commodity at a stipulated price. If the price has fallen the buyer will not exercise his privilege of demanding delivery, but will lose his "call" money. But in the event of a rise in price he will demand the goods and profit by selling them again at the higher price. By means of "future dealings," "spot" transactions, and "privilege" contracts, speculation relieves trade of the risks of fluctuating values by the organisation of a special class who stand ready to take or deliver commodities at market price. In so doing, this class performs a service to society by directing commodities to their most advantageous uses. This directive influence is exerted through prices, and it is necessary to examine the influence of speculation on prices before dealing with the assumption of risk by the speculating class.

(c) Beneficial Effects of Speculation.-The idea that speculation determines prices "regardless of the law of supply and demand" is erroneous, and based upon a misconception of the nature of value. "The more free the competition between buyers and sellers, the more minutely is price regulated by demand and supply, and nowhere is competition more free than on the exchange." It is through demand and supply, which are themselves speculative, that the forces of speculation operate. By carefully watching conditions controlling demand and supply, operators in the exchanges are in a position to make fairly accurate estimates of future prices. The speculator makes his offers to buy and sell entirely on his estimate of future values. In these circumstances it is essential that the closest scrutiny of all the factors that may influence future

*Emery, "Speculation." Page 113. 
prices is necessary. The most successful speculator is he who gets first-hand information, and his success depends entirely on the accuracy of his estimates. Thus it follows that where organised speculation is found the most perfected facilities for securing early and reliable information will exist.

Investigations on the influence of the operation of dealings in "futures" on the level of prices, all tend to show that the prices of commodities which are subject to such dealings are lowered both by the reduction of risks and the diminished cost of handling the commodity. While increasing the frequency of price fluctuations, dealings in "futures" decrease the range of these fluctuations. A Committee of the British Association for the Advancement of Science submitting their report in 1900 found these results after an investigation into the effects of "futures" on wheat and cotton. These conclusions, moreover, are in agreement with the work of Emery, who has made investigations in the United States." "Speculation," says Dondlinger, $\dagger$ " is the flywheel which imparts to the modern commercial machine a motion so uniform that all of its parts operate continuously and simultaneously." In various ways the effects of speculation are beneficial to the community. Thus speculation has the effect of directing production and consumption into the most advantageous channels. Speculators are the men best equipped for securing and interpreting news of variations in supply and demand; and thus a price is determined which, with slight local variations, prevails throughout the world. Again, speculation anticipates price-determining events, and tends to equalise prices at different periods. Through the speculative market flows a continuously moving stream of business which will carry the risks of merchant,

*See "Speculation." Chapter IV., Section II.

t"The Book of Wheat." Page 246. 
producer, and consumer alike. Speculation alone makes hedging transactions possible. Fluctuations in prices are lessened, the short seller being the most potent influence in preventing wide fluctuations in price, for he "keeps prices down by short sales, and then keeps them strong by his covering purchases."

(d) The Assumption of Risks by the Speculative Class.- "The manner in which trade risks are shifted to the speculative class is two-fold. First, through the existence of a continuous market, and secondly, through hedging sales. The former is due to a general change in trade conditions, the latter is a special device for insurance against loss." "*

The never ceasing opportunities for trade arising from market fluctuations, give rise to the continuous market, the existence of which is responsible for all the machinery of modern speculation, the bulls and the bears, the buyers and sellers, making new contracts with every indication of changed conditions of demand and supply. The bulls stand ready to purchase wheat at the current price and assume the risk of a fall, in the hope that a gain may be made by a rise in price, and for this purpose, they "bull" the market by purchasing. The bears, on the other hand, stand ready to sell wheat at the current price for present delivery, or at a fixed price for delivery at a given future date. The essence of "'bear" speculation is that the risk of a rise in price is assumed in the hope that a gain may be made from a fall in price.

Now the operations of these speculators are continuous, and into the market may enter at any time the merchant, producer, or manufacturer, to make such contracts as are necessary in his business. Here there is a fixed price for the delivery of goods of various qualities at various times. It may be said that this buying of wheat for

"Emery, in "The Economic Journal," 1899. Page 46. 
future delivery would be possible without the speculative market. This could happen to some extent, but without the speculative market there would be no continuous market in which a definite price for future deliveries is always quoted.

But the use of the continuous market is not, however, the only safeguard which the trader or merchant has against risk. By extending the system he has devised a second method, which consists of almost complete insurance against loss by "hedging" transactions. The practice consists in carrying two lines of compensating transactions, on the part of the merchant or manufacturer, one in the speculative market and one outside. These contracts are always of opposite nature, and thus act as a "hedge" against all price fluctuations. Thus for example, the dealer who buys wheat in the interior may sell immediately an equivalent amount for future delivery on some exchange, not meaning to deliver the wheat he has just sold. When "he does sell his actual holdings he may fulfl his exchange contract by covering in open market. The object of the exchange contract is, of course, to avoid risk. If the price falls, the dealer's wheat is worth less to him, but this loss will be made good by the profit on his exchange transactions where he sold short on a falling market. In the same way he sacrifices all chances of great profit."'*

This method of insurance by "hedging" is common in the United States of America, among most large millers, dealers, and elevator companies. So common has the practice become that one who does not "hedge" is looked upon as most reckless, and, paradoxical as it may seem, the man who strictly avoids the speculative market is the greatest speculator of all.

*See also "Report of the British Association," 1900. "Report of Committee on Future Dealings on Raw Produce Exchanges." Page 426. 
(e) Alleged Evils.-The speculation of modern times, it is alleged-mostly by laymen who do not understand the system-on the whole works havoc in the economic world. Its evils are more easily recognised than its benefits. From an imperfect understanding of speculation, it is easy to ascribe many evils to it with which it has no connection. ' The modern system of 'futures' has proved itself a convenient scapegoat for all the evils of the grain trade. It is charged with being the cause of low prices and of high prices, with increasing trade risks, and with diminishing them until there is no chance for profit. A few years ago the farming class clamoured for the suppression of the speculative market, while recently the Kansas farmer started a movement to contribute a cent a bushel on all their wheat to a fund for the benefit of the most daring speculator of the Chicago market."' But recently the operations of the speculator have come to be more understood, with the result that he is no longer regarded as a mere gambler, but a person with recognised and beneficial economic functions.

The really fundamental objection to speculation lies in the fact that an individual, or a group of individuals, may secure control of the market and manipulate it as they please. Manipulation may occur from either the bear or the bull side, but "bearish" manipulations, on account of their attendant difficulties, are rare. A successful "bear" manipulation consists in selling a commodity short in sufficient quantities to reduce the price, and then to cover these contracts at the low price. A sufficient body of short sales will depress price, but the price will rise again immediately the "bears" commence buying. The danger is so great that such a manipulation is seldom attempted. The biggest operations on the short of the market were those of

"Emery, "Economic Journal," 1899. Page 45. 
Pardridge, in 1891-2, at Chicago. It so happened that, contrary to the expectations of leading statistical authorities, the supply of wheat was in abundance, and Pardridge, who persistently sold wheat at a time when a scarcity was anticipated, was able to buy back at very much lowered prices. But the success of the manipulation was due rather to the operation of natural conditions of demand and supply than to the speculator's influence. The fall in price would have occurred without the influence of the manipulation.

Manipulations are more often successful on a small scale, but for every successful attempt, and such are noticeable, there are numerous unsuccessful ones which pass unobserved. Manipulations of the market are less common in the produce market than in the stock market; they are confined within very narrow limits; they continue but a short time; the volume of transactions is small; and they have little effect on the general course of prices.

On the "bull" side of the market such attempts at control of the market are more prevalent than on the "bear" side. "Bull" manipulations may culminate in "corners." A successful "corner" in wheat exists when the market is over-sold, that is, when the "bulls" have secured control of a considerable part of the local supplies, and have induced so much short selling that there are not sufficient supplies in the market to cover the volume of short contracts within the required time. The most noteworthy operations on this side of the market are those of a clique of "bulls" in 1897-8, headed by Joseph Leiter, a young man with unlimited selfconfidence, with an unusual capacity for appreciating and comprehending extensive business situations, with amazing audacity, and lastly, and of great importance, an unlimited supply of capital. At first the operations were successful, but Leiter's boundless ambition and 
unparalleled confidence led him to continue operating in adverse conditions, when the supply, which during the first ten months had been below the requirements, reached the usual consumption once more, and prices began to fall. The high prices during the earlier period of Leiter's operations were not mainly the work of Leiter. The fundamental cause was a shortage in supply, and as long as this continued the operations were successful. The real influence of the manipulation was found in the disorganisation of the wheat market for some ten months with great fluctuations in price, notably in December and May.

Generally speaking, successful "corners" in wheat are impossible, owing to the magnitude of the purchases which must be made, the impossibility of concealing for long the existence of that syndicate, and finally, because as price goes up enormous supplies are rushed into the market. Thus, if a "corner" is discovered, and it is found that sufficient wheat is not forthcoming for the settlement of short sales on, say, the Chicago Exchange, big millers at Duluth or Minneapolis dump their large supplies on to the market. They realise high prices, and relieve the situation. They are then able to buy back considerable quantities of their own wheat, which they had sold previously, probably by telegraph. The wheat never leaves their elevators, they are able to make a profit, and in almost all cases break up the attempted "corner."

( $f$ ) Conclusion. - Our conclusion, after a somewhat cursory examination of a highly controversial subject, rests in favour of speculation. The net result is a balance of good from dealings in "futures." Though there are certain temporary evils and pernicious practices in connection with such speculation, the most recent tendencies of great price steadiness, of the growing perfection of the speculative machinery, and 
of the knowledge of the conditions of supply and demand, are operating to eliminate these admitted evils. The very magnitude of the transactions and the methods employed necessitate the most scrupulous honesty on the part of operators, not that these speculators are a class notorious for their probity. The speculator himself is a man of unusual qualities, for his real economic function is practically the manager and director of the world's wheat movement. If, indeed, he be not a man eminently clear-headed and practical, with a vision as keen and penetrating as that of the prophets of old, he cannot continue long in his position of importance; for the stupendous undertakings which he often assumes are possible only with a boldness and a brilliancy of imagination possessed by few.

Such a discussion may appear a digression from the real question at issue. We commenced with the intention of investigating the factors which determine the price of wheat. These were mainly two sets, those operating from the demand side and those from the supply side. But it is not enough to consider the nature of these factors. The method of their operation must be considered. The study of the way in which these sets of factors are brought together is of no less importance than the discussion of the factors themselves. Now, it is just here where the importance of speculation attracts attention, and it is obvious that, without a consideration of this subject, our discussion on the determination of the price of wheat would be quite incomplete. We are therefore justified in going into the study of the matter in detail. Moreover, the study is perhaps one of the most fascinating in modern economics, as well as one around which much controversy has raged, and is still carried on. 


\section{Influence of the Area of Production on the Stability of Price.}

It is easy to reason a priori, to the conclusion that, ceteris paribus, increased stability of price will result from production over a wide and varied field. This conclusion follows from the fact that the total supply will be more regular and more evenly distributed over the year, when production is large and carried on over a wide field, than when the industry is of small dimensions. Wheat is one of the leading commodities of that group which is produced over an extensive area. Not only is the field of production wide, but wheat is also characterised by the variety of conditions under which it is produced. A temporary suspension of supply from one point in the wide field is, in most cases, counteracted by an abundance from another point. If the Australian supply is diminished by a drought, many circumstances are passible which may counteract any disturbing influence likely to arise from this occurrence. Thus the supply from Canada or the United States may be larger than usual at the previous harvest, or the yield in the Argentine may be sufficient to fill the gap in the supply. Since it is produced in the two hemispheres, and very widely in these, wheat experiences all the variations in climatic conditions which may occur over the whole world. It is highly improbable that a drought would prevail throughout the extent of either hemisphere in any one year, much less in both. Moreover, the growing seasons and harvesting periods vary greatly in different places, so that widely diffused adverse weather conditions would not be universally detrimental. In fact, it is more likely that what in one district is adverse weather, is in another, distinctly favourable. Thus, suppose that country A has continuously damp weather at harvesting, then country B may be fortunate in experiencing such 
weather simultaneously, for the wheat crop may not yet have reached maturity there. These considerations are strongly in favour of adopting the à priori conclusion that factors operating from the supply side tend to promote price steadiness.

The inelasticity* of demand for food-stuffs applies to the demand for wheat. Variations in price are not followed by variations in consumption of corresponding magnitude. It is true that in rye-consuming countries, such as Germany, where the taste for rye-bread is sufficiently strong to combat the forces tending to promote the universal consumption of wheat-bread, a rise in the price of wheat will be followed by the substitution of rye-bread for wheat-bread wherever it is possible. It is also true that in countries which consume wheat-bread only, economy in the use of bread (much of which is now wasted in New Zealand) will be practised should price rise. That such was the case in New Zealand after the rise in the price of wheat at the close of 1914, was indicated by communications to the Press at the beginning of the year, and the general complaints of bakers of a fall in consumption. But, despite the action of these two forces, the demand for wheat is fairly inelastic, and the general tendency of factors operating from the demand side is to promote price steadiness.

That supplies are fortheoming with some degree of regularity over long periods, is shown by a table giving the European Weekly Distribution or Deliveries to Consumption of Imported Wheat. The table is taken from The Corn Trade News, of June 9th, 1914, and shows the rate of weekly consumption (or distribution from merchants' hands) of imported wheat over the several months from August 1907 to May 1914.

*By inelasticity of demand is meant the quality a commodity possesses of retaining a fairly constant demand in all price changes. 
TABLE XXII.

EUROPEAN WEEKLY DISTRIBUTION OR DELIVERIES TO CONSUMPTION OF IMPORTED WHEAT.

(In thousands of quarters.)

\begin{tabular}{|c|c|c|c|c|c|c|c|c|c|}
\hline \multicolumn{3}{|c|}{ Weekly During } & $\begin{array}{c}1907 \\
\text { to } \\
1908\end{array}$ & $\begin{array}{c}1908 \\
\text { to } \\
1909\end{array}$ & $\begin{array}{c}1909 \\
\text { to } \\
1910\end{array}$ & $\begin{array}{c}1910 \\
\text { to } \\
1911\end{array}$ & $\begin{array}{c}1911 \\
\text { to } \\
1912\end{array}$ & $\begin{array}{c}1912 \\
\text { to } \\
1913\end{array}$ & $\begin{array}{c}1913 \\
\text { to } \\
1914\end{array}$ \\
\hline August & & & 938 & 1,068 & 998 & 1,183 & 1,095 & 1,420 & 1,249 \\
\hline September & & & 1,240 & 1,160 & 1,320 & 1,534 & 1,058 & 1,425 & 1,488 \\
\hline October & & ... & 1,273 & 1,128 & 1,514 & 1,519 & 1,275 & 1,430 & 1,510 \\
\hline November & .. & ... & 1,070 & 1,127 & 1,520 & 1,430 & 1,013 & 1,500 & 1,478 \\
\hline December & .. & $\bullet$ & 823 & 948 & 1,208 & 1,473 & 1,044 & 1,814 & 1,437 \\
\hline January & & & 870 & 736 & 908 & 1,244 & 905 & 1,125 & 1,180 \\
\hline February & & & 754 & 742 & 820 & 994 & 818 & 1,136 & 1,165 \\
\hline March & .. & ... & 1,044 & 1,041 & 1,027 & 1,124 & 813 & 1,277 & 1,093 \\
\hline April & & & 1,014 & 1,200 & 1,200 & 1,647 & 1,146 & 1,523 & 1,371 \\
\hline May & & & 1,229 & 1,100 & 1,160 & 1,677 & 1,074 & 1,594 & 1,530 \\
\hline June & .. & & 1,152 & 1,231 & 1,294 & 1,583 & 1,930 & 1,720 & \\
\hline July & ... & ... & 793 & 1,087 & 956 & 1,434 & 1,330 & 1,354 & \\
\hline $\begin{array}{r}\text { Average } f \\
\text { Weel }\end{array}$ & r 52 & & 1,000 & 1,034 & 1,162 & 1,400 & 1,122 & 1,400 & \\
\hline
\end{tabular}

Note.-During the period from August, 1913, calendar months were taken, and careful allowance was made for the varying duration in calendar months, whereas, formerly, periods of four or five weeks were taken.

But while it is necessary to note the change in the method of compilation, the result is not appreciably affected, and the statistics are comparable.

\section{Price of English Wheat.*}

In normal times the price of English wheat, as explained above, should not show violent fluctuations. From the commencement of the Napoleonic Wars until the middle of last century, price fluctuated over very wide ranges throughout, with few exceptions. In 1790, the monthly average Gazette price was 6s. 6d. per bushel, and during the next twenty-five years violent variations in price were registered. Rising from 9s. 10d. in 1796, to $14 \mathrm{~s} .11 \mathrm{~d}$. in 1801, after a temporary fall in 1798, price reached the fabulous figure of $15 \mathrm{~s} .10 \mathrm{~d}$. in 1812 . Fluctuations continued almost without cessation on a violent scale until after the middle of the century; but the

*For index numbers of the prices of English and New Zealand wheat see Table XXXVIII. Appendix I. 
general trend from 1800 showed a rapidly falling tendency until the "thirties," after which the average annual price was fairly stable.

For the purposes of instituting a comparison between English and New Zealand prices, a more intensive study of price movements from 1860 will be made.

At the close of the decade ending 1859, conditions had once more become normal after the disturbance caused by the Crimean War. In 1859 the price was $5 \mathrm{~s}$. $6 \mathrm{~d}$. per bushel, and conditions seemed to point to a falling tendency, but several circumstances postponed this tendency for almost 20 years.

(a) The Period 1860-75. Rising Prices.-The decade commencing in 1860 was a stormy one for the World, a number of minor European Wars, the American Civil War (1861-5), and the War between Austria and Prussia occurring in this period. The result of these disturbances was another series of price fluctuations, the average for the decade being $6 \mathrm{~s}$. $6 \mathrm{~d}$., and the trend rising slightly until the middle of the "seventies." During the early "seventies" the wheat market was again disturbed by war. The Franco-Prussian War of 1870-1 caused a rise in price with its subsequent reaction, the price in 1871 having risen to 7s. 1d., and falling after 1873 to 5 s. $7 \mathrm{~d}$. in 1875 .

Over this period from $1860-75$ the price of wheat showed a general rising tendency, maintaining the slight rise which had set in in the early "fifties." This rise was partly the result of the diminution in supplies caused by a series of wars and partly the result of the influence caused on the general level of prices by the increased supplies of gold. From 1849 to 1873 prices rose from 64 to 86 according to Jevons's figures. Prof. Irving Fisher assigns the increase in gold production resulting from Califormian and Australian gold discoveries and the rapid development of banking as the 
Index Numbers Base 1890-99

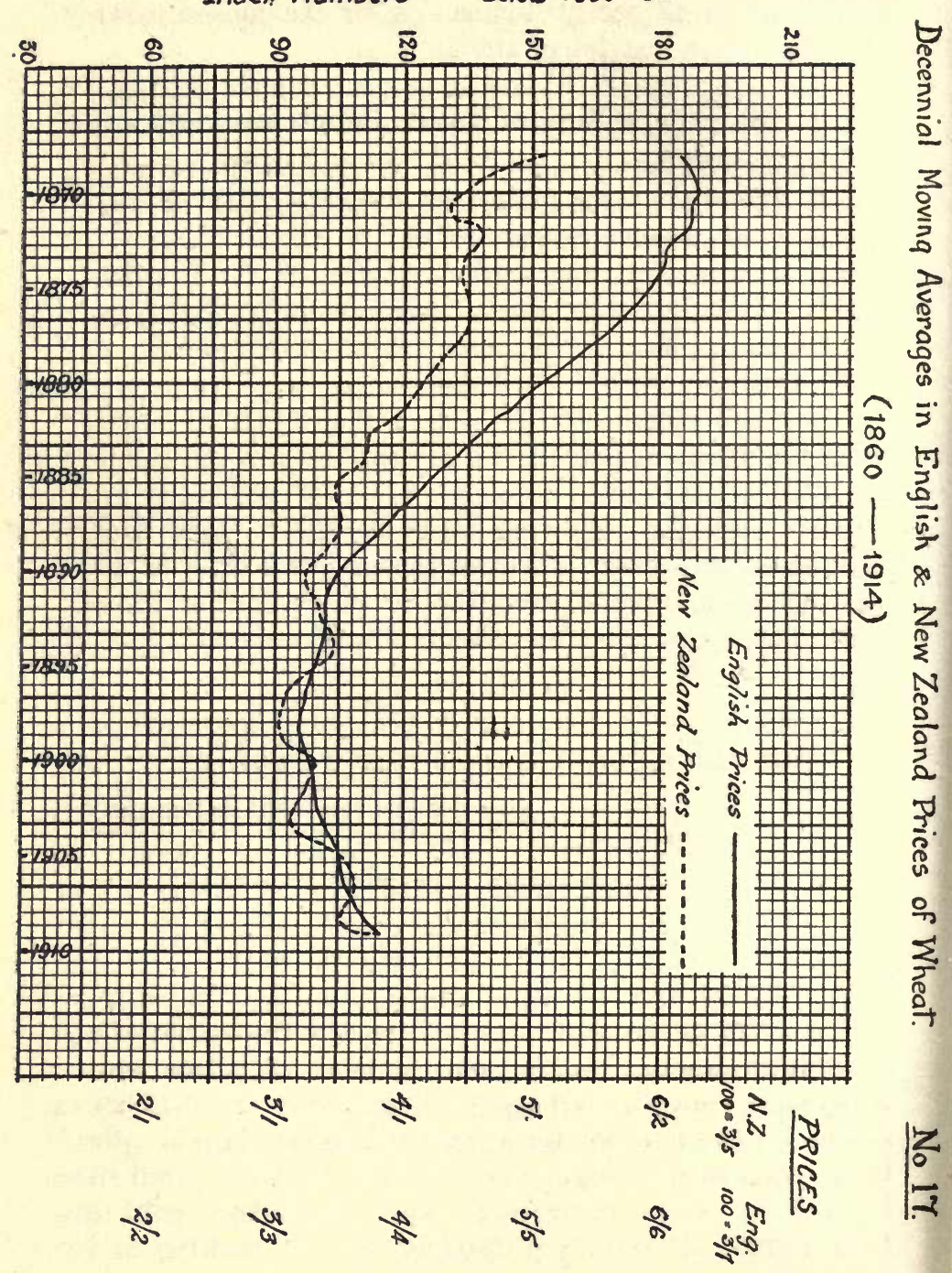


main causes of this rise.* According to Jevons's figures the rise in price was one-third. The rise in the price of wheat, however, was not so great, but the fluctuations were very much greater than fluctuations in general prices. Furthermore, the period of the rise in the case of general prices was earlier by about two years than that in the case of wheat, although the duration of both periods was about the same.

Two reasons, then, may be assigned to the steady rise over these years - the diminution of supplies owing to frequent wars and the increased production of gold.

During the period 1860-1877, the graph of wheat prices has four "crests" and four corresponding "troughs." It is significant to note that these prices follow the outbreak of war in all cases, while the falls are the natural consequences of a return to normal production after the cessation of hostilities. Moreover, the maxima prices occur at strikingly regular intervals of five years, commencing in 1862, and recurring in 1867 , 1872 , and 1877. The probability is that this regularity is merely a coincidence, and due in great part to the occurrence of wars, as rises occur regularly after the four wars :-
American Civil, (1861-5);
Austro-Prussian, (1866);
Franco-Prussian, (1870-1);
Russo-Turkish, (1877-8).

The fall of 1869 was due no doubt in some measure to the opening of the Suez Canal. But the influence would not be great immediately, and this event must be regarded as one factor responsible for the fall in British wheat during the next two decades. As such, it will receive notice in the succeeding section. 
(b) The Period 1876-1895. Falling Prices.-During the following two decades the price of English wheat continued to fall rapidly with only two important exceptions. The quinquennial average for the period 1871-5 was 6s. 10d., and in successive quinquennial periods it showed a considerable falling tendency until, in the period 1891-5, the average was as low as $3 \mathrm{~s} .6 \mathrm{~d}$. Thus during the period prices had fallen by one-half, the average price for the first quinquennial period in the two decades being almost 100 per cent. higher than that for the last.

This falling tendency was constant throughout with the exception of the year 1877, when the index number of wheat rose from 159 to 198 in 1876, and in 1891, when a rise in the index number from 112 to 129 was registered. The Russo-Turkish War of 1877 was no doubt responsible to a large extent for the sudden rise in that year, while a very deficient harvest had been experienced in the United States.

(i) Relation of Wheat Prices to the General Level.The fall in the price of wheat is again synchronous with a movement in the general level of prices. The period 1873-1896 was essentially a period of falling prices. The fall was presumably due to a slackening in the production of gold, and to the increased demand for gold due to its adoption by several nations with currencies previously organised on a silver standard basis. A further reason, and more important for our purposes, is the increase in production generally. The fall in the price of wheat was due to a combination of these causes-the diminution in the rate of gold production, and the general increase in production. According to The Economist (London) Index Number, the general level of prices fell from 134 in 1873 to 91 in 1896, whereas the index number of the price of wheat fell from 205 in 1873 to 92 in 1896 . This points to the fact that the fall in the price of wheat was due more to increased supply than to a relative decrease in the money material. 
But the fact that the price of wheat did not fall in exact proportion to the fall in general prices should only in certain circumstances lead us to this conclusion. In general, relative prices do not remain unchanged with changes in the general level. The abundance or scarcity of the money material is only one factor. When considering individual commodities we must take account of the important conception of the degree of elasticity of demand. If we regard the problem in its simplest form, we see that an individual will distribute his expenditure over the various commodities in such a way as to obtain the maximum satisfaction. Now, suppose the money material decreases and there is a tendency therefore for all prices to fall, will these decreases in relative prices be in proportion to the corresponding decrease in general prices which, ceteris paribus, will result from a diminution in the supply of money? Obviously not. The elasticity of the demand for the individual commodities differs greatly. Those commodities which are necessaries will not fall to such an extent as the fall in general prices, while those for which the elasticity of demand is unity will tend to fall, other things remaining the same, in the same proportion, and those commodities whose elasticity of demand is greater than unity, more than proportionally.

Professor Irving Fisher, pursuing this question in detail," selects four typical commodities and shows how, in each case, the effect on the general level will be different. In the case of highly elastic demand, the probability is that a fall in the price of the commodity will cause a rise in general prices, a proposition which Dr. Fisher regards as the pons asinorum in "the test of one's knowledge of the fundamental distinction between those influences affecting the general price level,

*6"The Purchasing Power of Money.", Fage 382. 
and those affecting the rise and fall of a particular price with respect to that level."'

(ii) Explanation of the Position in the Period.What, then, under normal conditions would be the position with regard to wheat on the occasion of a fall in general prices, such as took place from 1850-73? The demand for wheat is comparatively inelastic, and therefore it would be one of those commodities which would fall in price less than the fall in the general level, and certainly less than the fall in most commodities, for the demand for wheat is less elastic than that for other goods. But the fall in the price of wheat was vastly greater than the fall in general prices, and there must, therefore, have been other influences in operation. Had incomes decreased, then a slight reduction in wheat prices might be expected, à priori. But incomes did not decrease, and furthermore, such a decrease would be manifested in a slackening in demand for commodities other than necessaries, rather than in such commodities as wheat. From the data available, the only sound explanation of this phenomena, apparently contradictory to our $a ̀$ priori reasoning, lies in an increase in supply. Such, indeed, is the true explanation, and the validity of our contention at the outset that increased supply exerted an influence because wheat prices fell more than general prices is established, for normally wheat prices would fall less than the average.

(iii) Expansion in Production. - Stimulated by the high prices of the two decades ending in 1870, agriculture throughout the world had reached a stage of relatively high prosperity. Many new fields of production had attracted the attention of pioneering farmers, and a general movement in favour of developing certain new fields had set in. The United States, India, Argentina, Canada, Australia, New Zealand, all offered profitable fields to the enterprising farmer, and during the "seven- 
ties" production in these countries progressed rapidly. With a relatively small density of population, the amount of wheat required for home consumption was not great, and consequently there was a large surplus for export to European countries and principally to England, where acute agricultural depression beginning in the "seventies" was being experienced in the "eighties" and early "nineties." With ever-increasing supplies brought to the English market from these countries, the most natural result was a fall in price. During the period the chief exporter of wheat to England was the United States, the imports of wheat from this country in 1870 being $12,371,922$ cwt., while in 1880 they had risen to 29,634,820 cwt. The exports from the Argentine were also considerable, and those of Canada increasing, though the period of great development there did not commence until the beginning of the present century. New Zealand and Australian exports had also begun to exert an influence on the English wheat market, New Zealand, indeed, in the "eighties" having reached her maximum.

The great increase in the importation of wheat into England is shown by the fact that, whereas in the decade 1866-75 the average annual importation of wheat per head of the population was 134 lbs., during the decade 1876-85 it was $180 \mathrm{lbs}$., and in the following decade it was. $187 \mathrm{lbs}$. The absolute increase in importation is shown by the following short table:-

TABLE XXIII.

IMPORTS OF WHEAT INTO ENGLAND.

(In Million Cwt..)

$\begin{array}{cc}\begin{array}{c}\text { Quinquennial } \\ \text { Period }\end{array} & \begin{array}{c}\text { Imports } \\ \text { (Average Annual) }\end{array} \\ \mathbf{1 8 5 1 - 1 8 5 5} & 58 \\ 1856-1860 & 56 \\ 1861-1865 & 69 \\ 1866-1870 & 67 \\ 1871-1875 & 87 \\ 1876-1880 & 94\end{array}$


The rise from 1856 to 1865 is explanatory of the fact that wheat prices lagged behind the rising trend of general prices while an increase of nearly 30 millions in a decade when general prices had commenced to fall aggravated the fall in the price of wheat.

(c) The Period from 1896. Rising Prices.-The year 1895 witnessed a great depression in wheat prices. The average price for the year in British markets had reached the amazingly low figure of $2 \mathrm{~s}$. 10d. per bushel. Such a price was scarcely remunerative in many countries, and general depression was felt in agriculture, more so than in most industries, for, as before stated, wheat prices fell to a greater extent than general prices. According to Layton, average prices fell 40 per cent., but the price of wheat fell 51 per cent."

In the middle "nineties," however, the tide turned, and an era of great prosperity dawned. According to The Economist Index Number, general prices rose from 91 in 1896 to an average of 127 for the years 1912-14, and the corresponding figures for the Board of Trade are 88 and 116-a rise of 40 per cent. in the former case, and one of 32 per cent. in the latter case. According to Layton, the average rise of prices was 25 per cent. from 1894-8 to $1906-10$, the rise in the price of wheat being 17 per cent.

(i) Causes of Rise.-During this period the rise in general prices eannot be accounted for by any diminution in general production. On the contrary, under the stimulation of a prosperous outlook, many new avenues of production have been opened up, and existing ones increased on an extensive scale. An increased currency is the fundamental cause of this new rise in general prices. The increased demand for some commodities consequent on a higher standard of living among

* "An Introduction to the History of Prices in the 19th Century." Page 68. 
the lower classes would, $\grave{a}$ priori, in the absence of counteracting causes, bring about a rise in these. But such a rise in the prices of a few commodities would not cause a rise in general prices. It may indeed cause them to fall, as Professor Fisher has shown in his treatment of the problem.

It was rather the increase in the exchange media of all kinds which had the most important influence. Progress in metallurgical science has developed goldmining on an unprecedented scale, and the output of gold has been largely increased. Moreover, new fields have been opened up in North America, South Africa, and Western Australia. This increase in the gold supply has had a direct influence on the amount of credit money in circulation. With the general development of banking in the civilised world, the increase in credit instruments has been enormous-much greater in proportion than the increase in money proper-and it is due to this increase in the circulating media generally that we must look for the most powerful cause of rising prices. But not only have the general exchange media increased. Modern tendencies also promote much greater velocity of circulation. The progress of urbanisation resulting in a greater density of population, the growth of knowledge as to banking, the system of shop credits, the increase in small deposits, all tend to foster a higher velocity of circulation both of money, proper and of credit instruments. To put the whole position in a few words, all the factors on the right hand side of the "equation of exchange" have increased greatly, while the one independent variable on the left hand side has also increased, but not to such an extent. The result is, therefore, that the other factor of the left hand side, the one dependent variable of the equation, has increased, that is, prices have risen.

(ii) Absence of Violent Fluctuations.-The characteristic feature of the price of wheat since 1894 is the 
absence of any violent annual fluctuations. The graph has only two peaks of any importance, but neither is of much consequence compared with the rapid fluctuations during the first seventy years of the century. The first of these fluctuations occurred when the index number rose from 92 in 1896 to 119 in 1898, and then fell in the following year to 90 . A bad harvest in the United States in 1896 no doubt contributed to the rise in English wheat in 1897, while in that year the world's wheat crop had declined to 286 million quarters from 298 in 1896 and 305 in 1895 . Furthermore, the peak in the graph corresponds with the Spanish-American War which accentuated the already existing tendency towards rising prices. The year 1898 witnessed a remarkably good harvest throughout the Northern Hemisphere, bringing up the world's production for that year to 366 million quarters. The consequence was that in the following year price fell greatly, the rapidity of its fall strengthening the presumption that the Spanish-American War had exerted a certain influence in raising prices.

The second fluctuation occurred in 1909, when there was a sharp rise owing to bad harvests in various countries. The world's production of wheat which in 1906 had been 424 million quarters fell in 1907 to 389, and was only 398 in 1908 . Consequently, the years 1908 and 1909 were years of rising prices, the rise being more marked in the latter year. A good harvest in 1908 of 454 million quarters brought prices back again, the index number which had risen from 112 in 1908 to 129 in 1909, falling again to 110.

With the exception of these two fluctuations of 1898 and 1909 , the price of wheat was comparatively stable, though with a steadily rising tendency, until the outbreak of War in 1914. The great rise since the middle of 1914 will be considered later. It remains to indicate 
the causes which have been responsible for the rising tendency since 1894.

(iii) Relation of Wheat Prices to General Prices.As pointed out above, the general level of prices rose greatly in the period, mainly as a result of the increase in the circulating media. Wheat prices have risen some 8 per cent. less than the rise in general prices. Now the demand for wheat is inelastic, and we should therefore expect its price to rise relatively more than the rise in other commodities in a period of rising prices. Moreover, in a period of rising prices the margin of cultivation is being extended, and this should $a$ priori, accentuate the rise in price; for, as inferior lands are brought under cultivation, the marginal cost of production rises. These two factors both tend to accentuate, if anything, the tendency of wheat prices to rise. But we notice that the actual state of affairs was that, relative to the prices of other commodities, wheat prices did not rise to the same level. They fell short of the rise in general prices by some 8 per cent. For the explanation of this, attention must be paid to forces operating from the supply side.

European markets have been deluged with everincreasing supplies of wheat since the early "nineties." In 1890 the world's production of wheat was 2,296,000,000 bushels, while in 1912 it had reached $4,018,000,000$ bushels, an increase of nearly 75 per cent. in 22 years. For the three decades ending 1910 the average annual production was as follows:-

TABLE XXIV.

AVERAGE ANNUAL WORLD'S PRODUCTION OF WHEAT.

Decade

1881-1890

1891-1900

1901-1910

1910-1914
Million

Bushels

2,269

2,577

3,233

3,944 
When such an increase of production is considered, it is not surprising that wheat prices did not rise to the same level as general prices. What is, on the surface, surprising, is that prices rose at all. The phenomenon is interesting from the point of view of monetary theory, and is another link-an insignificant one-in the already long chain of statistical evidence in support of the classical quantity theory of money.

\section{Price of New Zealand Wheat.}

Changes in local prices are not the result of economic causes operating within the Dominion only. Reference must constantly be made to the operation of certain factors, the influence of which pervades the whole economic world. Therefore, reference will have to be made to some ground already covered in the discussion of English prices, but local conditions will be emphasised, as these are of greater relative importance in the explanation of fluctuations, especially in the early history of prices.

In Chapter I. we have already discussed the question of fluctuations within the year, that is, seasonal fluctuations, over a period of sixteen years, and a well-defined seasonal movement was found. This question does not require further elucidation here, and we may pass on to a consideration of annual fluctuations and an attempt to discover certain well-defined periods in these. To these topics we shall confine our attention in discussing the course of wheat prices in New Zealand.

Although great fluctuations occurred throughout the period, and more especially during the "sixties" and "seventies," certain periods of rising and falling prices can be discerned, and these coincide with similar movements in English prices.

(a) 1860-73. Slightly Rising Prices. - During the "sixties" price changes were frequent and of great 
magnitude. The graph showing the decennial averages registers a rising tendency, but the upward movement is so small as to be almost insignificant. During the early "sixties" very high prices prevailed, the index number being 254 in 1864 . In these years gold was being produced at a rapidly increasing rate, and agriculture was stagnant on account of the rush to gold-mining. The exports of wheat, which had in the middle "fifties", reached almost 100,000 bushels, fell to 12,000 bushels in 1860, while in 1863 and 1864 no exports were made at all, there being an importation of 294,000 bushels and 164,000 bushels respectively. After 1867 the gold production gradually declined, but rose rapidly in 1871 , and maintained a high annual average until 1874 . Corresponding to this there was a decrease in price in the late "sixties," with rising prices again in the early years of the following decade. Thus the influence exerted by the gold discoveries was considerable. The reasons for this are two-fold. In the first place increased output of gold means an increase in the circulating media, while, secondly, a gold rush is usually accompanied by economic disturbances. The latter factor operated with very considerable importance because of the efflux of labour from farming to the gold mines and the consequent stagnation in agriculture.

The high prices of the years '1860-6, due to these two causes, were instrumental in rendering the period one of stationary or almost falling prices, but the rise of the early "seventies" was just sufficient to counteract this tendency. The most marked feature of the period was the great fluctuations from year to year. In 1863 the price index number was 163 , and it rose suddenly in the following year to 254, falling again in two years to 150 . The following year witnessed a further fall to 101 , while another great rise to 178 occurred in 1868 , followed once more by a sudden fall to 124 the year 
after. The explanation of the fluctuations is found, as stated above, in the increased output of gold together with the interference of the gold rushes with the local harvests.

(b) 1873-94. Falling Prices.-Synchronous with the movement in general prices in New Zealand and throughout the world during the period 1873-94, the prices of wheat exhibited a steadily falling tendency. While general prices fell from 164 in 1873 to 93 in 1895, a similar movement is noticeable in wheat prices between the years 1872 and 1894, the index number falling from 129 to 81 . Throughout the period violent and frequent fluctuations were recorded; but the general trend is a marked fall, though not so great as the similar movement in general prices which fell by almost one-half, the price of wheat falling by a little more than one-third.

A sudden rise in 1877 gives to the graph an outstanding peak for the period. The index number rose from 126 in 1876 to 176 in the following year, and a similar movement is noticeable in English prices, due probably in part to the Russo-Turkish War. But the rise is greater in New Zealand, and we must look to local conditions for the explanation. During the years 1873-5 the price of wheat had shown a falling tendency, while for the same years wool had remained comparatively stable at the high average price of $14 \mathrm{~d}$. per pound. That farmers should have turned their attention to pastoral industries so far as possible for a time is not surprising, and consequently we find that the area under wheat fell in 1876 to 90,804 acres from 105,673 acres in the previous year. A high yield of 31.5 bushels per acre relieved the situation to a small degree; but price rose slightly, and the shortage experienced before next harvest raised the price in the beginning of 1877 very considerably. English wheat rose then, presumably on account of the War, and, as a high price could be 
obtained for exporting, obviously the tendency to export could be stopped only by offering a high price after the harvest of 1877 . Thus, the price was kept at a high figure until English wheat fell. A further cause of the high price is found in the increased gold production of New Zealand during 1871, Dr. McIlraith's index number of gold production rising from 123 to 144, while his index number of general prices shows a somewhat smaller rise. The increase in gold production was due to the discovery of a rich goldfield on the West Coast of the South Island. As this area lacks both extensive areas of fertile land and those climatic conditions which are necessary for the suecessful development of agricultural industries, the discovery, in addition to causing an efflux of the agricultural labouring population, created an extensive demand for food stuffs from the neighbouring farming provinces, which aggravated the already strong tendency for these to rise in price.

The high price of 1877 was not maintained, for in the two following years a rapid fall brought the index number from 177 to 116 . Encouraged by the high price of 1877 farmers extended their areas, and in both the following years production exceeded 6 million bushels. A further rapid development of agriculture kept price at an abnormally low figure, and the absence of disturbing influences brought about a few years of price stability in the early "eighties."

After 1884, however, the characteristic feature of the graph of New Zealand wheat prices is again in evidence, price falling rapidly and rising again with equal rapidity four times in a decade, the "troughs" in the curve being recorded in 1885, 1888, 1890, and 1893-4. Loeal harvests are in some degree responsible for these fluctuations; for the years 1884, 1888, 1890, and 1892, were years of prolific yields, and it is no mere 
coincidence that prices should have fallen in these years.

The explanation of the general falling tendency is to be found in the decreased production of gold together with the rapid expansion of the Colony, with consequent increased production of staple products. As explained in the previous chapter, progress in wheat growing in New Zealand was never so great as it was in the late "seventies" and early "eighties." With falling prices in the great world markets and over-production at home, the inevitable reaction occurred in the decade 1883-94, prices falling very low. Unfortunately for New Zealand, wheat, at this time, was one of her staple exports, and the great fall in its value brought severe depression upon the colonists.

(c) The Period from 1895-Prices Rising. - In the early "nineties" the tide turned in favour of the cereals, and from that time a marked upward tendency is recorded in price movements. Although the general trend is upwards, the outstanding feature of the curve is again violent fluctuations. Very high prices were recorded in 1897-8, 1903, and 1908, while the period 1899-1901 was one of very low prices, and falls of minor importance occurred in 1904-6 and 1910. The explanation of these fluctuations is again to be found to a large extent in local conditions of yield. Thus the years of $1897-8,1902$, and 1907-8, were years of low yields, and these corresponded with the years in which high prices were recorded. Then again, prolific yields were recorded in $1899-1900,1905$, and $1909-10$, where there is correspondence with low prices. In 1908 prices rose very high, reaching an average for the year of $4 \mathrm{~s}$. $7 \frac{1}{2} \mathrm{~d}$., the highest figure for almost 30 years. This relatively high price can be accounted for in turning to the production not only in New Zealand but also in Australia. For the years 1907-8 production in the Dominion had been 
slightly above $5 \frac{1}{2}$ million bushels, whereas the amount required for home consumption was more than $6 \frac{1}{2}$ million bushels. Obviously, for consumption to follow its normal course importation must of necessity be resorted to. But the import statistics show an average importation of only some 30,000 bushels for the two years. In 1907 Australia had experienced a bad harvest, only about $42,000,000$ bushels being produced, whereas in 1913 production exceeded $100,000,000$ bushels. Therefore, with no supplies to make up for the local deficiency, scarcity had to be contended with, and consequently prices rose, 6s. per bushel being reached in November, 1907.

The rise in the price of wheat has been greater than the rise in the general level of prices in this period. In 1893 general prices as measured by Dr. McIlraith's index number were 93, in 1894 the index number for wheat prices was 73 , but in 1912 both stood at 107, while in 1914 the former had risen further to 122, and the latter to 168 . On the whole, the circumstances responsible for this are to be found in decreased production of wheat and consequent scarcity in supply which, together with the factors operating to cause a rise in prices-increased gold production and more intensified demand-raised wheat prices relatively to most other prices.

\section{English and New Zealand Prices Compared.}

A comparison between English and New Zealand wheat prices at once brings into prominence the fact that there is a high degree of resemblance in the general trend for the two countries. The coincidence of the periodicity in price movements suggests at once that causes affecting English prices are not, in general, inoperative in New Zealand, that our distance from the centre of the indus- 
trial world does not cause isolation or even partial isolation. The connection between prices in the Dominion and prices in the Mother Country has already received passing comment, but as the subject is one which contains many pit-falls for the unwary, and as in fact popular reasoning about it exhibits many fallacies, it will not be irrelevant to give a brief discussion of it here.

From a discussion of the history of prices in New Zealand and England, we are now in a position to see that the price of New Zealand wheat is not determined altogether by local conditions up to the point when we have a surplus for export. Should the supply fall short of the annual consumption then economy must be practised or importation resorted to. The demand for wheat is fairly inelastic, for everybody must use flour. Especially is this the case in a country like New Zealand, where the adoption of a high standard of living among the labouring classes has led to the extensive consumption of the products of the wheat industry. In the case of scarcity in the local supply, what, then, is the limit to the price which producers can charge for their wheat? Obviously, a price no greater than that at which it would pay Australian or other producers, say, to export their wheat or flour to New Zealand. This price would therefore be an amount equal to cost of production in Australia, including rewards for management, together with cost of freight, insurance, commission, and the amount of the duty charged for wheat and flour entering New Zealand. Since Australia exports to Britain as well as to New Zealand on occasion, it is at once apparent that the New Zealand price cannot remain for long periods above the English price, unless, of course, Australian supplies are seriously impaired by adverse weather conditions there. But even in this event wheat from Argentine or Canada would be imported, were New 
Zealand prices to remain relatively high owing to scarcity of local supplies over a period of two or three years.

In the following table the prices of English and New Zealand wheat per bushel, in years of low production in New Zealand, are compared.

TABLE XXV.

AVERAGE ANNUAL PRICES OF ENGLISH AND NEW ZEALAND WHEAT.

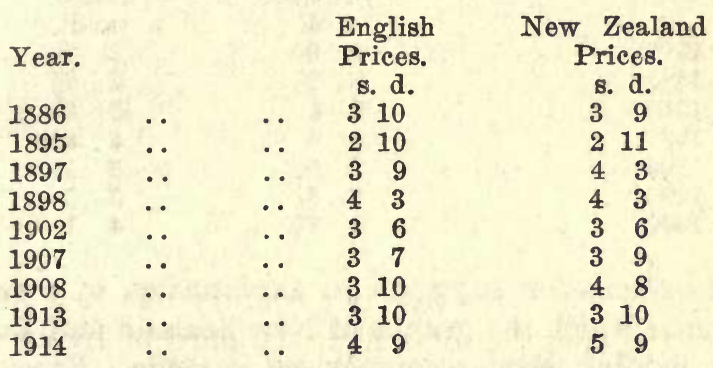

On the other hand, in times of plenty in our local supply, English prices have an appreciable influence on the level of prices in New Zealand. An extremely prolific yield, such as there was in 1899 when some 13,000,000 bushels were produced, eannot depress prices below a certain point, irrespective of foreign conditions. There is a limit below which, under normal conditions, price cannot fall. This limit is set by the cost of shipping wheat to the foreign market-England, so far as we are concerned.

The difference between the English price and the New Zealand price cannot exceed this amount over long periods. Obviously, if price in New Zealand falls below this limit then wheat will be exported to England. Thus, in 1899 the New Zealand price was 2s. 638d. per bushel and the English price was 3s. $2 \frac{1}{2}$ d. per bushel, a difference of $7 \frac{3}{4} \mathrm{~d}$. The cost of sending a bushel of wheat to London is about $8 \mathrm{~d}$., and if we compare prices in 
other years, when there has been an exportable surplus, it is apparent that this is the deciding factor, for the difference in all cases fluctuates about 8d. The following brief table illustrates the point:-

TABLE XXVI.

AVERAGE ANNUAL PRICES OF NEW ZEALAND AND ENGLISH WHEATS.

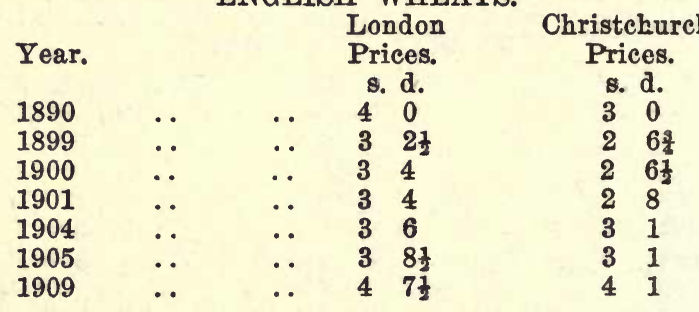

This discussion suggests an explanation of a certain difference which the graphs of New Zealand and English prices exhibit when a comparison is made. From 1870 until the "nineties" New Zealand prices are continually lower than English prices, with two exceptions in the years 1887 and 1889. After 1890 the curves of the two price movements frequently intersect, and the decennial averages approach one another closely. The explanation is obviously the fact that exports of wheat from New Zealand were relatively important in the earlier period, while in the latter one there is a marked decline until the exports are now relatively unimportant. Thus the years in which the curve for New Zealand is above that for England are 1897-8, 1903, 1907-8, and in all of these exports are very low.

\section{Price Steadiness.*}

An interesting comparison in the graphs of the price movements of wheat in New Zealand and England is the

*For the measurement of price changes see Appendix III. 
relative ranges and frequency of the fluctuations in each case. Throughout these are both more frequent and more severe in New Zealand prices than in English prices. Earlier in this chapter reference was made to this aspect of the subject, and it was demonstrated that England's sources of supply were so great and so varying in conditions of production, that in normal times supply was fairly constant. The comparison between New Zealand and English prices further confirms this conclusion. It is true that English wheat exhibited great fluctuations in price in the earlier years of our period, but these can be explained by a variety of circumstances which already have been indicated, and attention may be drawn to the fact that the Corn Laws were repealed so recently before the commencement of the period of our study as 1846 . This sudden opening up of English markets to foreign wheat, while it gave a great stimulus to progress in foreign fields, could not hope to develop them on a sufficiently large scale to render supplies constant. Consequently, a bad harvest in the United States or Russia would at once be reflected in a rise in the price of wheat in England. Since 1880 the English price curve, however, is free from great fluctuations, though changes of minor importance are not infrequent. The same cannot be said of the New Zealand price curve, which exhibits at frequent intervals violent fluctuations throughout almost its whole course. It must be noted, however, that during the "eighties" the extent of the fluctuations diminish, but their frequency does not. An explanation at once suggests itself. Wheat production was at its zenith during the "eighties," but has recently declined, the area under wheat showing a strong decrease. Of recent years the fluctuations in price have increased in severity, and consequently the conclusion can be drawn that price fluctuation is greater when the area of production is decreased. 
TABLE XXVII.

ANNUAL FLUCTUATIONS in the PRICES of ENGLISH and NEW ZEALAND WHEAT PER BUSHEL with CALCULATIONS of the CO-EFFICIENTS of VARIATION and MEAN YEARLY MOVEMENTS, 1881-1914.

\begin{tabular}{|c|c|c|c|c|c|c|c|c|c|c|}
\hline \multirow[b]{2}{*}{ 茎 } & \multicolumn{5}{|c|}{ ENGLISH PRICES } & \multicolumn{5}{|c|}{ NEW ZEALAND PRICES } \\
\hline & 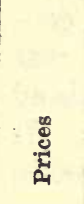 & 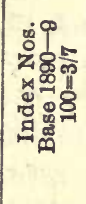 & 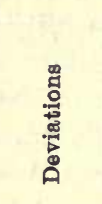 & 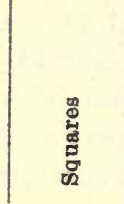 & 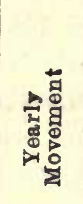 & 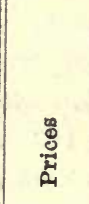 & 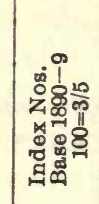 & 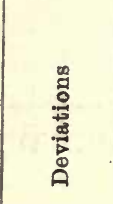 & 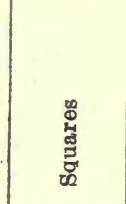 & 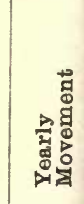 \\
\hline 1881 & $5 / 8$ & 158 & +41.7 & 1738.89 & & $4 / 1$ & 120 & +14.5 & 210.25 & \\
\hline 82 & $5 / 7$ & 158 & +41.7 & 1738.89 & 0 & $4 / 3$ & 126 & +20.5 & 420.25 & b \\
\hline 83 & $5 / 2$ & 144 & +27.7 & 727.39 & 14 & $4 / 3$ & 124 & +8.5 & 72.25 & 2 \\
\hline 84 & $4 / 6$ & 125 & +8.7 & 73.69 & 19 & $3 / 7$ & 106 & +.5 & .25 & 18 \\
\hline 85 & $4 / 1$ & 114 & -2.3 & 5.29 & 11 & $3 \%$ & 87 & -18.5 & 342.25 & 19 \\
\hline 86 & $3 / 10$ & 107 & -9.3 & 86.49 & 7 & $3 / 9$ & 110 & +4.5 & 20.25 & 23 \\
\hline 87 & $4 / 1$ & 114 & -2.3 & 5.29 & 7 & $3 / 9$ & 109 & +3.5 & 12.25 & 1 \\
\hline 88 & $4 /-$ & 112 & -4.3 & 18.49 & 2 & $3 /-$ & 88 & -17.5 & 306.25 & 21 \\
\hline 89 & $3 / 9$ & 105 & -11.3 & 127.69 & 7 & $3 / 11$ & 113 & +7.5 & 56.25 & 25 \\
\hline 1890 & $4 /-$ & 112 & -4.3 & 18.49 & 7 & $3 / 2$ & 92 & -13.5 & 172.25 & 21 \\
\hline 91 & $4 / 7$ & 128 & +11.7 & 136.89 & 16 & $3 / 10$ & 113 & +7.5 & 56.25 & 21 \\
\hline 92 & $3 / 10$ & 107 & -9.3 & 86.49 & 21 & $4 /$. & 117 & +11.5 & 132.25 & 4 \\
\hline 93 & $3 / 3$ & 91 & -25.3 & 640.09 & 16 & $2 / 9$ & 81 & -24.5 & 600.25 & 36 \\
\hline 94 & $2 / 10$ & 79 & -37.3 & 1391.29 & 12 & $2 / 6$ & 73 & -32.5 & 1156.25 & 8 \\
\hline 95 & $2 / 10$ & 79 & -37.3 & 1391.29 & 0 & $2 / 11$ & 86 & -18.5 & 342.25 & 13 \\
\hline 96 & $3 / 3$ & 91 & -25.3 & 640.09 & 12 & $3 / 7$ & 106 & +.5 & .25 & 20 \\
\hline 97 & $3 / 9$ & 105 & -11.3 & 127.69 & 14 & $4 / 3$ & 125 & +19.5 & 380.25 & 19 \\
\hline 98 & $4 / 3$ & 119 & +2.9 & 7.29 & 14 & $4 / 3$ & 124 & +18.5 & 342.25 & 1 \\
\hline 99 & $3 / 2$ & 89 & -27.3 & 745.29 & 30 & $2 / 9$ & 75 & -30.5 & 930.25 & 49 \\
\hline 1900 & $3 / 5$ & 95 & -21.3 & 453.69 & 6 & $2 / 5$ & 70 & -35.5 & 1260.25 & 5 \\
\hline 01 & $3 / 4$ & 93 & -23.3 & 542.89 & 2 & $2 / 5$ & 71 & -34.5 & 1190.25 & 1 \\
\hline 02 & $3 / 6$ & 98 & -18.3 & 334.89 & 5 & $3 / 6$ & 103 & -2.5 & 13.75 & 32 \\
\hline 03 & $3 / 4$ & 93 & -23.3 & 542.89 & 5 & $4 / 2$ & 122 & +16.5 & 272.25 & 19 \\
\hline 04 & $3 / 7$ & 100 & -16.3 & 265.69 & 7 & $3 / 1$ & 92 & -13.5 & 182.25 & 30 \\
\hline 05 & $3 / 8$ & 102 & -14.3 & 204.49 & 2 & $3 / 2$ & 92 & -13.5 & 182.25 & 0 \\
\hline 06 & $3 / 6$ & 98 & -18.3 & 334.89 & 4 & $3 / 2$ & 94 & -11.5 & 132.25 & 2 \\
\hline 07 & $3 / 10$ & 107 & -9.3 & 86.49 & 9 & $3 / 9$ & 110 & +4.5 & 20.25 & 16 \\
\hline 08 & $4 /-$ & 112 & -4.3 & 18.49 & 5 & $4 / 8$ & 135 & +29.5 & 830.25 & 25 \\
\hline 09 & $4 / 7$ & 128 & +11.7 & 138.89 & 16 & $4 / 1$ & 120 & +14.5 & 210.25 & 15 \\
\hline 1910 & $3 / 11$ & 109 & -7.3 & 53.29 & 19 & $3 / 8$ & $10 \mathrm{r}$ & +1.5 & 2.25 & 13 \\
\hline 11 & $4 \%$ & 112 & -4.3 & 18.49 & 3 & $3 / 9$ & 110 & +4.5 & 20.25 & 3 \\
\hline 12 & $4 / 4$ & 121 & +4.7 & 14.09 & 9 & $3 / 8$ & 107 & +1.5 & 2.25 & 3 \\
\hline 13 & $3 / 10$ & 107 & -9.3 & 86.49 & 14 & $3 / 10$ & 112 & +6.5 & 42.25 & 5 \\
\hline 14 & $4 / 4$ & 121 & +4.7 & 14.09 & 14 & $5 / 9$ & 168 & +62.5 & 3916.25 & 56 \\
\hline & $141 / 7$ & 3954 & & 12738.76 & 330.1 & $122 / 8$ & 3588 & & 1365,00 & 532 \\
\hline & $4 / 2$ & 116.3 & & 374.663 & & $3 / 7 \frac{1}{4}$ & 105.5 & & 401.4706 & 16.12 \\
\hline
\end{tabular}


ENGLISH PRICES.

STANDARD DEVIATION

CO-EFFICIENT OF VARIATION

MEAN YEARLY MOVEMENTS IN INDEX NUMBERS

$$
\begin{aligned}
& =\sqrt{374.663} \\
& =\quad 19.35 \\
& \hline
\end{aligned}
$$$$
=\frac{\text { S. D. }}{\text { Mean }} \times \frac{100}{1}
$$$$
=\frac{19.35}{116.3} \times \frac{100}{1}
$$$$
=\underline{16.6}
$$$$
=10
$$

$=$ 4.3d. per bushel

$=8.6 \%$ of mean annual price

NEW ZEALAND PRICES

STANDARD DEVIATION

CO-EFFICIENT OF VARIATION

MEAN YEARLY MOVEMENT IN INDEX NUMBERS

$$
\begin{aligned}
& =\sqrt{401.4706} \\
& =\frac{20.04}{S} \\
& =\frac{\text { S. D. }}{\text { mean }} \times \frac{100}{1} \\
& =\frac{20.04}{105.5} \times \frac{100}{1} \\
& =\frac{19.0}{=16.12} \\
& =6.6 \mathrm{~d} \text {. per bushel } \\
& =15.2 \% \text { of mean }
\end{aligned}
$$
annual price

In general, the above observations confirm the conclusion reached earlier in the chapter, that a wide area of production adds materially to price steadiness.

A closer examination of the price statistics of New Zealand and English wheat confirms the conclusion we have arrived at from a study of the corresponding graphs. Taking the period 1881 to 1914 , I have calculated the standard deviations for the index numbers of wheat prices for England and New Zealand. For English wheat the calculation gave a standard deviation of $19: 35$, and for New Zealand wheat one of $20 \cdot 04$. 
The standard deviations thus found are not directly comparable, for the averages of the two series differ. I have, therefore, calculated the co-efficient of variation," which is the ratio of the standard deviation to the average for each series, multiplied by 100 . This coefficient for English prices was $16 \cdot 64$, and for New Zealand prices was 18.99 , showing a difference of 13 per cent., for if we represent the co-efficient of variation for New Zealand prices as 100, then that for English prices is 87 . The significance of the result is that the degree of variation in New Zealand prices is greater than that in English prices, or, in other words, English prices are more consistently near their average than New Zealand prices over the period.

Pursuing the investigation a little further, I have calculated the mean yearly movement for the two series over the period, that is, the mean of the difference between the average annual prices. In the case of English wheat, the mean yearly movement was $4 \cdot 3 \mathrm{~d}$, and the figure for New Zealand $6 \cdot 6 \mathrm{~d}$., showing a much greater average yearly fluctuation in the case of New Zealand wheat prices. But the difference is greater when we compare these calculations with the average annual price for the period, for this figure is $4 \mathrm{~s}$. $2 \mathrm{~d}$. for English wheat, and 3s. $7 \frac{1}{2} \mathrm{~d}$. for New Zealand wheat. Thus the mean yearly variation in the price of English wheat is 8.6 per cent. of the average price; but for New Zealand wheat it is $\mathbf{1 5 . 2}$ per cent. of the average price for the period. From this calculation, then, the annual fluctuations in the price of New Zealand wheat are about 100 per cent. greater than corresponding fluctuations for English wheat prices.

*See Appendix III. 
LEADING FEATURES OF THE WHEAT INDUSTRY 183

\section{Chapter VIII.}

\section{LEADING FEATURES OF THE WHEAT INDUSTRY IN THE LAST PERIOD (1895-1914).}

\section{Retrospect.}

In Chapter VI the course of the organisation of wheat production in New Zealand since the period of early colonization was traced with a definite end in view. The gradual merging of one system of production into another was treated in more or less detail, until the closing years of last century, when the initial stages of our present systems of production were definitely shaped. Perhaps the most outstanding feature of the wheat industry during the latter half of the century was the large scale production of the "eighties." The interesting and suggestive nature of this period in the development of our wheat industry has been sufficiently discussed, but it may be well to refer again to the connection between this period and the preceding one. This connection is not difficult to trace. "Bonanza" farming was at length discovered to be relatively unprofitable on account of the many serious obstacles which it encountered." The operation of the law of decreasing

*See above Chapter VI., page 102. 
returns was quickly becoming a matter of no small consequence, and it was recognised more and more after each harvest that careful tillage was becoming necessary for profitable production. The dominance of agriculture, so characteristic of rural life on the Plains in the early "eighties," was rapidly giving way to pastoral interests; for the year 1882 had witnessed the successful exportation of a shipment of frozen mutton from our shores to the United Kingdom. To the farming community, indeed, to the whole country, this development almost meant salvation from something akin to ruin.

Almost in desperation, the country now pursued the new industry with an energy and perseverance common only to those who, after experiencing such gloom as our country passed through in the early "eighties," recognise that their last hope lies in their individual efforts in some new direction. So great was the expansion in this industry, that within a single decade our exports of frozen mutton had risen to over one million hundredweight, with a value of considerably more than one million pounds sterling. But it was not long before it was recognised that pastoral farming, suitable for producing fat stock, required English grasses for fattening the sheep in the final stage. The only way to provide these was to adopt the practice of mixed farming, and the pursuit of this required small holdings. The final blow to the large agricultural estate came in the early "nineties"' when the Graduated Land Tax was imposed, and proved a great hindrance to the existence of large holdings. In 1892 the Government decided, by the Land Act of that year, to purchase such estates as were procurable, and lease them in small holdings on the 990 years' lease system. Under the combination of these circumstances the large estates which had been the dominant feature of agriculture for almost two decades, 
gradually passed away, and the country adopted the small holding* for good or ill.

\section{Reasons for Choosing 1895 as the Commencement of a New Period.}

Although 1895 may be regarded as the commencement of the latest well-defined period in the organisation of wheat production, the actual transition period extended over the whole of the "nineties" into the early years of the present century. But co-existent with the large estates there were many comparatively small holdings springing up, and when the rise of the frozen meat trade promoted the method of mixed farming, these small estates were soon found to possess the greatest differential advantages in production.

The middle "nineties" is not chosen arbitrarily for the introduction of the last well-defined period in the wheat industry in New Zealand. Several forces were operating to bring about the change at this time. Thus it was in the year 1895 that the long continued and heavy fall in the price of farm products reached its lowest point. From this year until the end of the century farm products rose in price, and the rise has continued almost without intermission until the present time. Secondly, the year 1895 marks the beginning of the decline in the acreage under wheat. In the case of both Canterbury and Otago the area devoted to the production of wheat has decreased considerably since the year 1895. Thirdly, it is about the middle "nineties" that the yield per acre, which, owing to the exhaustion of the soil had shown a falling tendency for some years, began to rise again, and it rose very sharply and persistently until recent

*Relative to European conditions our holdings are large; for they range in size from 100 to 500 acres, and, where the country is mountainous, or of such a nature as to be useful for grazing purposes only, they are frequently much larger. 
years. These tendencies in yield and acreage both bear the mark of the influence of more intensive farming, and are strongly indicative of the fact that it was about the year 1895 that this influence began to be experienced. Fourthly, according to Dr. McIlraith, the rate of discount, a convenient measure of the rate of interest, had fallen in 1895 to about 5 per cent., and has remained at a figure between 5 per cent. and 6 per cent, until recently. It is obvious that this fall in the rate of interest would have considerable influence on the means whereby farmers might obtain sufficient capital to pursue intensive methods of cultivation, which of necessity involves not merely more labour, but also more capital. Finally, by this time the Government was promoting, by its system of taxation for social ends, and by its activity in purchasing large estates, an intensive method of cultivation. Furthermore, as internal development was progressing, the means of transportation by railway were becoming more prevalent; and the country, now quite recovered from the gloom of the "eighties," was pushing on the construction of roads and bridges, and making rapid progress in general development. It was circumstances such as these which favoured the initiation of a new system of agricultural and pastoral farming in New Zealand, the development of which will occupy our attention in the succeeding pages of this chapter.

\section{Iand.}

(a) Definition of Region Under Investigation. - In considering the question of the supplies of land available for wheat production in New Zealand, it is necessary for all practical purposes to confine our attention to Canterbury and North Otago as being the most suitable and probable areas for production. Since the year 1868, when regular annual statistics of crop and acreage for New Zealand were first available, only a very small portion of 
the total crop has been produced outside these areas. Consequently, I have confined my investigations of conditions in New Zealand to Canterbury and Otago.* It will be well to remember again that on account of the great diversity of industries, which the varying conditions in different parts of the Dominion favour, it is extremely unlikely that the land will again be subjected to the pursuit of one industry alone, such as was the case in the late "seventies" and early "eighties." Three main pursuits are open to our farmers-dairying, pastoral farming, and cereal growing. In the North Island the superiority of the land for dairying and sheep grazing has led to the rapid development of these industries in recent years. The conditions are eminently favourable for these industries, for the fertility of the soil and the abundance of the rainfall provide pastures second to none in the world. There is every prospect that this tendency towards pastoral and dairy farming will be maintained, and that cereal growing, which has never attracted the attention of farmers to any great extent, will be almost abandoned as far as production for the market is concerned. Moreover, of the cereals commonly grown in New Zealand, it is likely that least attention will be given to wheat, because the rainfall in most places is in excess of the upper limit for profitable wheat production.t Conditions in the South Island differ greatly from these in the North Island. This is due chiefly to the effect of the high western mountain ranges on the climate of the East Coast, and secondly to the geological formation of the land. The mountains

* See graph showing area for Canterbury and Otago com. pared with that for New Zealand, page 32.

tThese remarks must be accepted with slight reservation in regard to the area around Palmerston North, known as the Manawatu Plains. Here wheat production is still practised to a small degree, and the elements seem favourable for its continuation. 
of the West Coast serve as a barrier to the moisture-laden anti-trade winds which blow across the Tasman Sea. Consequently, they bring heavy rains to the West Coast, and come over the ranges as hot dry winds. Not only is the rainfall of the East Coast, some 25 to 30 inches, very favourable to wheat production, but the general character of the land in this area is suitable for agriculture. A great portion consists of the Canterbury Plains, the soil of which is loose and easily cultivated, while the Downs to the South present few obstacles. It is true that in Nelson and Marlborough there are small areas where wheat is produced, for example, the Waimea and Wairau Plains. But a glance at statistics shows that the production of these areas is small. I have already demonstrated graphically that the amount of wheat produced outside Canterbury and Otago is small.* Since the rainfall in the West Coast prohibits wheat growing, there remains only Canterbury and North Otago to be considered in estimating the land available for wheat production. In the extreme south of Otago the climate is not highly favourable to the production of the cereal, and although the Southland Plains are otherwise suitable, wheat is not produced in large quantities there. Of recent years separate statistics have been published for Southland, and these indicate that the production is comparatively small. For the harvest in 1916 the area in wheat in Southland was 8,795 acres, and in North Otago 48,462 acres. The corresponding figures for 1911 were 11,715 acres, and 62,171 acres. Thus, our present enquiry refers chiefly to Canterbury and North Otago, and in considering the supply of land available for wheat production reference will be made to these two areas only.

(b) Supply of Land.-The total area of Canterbury and Otago (not including Southiand) is almost 19,600,000

${ }^{*}$ See page 32. 
acres. Both provinces present varying types of land from rich fertile plains to rugged mountainous country. The land of Canterbury is divisible into three main classes-arable, pastoral, and waste lands. The arable land is composed of the Canterbury Plains and the Downs of South Canterbury, comprising an area of about $2 \frac{1}{2}$ million acres. Of the remaining land, some 7 million acres, about 5 million acres are suitable for pastoral farming, while the rest, highly mountainous country, riverbeds, lakes, and forests, is unfitted for occupation.

In Otago, a smaller proportion of land is available for wheat growing, for here no great plain is found within the wheat area, which is confined to the northern portion of the province and contains an area suitable for wheat production of, probably, not more than 500,000 acres.

The nature and character of this land have already been considered in Chapter III., but the whole area is admirably suited for the production of wheat, and the possibilities of New Zealand as a producer of wheat can be more readily comprehended when this fact is realised. Of the area of $3,000,000$ acres suitable for the growth of the cereal, and this is a conservative estimate, 750,000 acres could be devoted to wheat growing annually. If we, then, make the supposition that the yield per acre on account of the extension of the margin would be reduced to, say, 25 bushels, New Zealand would then produce $18,750,000$ bushels each year. This could be done, moreover, without any great disturbance in the present state of rural occupation, were sufficient supplies of capital and labour available. This consideration, in view of the desired increase in primary production on account of the War, opens up an interesting line of investigation which is not strictly relevant to present 
purposes.* But the conclusion that we could produce annually $18,750,000$ bushels of wheat without disturbing the normal course of agriculture to any great extent, is of far-reaching importance. Moreover, the transference of areas from pastoral and other pursuits to wheat production would be a matter of comparative ease in many parts of the country, notably Central Otago, which could quickly be turned to a cereal growing district by the adoption of irrigation and improved methods of cultivation, as is being done in similar regions in Australia and California.

The actual supply of land, however, is not an important consideration in arriving at a conclusion as to the merits and de-merits of a system of cultivation. Of more importance is the size of the farms, which will be studied after considering briefly the systems of land occupation.

(c) Occupation of Land.-(i) Relation of Freehold and Leasehold.- "In the earlier years of the settlement of New Zealand there were opportunities for men of capital and judgment to acquire large estates at reasonable prices, especially when money was needed for administration and roads and bridges. As the best land in the course of years passed from the Crown, the country became a series of agricultural communities interspersed with large properties, and as time went on, those in search of lands urged that they should be allowed to occupy these large estates instead of being compelled to go into inaccessible back country without roads and railways." $\dagger$ 'This latter movement became so strong that in 1892 was passed the Land for Settlements Act, already referred to, whereby the Crown undertook to buy up

*It is by no means certain that wheat supplies will be in abundance after the War. Should there be a continuation of the present scarcity considerable quantities may again be exported from New Zealand. The matter is discussed in the concluding chapter.

t"Now Zealand Official Year Book" (1914). Page 521. 
large estates for closer settlement. Consequently there are two types of occupation of land in New Zealand-freehold and leasehold. According to the last census (1911) there were about $19,500,000$ acres freehold out of a total of some $66,000,000$ acres in the whole country. The remaining portion is in the hands of urban owners, the Crown, Native owners, local bodies, churches, educational bodies, friendly and other societies. Of the occupied lands of New Zealand a little less than one-half is held freehold.

Although on account of the enterprise, perseverance and foresight of the intelligent freeholder, the freehold system is regarded as more advantageous to a community than the leasehold, a great deal can be said for the latter in New Zealand, and there is little doubt that the inauguration of such a system has played a great part in the development of the country. The conditions of tenure differ somewhat for different kinds of land, e.g., agricultural or pastoral, but here attention will be confined to the tenure of agricultural land.

(ii) Effects of 999 Years' Land Tenure.-Primarily, the main feature of the land tenure system was the provision for the 999 years' lease. The tenant, fortunate enough to be the successful applicant for a section of land, could assume the rôle of owner, for all practical purposes. Provided he farmed the land along sufficiently scientific lines, and paid his rent regularly, he retained the lease of the land, and at death it went to the heir. Under this Act many estates were purchased, and with what beneficial results anyone with a limited knowledge of country life in New Zealand can testify.

A single example will demonstrate this. An estate situated in the Pareora River Valley about 10 miles south of Timaru was acquired by the Crown in 1901, and opened up for settlement in the same year. At the time of purchase much of the land was still in its native 
state, and year by year only comparatively small areas were cultivated, the rest being devoted to pastoral farming. The general aspect of the country was anything but inviting, for settlement was sparse, there being only the homestead and a few houses-or rather, hutsseattered at considerable distances over the area.

The contrast presented by the same land now is, indeed, remarkable. Where before were wide stretches of tussocky downs with a few sheep wandering over them, and a field of wheat or oats here and there, one now sees on all sides signs of marked activity. All the way up the valley are smiling homesteads, each almost within hailing distance of its neighbour. The perseverance, enterprise, and diligence of the tenants have completely changed the whole aspect of the country. Every available piece of ground has been carefully cultivated and yields good crops of cereals, hay, or turnips. Mixed farming is in operation with great success, and so absorbed is the tenant in the fostering of good agriculture and the provision of conditions antagonistic to soil exhaustion, that the casual observer would at once conclude that he was the sole owner of the land; indeed, very often it is the half-yearly rent alone, which reminds the tenant himself that he is not the owner. Moreover, the standard of comfort on these farms is high, while the facilities afforded for social enjoyment add much to the pleasures of rural life. From observation of other similar estates in various parts of the country, the same impression of industry and activity is made on the observer.

The beneficial effects of this land tenure system, unfortunately, are greatly modified by the wholly inadequate provisions for the re-valuation of the land at short intervals. The adoption of these provisions was the only step required to render the system completely 
successful, for it has been shown that it met the requirements of the country remarkably well.

(iii) The Present Land Tenure System.-The most recent land tenure system is fundamentally opposed to the spirit of the original, in that it makes provision for the tenant to purchase the land at will within 25 years. Any time after six years of occupation the tenant can purchase the land and acquire the right of freehold; whereas, under the original plan, the Crown retained the land, and thus ultimately acquired the unearned increment which the State now forfeits to the individual.* The general prosperity during the last two decades has pervaded the agricultural community no less than other sections, and most of the tenants under the old system are now in a position to command the freehold. With much land still unsettled in outlying districts, those who were anxious for the freehold would have been stimulated to purchase such areas when holdings could not be purchased from the Crown. To the Government, at present, is left the duty of settling this land under the thirty years' lease system, with the right of purchase, and in so far as activity is shown on these lands there is no doubt about the beneficial results of our present land system. But where the tendency is for the Crown to purchase lands in prosperous communities already well settled, the features of the Act are not so commendable. Many people who would go to outlying and backward districts to acquire freehold are deterred from doing so by the prospects of obtaining the freehold relatively cheaper in prosperous communities. This

*Part of this unearned increment, and very often a large part, is due to the enterprise and energy of the farmer. But into it enter other factors to which the farmer has contributed but little. Thus there are railway construction, and better means of communication generally, closer settlement, with a greater demand for the land, the opening up of new markets, etc., all of which invariably increase the price of land. 
disadvantage can easily be overcome by the Crown confining itself to the purchase of the outlying lands, and offering them for settlement; for here, the prospect of ultimate freehold under the present Act is distinctly encouraging to intending settlers. From this point of view the present law is a distinct advance on the old one.*

New Zealand once experienced the "sweets" and "bitters" of a landed aristocracy with large estates in the two decades after 1870 . The democratic character of our people and the antagonism to "land monopoly,"

*The general principles laid down here in regard to the question of land tenure were to a large extent confirmed by a discussion at the Conference of the Agricultural and Pastoral Associations, in 1915, when Mr. W. D. Hunt moved:"That whereas a very large proportion of the pastoral lands of the South Island of New Zealand, including much of the national endowment lands let for pastoral purposes under Part VI. of the Land Act, 1908, and amendments thereof, have deteriorated very much indeed in stock-carrying capacity since they were first occupied, and whereas practically none of these lands have improved in stock-carrying capacity since their first occupation, now this Conference of $\mathrm{A}$. and P. delegates is of opinion-(a) That under proper and judicious management these pastoral lands could not only be brought back to their original carrying capacity, but they can be made much more productive than ever. (b) That the bringing about of this improvement will require the expenditure of a large amount of capital and time. (c) That the occupiers of these lands cannot be induced to make the necessary outlay of time and money unless they can see a reasonable assurance of being rewarded for their efforts and outlay. (d) That the only tenure that will give this assurance is the freehold. (e) That the Government be urged to introduce legislation enabling the land to be disposed of as freehold under suitable conditions and restrictions." (Proceedings of the Conference, page 26).

In the discussion which followed, it was contended that the only means of encouraging adequate development in these lands was to offer a tenure with the right of purchase on easy terms. This principle was not advocated for the more settled areas, and thus bears out the general principle laid down by the present writer. 
felt by the majority of our politicians, act as a safeguard against the recurrence of this system, which was gradually supplanted some twenty years ago by one infinitely better as results clearly prove. But the work of the early landowners is too often minimised by crities. By their pioneer work in agriculture they occupy an important position in the industrial history of the Dominion. Although it cannot be said that the position of the ordinary labourer was enviable at that time, it must be admitted that it was on these large estates that our present-day farmers first "found their feet." It is true that the landowner in some cases strongly opposed the settlement of the small farmer, but, on the whole, the latter owes much to the former. It was the enterprise of the landowner which gradually extended settlement, meagre though it was at first. It remained for the more modern farmer to develop an intensive settlement, and in this he has succeeded eminently.

\section{TABLE XXVIII.}

The following table shows the relative positions of leasehold and freehold in the provinces under investigation at the last census, 1911.

\begin{tabular}{c|c|c|c|c}
\hline PRovINCE & $\begin{array}{c}\text { Total } \\
\text { Occupied Land }\end{array}$ & Freehold & $\begin{array}{c}\text { Leased from } \\
\text { Individuals } \\
\text { or Public } \\
\text { Bodies }\end{array}$ & $\begin{array}{c}\text { Leased from } \\
\text { the Crown }\end{array}$ \\
\hline $\begin{array}{c}\text { Canterbury... } \\
\text { Otago } \\
\text { (Southland } \\
\text { excluded) ... }\end{array}$ & $6,587,587$ & $2,581,682$ & 926,471 & $3,060,112$ \\
\hline
\end{tabular}

(d) Size of Holdings.-The following table shows the total area (in thousands of acres), and the number of holdings in groups as classified in the Census of 1911:- 
TABLE XXIX.

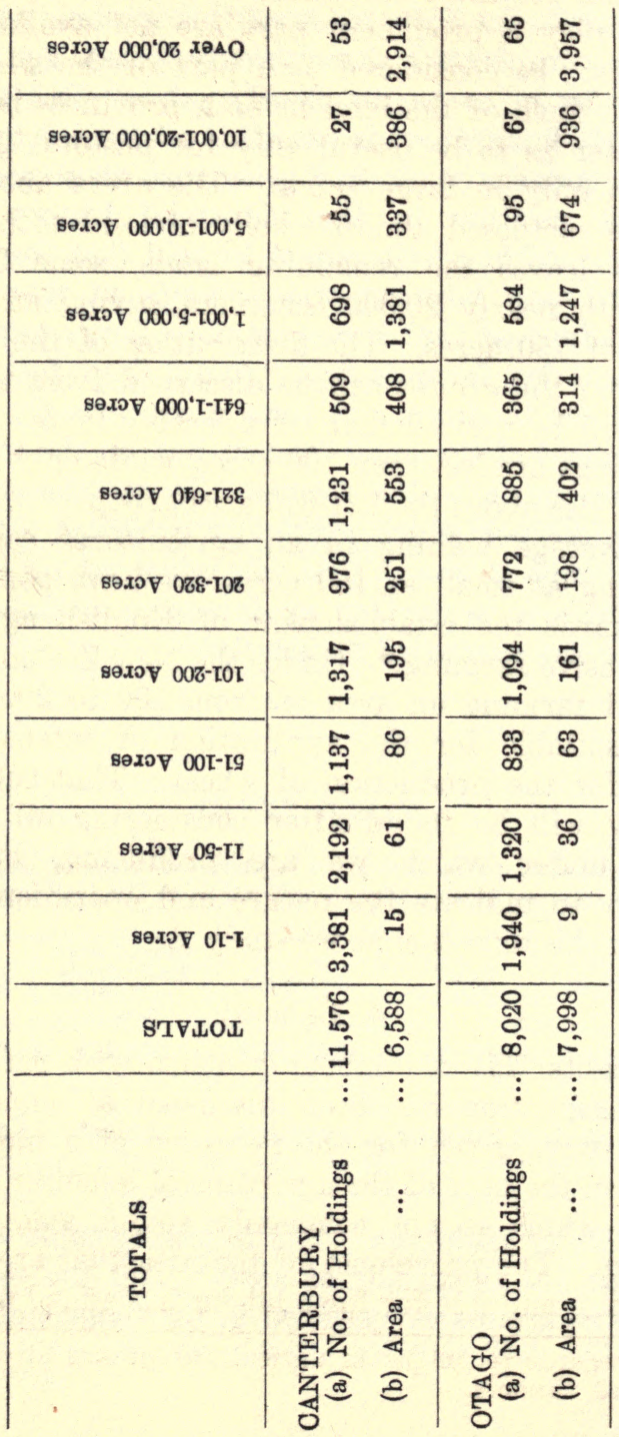


Statistics for those communities in which agricultural pursuits play a prominent part are not available, and these must be considered as a part of the whole land district. Much of the land in both provinces is of such a character as to be useful only for pastoral purposes, and then only in large tracts. The areas above 1,000 acres are composed almost wholly of land such as this, and this leaves the remaining lands, some $3,000,000$ acres, with nearly 20,000 occupiers, giving an average holding of 150 acres. The distribution of the holdings throughout the groups can be discerned from the table, and it will be noticed that considerably more than half the holdings are less than 100 acres, while only some ten per cent. lies above the 321-640 acre group.

The average holding in an agricultural community then being as small as 150 acres, we have gone a long way towards the establishment of English agriculture and intensive farming." Under the New Zealand system of mixed farming an area of from 100 to 200 acres is ideally suitable for the application of intensive agriculture for the production of wheat. That such is the tendency will be found after considering all the conditions under which we are producing, but it is necessary to indicate the nature and operation of each factor in this direction as we study it.

\section{Labour.}

In Chapter III. the labour problem with reference to wheat production has been discussed at some length. Reasons were given for the necessity of a high degree of skill on the part of the agricultural labourer, a degree of skill which is not commonly found among casual labourers. The prevalence of the idea that any kind of workman is suitable for farm labour has added materially

*As regards technique in agriculture we are already ahead of English farmers. 
to the difficulties which farmers experience in growing wheat. Indeed, many farmers declare that it is on account of this very difficulty that they have been forced to turn to pastoral pursuits. Whether this is exaggerating the position is a debatable point, but it is clear that our supply of agricultural labour is not efficient in all respects.

(a) Rural Depopulation.-The supply of farm labour not only lacks much of the necessary skill, ${ }^{*}$ but is also deficient in numbers. There is no doubt that rural depopulation has been in operation in New Zealand since the opening years of the present century. On this point the Cost of Living Report has a wealth of information.t In 1881 out of every 100 persons in the Dominion 59 were living in counties and 40 in boroughs. In 1911 the corresponding figures are 49 and 50.

\section{TABLE XXX.}

In the following table a comparison is made of bread-winners in the chief food-producing rural industries with the bread-winners in the total population of the Dominion.

\begin{tabular}{|c|c|c|c|}
\hline & 1901 & 1906 & 1911 \\
\hline \multirow{2}{*}{$\begin{array}{l}\text { Total of all classes ... } \\
\text { Agricultural, Pastoral } \\
\text { Dairying Number }\end{array}$} & 340,230 & 399,085 & 454,118 \\
\hline & 85,022 & 92,565 & 104,123 \\
\hline Percentage of Total Bread-winners & 24.99 & 23.19 & 22.93 \\
\hline
\end{tabular}

This clearly illustrates the movement of population from primary production into urban industries, but it does not of necessity follow that such rural depopulation is detrimental to national welfare. Such a movement may indicate that "an increasing proportion of the people are devoting themselves to the production of goods of a high order, such as the comforts and harmless luxuries of life, Government service, the growth of art, science, education, and truly recreative leisure."

*See Chapter III., Sec. 8, (b).

t"Cost of Living Report," 1912, H-18. Page lx. 
Further, it may indicate that "labour and directive ability are being set free by the progress of agricultural art and science for application to other spheres." If such were the results of the population movement in New Zealand its beneficial effect would not be questioned. But when we come to study the movements in the rural population itself, such results are not in evidence, and it is unquestionable that the continuation of such movements would be detrimental to the interests of agriculture.

(b) Movements in Rural Population.-

\section{TABLE XXXI.}

The following table shows a comparison of the total numbers occupied in the three leading rural industries in the census years 1901, 1906, 1911.*

\begin{tabular}{|c|c|c|c|}
\hline Industry & \multicolumn{3}{|c|}{ Total Numbers Occupied } \\
\hline & 1901 & 1906 & 1911 \\
\hline Agriculture & 63,046 & 64,965 & 48,894 \\
\hline Pastoral & 12,069 & 15,026 & 27,332 \\
\hline Dairying & 9,081 & 11,405 & 26,348 \\
\hline
\end{tabular}

An analysis of the numbers occupied in these industries in the same period is interesting.

The following table gives such an analysis:-

TABLE XXXII.

\begin{tabular}{l|ll|r|r|r|r}
\hline YEAR & CLASS & Employers & $\begin{array}{c}\text { Employers } \\
\text { on own } \\
\text { account }\end{array}$ & $\begin{array}{c}\text { Wage- } \\
\text { earners }\end{array}$ & $\begin{array}{c}\text { Relatives } \\
\text { assisting } \\
\text { or } \\
\text { Indefinite }\end{array}$ \\
\hline 1901 & Agriculture & $\ldots$ & 13,055 & 15,480 & 20,815 & 12,960 \\
& Pastoral & $\ldots$ & 1,910 & 1,410 & 7,867 & 697 \\
& Dairying & $\ldots$ & 1,546 & 3,156 & 1,067 & 3,307 \\
\cline { 2 - 6 } 1906 & Agriculture & $\ldots$ & 15,389 & 14,721 & 21,937 & 12,177 \\
& Pastoral & $\ldots$ & 2,512 & 1,428 & 9,021 & 1,880 \\
& Dairying & $\ldots$ & 2,405 & 4,767 & 1,430 & 2,789 \\
\hline 1911 & Agriculture & $\ldots$ & 9,027 & 12,185 & 19,028 & 7,986 \\
& Pastoral & $\ldots$ & 5,466 & 5,197 & 12,994 & 3,246 \\
& Dairying & $\ldots$ & 4,538 & $9 ; 909$ & 4,845 & 7,005 \\
\hline
\end{tabular}

*A census is now overdue. One was taken late in 1916, but the returns are not yet available. 
The main movement of population within rural occupations themselves is the shifting from purely agricultural branches to the pastoral and dairying branches. Thus, whilst the numbers engaged in agriculture fell during the period 1901-11 by more than 25 per cent., the numbers employed in the pastoral industries more than doubled, while those in the dairying industry nearly trebled.

(c) Causes of the Relative Decrease in the Supply of Farm Labour.-The key to the retardation in the rate of growth of rural population and the acceleration in the expansion of numbers in urban areas is to be found in the relative attractiveness of town life compared with country life. This, obviously, is not the the result of a single cause, for of recent years many circumstances have combined to make this influence felt more keenly.

In the first place, until quite recently, our education system has not been of such a nature as to interest children, even in the country, in the natural objects surrounding them. The whole trend of the system for at least the first decade of the present century was to isolate the child from his environment in the mad rush to obtain good results at the forthcoming examinations, based on a curriculum which prepared mainly for clerical pursuits. The Education Commission of 1912 found the outstanding weakness of the system to be "want of facilities for rural training," and that "in respect of the great importance of agriculture to the Dominion, this subject is not receiving the attention it deserves."

Fortunately, this advantage is being remedied now by the growth of the idea that "instruction in the elementary principles of agriculture that can be properly included in the programme of primary schools ought to be addressed less to the memory than to the intelligence of the child. It should be based on observation of the everyday facts of rural life, and on a system of simple 
experiments appropriate to the resources of the school, and calculated to bring out clearly the fundamental scientific principles underlying the most important agricultural operations." Such a programme is now incorporated in our curriculum in the State schools, and our teachers are pursuing it in a highly commendable manner, which should once more turn the scales of public opinion in favour of agriculture.

In the chain of causation to bring about an acceleration in the rate of growth of urban population to the disadvantage of rural population, an important factor is to be found in the increasing demand for labour in the towns for handling primary products and performing the official work. In our present organisation of marketing, the labour involved in handling produce is of considerable extent, and moreover, not decreasing, while the official work in inspecting and grading primary products, as well as the expansion of postal, railway, and other transport services, requires an ever-increasing number of workers, many of whom have been drawn from the country.

Rising partly from this increased demand for town labour is to be found another cause of no less importance, in that a higher rate of wages rules in the town as a result. Over long periods there is, undoubtedly, a steady tendency towards the equalization of town and country "real" wages, but in the present stage of transition the town seems to offer a higher rate of remuneration for skilled labour. Of more importance in this connection, and exerting the same influence, are the opportunities for pleasure, recreation, social life, better education, etc., all tending to increase "real" wages in the town. There is reason to believe that the present tendency is for the wages of rural workers to improve at a greater rate than those of urban workers, though there is still a considerable disparity. Labour conditions in the North, in the 
dairying and pastoral industries, are probably superior to those in the long-settled districts of the South. But for present purposes we are concerned only with conditions in the wheat producing area.

A fourth cause of the deficiency in the supply of agricultural labourers-and this has special reference to the wheat industry-is the difficulty married country workers meet in finding suitable housing accommodation, and the lower standard of living in the country compared with that in the town. This difficulty was frequently referred to in the evidence given before the Cost of Living Commission, and many witnesses stated that this was the chief reason why workers migrated to the town. Coupled with the scarcity of good house room for country workers is a group of other influences tending to lower the standard of living in the country. The opportunities for social intercourse, the variety of amusements, the manifold means of recreation and other social advantages which town life offers, are conspicuously absent in the case of the rural worker. Greater than these disadvantages is the absolute lack of attractions which the country offers to the wives of ordinary farm labourers on almost all sides. In many cases the only way in which a married man may get employment on a farm is by taking a situation where his wife must be prepared to take up the position of housekeeper to all hands on the farm, be there only one extra worker or any number up to seven or eight. The town worker is generally able to give his wife the position in a quiet home which she should rightly have, judged by any standard, be it from the individual's point of view, that of the community, or that of the whole State. But such is not always the case with the rural worker. It is true that there are a relatively small number of positions ideally suitable for married workers in the country, but very often in these the work of the wife is no less than that of her husband. 
(d) Some Remedies - Such a state of affairs is indeed appalling, and a solution of this particular problem would contribute largely towards establishing a solution of the whole farm labour problem. The Cost of Living Report embodied in its remedies a partial solution, but, unfortunately, our politicians have not yet comprehended the vast wealth of information on social problems contained in that valuable Report, and the suggestions have been carried out only in part, if at all. Of fundamental importance in the solution of the problem are

(1) The provision of small holdings sufficiently large to enable the holder and his family to live independent of outside employment.

(2) The extension of village settlements in proximity to towns, always on the understanding that these offer pleasures of the higher and ennobling type.

(3) The extension of the scheme for the erection and maintenance of workers' dwellings by the State to include country districts, with the provision that there should be some discrimination in rents, those for rural districts being lower than those for urban districts.

(4) The encouragement of country settlers by the Government offering better facilities in the country for communication and transportation, including telephone services, railway facilities, and good roads.

(5) Lastly, the Commission recommends that the Government should give country settlers every facility for obtaining maternity nurses, as, undoubtedly, such a provision would materially aid in making rural life more desirable, and rural industries more efficient.

(e) The Importance of the Labour Problem. - The discussion on labour supply has here, as in Chapter 
IV., been pursued in detail, because I am forced to believe that in its scarcity and comparative inefficiency lies a very serious obstacle, though by no means the only one, preventing further progress in the wheat industry, and diverting much land from purely agricultural pursuits to pastoral and dairy farming. If any disproportionate digression has been made, it is to be hoped that this in itself will result in attracting greater atten. tion to the gravity of the situation caused by the present state of our farm labour supply, and in assigning to the problem an importance adequate to the grave economic consequences which will follow, unless it is seriously studied. Indeed, it is surprising that many farmers should so easily have given up the problem in disgust as insoluble at present. Of course, while one hears it commonly asserted among farmers that the labour problem is the fundamental cause of the present transition from wheat growing to pastoral pursuits, this opinion must be accepted very cautiously. The real position is probably that lack of labour has accelerated the tendency towards sheep farming, and even pushed the movement further than it would otherwise have gone. The relative degree of profit, over and above cost of production, obtainable from agricultural and pastoral farming, is the real cause of the transition; but this transition is not likely to be completed in the wheat producing area on account of the operation of a third cause-the relatively high rate of profit arising from mixed farming. For these reasons, the greatest precautions must be observed in analysing the results of the inadequacy of the labour supply, both in numbers and efficiency. The most recent tendency in farming in Canterbury is the rise of mixed farming, and this requires, probably, more labour than is forthcoming at present. 


\section{Capital.}

According to economic analysis, the third factor in production is capital. The industries least commonly associated with capitalistic production are the agricultural and pastoral ones. Closely connected with the conception "capitalistic production" is the factory system, or modern means of transportation, or the enormously increased use of machinery in the extractive industries. To the minds of many, the pursuit of agriculture still signifies the direct application of human labour to the soil, with little intervention of machinery. If this machinery is considered, it is subordinated to the other two factors.

Such a view obviously betrays incomplete observation. Many believe that all one needs to begin farming is a sum sufficient only for a deposit on the purchase of the land, which need only be a small fraction of the total capital value. Having obtained the land by this means, the fortunate individual can at once proceed on his way to riches with little thought of the necessary outlay.

That the absolute amount of capital required for manufacturing industries is greater than that required for agricultural industries, as such, the least observant would not deny. But what of the relative proportions of capital and labour in the two groups? The farmer employs but one or two labourers, while the "captain" of industry gathers together in one business, scores, hundreds, and even thousands. On this account the ratio of the amount paid in wages to the amount of capital required, it is not unreasonable to conclude, is greater in manufacturing industries than in the purely agricultural ones. In other words, the provision of capital to the farmer is a relatively greater problem than it is to the manufacturer. Such, then, being the case, it is a matter of paramount importance that in his quest for capital adequate for the most efficient pro- 
duction, the farmer should meet with as little difficulty as possible.

(a) Definition of Capital.-We now proceed to define the nature of the farmer's capital, to analyse it into two main divisions, fixed and eirculating, to discuss the facilities for obtaining capital, and finally, the methods of financing farmers.

Broadly speaking, capital may be regarded as all those things which yield an income. Under this definition capital "will include all things held for trade purposes, whether machinery, raw material, or finished goods, home farms and houses, but not furniture or clothes owned by those who use them." With this provisional definition we can roughly classify farmers' goods as capital and non-capital. Briefly, farm capital may be defined as that part of a farmer's goods which is used in the production of other goods. This will include all goods used in direct production, such as farm implements, as well as goods used in transportation and communication in so far as these affect production. For the purposes of estimating the cost of production of wheat* it will be advisable to classify farm capital as fixed or circulating. Fixed capital is that part of capital "which serves a purpose continually." It is comprised of such goods as are not consumed at their first employment. Circulating capital, on the other hand, serves its purpose but once, being consumed in its first use. The line of distinction between the two is not always clear, for certain goods, not consumed in their first use, are not sufficiently durable to be designated as fixed capital. Of more importance is the ratio of fixed to circulating capital. It is obvious that where relatively large quantities of capital have to be replaced year by year, that is where this ratio is small, cost of production

*See Chapter IX. 
will be high. Though much of farm capital is durable, there are a large number of goods which the farmer finds it necessary to renew annually, and thus his outlay on working capital is increased. It would be a difficult matter to arrive at a definite statement as to the actual outlay on capital; for the size of the holdings, the method of cropping, the general outlay of the farm, the system of farming pursued, all differ greatly in different communities, and even in the same community. The ratio of the amount paid in wages to the interest on fixed capital plus the amount spent in circulating capital is undoubtedly smaller in agriculture than it is in the manufacturing industries. This fact is often lost sight of in discussing the relation of the rural industries to the urban industries. It should be remembered that the smaller the above ratio is the greater is the total output per individual, and the more productive is an industry.

(b) Financing of Farmers. - But having arrived definitely at the conclusion that the necessary capital for farming is a relatively large sum, in logical sequence we must ask ourselves what facilities are found in the wheat growing area for the provision of this capital. Two main sources of credit are open to the farmer. These are "stock and station" firms, and the banks. The former are more enterprising in this matter than the latter. That such should be the case is not surprising; for the banks have call obligations which demand a more cautious policy than is the case with commercial firms. In consequence we find that the banks prefer to have as customers only those men who have considerable securities in land or buildings to offer as a basis for credit. Thus, a man who has the freehold of a considerable area can obtain at the bank a substantial overdraft as working capital; but on account of the nature of the security the banks do not make it a part of their 
general policy to grant such loans on an extensive scale. They prefer to give a farmer only temporary assistance on the understanding that in a season or two he will be in a position to cancel the overdraft. A departure from this conservative attitude is an infringement of the laws of good banking, as was well demonstrated during the optimism of the "seventies." The advent of several land and mortgage companies was threatening to deprive the banks of some of their commercial functions, and during the "seventies" a keen rivalry sprang up between the banks and the firms. The ultimate issue was that in the "eighties" many of our banks could almost be classed as land banks, with the disastrous results well known to those who remember the crisis of 1894, when the Government had to come to the assistance of the Bank of New Zealand. It is well that the banks have now realised the risk involved in granting credits too extensively on such non-liquid assets as land.

The pioneer work in providing capital for farmers is left to the enterprise of "finance and auctioneering" firms. While, from the point of view of waste of energy and labour, the competitive system is seen here, probably, at its worst, the total net result of the operation of these firms is distinctly beneficial to the community. An enterprising and efficient man, with comparatively little capital, has at his disposal the full confidence of the firm which supplies him with adequate working capital, provided he maintains his efficiency and enterprise. But at the same time the firm makes the stipulation that his produce shall be bought and sold through its agency, and thus the firm reaps a double gain. But in providing the young farmer with the necessary capital at the risk of losing a great part of it, the firm is performing an extremely useful function viewed from whatever standpoint. 


\section{Organisation.}

(a) Managing Capabilities Necessary in Farming.-So much, then, for the three agents of production, land, labour and capital. Let us now look into the way in which these three are gathered together in production by the average farmer. In other words, we are about to study the efficiency of the farmer as an organiser, who, because of his varying range of duties, should possess a relatively high degree of managing capabilities. In discussing the difficulties of large scale production in agriculture in Chapter VI., we have already seen that the problems of farm management require special skill and tact on the part of him who would undertake them.

The position of a farmer as a manager is a difficult one. Not only has he to study the technique of production and the grouping of capital and labour, but the commercial functions connected with his industry must also receive his attention. To perform these functions efficiently special qualities, other than those necessary for the management of production on the farm, are required. Much attention is being paid to the promotion of scientific farming by the Agricultural Department and the Experimental Farms, but steps should also be taken towards the wider dissemination of knowledge upon farm economics. That there is a lack of this knowledge has been demonstrated recently in popular discussions on the rural industries, consequent upon the action of the Government in fixing the prices of certain products. It is evident from these discussions that the possession of knowledge of even the elements of agricultural economics is a rare quality. While it is necessary to encourage further the development of scientific farming, the Government should establish some really reliable source of 
information on farm economics. But in order to illustrate the nature and ability of our farmers as organisers a close study of general farming methods is necessary. Two main topies suggest themselves-first, the methods of cropping, including a consideration of the general working of the farm; and secondly, the general outlay of farms, including a discussion on the inter-relation of the different pursuits to which the farmer diverts his attention, pastoral, dairying, or agriculture.

(b) Methods of Cropping. - So far as New Zealand is concerned, the days for the exploitation of the soil by continuous cropping are over. Happily, modern scientific farming is well in view, and even in some districts in actual operation. Perhaps the most important direct influence operating to produce this result is the Lincoln Experimental Farm in the centre of the wheat growing area. The dessimation of general agricultural knowledge is a primary consideration in the work of this institution, and it would be a great and beneficial step were the Government to endow a similar institution in South Canterbury, where the farmers could obtain first-hand knowledge of agriculture, and witness the application of the methods of scientific discovery to the cultivation of the soil.

Among indirect influences operating to stimulate "high" farming I would mention the growing exhaustion of the soil at the commencement of the last period, 1895. and more recently, the recognition of the supreme importance of pursuing mixed farming in New Zealand.

But, despite these influences, many are still blind to the benefits which have accrued in the agricultural world from scientific discovery and superior methods of management. These indeed persist in a policy which in the end must prove disastrous to both farmers and community. As long as new soils within a reasonable distance of the market are at the disposal of a community, 
these "exploiters" of the soil will be found. The United States has experienced the effects of such predatory cultivation. Canada and the Argentine are experiencing it to-day. New Zealand, too, has tasted the "bitters" and "sweets" of extensive cropping, but the rapid and serious fall in agricultural products in the early "nineties," the stimulus given to pastoral interests by the development of the frozen meat industry at the same time, and the dawn of more enlightened methods of farming came in time to counteract the effects of such predatory cultivation.

The result of this movement towards far-seeing and beneficial methods of cropping the soil can best be seen in the increased yield of wheat per acre during the past twenty years. This phenomenon of increasing yield is the result of two causes, the exact influence of each of which it is difficult to measure. The decrease in the area of production, by causing the margin to recede, has exerted considerable influence in this direction, but even so, the increase in yield has been so great, no less than 10 bushels per acre since 1893, that it is obvious there has been some other influence operating. This factor is summed up in the greatly improved methods of cultivation of the last two decades, notably in the case of Canterbury, where the area in acres has been reduced relatively less than in Otago. But Canterbury shows an absolute rise in yield, almost twice as great as the increase in yield for Otago, and for the past six years has shown a higher yield per acre than Otago, despite the fact that the latter province has a differential advantage from the point of view of soil fertility.

These observations then lead to the conclusion that farming methods have greatly improved of recent years, and it is unquestionable that New Zealand farming methods are relatively superior to those of any other new country, though they are undoubtedly surpassed 
by the extremely intensive culture of many European countries.

From the point of view of methods of cropping, the farmer must consider two questions:-

(1) The system of crop rotation which he considers the most advisable, and,

(2) The methods of cultivating the soil for each individual crop.

In a discussion of these questions it would be inadvisable to consider each individually, because they co-operate in such a manner to produce the common result that it is difficult to trace the operation of either in detail with any exactitude. Thus the intention to grow wheat after a root crop vitally affects the manner of cultivating the soil for that crop. Again, the fact that a particular crop has been grown on a field will have a considerable effect on the method of tilling the soil for a certain other crop. It is, therefore, most advisable to study both questions at once; and for this purpose I have obtained from leading farmers a statement of the methods they are accustomed to follow in this matter, a typical example of which is given below. This may be considered representative of the general community of "high" farmers of which this particular farmer is probably one of the leaders.

(c) A Rotation System. - The rotation extends over a period of seven years, during three of which the land is "lying" in grass. The rotation, together with the methods of cultivation for each crop, is as follows:-

First Year.-The land is "broken up" from the grass by light or "skim" ploughing in the early summer (November), and left in this state until March, when it is disced twice and then harrowed. In April it is ploughed, this time the ploughing being deep, after which, according to the nature of the season, it is harrowed or disced. The wheat crop is then sown in 
April, without manure, about 1 to $1 \frac{1}{2}$ bushels of seed per acre being used. The last operation is a rolling or harrowing of the crop in the spring according to growth. Harvest operations commence soon after the New Year, being followed along the course already noticed in Chapter IV.

Second Year.-Immediately after harvest the land is fallowed, after which it is subjected to various forms of cultivation by discing, cultivating, or harrowing. In April again the land is deep-ploughed, and the same system of cultivation follows as was pursued in the first year.

Third Year.-After the second wheat crop has been harvested, the land is once more ploughed and left in this state over the winter. Ploughing, it may be mentioned, in this case does not occur until early winter. During the summer the land is thoroughly cleaned, and in December a root crop is sown with manure. The crop provides excellent winter feed for sheep, and is eaten off by July.

Fourth Year. - Immediately the land is free it is ploughed again, and after a short period of cultivation is sown in oats with grass. The crop is harvested at the usual time, and then the land is left in grass for some three years, after which it is again cultivated and devoted to the same system of cultivation as before.

This system of farming undoubtedly produces good results; for, during the years 1905-14 the yield per acre for the whole farm has never been less than 37 bushels per acre, and has been as high as 53 .

Such an intelligent and far-seeing system of cultivation is not prevalent throughout the whole producing area; if it were, our efficiency as producers of wheat would be increased greatly. The general tendency, however, is towards such rotation systems with careful cultivation of the land for each crop. In so far as New Zealand 
farmers have attained such a high standard, their efficiency in organisation must be regarded as relatively high.

(d) General Lay-out of Farms.-A question of organisation connected closely with the problem of combining a good rotation of crops with efficient methods of cultivation, arises from the problem of "laying out" the farm in such a manner as to obtain the maximum of efficiency in production. Under this particular line of investigation a consideration of the whole question of mixed farming is strictly relevant, as well as a general discussion on matters such as the most convenient size and shape of fields, the relative position of the fields, the site of the homestead, implement sheds, stables, grain stores, etc., the provision of an adequate water supply and the whole question of irrigation or distribution.

In pursuing any one line of action, the farmer is guided by the consideration of the relative degrees of profit which the various pursuits offer. Consciously or otherwise, it is this principle of "substituting" a higher profit for a lower one, of so distributing his energy that he obtains equi-marginal returns, that guides the farmer in his choice of occupation. The recent transition from agriculture to pastoral farming affords certain phenomena undoubtedly confirmatory of the economic law of substitution. Irrespective of what reasons farmers offer for their change in attitude towards agriculture, there still remains the fact that the predominant motive in the economic world is that of self-interest, widely interpreted. Individuals pursue that line of occupation which offers the greatest relative advantages, and obviously farmers would not be partially giving up wheat growing, were it not for the fact that pastoral farming still affords a relatively higher profit.

But New Zealand of comparatively recent years has developed a great industry, the inception of which 
relieved the most serious effects of the greatest depression the country has ever passed through, and was instrumental in changing the whole aspect of rural life. Prior to this, two lines of policy were open to the farmer. He had to be either a cultivator, or a pastoralist herding relatively few sheep for the sake of their wool. Now, however, there is a middle course. It is expedient and often necessary to combine these two formerly separate lines of action into one, now that the freezing industry is established. Thus arose the system of "mixed farm. ing,' under which pastoral and agricultural pursuits are carried on together. The relative advantages of this system have been discussed in Chapter III., and mentioned in other parts of this work; but an interesting line of discussion from the point of view of organisation at once suggests itself.

Under this system the farmer's interests are two-fold; he is combining two lines of action which are independent of each other, from the point of view of immediate profits, and yet are so connected that successful cooperation will greatly enhance profits on the whole. The question then arises, what principle controls the farmer in his attitude to these two lines of action? What factor, or set of factors, guides his choice of the relative extent to which he will follow out these lines of action?

The farmer, again consciously or otherwise, is being guided in his actions by certain economic forces, and is working in accordance with a principle which is an indirect deduction from the predominating economic force of self-interest. Each occupation will be pursued to the point to which any further energy spent in it will produce a relatively smaller rate of profit than that obtained by the last unit of energy spent in any other occupation. This is the principle of equi-marginal returns, and it is to this principle that we must look if we would 
answer the questions we have raised. The marginal rate of profit from agriculture will tend to be equal to the marginal rate of profit in pastoral farming, and according to the degree in which this tendency is realised so will the total profits from mixed farming approach a maximum. It is because the marginal rates of profits from the two occupations are relatively higher when they are carried on in conjunction, that mixed farming is tending to become the predominant feature of rural industries in those districts where formerly purely agricultural pursuits were in existence. 


\section{Chapter IX.}

\section{COST OF PRODUCTION.}

\section{A Controversial Question.}

An investigation into the present position of the wheat industry in New Zealand, of necessity involves an estimate of the cost of producing a crop. This estimate must be sufficiently accurate to enable us to draw a conclusion on the much discussed question, whether wheat growing in New Zealand is really a remunerative pursuit. In recent years there has been much discussion of this matter. Much public controversy has resulted, and the arguments revealed in this controversy have shown a lack of knowledge on the part of those who are directly concerned with the industry, and who should make it a matter of first importance to collect reliable information on the question. On the other hand, those who complain of a "dear loaf" have affirmed much but proved little. The farmer stoutly maintains that he is unable to produce wheat at a profit under present circumstances, and the miller sympathises with him mainly for the purpose of keeping up the import duty on wheat and flour, the abolition of which would, in his opinion, be most disastrous to the community at large, not to mention the shock it would give to his interests in the country. Equally unreasonable in his arguments is the average consumer, who sees the farming community prospering, and who fancies fabulous profits must fall to the farmer's lot from every field of wheat he grows. It is not expected that he should know what are the expenses incurred in producing a crop, but the producer himself should be held guilty of 
gross negligence if he has no accurate idea of what his yearly outlay is for each particular crop. The fact is that a great majority of our farmers keep only meagre records of receipts and expenditure. Among them are to be occasionally found some who can give a reliable estimate of the cost of producing a crop, but in the vast majority of cases the pursuit of such information is fruitless. It is a matter for regret that some sound system of farming accounts has not been adopted by the farming community generally.

The writer is well aware of the controversial nature of the problem of "Cost of Production" in relation to the wheat industry. The controversy which has led in recent times to an increasing number of public statements on the problem from a variety of sources, reveals all the faults and inconsistencies which characterise popular discussions on economic questions. Few, if any, of the participants in the discussion have attempted to envisage the problem at the outset, but most have chosen for their criticisms questions of minor importance, and even then they have not considered these in relation to the question as a whole.

\section{The Meaning of Cost of Production.}

It is necessary to state clearly what is meant by "cost of production," as the phrase will be used in this investigation. Professor Marshall defines cast of production of an article as follows:- "The exertions of all the different kinds of labour that are directly or indirectly involved in making it, together with the abstinences, or rather the waitings required for saving the capital used in making it: all these efforts and sacrifices together will be called the real cost of production of the commodity." "*

*Marshall's "Principles of Economics." Page 339. Sixth edition. 
Such is the comprehensive idea of cost of production, but, as it stands, it is of little direct avail for the purposes of making our estimates. It will be well to remember, however, that such is the idea with which we start. These various efforts and sacrifices will find a suitable measure in the money which has to be paid for them, and this will constitute the money cost of production, or the expenses of production. These expenses will differ on different farms, some farmers being able to produce at a lower cost per unit than others. Account must be taken of this fact, and in the case of a commodity such as wheat, which obeys the law of decreasing returns, the expenses of production are best estimated with reference to the "margin of production," for it is here that the amount which can be produced is determined. For our purposes, however, the margin is not at present situated among vastly inferior soils, where great differences in yield are noticeable. It is methods of production which bring about such widely differing yields more than differences in soil fertility, because with a relatively small area of production there are still large tracts of fertile land open to the farmer. With sufficient regard for these difficulties an attempt will be made in the succeeding section to summarise the chief factors which enter into the cost of production of wheat in New Zealand. Actual statistics so far as they are available will be used for the purpose of setting out some fairly reliable estimate. Such an estimate will doubtless be open to correction, but it is given after a careful observation of the wheat industry for some time, and as a result of an investigation into the actual conditions. The recent extraordinary conditions created by the general rise in prices are not to be considered as relevant to the discussion, only pre-war conditions being considered. 


\section{Rent.}

Remembering, then, that expenses of production are to be taken as the money costs of the various efforts and sacrifices which are required in making the commodity, an analysis of the various costs to be taken into account in estimating cost of production can be considered. Not only must the costs of "putting the crop in" and "harvesting" it be accounted for, but all subsidiary costs such as transportation, distribution, and marketing must receive consideration. Perhaps the most frequently misrepresented item is rent, and this quite apart from the controversy over the length of time for which rent must be calculated. A lengthy analysis of the conception "economic rent" is not necessary here, but it may be stated briefly in order that no misunderstanding will arise in regard to the position taken up.

Economic rent in regard to land means the surplus produce of any tract over and above that of the least productive soil, which pays no economic rent, and produces for the same market. It is a payment for a differential advantage, and in regard to land this differential advantage is superior fertility or greater proximity to the market, or a combination of these.* Now, it is important to notice that rent is a phenomenon of price but not a cause of high price. This can be established by considering the origin of economic rent in the superiority of certain soils over others in fertility or proximity to the market. A higher price will always bring into production inferior soils, and thus the rent on the other groups will rise. It is quite clear that this is a result of the high price and not a cause of it. The statement that the high price of land renders wheat growing unprofitable is misleading because of this. What is the cause of this high price? Surely one of the most important factors in recent years is the extra-

*For an analysis of economic rent the reader is referred to a text-book on "Economies" by Marshall, Taussig, or Chapman. 
ordinary rise in the prices of primary produce. At the same time there are reliable indications that better methods of farming have increased the fertility of the soil, but this operates to produce the same result as the high prices of produce - namely, a greater return per acre from the land. We thus arrive at the conclusion that, broadly speaking, the price of land is determined by the return which it is expected to yield-a conclusion so obvious that it is almost unnecessary to dwell upon it. But what is to be said to those who attribute the supposed loss on wheat growing to rising land values, when these values are themselves a result of the rise in the prices of primary produce, including wheat? In so far as the rise in pastoral and dairy products have brought about the increases in land values, the contention may be correct. But wheat lands have also risen in value, and in view of this it is not wholly consistent to claim this rise as a cause rendering the pursuit of the industry unprofitable. While this idea is repudiated, it must not be thought that the price of land does not enter into cost of production. This is in no way inconsistent. Obviously rent is a factor in estimating the cost of production, but this does not mean that high rents cause high prices. High rents are largely the result of high prices.

We are now in a position to undertake an analysis of the rent of land as that term is customarily understood. The full rent of a farm in New Zealand, or in any country, with the possible exception of those which are only in the embryo stages of their development, is made up of three elements. The first is due to the natural inherent value of the soil, or the "natural and indestructible powers of the soil." The second element arises from improvements made on it by man, and is in reality interest on capital invested. Very often most important of all is the third element, which is the result of the growth of a dense and rich population, of the progress 
of facilities for communication, and the general prosperity which is a resultant of this. These three elements together constitute rent as that word is used in current speech. The departure from this use of so common a term would give rise only to confusion, and therefore we accept the current use. From this point of view rent in part must be included in our estimate of cost of production-in fact, it is a very vital part of it; for in New Zealand the price of land has reached a relatively high level, and the farmer, desirous of obtaining land near a large centre, finds this a serious obstacle to overcome. With highly improved land as dear as $£ 40$ per acre, and very often dearer, it is at once obvious that not a little of gross receipts goes in the form of rent.*

\section{The Difficulties of the Problem.}

Having cleared up these initial difficulties, we are ready now to proceed directly with our investigation. But before doing so, it will be well to point out a few of the difficulties which will be encountered, and which will probably affect our result, though not wholly destroy its efficacy for the purpose for which it is being devised.

In the first place, there is the obstacle arising from the lack of reliable data-not an uncommon obstacle in

*This high price is due to several factors, all of which tend to augment rent as that term is used in current language. In the first place, there is the payment for capital invested in improvements, an element which is of great importance in New Zealand. Secondly, there is the increase in value due to general progress in communication and transportation facilities, and the increase of population, which gives to good lands a scarcity value. Thirdly, the anticipation of profit from a given line of action increases the price of land, and rent often includes interest on the additional capital invested in the land on this account. Finally, all super-marginal lands have a high value owing to differential advantages in production, due to either superior fertility or more convenient situation. This gives rise to pure economic rent, which, while entering into price, is itself governed by conditions which determine price, and is really a phenomenon of high price. 
economic investigations, and one very often surmounted by the use of an ingenious device. Unfortunately, the scope for such a device is also lacking here, and wholly reliable estimates can be made only when sufficient data are forthcoming. The difficulty has been partly overcome by the use of detailed information from certain "representative" farms, but, as we shall see, even this presents somewhat formidable difficulties.

But an even greater disadvantage under which we are labouring arises from the fact that the interests of the New Zealand farmer in the vast majority of cases lie in at least two directions. His policy must be to distribute his time and labour in such a manner over two occupations-agricultural and pastoral pursuitsand sometimes even three-that he obtains the maximum profit on his total capital. These pursuits are so related that it is a matter of great difficulty -in fact, almost an impossibility-to discover a clear line of demarcation between them. With farming accounts as they are we must leave the problem unsolved. But even were we able to discriminate in any individual year, such a discrimination would be useless over a long period, for we have already comprehended the nature of the influence of mixed farming. The pursuit of agriculture fosters the pastoral industries, while these in their turn influence greatly the degree to which our land is suitable for wheat production. For the permanent existence of one, the other is almost a necessity, in a district such as the wheat growing area of New Zealand." Now, this consideration further complicates the attempt to estimate the cost of production of a wheat crop. In the first place, much labour spent directly in producing wheat goes to augment

*For an account of the connection between agricultural and pastoral pursuits see the article in the Journal of the Canterbury Agricultural and Pastoral Association (1914, page 10), by Mr. Alexander, Director of the Canterbury Agricultural College. 
receipts from other pursuits, and the opposite is equally true; and, secondly, the total receipts are the joint result of the several pursuits, and therefore the question of the degree of profit which is obtained from an individual pursuit, does not resolve itself into a matter of isolating that pursuit, if, indeed, isolation were possible. The receipts from wheat production alone may apparently be less than the direct expenditure on that crop, and yet it is quite possible that the farmer will find wheat growing a remunerative pursuit; for this occupation fosters efficiency in the pastoral industries. We, therefore, see that the system of mixed farming complicates our problem greatly, the true solution of which lies in the collection of data over the whole field of farming occupations.

A third great difficulty presents itself in the lack of time for a comprehensive investigation. Expenditure cannot be estimated for an individual year. The farmer spends much one year in the anticipation of reaping the benefit at some future date, often spread over years. On the other hand, the growth of certain weeds or the prevalence of pests may incur expenditure in an individual year which would be unnecessary at ordinary times. The expenditure should be calculated over a series of years, at least four in accordance with our rotation system, and even then a considerable part of the total expenses is devoted only indirectly to wheat production.*

*There is no unanimity of opinion among wheat growers as to whether wheat production has resulted in a net profit over the past, say, 10 years. Some declare that the result has been quite satisfactory, while others are of the opinion that they have been growing wheat at a loss for many years. Strangely enough, in spite of the alluring prospects which pastoral farming offers, many of the latter class have continued to grow wheat. But our debt to them is great, and this will probably become more evident as time reveals the actual shortage of wheat in the world as a result of the ravages of war. 
Another difficulty arises from the fact that the varying nature of the soil in different localities together with transportation and other differences gives rise to varying costs of production. Many critics consider this difficulty as almost unsurmountable, and it is put forward as a strong reason why no fixed price should be stated, just as if this varying cost of production was itself a factor in the determination of prices in the immediate future. What, it may be asked, has been the pasition of producers in the past when at any one time there has been approximately one price in all markets of the country, irrespective of the varying casts of production?

\section{Previous Work in Estimating Cost of Production.}

Very little reliable work has been done in this matter up to the present, although many farmers are ready to make a hazardous guess at the question, and to maintain with vehemence that it is unprofitable to produce and sell at less than $5 \mathrm{~s}$. or even $6 \mathrm{~s}$. per bushel. The New Zealand Farmer, a stock and station journal, in a recent issue,* arrives at this conclusion, in a discussion of the question of the fixation of price by the Government soon after the outbreak of war. But such estimates cannot be regarded as truly representative, and in reality are only speculative and with no absolutely reliable foundations.

Two estimates of interest, however, have been brought under notice. These estimates are the result of widespread experience, but they do not rest on a detailed investigation over a series of years. Moreover, the method employed is to isolate the pursuit of wheat production from other pursuits, and argue from this alone, irrespective of the influence of occupations other

*November, 1914. This was before the high prices of war conditions were operative in raising the cost of production, as is commonly alleged now. 
than mere wheat production. The estimates will be given here, and then the merits and demerits of each can be considered. Suffice it to say that both estimates were compiled by men experienced in farming and farm accounts.

In the following table I set out the two estimates of the cost of production of an acre of wheat in North Canterbury:-

TABLE XXXIII.

COST OF PRODUCTION.

Estimate I.

Skim ploughing

Harrowing

Two grubbings

Deep-ploughing

Harrowing ...

Drilling

Harrowing .

Rolling

Harrowing . .

Manure

Seed

Reaping

Twine

Stooking and stacking

Threshing, straw stacking, sack covering

Carting (two miles) ..

Fence training, etc. ..

Breakages etc.

Rent, or interest on land worth $£ 30$ per acre

Road rates and water rates ..

Sewing twine, and loss on sacks

Loss through death of horses

Repairs to buildings, etc. ..

Per acre.

$£$ s. d.

. 050

. 0010

.. $\quad 0 \quad 4 \quad 0$

.. 0069

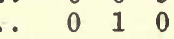

.. $\quad 019$

.. 0110

.. 0010

$\begin{array}{llll}\text {.. } & 0 & 1 & 0\end{array}$

$\begin{array}{llll}\cdots & 0 & 5 & 0\end{array}$

$\begin{array}{llll}. & 0 & 6 & 9\end{array}$

. 039

.. 020

. 070

$\begin{array}{llll}\text {.. } & 0 & 12 & 5\end{array}$

$\begin{array}{llrr}\cdots & 0 & 3 & 0\end{array}$

. 016

. 016

$\begin{array}{llll}\text {.. } & 1 & 10 & 0\end{array}$

$\begin{array}{llll}\text {.. } & 0 & 1 & 6\end{array}$

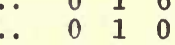

.. 020

. 016

Total cost ..

£5 $\quad 1 \quad 5$

Cost per bushel*

$\begin{array}{lll}0 & 3 & 8\end{array}$

*The number of bushels per acre was taken as 38 , but according to the compiler, as the farmer once in five years has a complete loss through adverse weather conditions, pests, etc., tive average is brought down to 30 bushels per acre. 
TABLE XXXIV.

COST OF PRODUCTION.

Estimate II.

Per acre.

\& s. d. \& s. d.

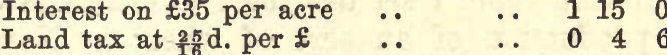

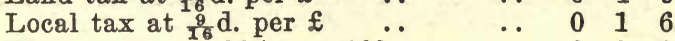

Water rates at $30 \%$ per 100 acres .. 000004

$\begin{array}{llllll}\text { Total rents and taxes... } & \ldots & 2 & 1 & 4\end{array}$

Add $5 \%$ for land occupied by buildings, gardens, hedges, etc.

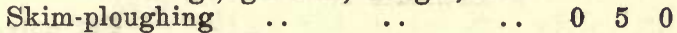

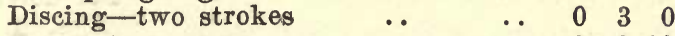

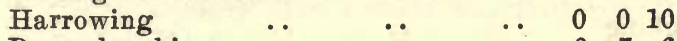

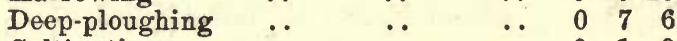

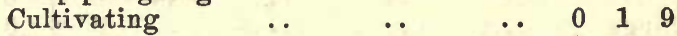

$\begin{array}{lllllll}\text { Harrowing } & \ldots & \ldots & \ldots & 0 & 0 & 10\end{array}$

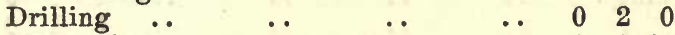

$\begin{array}{lllllll}\text { Harrowing } & \ldots & \ldots & \ldots & 0 & 0 & 10\end{array}$

Seed, $1 \frac{1}{2}$ bush. at $4 /$ per bus. $\quad \ldots \quad 0060$

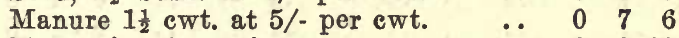

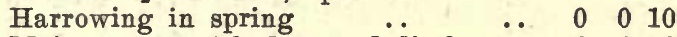

Maintenance of hedges and ditches ..

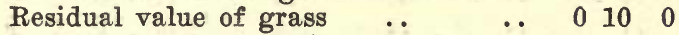

$\begin{array}{lllll}\text { Total cost of putting crop in } & \ldots & 2 & 7 & 1\end{array}$

Cutting, stooking, and stacking $\quad \ldots \quad 0 \quad 13 \quad 0$

Threshing at $3 \mathrm{~d}$. per bush. on 45 bush. $\quad \begin{array}{llll}0 & 11 & 3\end{array}$

Carting at 1d. per bush. on 45 bush. $0 \begin{array}{lll}0 & 3 & 9\end{array}$

Bags at 1d. each net cost .. $\quad \ldots \begin{array}{llll} & 0 & 1 & 2\end{array}$

Total expenses of taking crop off

Total cost per acre .. ..

\begin{tabular}{rrr}
1 & 9 & 2 \\
\hline$£ 5$ & 19 & 6 \\
\hline 0 & 2 & 8
\end{tabular}

Cost per bus. (45 bus. per ac. yield)

$\begin{array}{lll}0 & 1 & 11\end{array}$

These estimates have much in common, and little need be said of individual items. During the last decade the average price of wheat has been about 3s. 11d. per bushel, and hence, according to the first estimate, the profit is only $3 d$. per bushel, while the profit on the second estimate is as high as 1s. $3 d$. per bushel. It must be noted that the specific lands to which these estimates refer, lie close together, and both areas are well adapted to 
wheat production. The average yield per acre for the whole of New Zealand for the last decade has been a little over 30 bushels per acre, and on these lands where cultivation is so intense, there is no doubt but that the yield is considerably higher than this average.

By careful husbandry, the Canterbury Agricultural College farm has yielded an annual average of about 45 bushels per acre over the past eleven years, taking into consideration the last two-1916 and 1917-exceptionally bad years. Dr. Hilgendorf's estimate of 2s. $8 \mathrm{~d}$. per bushel is thus fairly reliable as far as the College farm is concerned, for farmers frequently stated, until quite recently, (and many affirm it now), that $£ 6$ per acre is sufficient to produce a crop of wheat. The position assumed in Estimate $I$. in regard to the average yield per acre does not appear to meet the facts of the case. It is very unlikely that a farmer will suffer a dead loss once in five years, and consequently the yield per acre is unduly lowered. If it is stated that the average yield per acre is 38 bushels, it means that this is the result over a number of years considering good and bad. The compilation of cost per acre itself is not unreasonable, though, as stated above, an estimate which is compiled by means of considering the absolute cost of each item does not appear to me to be reliable. If it be argued that the items mentioned are lower than contract rates, it must be remembered that the contractor expects to reap a profit from his operations, and that the farmer's profit comes from the return obtained from the crop after expenses have been deducted. Allowing for the fact that additional costs arising from taxation be added to the total given in Estimate I., the cost per bushel given is probably too high when a higher yield per acre is considered.

Statistics of cost of production in Australia are not irrelevant, and will perhaps throw some light on the 
problem. In the Agricultural Gazette for New South Wales of November 2nd, 1914, the cost of growing wheat and harvesting it by methods similar to those of New Zealand (though less intensive), is estimated at $£ 35 \mathrm{~s}$. per acre. The items are as follows:

TABLE XXXV.

COST OF PRODUCTION.

Estimate III.

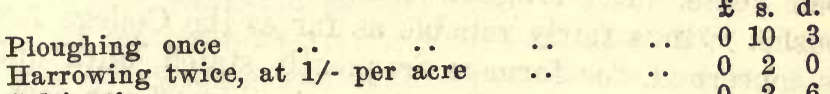

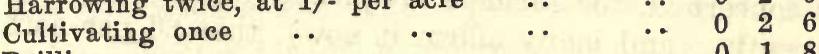

$\begin{array}{lllllllll}\text { Drilling } & \ldots & \ldots & \ldots & \ldots & \ldots & 0 & 1 & 8\end{array}$

Seed, 60 lbs. per acre, at 5/- per bush... $\quad \ldots .00050$

Superphosphate, $\frac{1}{2}$ ewt., at $5 /$ - per ewt. $\quad \ldots \quad 0026$

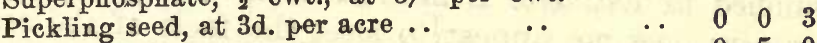

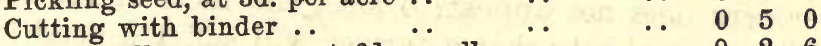

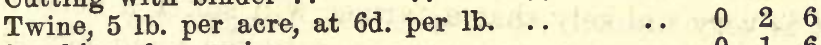

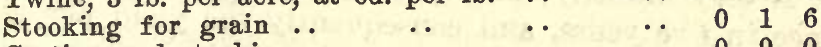

$\begin{array}{lllllll}\text { Carting and stacking } & \ldots & \ldots & \ldots & 0 & 9 & 0\end{array}$

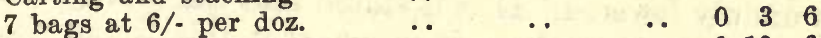

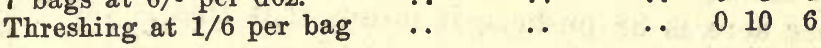

Total cost of growing and harvesting .. $\begin{array}{lll}16 & 2\end{array}$

Rent, one year

Cartage to rail., 20 bush. at $\ddot{2}$ did. per bush. $\quad \ldots \quad 000$

Total

.. $\quad £ 3 \quad 511$

Yield per acre, 20 bushels.

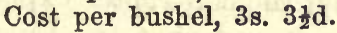

But the most reliable estimate under notice at present is one recently made at the Central Research Farm, Werribee, Victoria. An excellent account of this is given in two articles in the Victorian Journal of Agriculture, in the numbers for July, 1915, and May, 1916. Details are not given here, but it is sufficient to say that the operations are quite similar to those undertaken in New Zealand, and that the most careful account has been 
taken of every element of cost. The previous history of the land and the nature of the soil did not in any way operate to cause extraordinary conditions and thus to nullify the experiment. A field of 345 acres was taken, and of this amount 12 acres were cut for hay, and 24 acres of special varieties were harvested by stripping and winnowing. We are thus concerned with the remaining 309 acres. The method adopted is commendable, because each item of cost was calculated as the operation was performed, and there was thus no uncertainty about the result. The total cost of the crop per acre was £3 12s., deducting the cost of pressing and carting the straw. Thus the cost is comparable with conditions in New Zealand. The total yield was 7,171 bushels of "firsts" and 683 bushels of "seconds," which may be reduced to about 400 bushels because their value is assumed to be about two-thirds that of the firsts." We may thus place the yield at about 7,500 bushels, or an average yield per acre of 26 bushels. The actual cost per bushel was thus 2s. $91 \mathrm{~d}$. The only important consideration which rendered this figure slightly abnormal was the fact that harvesting operations were carried on at a time of high prices due to war increases. A table of normal costs is also shown, and the cost of production per bushel comes to $2 \mathrm{~s}$. $7 \frac{1}{4} \mathrm{~d}$. With wheat selling at 3s. 4d. for "firsts," and 2s. 9d. for "seconds," a profit of about $£ 1$ per acre is possible with this cost. The article concludes, "It will be seen that a wheat farmer who exercises ordinary care and economy and who attends consistently to the thorough cultivation of his soil, liberal manuring of the crop, and judicious selection of his seed, can assure himself of a good return on his capital and industry in a normal season."

Now, it is not claimed that the average cost of pro-

*As a matter of fact the "firsts" were sold at $4 / 9$, and the "seconds" at $4 /$. . 
duction in New Zealand is as low as the figure arrived at by this Australian experiment, but there is a very considerable discrepancy between this estimate and current statements of costs. Even supposing that taxes and rents are higher in New Zealand than in Australia, the average yield per acre is also higher." It is obvious that there is some error in present estimates for New Zealand, which frequently run as high as $5 \mathrm{~s}$. to $6 \mathrm{~s}$. The writer obtained a number of estimated costs of production from leading wheat producers in the Dominion, in the autumn of 1915, and in only one case (where the estimate per acre was given), did the cost stated exceed $£ 5$. The average of the estimates was about $£ 45 \mathrm{~s}$. In a few cases $4 \mathrm{~s}$. per bushel was considered a fair price. At 30 bushels per acre this would involve a cost of $£ 6$ per acre, and where the yield is 30 bushels per acre it is difficult to arrive at a much higher cost. In normal times the cost per acre is generally lower for areas in which the yield falls below 30 bushels per acre.

\section{The Presentation of Data from "Representative" Farms.}

The last stage of the investigation is the presentation of the data collected from three "representative" farms. These data are open to the serious objections mentioned above, in that we cannot isolate wheat production from other rural pursuits, and that sufficient time has not been available for the comprehensiveness of the estimate. The farms, however, may be considered as representative, and the costs fair average costs for an individual year.

The plan adopted in the estimates given here has been to obtain from certain farmers a statement of their actual receipts and expenditure in the production of a crop on

*Though conditions in Australia and New Zealand differ greatly, on the whole there was remarkable similarity between the conditions under which the above mentioned cost was obtained and the general conditions in New Zealand. 
a particular field. The total expenditure has been divided into three main groups as far as possible. These are payments arising from the use of land; the employment of capital; and the hire of labour and the necessity for managing capabilities. A fourth group of miscellaneous factors is necessary, for it is difficult in some cases to assign any particular item to any of the four main groups, the most noteworthy example being that of threshing.

The farms from which the estimates are made are certainly representative, in that their areas lie within the range of 250 to 400 acres; the two pursuits, agricultural and pastoral, are followed, and as will be seen from a more detailed study, the methods of cultivation are typical of the average farmer. In respect of the quality of the land, and the distance from the railway station, they differ greatly, a difference which makes the estimates all the more representative of the whole area. We shall call the farms A, B, and C, A being situated in North Canterbury, within a mile of the railway station, and B and C being situated in South Canterbury, six and ten miles respectively from a railway station. A is composed of land of first-class quality for the wheat. producing area of New Zealand; the land of $B$ is of good quality, but relative to $\mathrm{A}$, is inferior, occupying a position slightly above second-class land. The structures of these two soils are different, in that the former is loose and very easy to cultivate, while the latter is of a heavy nature, much more difficulty being experienced in culivation. $\mathrm{C}$ is composed of fair average secondquality land, with about $3 \frac{1}{2}$ inches of good black soil, and a very hard clay as subsoil. It is inferior to B both in fertility and the ease with which tillage operations can be performed, but the difference of quality between $\mathrm{C}$ and $\mathrm{B}$ is not so great as that between $\mathrm{B}$ and $\mathrm{A}$. The estimated values per acre of $\mathrm{A}, \mathrm{B}$, and $\mathrm{C}$ respectively 
are $£ 30, £ 18$, and $£ 13$. No doubt $\mathrm{A}$ has a large situational value accruing from its position close to the railway station, and in the centre of a prosperous community, but a great part of the excess in the price of $\mathbf{A}$ is due to the superior quality of the land.

The following table shows the total cost of production in the three cases of a crop of wheat in a particular field. The size of the areas in the case of $\mathrm{A}$ is 30 acres, while that for $\mathrm{B}$ and $\mathrm{C}$ is 60 acres. The estimates are calculated directly from the actual costs supplied by the individual farmers who have kept a careful record of expenditure.

\section{TABLE XXXVI.}

COST OF PRODUCTION ON THREE REPRESENTATIVE FARMS.

SIZE OF AREA

1. RENT OF LAND

2. WAGES:-

Labour

Manager's wages Total

3. OAPITAL :-

a) Fixed :

(b) Circulating :

Horse-feed

Manure ...

Seed ...

Sacks ....

Twine ...

Extras ...

Total

4. MISCELLANEOUS :-

(1) Up-keep hedges, ditches, eto.

(2) Threshing ...

Total

\section{TOTAL COSTS}

Cost per acre

Yield in bushels

Yield per acre

Cost per bushel
A.

30 Ácres

\& s. d.

4500

\begin{tabular}{rrrr}
$\ldots$ & 12 & 10 & 0 \\
$\cdots$ & 43 & 10 & 0 \\
$\cdots$ & 56 & 0 & 0 \\
\hline
\end{tabular}

$\begin{array}{lll}12 & 0 & 0\end{array}$

$\begin{array}{llll}\ldots & 10 \quad 8 & 0\end{array}$

... $\quad 10 \quad 0 \quad 0$

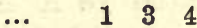

$\begin{array}{lll}1 & 12 & 0\end{array}$

$\begin{array}{lll}0 & 2 & 6\end{array}$

$\begin{array}{llll}23 & 5 & 10\end{array}$
B.

60 Acres

$£$ s. d.

$\begin{array}{lll}54 & 0 & 0\end{array}$

$4210 \quad 0$

\begin{tabular}{rrr}
43 & 10 & 0 \\
\hline 86 & 0 & 0
\end{tabular}

21190

$1513 \quad 4$

$\begin{array}{lll}47 & 19 & 6\end{array}$

$\begin{array}{lll}14 & 19 & 0\end{array}$

22100

250 .

4136

\begin{tabular}{rrr}
2 & 7 & 0 \\
\hline 94 & 14 & 0 \\
\hline
\end{tabular}

$\begin{array}{llll}\ldots & 2 & 0 & 0\end{array}$

$\begin{array}{llll}\text {... } & 13 \quad 12 \quad 0\end{array}$

... 15120

1511710

$5 \quad 13$

931

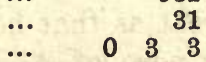

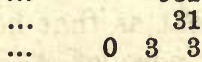

\section{$\begin{array}{lll}2 & 0 & 0\end{array}$ \\ \begin{tabular}{lll}
30 & 1 & 8 \\
\hline 32 & 1 & 8 \\
\hline \hline
\end{tabular} \\ $28814 \quad 8$}

4163

1805

30 $\begin{array}{lll}37 & 12 & 0\end{array}$

$\begin{array}{lll}13 & 10 & 0\end{array}$

$\begin{array}{lll}22 & 0 & 0\end{array}$

1100

4100

\begin{tabular}{rrr}
0 & 13 & 6 \\
\hline 79 & 15 & 6
\end{tabular} $\underline{9015}$

...

$\begin{array}{lll}2 & 0 & 0\end{array}$ \begin{tabular}{lll}
22 & 10 & 0 \\
\hline 24 & 10 & 0
\end{tabular}

250128

$\begin{array}{lll}4 & 3 & 6\end{array}$

1200

20

$\begin{array}{lll}0 & 4 & 2\end{array}$ 
The similarity noticeable in these tables is remarkable; but a few points of difference require explanation. Equally imperative is it that the basis of the calculation of each item should also be made clear.

The "rent" of the land is in reality: first, interest on capital invested in improvements; secondly, the economic rent; and a third element springing from the scarcity value of the land. This "rent" has been calculated by taking the interest on the capital value of the land, interest being at 5 per cent. It will be noticed that land $\mathrm{A}$ has the highest rent, and $\mathrm{C}$ the lowest.

The wages for labour are the actual amounts paid during the whole of the time during which labour was applied to the land for the specific purpose of "putting" in and harvesting the crop. The amount includes an estimate of the expenses incurred by the farmer in giving his labourers board and lodgings.

The wages for managing are calculated on a basis of £3 7s. 6d. per week during the whole year, and it is assumed that the management necessary for the production of the crop is equivalent to one-fourth of the management necessary for the whole farm. This proportion may appear too high, but it must be remembered that $£ 37 \mathrm{~s}$. 6d. per week is not a high estimate for managing capabilities.

The only item of fixed capital is interest on money invested in machinery. The value of the implements used in each case was earefully calculated, the prices being what the farmers paid for the implements. For such items as harness and general equipment a liberal estimate was made. Thus, harness for a four-horse team was reckoned at $£ 40$.

The total sum thus invested was calculated, and depreciation on the whole was taken at 10 per cent. That is, during ten years the whole of the farmer's stock is replenished. The total stock of implements thus held 
by the farmer for agricultural work was regarded as being used for the production of this particular crop, in relation to the total work on the farm to which it is put, in the proportion of 1 to 3 . It is evident that this estimate, if anything, is in error on the side of being too liberal, for while it is true that a small part of the total stock, such as the reaper and binder, is used for a few operations only, a great many items are devoted to a wide range of uses, such as horses, ploughs, drays, etc. Thus, the total fixed capital is in reality the simple interest at $3 \frac{1}{3}$ per cent. on the capital sum invested in implements.

The circulating capital is the actual amount paid for the various items which are required from year to year, such as horse-feed, twine, etc.

In the miscellaneous group are various items, the expenses of which cannot easily be divided into the several parts. Thus, threshing is paid for at a rate of a few pence per bushel; but an estimate of the amounts due to capital, fixed and circulating, and to wages, would necessitate an enquiry into threshing accounts.

\section{Observations on the Relative Costs.}

The items B and C are in agreement throughout, but the average production per acre for $B$ is more costly than that for C. Thus, both wages for labour and horsefeed are higher in amount, and interest on capital is also higher. Similarly, rent and all the items of circulating capital are higher for B. The chief reason for this is that the land in the case of B was tilled more intensively than that of $\mathrm{C}$, with the result that the increase of yield from $\mathrm{B}$ over that of $\mathrm{C}$ was higher than the difference in soil fertility would lead one to expect. On account of the higher yield, the cost per bushel is very much smaller in B than in C, and it is evident that the farmer of $B$ is adequately repaid for his intensive culture and careful husbandry. 
On A, production is relatively cheap, wages for labour and the cost of horse-feed being remarkably low. Cultivation is easy of accomplishment here, and the land is tilled intensively, which, together with high fertility, obviates the necessity of the use of manure. The yield of 30 bushels per acre is exceptional for this land, as it is not unlike the land at the Agricultural College from which an average yield of 45 bushels per acre is obtained. The low yield for this particular harvest was due to the detrimental effects of a very severe gale in October, while the crop was still only a few inches above the ground. "The wind swept the soil away from the roots of the crop," and consequently, "when the heads got filled, the straw fell down and a great quantity of it was not picked up by the reaper." Had it not been for the wind, the yield would have been 40 bushels per acre, according to the estimate of the farmer who produced it.

Production on land $\mathrm{C}$ is much more costly than that on land A or B, according to the estimate. The high cost of production on land $\mathrm{C}$, however, requires a few comments before we can draw conclusions from it. The cost per acre on land $\mathrm{C}$ is considerably lower than that for either of the other lands. But the great difference in yield per acre between lands $\mathrm{B}$ and $\mathrm{C}$ is only in part explained by this difference of cost per acre.

The valuations of the land are in the ratio of 13 to 18 ; but as B has a superior situational value, this ratio does not measure the difference in fertility. If we allow for the superior situational value of $\mathrm{B}$, then, according to estimated value of the two lands, their fertility would be in the ratio of about 13 to 16 . But the yields per acre are in the ratio of 2 to 3 , or 13 to $19 \frac{1}{2}$. Now, were farming methods equally efficient on both lands, since they are situated within an area where climatic conditions are very much alike, we should expect the ratio 
of the yields per acre to approximate closely to the ratio of the fertility of the land as measured by their prices per acre, after allowing for differences due to situation. The discrepancy between these ratios suggests that the efficiency of methods of farming is unequal in the two cases. The amount spent in cultivation, that is, the items wages and capital, differs by some $6 \mathrm{~s} .8 \mathrm{~d}$. per acre. This shows that degrees of the intensity of cultivation are not wholly in agreement, but the difference is not sufficient to explain the difference in yield. The real explanation is that in the one case there was much better administration of the cultivation, and, moreover, the observer is struck by the general superior efficiency of farmer B. Farmer $\mathrm{C}$ happens to be young and comparatively inexperienced, and his land has not yet had time to show the effects of good farming such as is the ease with B. In particular, land $\mathrm{C}$ was not ploughed until late autumn, and cultivation was proceeded with until seeding time without a break. Land B, however, was fallowed in the summer, and in this condition it remained for some three months until autumn, when cultivation for the crop was commenced. Obviously, other things being equal, we should expect a higher yield from the latter land.

The high cost of production in the case of $\mathrm{C}$ must be looked upon with the reservation, then, that better administration would yield a higher return. Be it noted that the same land has yielded 30 bushels per acre quite recently, and, generally speaking, crops here have been considerably above 20 bushels per acre.

\section{Cost of Production and Market Price.}

If any error has been made in making these estimates, it has undoubtedly fallen on the side of exaggerating the importance of expenditure. There is no necessity to consider this matter in detail, for a glance at the estimates themselves will show at once that such is the case. For 
example, with reference to stock, it is assumed that onethird of its use is devoted to producing this particular crop. Manager's wages are over-estimated, as is also horse-feed in two cases. But to be in error on this side is a matter of small consequence for our purposes.

An average of the three estimates is probably the best figure from which to draw conclusions. The simple arithmetic average is $3 \mathrm{~s} .6 \mathrm{~d}$. per bushel, but the weighted average is more important. Weighting according to the number of bushels the average is $3 \mathrm{~s}$. $5 \mathrm{~d}$. It is not that there is any actual case in which the cost of production is this amount, but the statement merely implies that the average cast of production is $3 \mathrm{~s}$. 5d. per bushel. Land $\mathrm{C}$ would be considered as marginal land, but the estimated cost of production here is too high on account of a relatively low yield in the particular year. On this a conservative estimate of the yield would be 24 bushels per acre, when the cost would be 3s. 6d. per bushel. Our investigations then lead us to the conclusion that the average marginal cost of production is $3 \mathrm{~s}$. $6 \mathrm{~d}$. per bushel. Now, since the average market price for the ten years 1904-13 was $3 \mathrm{~s}$. $7 \mathrm{~d}$., it is obvious that unless a higher price can be maintained, the margin of cultivation will not be extended further.

On the higher grade lands the cost of production is slightly above 3s., and very often below this amount. Price for the most part is quoted at the nearest railway station, and the purchaser bears the cost of carriage. This leaves a clear profit of some $6 \mathrm{~d}$. per bushel for most land above the margin.

\section{Conclusion.}

The consideration of the importance of these estimates in forecasting future tendencies in the wheat industry is left till the concluding chapter. It was for this purpose, primarily, that the investigation on these par- 
ticular lines was made, and the result thus far, when we take into account the lack of time and the scarcity of data, must be regarded as satisfactory. Comprehensiveness is not in any way claimed as an advantage of the investigation. Far from it. In fact, the work is open to some of the greatest objections to which statistical work is liable. The limited area which the investigation covers, and the shortness of the period for which it was made, are such fundamental disadvantages. But adequate support has already been given to the claim that the estimates possess the advantage of being representative.

The method employed in the work is certainly more accurate than that wherein certain estimated values are given to each operation in production. These are probably contractor's prices, but they have little or no equivalent in actual practice, for the contract system has become obsolete, and now farmers almost universally own all the implements and stock necessary for production. Much of this is kept for several other purposes besides wheat production, so that cost of production is lowered to a certain degree.

In the light of the various estimates which have been presented, what position must be taken up in regard to the question whether wheat growing is profitable or not? With pre-war prices it cannot be denied that the margin of profit was not large when the many difficulties which the producer experiences are considered. Such problems as the labour supply, satisfactory marketing, uncertainty of yield, probable losses of fertility, are rather formidable with even the most resourceful of producers. If the problem is considered relatively to pastoral farming, it must be admitted that the latter pursuit is much too alluring for the wheat farmer in the light of recent events. But it is very uncertain how far the transition from cereal growing to pastoral farming in Canterbury 
can be successfully developed, for there arises the important problem of ensuring sufficient and satisfactory pastures. The small farm on which mixed farming is practised offers a solution for the difficulty. At present, however, the farmer has awakened to the fact that sheepfarming or dairying, where it is possible, offers a greater return per unit with probably less actual labour and worry. It is becoming more and more evident that in the immediate future our wheat supply will be endangered by the allurements offered by pastoral pursuits, in spite of the fact that with current prices wheat production is not unremunerative. In view of these facts the writer has been forced to adopt the opinion that our attitude towards the wheat industry should be radically altered. To this we shall return in the concluding chapter.

Note.-After this chapter had gone to press, the results of an experiment carried out on the Leeston Soldiers' Settlement by the National Efficiency Board were brought under the notice of the writer. The following statement is an extract from "The Press"' (Christchurch) of May 6th, 1918:-

"With a view to throwing some light on the much-debated question of the cost of wheat growing, the Ellesmere County Committee of Advice to the National Efficiency Board recently asked the Lands Department for a return of the cost of wheat growing on the Leeston Soldiers' Settlement, formerly the property of Messrs. Holley Bros. The information sought has been furnished to the Committee by the Commissioner of Crown Lands, and by Mr. W. Holley, who acted as honorary supervisor. The area sown in wheat was 98 acres, and the yield averaged 27 bushels to the acre, which is considered to be at least two bushels above the Ellesmere district average for the season just concluded. The statement is as follows:- 


\section{EXPENDITURE.}

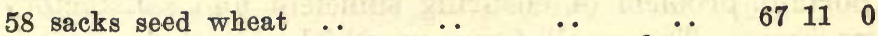

Ploughing, cultivating, and sowing crop, purchase

of wheat protector, eartage of seed wheat, and pickling of same.

Labour, cleaning creek, etc.

Spring rolling and harrowing .

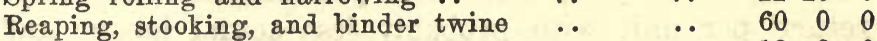

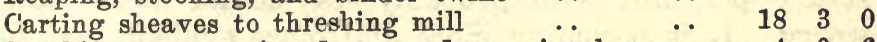

Stacking straw, tying down, and covering bags ... $\quad \begin{array}{llll}4 & 0 & 6\end{array}$

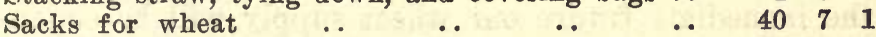

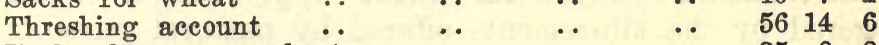

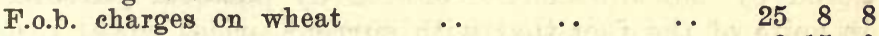

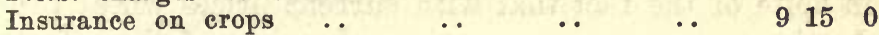

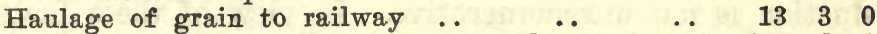

Government rent on 98 acres at 35s. 6d. per acre.. $\quad \begin{array}{rrrr}176 & 8 & 0\end{array}$

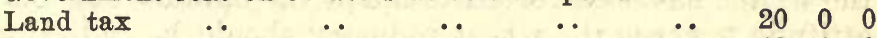

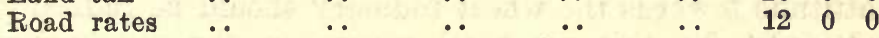

$\begin{array}{llllllll}\text { Profit } & \text {. } & \ldots & \ldots & \ldots & \ldots & 2021311\end{array}$

$£ 8331311$

RECEIPTS.

Sale of 2,426 bush. $50 \mathrm{lb}$. milling wheat, at $5 \mathrm{~s} .10 \mathrm{~d}$.

per bush. ... ... ...

Sale of 170 bush. $59 \mathrm{lb}$. seconds, at $5 \mathrm{~s}$. per bush.

Sale of 33 bush. $20 \mathrm{lb}$. seed wheat, at 5s. 10d. per

bush.

796 sacks at $10 \frac{1}{2} \mathrm{~d}$. each

6 straw stacks

5 per cent. rebate on Government rent ...
\&. d.

$70716 \quad 6$

421410

$914 \quad 6$

$3416 \quad 6$

$\begin{array}{lll}30 & 0 & 0\end{array}$

8116

$£ 8331311$

It should be stated that Mr. W. H. Jamieson gave the use of his implements and team of horses free of cost for a short time during the ploughing and eultivating operations."

The total cost of growing the crop was $£ 631$, and the total yield was 2,646 bushels. Thus, if all other receipts are excluded, the cost per bushel was about 4s. $9 \frac{1}{3} \mathrm{~d}$. This experiment was carried out under war conditions three years after the experiments in estimating costs which are given above. As general prices have risen considerably in this period, the results of this experiment can be considered to confirm the results obtained in this chapter. It is interesting to observe that the total outlay was £631, and the profits $£ 202$ 13s. 11d., showing a profit of over 32 per cent. 
Chapter $\mathrm{X}$.

\section{RELATED TOPICS.}

Before proceeding to summarise the results of the preceding chapters it is necessary to consider certain problems connected with the wheat industry and agriculture generally. These problems enter largely into the conclusions arrived at in the concluding chapter. This is the main plea for considering them here. But the nature and importance of the problems are not clearly understood by the general public. While the author hopes that the present discussion will arouse public attention to them he fully realises that they are all the objects of much controversy. But it is hoped that the treatment which follows will rise above mere controversy and party faction. Nothing but the keenest interest in the future of the rural industries of New Zealand prompts the writer to express opinions in regard to these problems. But ample reasons will be given for any such opinions. There are four main topics which require such consideration:-(1) The Flour Millers' Association, (2) The Farmers' Union, (3) The Policy of Protection in Relation to Agriculture, (4) The Public Control of Prices.

\section{The Flour Millers' Association.}

The report of the Cost of Living Commission of 1912 was strongly indicative of the fact that monopolies, 
combines, and trusts, either wholly or partially, were beginning to operate extensively in the commerce of New Zealand. "An isolated, highly protected, and sparsely populated country like New Zealand, so far distant from the world's markets, especially lends itself to the manipulations of trusts and combines. It is a comparatively easy matter for a few wealthy individuals in any given industry or business to secure control of the output, and by slightly raising prices, to levy taxation on the whole community."**

The object of combinations in New Zealand, as disclosed by the investigations made by this Commission, is not the elimination of the unnecessary expenses in the cost of manufacturing and distributing. These forms of combination are beneficial to the whole community from the improved services they would have rendered in many directions. But the operations of the combinations in New Zealand "have had an exactly opposite effect, for their avowed object is to corner supplies and increase prices to the detriment of the people." This does not imply condemnation of combination. The whole tendency of economic evolution is towards combination. Where traders combine to secure cheaper wholesale purchases or better transportation, combination is rather to be commended. A good instance of this is the cooperative movement.

(a) The Origin and Nature of the Flour Millers' Association.-The New Zealand Flour Millers' Association was instituted on March 1st, 1901, and in the preamble to the agreement which bound individual millers to the Association, the following quotation is illustrative of the alleged objects of the Association:"Whereas for many years the business of flour milling in New Zealand has been carried on practically without

${ }^{*}$ Cost of Living Report, Parliamentary Papers, 1912. H-18, page lxvi. 
profit, and very frequently at a loss, largely owing to heavy expenses of distribution in consequence of each mill-owner in the past having separately disposed of the product of his mill to buyers residing in various parts of the colony . . . . AND WHEREAS unless the cost of distribution is lessened

a large number of persons now engaged in the business will have to incur further heavy loss and ultimately retire from it, leaving it in the hands of those who are longest able to bear the loss resulting from the unsatisfactory condition of the trade, and other circumstances detrimental to manufacturers and consumers alike will follow. AND WHEREAS the system of sale and joint distribution by the form of agreement hereinafter contained, by which it is intended that each mill-owner shall supply to the said Association flour manufactured in his mill to the extent and on the terms hereinafter mentioned, will minimise the cost of distribution and largely tend to ameliorate the condition of the business and obviate the consequences before referred to, besides enabling the output of the mills to be sold at a less cast to the consumer than would otherwise ultimately be the case etc."

From this, it would appear that the Association had for its objective the combination of New Zealand millers for the purposes of minimising the commercial costs of the industry. Wheat was to be purchased by the central authorities of the Association, and parcelled out to the millers who would sell their flour through the central authority again. It will be noted that the individuality of each miller was to be retained, but he was subject to control by the central authority. The directors of the Association were to fix prices for flour according to "the cost of wheat, and the value of its by-products, and other matters that ought reasonably to be taken into consideration." The individual mills were 
to receive supplies of wheat in accordance with the "sack capacity" of the particular mill. We therefore see that everything was controlled by the directors of the Association, who formed a central board.

The Association thus, from a statement of its objects, bears a close resemblance to the modern development of combination in Germany. The analogous case is the German kartel, which is "commonly an elaborate organisation, public and formal, which fixes prices and prevents the members from competing with each other."* It has a central agency, to which orders go, and by which sales and prices are effected. So far, then, the objects and methods of the Association are in accord with the general aims and methods of the kartel. But the kartel has as its objective the limitation of output, and it is doubtful if the Millers' Association here has ever endeavoured to restrict the total output, though it has apportioned and controlled the output of individual mills. But it is difficult to determine whether or not such would have been attempted had the Association realised the anticipations of its promoters. The probabilities are that such would have been the case; for with an import duty on flour the flour-milling industry is sheltered, and the temptation to raise prices artificially would doubtless have been too great. This Association then must be classed in the same category as the kartel.

(b) The Operations of the Association.-At the time of foundation, out of a total of 40 mills in the Dominion. 30 had become incorporated in the combination. Soon after the number increased to 33 , but since that time it has dwindled somewhat, and now about half the milling strength of the Dominion, as tested by output, is outside the Association. This is due to two large mills, which have kept outside the Millers' Association, and succeeded in their struggle with it to

*Taussig, "Principles of Economics." Vol. II., page 423. 
obtain supplies of wheat. But this can best be studied after we notice its operation in the early stages of its existence.

At the instance of the late Mr. T. E. Taylor, M.P., Parliament authorised an enquiry, in 1903, into the nature and methods of the Association. It was then believed that the Association had become connected with the Master Bakers' Union in an attempt to form a complete monopoly in the baking industry. The Association was also charged with restricting output, causing a rise in prices, and other matters which are of general application in combination problems. The report of this Committee of Enquiry is important, but sufficient evidence against the interests of the Association was not taken. It was found, however, that several mills had never joined the Association; and that the Association had been formed "for the purpose of self-protection," but at the same time "had endeavoured to secure control of the sale of flour throughout the Colony." The price of flour had not been raised, but there had been shown a "tendency at times to raise the price of bread beyond what might be regarded as a fair profit," on the part of the Bakers' Union, which was for a period acting in conjunction with the Millers' Association.

When, however, in 1912, the Commission on the Cost of Living took evidence on this question, it was shown clearly that the Association had endeavoured to force free millers into the pasition of associated millers by restricting the supply of wheat to them, and "dumping" flour into the markets controlled previously by these millers.* It was further shown that the Association had endeavoured to cut away the supplies of flour from bakers who refused to become members of the

*See Report H-18. Evidence of Mr. Virtue, pages 243-6; evidence of Mr. Gardiner, pages 102-6; evidence of Mr. Williams, pages 177-180. 
Master Bakers' Union. With such evidence the Commission attacked the problem vigorously, and proved that in many respects the charges brought against the Association in 1903 were well founded. Thus, one miller on withdrawing from the Association, found the prices of flour cut down within a week of his withdrawal. The object of this is obvious, but fortunately this miller and several others are still in a position of stability.

(c) Monopoly Aimed At. - Undoubtedly, then, this combination has not adhered closely to its original intention as embodied in the agreement. That monopoly was aimed at is a practical certainty, for in the first place those very men ( or at least the majority of them). who were in the best position to endure bad times and ultimately capture the milling industry, were most vigorous in their agitation for its establishment. They evidently preferred the monopoly by the easier road than by at first killing competition. Secondly, the practices adopted by the Association are unquestionably those of monopoly. At present there are some 30 "associated," and about 10 free mills, but the latter class comprises almost half the milling strength of the Dominion. There has, therefore, never been a wholly successful monopoly; but "the ever present danger exists of a complete monopoly being organised, and the usual methods of monopolistic control being adopted."

What dangers have we then to fear from such a monopoly? There is no doubt that flour prices would be fixed by the Association, as would output also. The Association would also have a monopoly of the purchase of wheat in the Dominion, with the exception of the relatively small amount purchased for export purposes. There would, therefore, be three lines of action open to the monopolists. The price of wheat could be forced to its lowest figure; flour could be raised in price to an unreasonable figure; or by a combination of these two lines of action the medium course would be possible. 
A President of the American Sugar Refining Company has well said that "The tariff is the mother of trusts," and the maternal relationship is well exemplified in this case. Sheltered behind the import duty on flour, the monopoly could raise the price to a high figure, but not high enough to make imports from Australia profitable. On the other hand, the price of wheat could be lowered considerably, for London is our outside market, and provided that New Zealand prices are not lower than English prices by more than the cost of freight, insurance, interest, and other shipping and landing charges, export is relatively unprofitable.* With reduced prices the margin of cultivation would probably recede, and production would be limited to the higher grade lands, that is, so long as sufficient supplies were forthcoming to give the monopoly the maximum net revenue. But the problem if pursued in detail would lead us into a consideration of the relative positions of the various rural industries, and indeed, the whole question of the prosperity of the community in general. Enough has been said to show the nature, extent, and operation of the Flour Millers' Association, the relation between it and the wheat industry, and the fruitful path of investigation it opens up. With the present regulation of prices by the Government, the problem of monopoly is out of the question. This, however, is no reason why it should not be discussed. After-war conditions may again be favourable to such a monopoly, and it is necessary to realise now what attention is likely to be given to trade combinations in the reconstruction policy, if any, after the War.

*At the present time when wheat is relatively scarce, the miller is not in so fortunate a position. It is an interesting subject of speculation, however, to reflect on the possibility of an agreement with the farmers in times of scarcity. 


\section{The Farmers' Union.}

(a) General Principles. - The treatment of this subject involves reference to the general question of combinations of capital and labour. What is said in this connection is nothing more than what is evident in the social order of to-day. The avowed objects of the Union will be given later. It must not be thought, however, that the relations of capital and labour are the only topic which our subject gives rise to. That topic is taken as the starting point because it seems more and more evident to the author that the true importance of the Farmers' Union can best be realised in relation to it.

In the modern economic order there is undoubtedly a class war. "We have in our day a two-fold movement ; first, a weakening of the old classes based on political privilege and established by positive statute and long continued custom; second, a growth of economic classes, and especially the emergence of rather sharply defined classes of employers and employees, each with a menacing class-consciousness. The word class-consciousness has played and is still playing a great rôle in socialist agitation."* The causes of this development need not be stated here. They require elaborate treatment of the very foundation of the economic system.

To state that a class-war exists is a very different matter from advocating it as a means of settling the economic problem. There may be those who say that there is no economic problem to settle. Certainly, New Zealand is fortunate in this respect, for the predominance of rural pursuits has saved her as yet the trials of a big industrial problem. But in spite of this there is evident the same tendency, though to a less extent, as is present in great industrial centres. This phenomenon of industrial unrest has received more

*Ely, "Property and Contract in Relation to the Distribution of Wealth." 
attention during the past two years than ever before. It is now fully recognised by most countries, and the discussions on Reconstruction after the War show that Governments are anxious for a solution. This is borne out in England by the Whitley Report already mentioned in this work. There is no doubt that even in the rural industries of New Zealand the same economic problem is becoming evident. The long and important case on Unionism in Agriculture before the Arbitration Court in 1908 brought out many statements indicative of this. Recent discussions on rural problems show the same tendency. There is still a strong agitation for an agricultural labourers' union. The special circumstances of employment in many rural industries make Unionism difficult, and the farmers in many cases view it as dangerous. But it appears that in some form it is inevitable. The outstanding feature of recent economic evolution is the strengthening of combinations of capital and labour. In his lectures on "The Economic Organisation of England," Prof. Sir William Ashley speaks of "the growth of the feeling of solidarity among employers, and the steady strengthening of their organisations for collective bargaining." * This principle of collective bargaining has now received general legal recognition, and there are signs that this has not led to increased industrial strife. "In spite of recent storms, the situation is really far more hopeful than it was when the combination of the work-people was actually far weaker; and the remedy would seem to be, in part at any rate, in the direction of an even completer combination of the parties concerned." $\dagger$

(b) General Nature of the Union. - The relation of our subject to this general discussion may not seem clear at first. But the real plan of the Farmers' Union in the

*Ashley, "Economic Organisation of England." Page 189. †Ibid. Page 172. 
social order can best be realised in its relation to this general tendency. Two early mottoes of the Union were, "Policy-not party," and "Defence not defiance." The record of the achievements of the Union shows that it has been an important factor in moulding legislation in the Dominion. In some respects this legislation was very contentious, especially that referring to land tenures. It is claimed for the Union that it was responsible for the Land Act of 1912, which reversed almost completely the land policy of the Dominion during the preceding 20 years. In fact, this was one of the main questions upon which the election of 1911 was fought. Whatever may have been the intention of its founders the Union has found it almost impossible to keep clear of politics. To secure its policy it has turned to the legislature, and, justly or unjustly, has often been associated with a certain brand of politics.

But during recent years the activities of the Union have shown more and more its tendency to class interests. This is clearly shown in the words of the President, Sir James Wilson, when giving an account of the work of the Union.* After dealing with the progress of the agricultural and pastoral industries during the last two decades of last century, the President spoke of the restiveness of labour and the forcefulness of some leaders of Trades' Unions. He even goes so far as to say that the Union was formed as a combination of farmers, "so that their side of the case might be heard."' $\dagger$ Further, the President wishes "to emphasise the determined attitude we have adopted towards Socialism, Land Nationalisation, Single Tax Theories, Syndicalism, and

*See "The Journal of the Canterbury Agricultural and Fastoral Association." Vol. I., 3rd series, page 28, (April 1913).

tThe first Annual Conference does not support these words, and $I$ am assured by one of the founders of the Union that such was not the cause of the origin of the Union. What it does show is the inevitable tendency already spoken of above. 
the other 'isms which the body politic is heir to." For the purpose of advocating their cause in this matter "as well as to give useful information as to what the Union is doing, and disseminating agricultural knowledge," an official organ-The Farmers' Union Advocate - has been established. All this shows that there is the same tendency towards class consciousness in rural New Zealand, as is evident in other places. This is distinctive of modern developments in the economic world. The writer states it as a fact; he does not in any way attempt to pass a judgment, for farmers and workers will doubtless continue to express their points of view through their respective Unions. There is strong ground for the belief that even a stronger growth of the Farmers' Union along with the organisation of rural labour would be of permanent benefit. This is undoubtedly the tendency in industrial centres, and it is recognised by many as a force working to a better understanding between capital and labour, and a more lasting industrial peace. There is little strife in the rural industries, but equally important benefits may spring from better organisation there.

(c) The Objects of the Union.-We pass from these general considerations to the specific objects of the Union. In "the Objects, Platform, and Rules of the New Zealand Farmers' Union," the following is the statement of declared objects:-

"The objects of the Union are to foster the interests of the farmers, fruit growers, and settlers of New Zealand; to encourage co-operation amongst its members ; to promote the opening up and settlement of Crown and Native Lands, and the formation and improvement of means of communication; to obtain cheap freights, and to place the sale of produce and the purchase of material required by agriculturalists on a satisfactory basis; to keep a vigilant watch on all measures brought 
before the House of Parliament, and on the working of the present laws; to protest against any measures deemed injurious to farmers' interests; to secure proper repre. sentation of farmers' interests in Parliament. To secure this, members of the Union are advised to vote only for those candidates who agree to the platform of the Union, and to place the interests of the Union above those of party."

The general principle of such a Union is to be commended. It shows that the farmers form an active community, and are alive to their responsibilities. By means of the Union the farmers throughout the country are united and bound together by common interests, and exchanges of opinion and ideas are likely to become very valuable. The dominant note in such an organisation is the interest of the farmer, a most important matter for the Dominion as a whole. The platform of the Union clearly shows this. It deals generally with the questions of land settlement, advocating the freehold as a general principle, Government grants for roads and bridges, taxation of rural lands, customs duties, freedom of contract and local franchise. To state that a Farmers' Union is desirable is not to advocate the platform as laid down at present. But in spite of the avowed tendency to preserve purely class interests, the Union has already achieved much which will be of permanent benefit to the community. It has aroused public.interest in the rural industries at a time when there was a tendency to regard urban occupations as more important. A staunch advocate for agricultural and general education it has assisted in improving the education system. The frequent meetings have been beneficial to the farmers themselves, and have developed a solidarity of interest. Finally, the Union has frequently stood out against commercial and trade monopolies, with no small degree of success.

But many of its activities have been somewhat narrow. 
For instance, it assisted in successfully fighting an attempt to establish Unionism among the agricultural labourers. Farm labourers "who are not members of or contribute to, any society whose aims and objects are inimical to the farming community" may become members of the Union. The principle involved here is obvious. Then, again, one of the planks of its platform is that "no interference with contracts should be enacted." Does this signify that our present system of contract is the best possible?

In the revised statement of the objects and platform of the Union there is no mention of education or scientific farming. Members of the Union are proud of their activities in this direction in the past. In presidential addresses and in other ways it has been the policy of the Union to encourage both agricultural education from an early age, and scientific farming as expounded at the experimental farms and agricultural colleges. At present it is more than ever necessary that the Union should continue its labours in this way. The War has demonstrated to New Zealand the importance of her rural industries, and it is probably no exaggeration to say that, pro rata, her wealth has increased more and her prosperity has been greater during the past three years than those of any other belligerent. The dissemination of knowledge on the science and art of agriculture, on rural economics, (hitherto almost untouched), and the general enlightenment of the public in matters relating to the rural industries, should form a cardinal feature of the activities of the Union. Greater opportunity should be taken of the meetings and conferences of the Union to the reading and discussion of papers by experts. This is the proper sphere of the expert. His investigations should be laid before those who have had practical experience in the matter. He can give information much less on the art than on the science 
of agriculture. There is also the greatest need for sound information on rural economics, and, in part, on social and economic questions generally. The discussions on these questions throughout the whole community show that a clear grasp of the principles involved is almost entirely lacking.

There is an ever present tendency for the policy of such a Union to become narrow, and confined too much to class interests. This is quite a natural tendency, and is scarcely reprehensible, for such a Union can scarcely exist without a strong class bias. The Farmers' Union, however, has special opportunities to rise above this. Connected as it is with the greatest of our industries, the very foundations of our national prosperity, it can exert an enormous influence throughout the whole community. Perhaps the most important task it has before it is to develop to a fuller extent genuine public spiritedness throughout the rural community. Greater toleration coupled with more self-reliance would be valuable assets to our farmers and to the people of the Dominion generally.

\section{Protection for the Wheat Industry.}

(a) Protection in New Zealand. - There are two reasons for discussing this problem. First, the subject is of the greatest interest to New Zealand. The fiscal policy which the Dominion adopts will re-act on her economic development, and is usually connected with her prosperity. Secondly, the War has brought the question before the public again in a new and somewhat misleading manner. The outcry against German goods, the alleged attempted economic domination of Germany, the supposed superiority of protected countries, are all powerful arguments to the average man. At a time when popular sentiment on these matters is running high, the danger that "partial and incomplete reasoning 
may have a superficial advantage" - a danger which is always present in popular arguments on economic questions-is exceptionally great. The recent attempt to found a New Zealand Board of Industries demonstrates this, ${ }^{*}$ and the report of the New Zealand Efficiency Board wherein the first statement refers to the desirability of higher protective duties. No reasons are given for this, and one may well enquire as to how higher protection would increase our efficiency as producers.

In New Zealand import duties were first imposed to raise revenue. During the last three decades our attitude towards the tariff question has changed; and now New Zealand fiscal policy has a distinct bias towards protection. Most manufacturing industries are highly protected, 20 and 25 per cent. being in most cases the extent of the protection, a high duty when we remember the natural protection enjoyed by the New Zealand manufacturer through the high freights on over-sea goods. The milling industry is protected by an import duty of $£ 1$ per ton on flour, which amounts normally to 10 per cent., while the wheat industry also receives protection from a duty of $9 \mathrm{~d}$. per cental, or $6 \mathrm{~d}$. per bushel, which at normal times is equivalent to over $12 \frac{1}{2}$ per cent. A study of the effects of these import duties is difficult from two standpoints. In the first place, there is the difficulty peculiar to the study of dynamic economics-namely, the impassibility of isolating phenomena which it is desired to study. Secondly,

*An interesting controversy on "Scientific Tariff" sprang from this. The writer had the opportunity of following it closely. Those favouring Protection were unable to meet the criticisms of their opponents, and a reviewer of the controversy gave the honours to the Free-traders. This is of interest as it shows how easy it is to argue the case for protection to the satisfaction of the less critical. But where strong arguments based on economic knowledge had to be faced, the Protectionists withdrew. 
we cannot with equity deal with an individual item of the tariff without a consideration of the whole fiscal system. This difficulty is of special importance in this case; for while the farmer is protected, he has to purchase supplies of both production and consumption goods from other protected industries.

(b) General Effects of Protection.-A priori reasoning proves conclusively that, other things being equal, the imposition of duties on imports raises prices to the consumer, but not necessarily by the amount of the duty. Such conceptions as the inelasticity or elasticity of demand, the conditions of production, whether decreasing or increasing return, whether the country is a monopoly buyer, etc., alter the degree to which price will rise.* Thus, to take one example of particular interest to our problem, let us consider what will happen if an import duty is levied on a commodity "obeying" the law of diminishing returns. With protection granted to the industry, production, in the absence of counteracting causes, will be extended. In the case of the wheat industry, the margin of cultivation will be extended, that is, recourse will be had to poorer soils, a factor which will aggravate the tendency for prices to rise, originated by the protective tariff. An import duty on wheat therefore raises the price of wheat to the consumer by more than the amount of the duty.

But the question is so important that a general discussion of the relation of protection to the rural industries generally is not irrelevant. The advocates for protection who wish to examine the problem thoroughly have evidently forgotten the valuable Report on the Cost of Living in New Zealand in 1912.

*For a full discussion of this, see Taussig, "Some Aspects of the Tariff Problem." Pages 3-17.

IIn practice, however, this argument is modifled by the importance of the outside market in determining prices in New Zealand. 
Protection as a general policy was condemned, and it was considered desirable that the duties, as far as possible, should be abolished.*

The whole question is closely connected with the degree to which we realise the importance of the rural industries in our national life. Many who advocate protection evidently think that the manufacturing industries form the greatest element in our economic system. The economic history of New Zealand since the early days has been the history of her primary industries. The varying periods of depression and prosperity which the country as a whole has passed through have been synchronous with fluctuations in value of the products of these industries, and at present it is patent that our unbounded prosperity is a result of the rapidly rising values of farm produce. Moreover, an examination of our exports reveals the interesting fact that the products of the great primary industries are responsible for almost 90 per cent. of the totals, the chief other items being gold, coal, kauri gum, flax, and timber, themselves direct products of the soil. Furthermore, the value of these exports has almost doubled during the past decade, and between 1905 and 1910 it rose by nearly 50 per cent. At the same time it must be remembered that the produce consumed locally increased greatly during the same period; for there was both an increase in population and a rise in the standard of living.

We proceed to examine our manufacturing industries during the same period-1905 to 1910 , years for which we have statistics based upon census returns. In 1905 the total value of raw materials used in factories was $£ 12,681,358$, and the value of the output was $£ 22,422,726$.

* See Report of the Commission on the Cost of Living in New Zealand, 1912. Parliamentary Papers, H-18. Pages IxxviiIxxxi, xcii-xciii.

One Commissioner dissented from this view. 
The corresponding figures for the year 1910 were $£ 19,937,853$ and $£ 29,534,632$. That is to say, the value added by our manufacturing processes in 1905 was $£ 9,741,368$, and $£ 9,596,779$ in 1910 -an actual decrease, despite the fact that meat freezing, butter and cheese factories are included, for which the corresponding statistics would undoubtedly show a large increase.

Now, what conclusions do these statistics furnish? I am fully aware of the fact that without studying fluctuations in prices mere comparison of values is misleading. The simplest way of making a rough estimate of the effect of price changes is to consider the relative changes in the price index number of the two main groups of products-farm and non-farm products. We find from Dr. McIlraith's index numbers that both groups rose in price in 1910 compared with the prices for 1905 , but that non-farm products have risen less in value than farm products, as is always the case in a time of rising prices. But this difference alone is not sufficient to account for either the stagnation in the progress of manufactures or the rapid strides which the primary industries have made. The general conclusion is that while the period 1905-1910 was a prosperous one generally, our manufacturing industries were at a standstill, and this despite the fact that they were protected to an extent of at least 20 per cent. all round.

The truth probably is that they had already suffered reaction after the false stimulus given them by the protective tariff which our manufacturers had secured for their industries previously. Under these circumstances we are not surprised that they now require another stimulant. Hence the recent cry for more protection and still more protection, even though the protected industries of the country afford employment for only some 5 per cent of the population. The pro- 
duction of these industries is but a small fraction of the total supply necessary to meet the demands of local consumers, consequently prices are raised more or less on the whole supply, imported and locally produced alike, and the consumer pays for the protection, while at the same time the fostering of "parasitic" industries retards progress in the great rural industries.

But the protectionists will ask, "Why raise huge quantities of primary produce for export? Why devote our whole energy to agriculture?"' A few observations are sufficient to establish the wisdom of such a policy. The fundamental fact is that capital and labour applied to rural pursuits in New Zealand give a greater return than would the application of a similar quantity of capital and labour in any other pursuit. Secondly, we require capital in the form of machinery and other requisites for the further internal development of the country, and, as must be admitted, these can be obtained most cheaply from other countries, and can thus best be paid for by exports of primary produce. Thirdly, we have built up a huge National debt, the interest and sinking fund on which cannot be less than $£ 4,000,000$ per annum, and this ean be paid for only in produce.

(c) Some Arguments for Protection to the Wheat Industry. ${ }^{*}$-Returning to the question of protection in relation to the wheat industry, let us examine some of the arguments which are brought forward by the advo.

\footnotetext{
"Clause 8 of the Platform of the Farmers' Union states that "'taxation through the Customs should be for the purpose of raising revenue, and not for protective purposes." Yet many farmers of influence in the Union advocate protection for the wheat industry generally, and, in particular, retaliation against Australia.

I have seen it stated in relation to the present (1917) dearth of wheat that there was only one way out of the difficulty. "The import duty on all flour should be raised to £3 per ton, and on wheat to 1s. $9 \mathrm{~d}$. per cental." It is hoped that the discussion given here will prove that this is both unnecessary and unwise.
} 
cates of the duty on imported wheat. The millers are more enthusiastic for the retention of the duty than are the farmers themselves; but it is primarily for the farming community (so these protectionist enthusiasts tell us), that the agitation for protection is maintained by the millers. Some have gone so far as to say that a community should be self-sufficing. The elementary principles of international trade are sufficient to prove the absurdity of this opinion. Absolute self-sufficiency would mean the total absence of imports. The argument need not be pursued further except to state that, other things remaining the same, no community can have an export trade unless it has a corresponding import trade.

Again, if we consider the argument in its less extreme form-self-sufficiency as to wheat production - its refutation is no less easy. If other countries can send wheat to New Zealand in sufficient supplies cheaper than it can be produced here, would it be disastrous to this couuntry to import a great part of its wheat supply? So long as the supplies from abroad were forthcoming with regularity, we should surely benefit if wheat prices were lowered, even though the wheat industry were to decay, and wheat growers to sustain a temporary loss, that is, assuming that other things were equal. How far we can expect regular supplies from abroad will be discussed in another section on this subject. But we can readily see that, ceteris paribus, it would not be disastrous were we forced to make regular annual importations of wheat. The degree of probability of such a necessity will be made clear in discussing the next argument in support of protection, noted below.

Another argument put forward is that the abolition of the duty would lead to the decay of wheat production in New Zealand. It is alleged that New Zealand would become dependent on Australia for her supplies of wheat, 
because Australia would be able to export to us yearly large quantities at lowered prices. Moreover, the millers prefer Australian wheat on account of its superior quality, and they would therefore welcome the change. This view of the matter is unquestionably more reasonable, but it is not convincing.

If we ignore the effect of the import duty, New Zealand prices, as well as Australian, are determined by conditions in the world's markets. It is not local conditions which primarily determine these prices, though no doubt they exert a certain influence, already described in Chapter VI.* Now, Australia finds a ready market in London for her wheat, and a regular shipping service exists between the market and the seat of production. New Zealand would be prepared to take only comparatively small supplies; for with her high yield per acre, a small area would produce almost sufficient quantities for home consumption. Thus, 150,000 acres of superior land could easily be found yearly, and with careful husbandry this would yield, say, 6,000,000 bushels, that is, 40 bushels per acre-not an impossibility when we consider that Lincoln Agricultural College Farm has had an average yield of $47 \cdot 2$ bushels per acre during the past nine years. $t$ Moreover, since cereal growing is an assistance to successful pastoral farming, this area would probably be forthcoming.

* See page 97.

tThis is not the only farm where high yields are obtained. The writer is informed that improved methods of farming would rcsult in an increase in yield per acre which might bring it as high as 40 bushels. In 1903 the yield was $38 \cdot 37$ bushels, and the average for the years $1905-14$ was over 30 bushels. No country has better opportunities for obtaining such a high yield, and the further development of intensive farming in Canterbury is likely to work in this direction. It is hardly necessary to point out that the writer does not declare that New Zealand will produce wheat at the rate of 40 bushels per acre. $\mathrm{He}$ merely states it as a possibility for which there is good evidence. 
But granted that production would permanently diminish so that we should have no exportable surplus, then can we say that our position is serious enough to be alarming? Here, indeed, is the main argument for protection. The possibility of a drought in New Zealand and Australia at the same time must cause some anxiety, if we are to become dependent upon the Commonwealth for supplies of primary products.* But we have shown that New Zealand is very rarely seriously affected by a drought, that is, from the point of view of wheat yield. Thus, during the season 1914-15 when the "useful" (May-November) rainfall in Canterbury was about 11 inches, a low figure, the yield per acre was no less than 28.9 bushels. It was not until 1915-16 that the yield fell considerably. But the "useful" rainfall in that year was less than 7 inches. Even then the yield was above 20 bushels per acre. But we may rely on past experience to guide us to some extent in this matter. An examination of the harvests for Australia and New Zealand during the last 32 years (1874-1915), reveals the interesting fact that only once has a bad season in Australia coincided with a bad one here. In other years of bad harvests in Australia we have enjoyed good yields. Thus, a very low return was registered in Australia in 1888, but in New Zealand production was a maximum in that year for the period 1885-1891. But in 1902 Australia had an exceptionally poor harvest, which coincided with low production in New Zealand. In this year, however, prices remained abnormally low, being only $2 \mathrm{~s}$. $5 \mathrm{~d}$. per bushel in New Zealand; this shows that our price is not the result of conditions affecting local supply merely. Even were

*Even in times of drought the wheat yield of the Common. wealth is generally in excess of the requirements for home consumption, and there is an exportable surplus. But this was not so in 1914. 
supplies to be less than the amount required for home consumption, price could not rise much higher than the English price; for the prospects of a high price here would soon attract supplies from India or Canada.* At present if we are threatened with wheat shortage, the price must rise higher than the price in outside markets by the amount of the duty, together with the total cost of transport. The very evil which advocates of the duty anticipate is accentuated by the imposition of the duty. Again, were the duty not to ensure a sufficient home supply in the event of a serious drought, and assuming that a serious shortage existed in Australia at the same time, the very fact which the advocates of the duty fear, we should then be under a more serious disadvantage in this respect than if we had free trade. Even were the duty suspended for the time, the evil would not be dispensed with, for the difficulty of securing importation where there had been none previously would cause some inconvenience.

Protection is, therefore, on the whole not necessary for the industry. Production would be carried on even were it abolished. The system of mixed farming makes this necessary. Then, again, Australian millers would welcome supplies of "soft" wheats like the New Zealand varieties for blending purposes. It has also been shown that production is profitable here at about $3 \mathrm{~s}$. $3 \mathrm{~d}$. per bushel. Now, Australia would not export wheat to New Zealand unless the price was an approximation to the English price, the difference being the amount by which cast of transport to New Zealand is less than that to England. This, indeed, in the long run, would amount to very little, for the shipping service between New Zealand and Australia is relatively more costly and

*During the first year of the War, when wheat prices rose so much in New Zealand, they were rarely above the English prices. 
much more intermittent. It would appear, then, that our price would not fall to any great extent, and production would therefore be continued, at least at its present level, largely because of the interdependence of agricultural and pastoral farming.

(d) General Free Trade would benefit the Farmer.The New Zealand farmer has everything to gain by a general abolition of protection in the Dominion. His industry is the least protected of all, manufactures receiving protection at least to double the amount. While Australia retains her protective duties on wheat and flour (and these are about 25 per cent.), it is said that New Zealand must also retain her duties. But London is the chief market for New Zealand wheat, and in any case Australia herself is an exporting country. Then, again, even if the abolition of the import duty on flour caused the milling industry in New Zealand to decline, (not that it would), this might be a boon to the country. Supplies of flour could be obtained from Australia, and capital and labour thus set free from the flour-milling industry could be devoted to the development of our primary industries.

But were the farmer to advocate general free trade in New Zealand, including the abolition of the duty on wheat, not only would he be a public benefactor, but he himself would probably be the greatest gainer of all. At present, protection is afforded to industries employ. ing only some 5 per cent. of the population." These are for the most part manufacturing industries, which produce only a fraction of the total supply necessary. Consequently, prices are raised to the consumer on the whole supply. The farmer would discover that many articles necessary for the production of wheat would be

*See Cost of Living Report, H-18, page lxxx. 
procurable at reduced prices, while the labour market would no longer present the difficulties it does now.*

\section{Public Control of Prices.}

(a) Wheat Prices during the War. - A general scarcity in local supplies of wheat in August of 1914 soon began to attract the attention of the public of New Zealand. At the same time people were apprehensive of disaster to the world's wheat supply on account of the outbreak of War on a colossal scale. Moreover, a serious drought in Australia promised to ruin the prospects of a good harvest just at a time when it was anticipated that the European demand for wheat would be of greater magnitude than previously, on account of the vast numbers employed, both directly and indirectly, in "unproductive" works. Reassuring statements from the millers and the Prime Minister to the effect that sufficient supplies were available within the country for home consumption until the coming harvest, tended at first to assuage public apprehension, but a steadily rising price soon undermined this optimism, and at the close of August the outlook was gloomy. By August 26th wheat was selling at 5s. per bushel, and flour at $£ 12$ per ton, a rise of 25 per cent. and 20 per cent. respectively since the beginning of the month.

This engendered a feeling that exploitation was prevalent, and more especially were the millers and merchants suspected of it. Reference was made to the matter in Parliament in a vigorous speech by the Leader of the Opposition, and on August 28th a deputation from the South waited upon the Prime Minister praying that the Regulation of Trade and Commerce Act be applied

*It should be stated that for many years farmers generally have been staunch supporters of the free trade policy, and in spite of the attitude of many over the wheat duties, there is reason to believe that they still adhere strongly to this policy. 
to wheat to control prices. The result was the establishment of a Food Commission to enquire into the matter and report on the available supplies of wheat and flour in relation to the demand for these articles. The advisability of fixing prices was also to receive consideration. The Commission took the greater part of a month to make its report, and in the meantime flour had been selling at from $£ 12$ per ton, and wheat at about $5 \mathrm{~s} .3 \mathrm{~d}$. per bushel; but very little wheat was offering, and the millers who had bought up supplies prior to August at about 3s. 6d. per bushel were now taking advantage of the high prices of wheat to raise the price of flour to an exorbitant figure.

(b) The Fixation of Price.-On September 29th the Commission made its first report, and as a result the maximum price of wheat was fixed at $4 \mathrm{~s} .9 \mathrm{~d}$. per bushel, and flour at $£ 11$ 10s. per ton*. The result was not satisfactory; for prior to the proclamation fixing the price, wheat had been selling at $5 \mathrm{~s}$. $3 \mathrm{~d}$. to $5 \mathrm{~s}$. $6 \mathrm{~d}$. per bushel, and the price had been high for some seven or eight weeks, so that millers in being forced to sell flour at $£ 11$ 10s. per ton were milling at a loss. The Commission again reported, and on October 21st, prices were fixed at the maximum of $5 \mathrm{~s}$. 3d. per bushel for wheat, and flour at $£ 13$ per ton. During November and December wheat was reported to have been sold by the evasion of the law at prices equivalent to $6 \mathrm{~s}$. and $6 \mathrm{~s}$. $3 \mathrm{~d}$. per bushel; but those farmers who had supplies for the most part preferred to hold them, for the Government had made purchases of Canadian wheat at $6 \mathrm{~s}$. $3 \mathrm{~d}$. per bushel. $t$ It was anticipated that the first supplies from Canada would reach New Zealand early in January, and the

*In spite of this flour was selling at $£ 125 \mathrm{~s}$. per ton in September, and $£ 139 \mathrm{~s}$, in November. See Report of the Board of Trade on the Wheat and Flour Question-Parliamentary Papers, 1916, H-33.

tAccording to the Report of the Board of Trade the price in December was 6s. 5d. per bushel. 
Government would then raise the price in self-defence, since they had bought at a price which was equivalent to 6 s. 3 d. c.i.f. This anticipation was realised, for on January 8 th, 1915, a third proclamation was issued, when the maximum price was fixed at 5s. $9 \mathrm{~d}$. per bushel, and at this price the Government sold the imported wheat, thus losing $6 \mathrm{~d}$. per bushel on the transaction. The position was unsatisfactory, for the law was being evaded, and bread had risen to $9 \frac{1}{2} \mathrm{~d}$. for the $4 \mathrm{lb}$. loaf. Pressure had been brought to bear on Parliament from the merchants and the farming community, and on February 8th, all restrictions on the sale of wheat and flour were removed. Flour rose to $£ 16$ and $£ 17$ per ton in March and April as a result, and sales of wheat at $7 \mathrm{~s}$. per bushel on trucks at country stations were not infrequent.

In the absence of control the prices of wheat often remained at a very high figure for several months. The rise was accentuated by a miscalculation in the esti. mates of the 1915-16 erop. At first it was thought that the yield would be less than 5,000,000 bushels, and a scarcity was predicted. The price of wheat rose steadily, and in September, 1915, was 7s. 61d. per bushel. But later information as to area sown and probable yield per acre showed that the harvest would reach $6,500,000$ bushels.* This was due mainly to a much larger area than usual of spring wheat being sown. Although it was unfortunate that such a scarcity had been predicted, the error appears to have been largely unavoidable. Price then fell, and during the later months of 1915 was about 4s. 10d. per bushel, but there was another rise early in 1916. All this time the price of flour was disproportionately high; for, in January, 1914, when the price of wheat was $4 \mathrm{~s}$. $5 \frac{1}{2} \mathrm{~d}$., the price of flour was $£ 105 \mathrm{~s}$. per ton. The corresponding

*The actual harvest of 1916 was $7,108,360$ bushels. 
figures in October, 1915, were 4s. 7d. and $£ 13$ 10s. Furthermore, the Board of Trade, after careful consideration of the question, recommended in June, 1916, that the price of flour should be $£ 11$ 15s. per ton, when the price of wheat was $4 \mathrm{~s}$. $6 \mathrm{~d}$. to $4 \mathrm{~s}$. 9d. per bushel.

The following table giving the prices of wheat and flour from January, 1914, to May, 1916, is taken from The Report of the Board of Trade on the Prices of Wheat, Flour, etc., in June, 1916.

\section{TABLE XXXVII.}

Monthly Prices of Wheat and Flour from January, 1914, to May, 1916.

\begin{tabular}{|c|c|c|c|c|c|c|c|c|c|c|c|c|}
\hline & & $\begin{array}{c}\text { Wheat } \\
\text { \&.t } \\
\text { Mill }\end{array}$ & & $\begin{array}{l}\text { 7our } \\
\text { in } \\
\text { ruck }\end{array}$ & & & & $\begin{array}{r}\text { Whe } \\
\text { at } \\
\text { Mil }\end{array}$ & $\begin{array}{l}\text { eat } \\
\text { t } \\
\text { ill }\end{array}$ & & $\begin{array}{l}\text { Flou } \\
\text { in } \\
\text { rnel }\end{array}$ & \\
\hline 1914 & & s. d. & $f$ & s. & & 1915 & & s. & & $\mathscr{E}$ & s. & d. \\
\hline January & $\ldots$ & & 10 & 5 & 0 & April & ... & & & 16 & 5 & 0 \\
\hline February & ... & $40 \frac{1}{2}$ & 10 & 5 & 0 & May & $\ldots$ & 72 & 2 & 16 & 5 & 0 \\
\hline March & ... & 41 & 10 & 5 & 0 & June & & & 4 & 16 & 5 & 0 \\
\hline April & ... & $\begin{array}{ll}4 & 1 \frac{1}{2}\end{array}$ & 10 & 5 & 0 & July & 1 & & 6 & 16 & 7 & 6 \\
\hline May & $\ldots$ & $\begin{array}{ll}4 & 3\end{array}$ & 11 & 0 & 0 & August & & 7 & $5 \frac{3}{4}$ & 15 & 7 & 6 \\
\hline June & ... & $\begin{array}{ll}4 & 4 \frac{1}{2}\end{array}$ & 11 & 0 & 0 & September & & & $6 \frac{1}{4}$ & 14 & 12 & 6 \\
\hline July & $\ldots$ & & 11 & 0 & 0 & October & & & 7 & 13 & 10 & 0 \\
\hline August & $\ldots$ & $4 \quad 4 \frac{3}{4}$ & 11 & 14 & 0 & November & & 411 & 11 & 13 & 5 & 0 \\
\hline September & $\ldots$ & 4111 & 12 & 5 & 0 & December & & & 4 & 13 & 5 & 0 \\
\hline October & $\ldots$ & $5 \quad 3 \frac{3}{4}$ & 12 & 17 & 6 & & & & & & & \\
\hline November & $\ldots$ & $5 \quad 9$ & 13 & 9 & 0 & 1916 & & & & & & \\
\hline $\begin{array}{c}\text { December } \\
1915\end{array}$ & ... & 65 & 13 & 17 & 6 & January & ... & 6 & 0 & 13 & 17 & 6 \\
\hline January & $\ldots$ & 67 & 14 & 7 & 6 & March & ... & & $\begin{array}{l}1 \\
6\end{array}$ & $\begin{array}{l}10 \\
13\end{array}$ & 5 & 0 \\
\hline February & $\ldots$ & $7 \quad 0 \frac{8}{4}$ & 16 & 5 & 0 & April & ... & 5 & $6 \frac{3}{4}$ & 13 & 5 & 0 \\
\hline March & $\ldots$ & $7 \quad 2 \frac{7}{2}$ & 16 & 5 & 0 & May & $\ldots$ & 52 & $2 \frac{1}{2}$ & 13 & 8 & 0 \\
\hline
\end{tabular}

Prices continued to fall slowly until October, 1916, when a strike in Australia and the possibility of a wheat shortage in New Zealand altered the position, so that by the end of November the prices of wheat and flour were as high as 6s. 6d. per bushel and $£ 15$ per ton respectively. The question of controlling prices was again raised, but this time the Government had some machinery to deal with the position. The Board of Trade set up in March, 1915, had been considering the 
question during the year, and had worked out carefully the cost of production of wheat, flour, and bread, and other products of the wheat industry. After negotiating with the producing and commercial interests for some time the Board recommended the fixation of maximum prices for wheat and flour, bread, and other products of the wheat industry, and the guarantee to wheat-growers of a fixed price for the next season's crop. The order was Gazetted by the Government on February 6th, 1917, by which the maximum prices of wheat and flour were fixed, varying from 5s. 8d. in February to 5s. 11d. in July, 1917, or after. Wheat-growers were also to be guaranteed 5s. 10d. per bushel for the next season's crop.

By the end of 1917 the policy of the Government had again altered. Instead of merely fixing prices it was decided to effect a more rigid control over the wheat industry. By an Order in Council of December 22nd, 1917, private dealings in wheat were forbidden; a whea controller was appointed, and the whole business of purchasing the wheat crop and re-distributing the wheat to millers was handed over to the Board of Trade." The prices at which purchases were to be made varied from 5s. 10d. in January to 6s. 1d. in or after September, 1918. A critical account of these various measures is given below. We now proceed to discuss the causes of the high prices during the War.

(c) Causes of the Recent High Prices.-The following account is reproduced from an article the writer contributed to the Christchurch Press on October 21st, 1917. and it is also the substance of the evidence he gave before the Board of Trade earlier in the year.

"In July, 1914, wheat was selling at about 3s. 9d. per

*In the original M.S. of this work written in November, 1915, as a University thesis, the writer suggested a scheme of Government control of this kind. 
bushel. Six months later this price had almost doubled. What were the circumstances which caused such a rise? Here, again, it must be remembered that the prices determined in the great central markets for wheat are reflected in the prices at which wheat sells in the small producing areas. According to the International Institute of Agriculture at Rome, between July, 1914, and February, 1915, wheat prices rose in several countries as follows:-

$\begin{array}{llll}\text { Great Britain } & \ldots & \ldots & 86 \text { per cent. } \\ \text { Italy } \quad . . & \ldots & \ldots & 57 \text { per cent. } \\ \text { Canada } \quad \ldots & 0 & \ldots & 70 \text { per cent. } \\ \text { United States of America } & \ldots & 93 \text { per cent. }\end{array}$

We thus see that the rise in prices was general. Before enquiring into the position in New Zealand, let us consider briefly the causes of the rise in price in the world's market. Several factors combined to cause an increase in prices over pre-war prices.

In the first place, there is the increased cost of freight, war risk, and exchange. The influence of these factors is shown by the following statistics giving cost of seacarriage per ton:-

$\begin{array}{llll}\text { From New York to Liverpool } & \ldots & 15 \mathrm{~s} . & 34 \mathrm{~s} .5 \mathrm{~d} . \\ \text { From Bombay to Liverpool } & \ldots & 19 \mathrm{~s} . & 50 \mathrm{~s} . \\ \text { From Melbourne to Liverpool } & \ldots & 30 \mathrm{~s} . & 85 \mathrm{~s} .\end{array}$

(10d. bush.) (2s. 3d. bush.)

Secondly, there was the obstruction of supplies caused by the locking up of stores in some producing countries, notably Russia, where, owing to the closing of the Dardanelles, there will soon be two years' supply awaiting shipment, amounting to some $300,000,000$ bushels now, and further increased after the present harvest. We notice the effect of this on the wheat market in February, 1915, when the British Fleet attacked the 
Dardanelles, for the price fell to 52s. per quarter, but when the attack failed it soon rose again, and in May, British wheat was selling at 68s. 6d. per quarter.

The most important factor arose from the fact that there was a shortage in the world's wheat supply at the harvest of 1914. In 1914 the wheat supply was only 90 per cent. of the previous year's supply. The total supply in 1913 was $4,241,528,000$ bushels, while in 1914 it was $3,914,000,000$ bushels. This was due to the low yields in Europe and Canada, and the failure of the Australian crop. Added to this there was the destruction of supplies in the zone of conflict during the summer of 1914. Immense quantities of grain and flour must have been destroyed in Poland, East Prussia, Galicia, Belgium, and France, in the ebb and flow of the fight on so lengthy a battle line.

Fourthly, there is the psychological factor, always in operation in extraordinary circumstances, but never so great in the commercial world for many years. With so many strong Powers plunged into war at a moment's notice there was no certainty for weeks as to what might happen in the commercial world, and this caused a general rush among belligerents to increase their supplies of wheat by importation.

Now, all these factors operated to raise the price of New Zealand wheat, but two other forces were also in operation which accentuated the tendency of prices to rise. First there was the knowledge that the Australian crop was almost a total failure, and secondly, there was an unfortunate and apparently unavoidable mistake in the estimates given in the official publications of the area under wheat. This latter factor was the more important owing to the deceptive nature of the season which led to an underestimate of yield. When, therefore, the official estimate was given at 4,630,000 bushels, and it was known that supplies would not be available 
from Australia, there ensued something of a panic in the local wheat market. Fortunately for New Zealand it was found at length, that the supply of wheat was actually over $6,600,000$ bushels, and this supply, as a matter of fact, was sufficient for the demands of local consumers until the harvest of this year."

(d) The Problem of Price Control.-Of recent years the attitude of economists towards the possibility of public price control being efficacious has changed considerably. The classical economists were opposed to the assumption of this duty on the part of the State, as they were to State interference generally. This attitude was undoubtedly the product of their own experience, and they did not anticipate the most recent development of capitalism, the concentration of capital with monopoly as its objective. In a recent work on Monopolies* Dr. W. Jethro Brown shows clearly that "the advent of the trust and the combine invalidates the assumptions of classical economists ; and many economists of to-day advocate extensions of the sphere of public control which in former times would have met with universal condemnation. 'I see nothing for it,' writes Prof. Sir. W. J. Ashley, 'but that in countries where the monopolising movement is well under way, governments should assume the duty in some way of controlling prices.' Prof. Wyman, of Harvard, after advocating the creation of an Inter-state Trade Commission, with power to give relief against extortionate charges, concludes, "confine its power over prices to reducing prices against which specific complaint has been made to it, but disposing of such complaints let it fix the price in question for the future.' 'I feel constrained to advocate,' says Prof. Seager, of the Columbia University, 'government regulation of prices, just as most of us

*'The Prevention and Control of Monopolies.' (August, 1914), page 142. 
now advocate government regulation of railroad rates.' ,'

That it should be both possible and desirable for the Government to fix prices in a monopoly industry, where regulations can be enforced rigidly, will at once be conceded by all. The monopoly itself fixes prices with a view to the maximum net revenue. It should be possible for another authority, with adequate knowledge as to how far it is safe to go, to fix prices in the same industry. According to Prof. Jethro Brown this control implies little more than the extension of the principles which underlie existing legislation for the protection of the wage earner. If prices are fixed directly, then this is the policy of the legislative minimum. By authorising representatives of the various branches of an industry to agree to prices, the policy of the wages board will be followed. If an impartial tribunal is given the duty of fixing prices, then use is made of the policy of compulsory arbitration. Moreover, it must also be conceded that price fixation may take various forms. It may be direct; or a maximum or a minimum price may be declared; or further, a monopoly may be called upon to revise its prices; finally, a sliding scale may be used. Thus we find a very plausible argument in favour of price control.

But this analogy between attempts to fix prices and the declaration of standard wages is an imperfect one. Labour is only one element in the cost of production, and when wages are fixed it is this element only which is controlled. When, on the other hand, prices are fixed at standard figures, then all the elements in cost of production are controlled in a greater or less degree. Thus, not only wages but also profits, interest, wages of management, rent, etc., are all interfered with. Moreover, the difficulties encountered in fixing rates are at a minimum, and the advantages at a maximum in the case of those wages which are controlled at present by 
various devices, but when an attempt is made to control the other elements, the reverse is probably nearer the actual facts. We should therefore be cautious in accepting such a simple view of the problem.

The efficacy of the policy rests on two assumptions:-

1. Can the public authority determine what shall be a "reasonable" price?

2. Can the administration of the Act be enforced rigidly enough to make evasion impossible?

In many industries which have reached the monopoly stage these two assumptions are both realised. Thus, in fixing railway rates, the policy is efficacious. Again, in the coal industry or other mining industries, there is no reason to see why such a system should not be effective, if monopoly conditions are in evidence. We must therefore arrive at the conclusion that the public control of prices under certain conditions is possible.

The attempt at price fixation by the Government during the last quarter of 1914 in the wheat industry was of a nature very different from the problems discussed above. Monopoly conditions were not prevalent in that industry, and a "corner" in wheat or flour was scarcely possible, since our millers are divided into two hostile eamps. The fundamental object of the Government's action was to protect the consumer at a time when the high prices consequent on an anticipated scarcity were being aggravated by the general apprehension which was felt during the initial stages of the War. How far such action attained its object is at once obvious. Had the Government been able to maintain the first price fixed (4s. 9d. per bushel), the consumer could not have grumbled at the unreasonableness of the price. But at the very time the price was fixed, wheat was being sold at 5s. 3d. per bushel, and in the period during which prices were fixed, as we shall see, the law was being evaded. The rise of the maximum 
price limit fixed by the Government from 4s. 9d. to 5s. $3 \mathrm{~d}$. in October, and subsequently to $5 \mathrm{~s} .9 \mathrm{~d}$. in January, showed the futility of the Government's action. The experiment thus ended in failure, the reasons for which are apparent.

In the first place, the indecision of the Government when the gravity of the situation was realised in the middle of August is not excusable. In referring the matter to a Commission Parliament was probably right; for a "reasonable" price must be arrived at before control commences. But why wait a whole month for the Commission to report? The practical knowledge of our politicians could easily have been brought to bear on the question, and a reasonable temporary measure brought in. When the Commission did report the price had reached 5s. per bushel and over. Consequently our farmers did not like "backing" down. By much agitation, however, they, along with the millers, got a new scale of prices fixed, and the price of wheat was to be a maximum at 5s. 3d. per bushel.* This shows clearly that the Government had sacrificed its primary object-keeping price low-to the wishes of an influential section of the community. Later, when in January the price was fixed at 5s. 9d. per bushel, the vacillation was again apparent; for in order to dispose of supplies of Canadian wheat without too serious a loss to the taxpayers, the Government again raised the price. Finally, just at a period when the new season's supplies were about to come in, all attempts at control were abandoned, and the market opened for the harvest at an exorbitant price of $7 \mathrm{~s}$. per bushel. Indeed, it may be said that the action of our Legislature was worse than futile, for the

*A critic has suggested that this price was lower than that at which the Government could purehase wheat from abroad. This did not enter into the question at the moment. A low price was aimed at. 
existing excitement at the anticipated shortage was intensified by its action, which at times tended to promote a panic.

But not only was hesitation responsible for failure. The conditions of marketing were such that rigid administration of the law was impossible, and the openings for fraud and evasion were at a maximum. Moreover, the Government trusted to the integrity of the dealers themselves, and made no attempt to enforce the law. The natural consequence was almost universal breaking of the law. The farmers took the highest price they could get, while the millers desired high prices so that the price of flour would be kept up, and they would be able to secure large profits on their stocks of wheat which they had purchased at 3s. 6d. per bushel, and under, before August.

By selling equal quantities of wheat and oats at the same time, it was an easy matter to evade the regulations. Nominally, the wheat was sold at the regulation price, but by selling the oats at a figure much in excess of their market value, an illicit addition was made to the price of wheat. Then, again, in selling wheat, exorbitant figures were paid for the sacks. The custom is to allow 1d. lower than cost price for these; that is, the miller pays $7 \mathrm{~d}$. or $8 \mathrm{~d}$. for each sack, and he afterwards has the use of an almost new sack in which to distribute his flour. By selling the sacks at prices ranging from $2 \mathrm{~s}$. to $3 \mathrm{~s}$. each the farmer easily evaded the law, and as much as $9 \mathrm{~d}$. or $10 \mathrm{~d}$. per bushel was added to the regulation price of wheat, for each sack contains only $3 \frac{1}{3}$ bushels.

Furthermore, secret dealings were made with very little trouble, so that the law was evaded on all sides. In short, the wheat industry, as organised in New Zealand, was the last one in which price control should have been attempted. It was easy to fix a "reasonable" 
price; but the administration of the law was a matter of extreme difficulty. Whether such was recognised by the Government is a matter for speculation. There is certainly no doubt that no serious attempt was made to enforce the law rigorously. Failure was admitted by the Government, but the Prime Minister in making the admission attributed it to the fact that regulation of economic forces is no greater a possibility than controlling "the laws of the universe." But New Zealand has not been alone in price-fixing experiments. In Australia the policy of price fixation has been adopted on a fairly large scale by all the States except Tasmania, and latterly by the Federal Government. The methods adopted have been two-fold; first, direct price-fixing legislation; and secondly, indirect legislation, such as anti-trust legislation, state purchasing, or state marketing. The former method has been the most common. In a recent work on Price Fixing in Australia, Mr. H. L. Wilkinson concludes that the policy has not been successful. "When the legislation was first proposed, and the price-fixing tribunals began their operations, only the ultra-conservative section of the Australian people opposed price fixing, or were openly doubtful of its efficacy. After some two years of the operations of the policy, it has become generally recognised that, although fixing maximum rates may keep prices down for the time being, it has not to any appreciable extent, at any rate, prevented a very large increase in the cost of living throughout the Commonwealth. The more strenuous advocates of the policy point to certain conspicuous successes, and put its apparent failure in other cases down to incapacity or want of energy on the part of the price-fixing tribunals or the Governments, but the mass of the people have become very sceptical as to the policy being of much advantage to them in the long run." Undoubtedly the policy has prevented certain forms of exploitation, and has 
regulated scarcity values to some extent. But, generally speaking, the problem has not been attacked in a comprehensive manner. The piece-meal policy of most of the State Governments has resulted in dissatisfaction to both producer and consumer. At present, pricefixing is chiefly in the hands of Federal Prices Commissioners, whose policy it is to establish fair competitive rates with rises or falls according to the trend of general prices.

The same may be said of other countries where this policy has been adopted. The British Government first tried direct price fixing, but the heavy importations of food-stuffs made this a difficult matter, and now the policy in regard to the more necessary commodities is for the Government to purchase supplies and re-distribute them. In some cases the goods are sold at lower than the cost price to the Government, and the loss is a charge on the general revenue of the country. The German Government, too, has found price fixing a relative failure, and has taken up the policy of commandeering and nationalising supplies together with restrictions and prohibitions of the consumption of various articles. All this proves that the determination of prices is a very complex problem, and the attainment of a stable standard of value is quite as difficult as economists have for many years endeavoured to show.

(e) The Policy of Commandeering the Supply.-The following paragraphs appeared in the original manuscript of this work as it was presented in November, 1915, for academic purposes. At the time it was written many others interested in the problem were in agreement with the policy laid down. It is interesting to observe how time has proved the necessity for it:-

"There was much discussion about the State taking over the milling industry, and also establishing State bakeries. But these were more of the nature of threats than proposed actions; for the difficulties of the situation 
were so great as to cause our already timid legislature to abandon any definite policy, and the threats fell on deaf ears. A more rational procedure would have been the public purchase of all wheat supplies at a fixed maximum price. The State having thus commandeered the whole supply, it could have been parcelled out to the millers at a fixed price also, and probably high enough to pay the State for its action. As it was, the whole supply was raised to the consumer, and the Government lost very considerably, with the result that not only the failure of the enterprise, but the additional burden on the tax-payers, caused by the loss on the Government wheat, called forth severe criticism from all parts of the country. Difficulties, no one will deny, beset the path of the policy of purchasing the whole supply, but if drastic action were necessary, these difficulties were easier to overcome than the corresponding obstacles in the way of price control. It is not unlikely that the eo-operation of the grain merchants could have been obtained, had the Government shown itself firm from the outset."

This is precisely what the Government has now done. After December, 1917, all wheat for milling is to be purchased by Government brokers under the charge of the Wheat controller, who is the Chairman of the Board of Trade. The Wheat Controller will then allocate to each flour-mill its due quota of wheat. Thus not only is the price fixed, but private dealing which hitherto has been a considerable obstacle to a successful policy of price control is abolished. If some form of control is necessary, this is probably the best form. If the Government is successful in administering the scheme satisfactorily any opposition will be beaten down. There is reason to believe that the scheme is now viewed with favour among the various "interests" concerned, and when the general public realise that the price fixed is 
the result of much inquiry, it will receive general support. In fixing the price at what seems so high a figure the Board of Trade had to consider the amount sufficient not only to cover the cost of production, but also to encourage growers to produce the supply necessary for home consumption. There is general prejudice against wheat production at present, and many farmers would turn to pastoral pursuits exclusively. But this is trespassing on the grounds of the concluding chapter.

It should be remembered that the Australian wheat crop has been purchased under a somewhat similar scheme for the past three years. A "wheat pool" was arranged by the Governments of the Commonwealth and the States concerned. There is now no private dealing, and the wheat becomes the property of the several State Governments which arrange for sale either by distribution to millers, or by export, through the Australian Wheat Board, which was set up mainly for the purpose of distributing freights among the States, and fixing local prices. The price thus fixed is $4 \mathrm{~s}$. 9d. per bushel, but this does not refer to exported wheat. Growers are paid a fixed minimum price in advance (2s. 6d. per bushel on 1916-17 crop), and the amount which they will ultimately receive is dependent on the price the Governments realise on their exports. Shipping difficulties have been the most serious problem, but in spite of the scarcity of freights the exports during the past eighteen months have been in excess of the averages. So far as my investigations have gone, it seems that the scheme has been more successful than any other type of price control. The special problem of making advancements to farmers on their crops has given it added importance. It seems certain that this method of control will be adopted more generally. The methods of exchange are the real obstacles to price fixation, but by commandeering the supplies this difficulty is removed 


\section{Chapter XI.}

\section{CONCLUSION.}

\section{The Aim of the Investigation.}

In many of its departments economic science has reached the stage at which application to practical problems long since desired is now possible. The fundamental ideas in the general abstract theory are almost universally accepted now, and, while many problems mainly in Distribution and Exchange yet remain unsolved, sufficient work has been done to warrant the application of general theoretical knowledge to practical problems. In a lecture on "Economic Science in Relation to Practice," Prof. Pigou points out emphatically that economics deals with real life, not with mere abstractions; that it should therefore be a practical study. He classifies the sciences as "light-bearing" and "fruit-bearing," according to the nature of the knowledge which they impart, and in a comparison of economies and astronomy, he claims for the former the distinguishing characteristic of "fruit-bearing." While economists in the past have generally and rightly confined their attention to an analysis and interpretation of the facts of economic life, their ultimate aim is undoubtedly the accumulation of scientific experience to guide mankind to those ideals which it is the function of economic ethics to set up. "It has been frequently assumed, even by economists, that pure economics, concerned as it is with general theories, can have but scant relation to the varying succession of particular instances of concrete life. And, indeed, it is sometimes regarded as futile to attempt to bring the two into factual relation. 
But there can be little doubt that the despairing note is due to our ignorance of the empirical laws that bind together the whole social organism. A definite conception of the character and strength of these binding ties must lead to a perception of the direct connection between pure theory and concrete life." *

This recent tendency in economics - the solution of problems of real life by the employment of mathematical and statistical methods to supplement theoretical analysis-is embodied in the growing mass of statistical work undertaken of recent years by the advanced section of writers on economic questions.

So this essay has been written on a small part of the economic field of New Zealand, in the hope that, by presenting some reliable knowledge of one of the Dominion's primary industries, the present position of that industry may be the more fully understood, and a suitable view-point may be found for forecasting the course of future progress. The necessity and opportunity for work of this kind in all departments of New Zealand life are equally great. On account of her homogeneous population, her partial isolation from the world of industry and commerce, her rich natural resources, her opportunities for State enterprise-in short, on account of the peculiar and interesting character of the general social phenomena which her economic life manifests, New Zealand offers a wide field of investigation for the economist,

But the need for investigation is imperative, because of the peculiar sociological activity of the Government. Owing to our lack of the necessary fundamental knowledge of the nature and effects of the very phenomena which our democracy is creating we are in danger of placing our fair country in an embarrassing situation, by the pursuance of such a policy. Little attempt has

"Moore, "Laws of Wages," page 23. 
been made at investigation into social and economic questions, except for political purposes, and these are largely valueless, since the investigators, for the most part, have been imbued with prejudice, and are content with superficial views. It is claimed, therefore, for this essay that it is one of a number of similar investigations undertaken comparatively recently, for the purpose of disseminating wider knowledge of the economic and social problems of the country, the possession of which should be the duty and privilege of every citizen.

\section{The Importance of the Wheat Industry to New Zealand.}

The preceding pages have shown, if nothing else, the relative importance of the wheat industry, and the rural industries generally, in our industrial sphere. There is no need to recapitulate the qualifications of New Zealand for the pursuit of wheat growing. We have already discussed these fully, and made interesting comparisons with conditions prevalent in other countries, in Chapters II. and III. They lie chiefly in a salubrious climate, a rich fertile soil, a well-developed means of transportation and communication, an intelligent and efficient population, and lastly, a good system of democratic government. It is primary production which this country is most suitably adapted for; in fact, it is upon the great primary industries-agricultural and pastoral-together with the extractive industries, that we depend for national existence. The dreams of those who advocate the establishment of manufactures on a large scale cannot, in the normal course of affairs, be realised for generations; for we must of necessity make large annual importations of materials for the internal development of our country, and this brings upon us the obligation of exporting each year products of at least equivalent value. Moreover, the 
burden of our National Debt is pressing upon us with ever-increasing severity. For the maintenance and clearance of this, our resources must be drawn upon extensively, and we must ever stand prepared to meet the demands of our numerous foreign creditors. Just at this point, knowledge of certain economic phenomena is a very valuable aid in estimating the attitude, which we should now and eventually must assume, with reference to our industrial activities. In the light of the comparative cost theory, and of the advantages that should flow from territorial specialisation of production, New Zealand should concentrate attention upon her farming industries, and the development of her natural resources of coal, iron, gold, and timber. The present attitude of a large section of the community, and of our politicians, to manufactures must undergo a considerable change. Our protective policy has as its objective the fostering of many manufacturing industries for which this country is not in reality adapted. The gradual abolition of this protective policy would benefit the community by lowering prices in the protected industries, and by turning the fresh supplies of labour and capital of the country into more profitable channels. The obvious conclusion, then, voiced throughout the preceding pages, is that the wheat industry is of great importance, and the future will witness progress in this industry as in the other great rural industries.

Although indeed in many places our treatment is rather hurried and incomplete, we are nevertheless able to offer a foundation for this conclusion. As already stated, New Zealand must find annually a large surplus of exports to maintain her growing National Debt, which, for the most part, is held outside the country. Eventually, also, this debt will be repaid and repayment will require exportation on an extensive scale. For these purposes, the Dominion must rely upon the constant 
development of her rural industries, and the other industries that naturally follow in their train.

But the question arises: Can the farmer hope to continue growing wheat at a profit? In a recent article* the Director of the Canterbury Agricultural College shows clearly that the cessation of cultivation for cereals would ultimately cause greater loss than the saving in expenses of cultivation. This point has been stressed in many parts of this work, and we are now in a position to state a conclusion of great importance. The system of farming best suited to the wheat producing area is mixed farming. Especially is this the case in Canterbury, where over 70 per cent. of the wheat crop is grown; in this Province, of comparatively recent years the development of the frozen meat industry has rendered pastoral farming a very remunerative pursuit. This accounts very largely for the diminution in the production of wheat, but it is well known that "Prime Canterbury Mutton and Lamb" require special forage during the fattening period. This can be provided for in Canterbury only by the systematic cultivation of the soil, and, as wheat is the most profitable cereal, the farmer will undoubtedly continue production.

But in Chapter VIII we have seen that our farmers are commencing to farm in a more enlightened manner. Though there are still members of the old school of the "eighties" who exploited the soil by their predatory cultivation, their numbers are fast diminishing, and "high farming" is being taken up on all sides. The Agricultural College in the wheat producing area has demonstrated the fact that intensive cultivation on average land induces good yields, and the farming community is at last realising this. We are, then, entering on a new era of farming for New Zealand, in

*The Canterbury Agricultural and Pastoral Journal,' 1914, page 10. 
which intensive cultivation, the application of science, and the beneficial reactions from pastoral farming, will raise our yield and diminish our unitary cost of production which we have already shown in Chapter IX., is even now low enough to provide a good profit in normal seasons.

Wheat production is likely to remain confined to the provinces in which it is now carried on. Throughout the North Island an abundant rainfall provides excellent pastures, and the rise of the dairying and freezing industries has caused unprecedented development in many places. With a minimum of cultivation these vast tracts provide excellent forage for fattening, though not as good as that in Canterbury, while on the mountain ranges thousands of sheep are grazed yearly for the wool they produce. Even greater developments have taken place in the dairying industry, for a rich soil, with a heavy rainfall, provides an abundance of pasture, and the industry has proved a highly profitable one. In the southern portions of the South Island, the late growing season causes harvest operations to be rather late in the autumn, when unfavourable weather conditions often prevail. Moreover, in these districts, wheat gives way to oats, a crop which has been found to be relatively more profitable. Therefore, while the other rural pursuits in the North Island continue to offer a higher profit, it is unlikely that wheat growing will progress to any great extent outside the provinces of Canterbury and North Otago.

\section{Some Subjects for Further Treatment.}

In the investigation of the main problems of the wheat industry, many problems of minor importance to the research have suggested themselves. Some of these have received partial solution, while others have been passed by, with bare mention. 
The farm labour problem has received special consideration throughout, because I am constrained to believe that a solution of this question would go far to solve the whole wheat question. Though the present treatment is preliminary and part of a discussion of the general wheat question, I have been tempted, as one who has spent much time among rural workers, to suggest some improvements; and from a careful study of the whole question, combined with practical experience, have arrived at certain conclusions of fundamental importance, which are set out in Chapters III. and VIII., and are supplemented below.*

In our treatment of problems connected with successful cultivation of the soil, we have still many questions to investigate. The suitability of different manures to New Zealand soils is, rightly speaking, a matter for the agricultural chemist, whose conclusions should form the hypotheses with which a treatment of the question in a work of this kind should commence; for the economist, as such, is concerned with the physical and natural sciences, only in so far as the conclusions arrived at by these affect his premises and deductions.

On the problems of fallowing and irrigation, I had collected much information from experimental farms in the United States of America and Victoria. As was shown in Chapter III., fallowing is important in New Zealand, and experience in the United States of America supplements the important deductions made in the treatment given in that Chapter. Experiments carried out in California, where the so-called system of "dry" farming is in operation, are of particular importance to the dry regions in Central Otago, and attention to this question there would be well repaid. Irrigation is also a problem of vital importance, in that portion of the wheat growing area known as the Canterbury Plains. Although several

"See page 291. 
rivers traverse these plains from the mountains, for some time great inconvenience was experienced, owing to the lack of water in the districts lying between the rivers. Since the country has been intersected with innumerable water-races this difficulty has been largely surmounted, but there are still many problems of irrigation which remain unsolved.

The experiments carried out at the Agricultural Colleges, and in particular at the Canterbury Agricultural College, should prove an interesting chapter in a work on Agriculture in New Zealand. Not only has it been demonstrated that our lands yield between 30 and 50 bushels of wheat per acre if farmed on scientific principles, thus proving the efficacy of intensive culture, but many other questions, - such as the endeavour to discover a variety for New Zealand which will adjust itself to the peculiar conditions of the country, or, again, the prevention of smut and other pests in wheat, and the processes by which noxious weeds can best be exterminated, - are receiving the closest attention on the farms connected with these Colleges. Much good might be done by a treatise which would bring this work under the notice of farmers even more than it is at present. Dr. Hilgendorf has done this for the problem of wheat selection by his contribution in Chapter V. of this work.

Among other problems which provide ample scope for future research work is one, the probable solution of which I had anticipated at the outset. In Australia, where the conditions of successful study are more closely realised, the problem has received a fairly definite solution.

It was my intention to discover the connection, if any, between the yield per acre and the rainfall for New Zealand. The steps taken to discover this connection need not be described again here; they are set out in Chapter III. The chief difficulty has been lack of 
suitable data. No farmer with whom I came in contact was able to give me any record of yield for more than a very few years, while there was almost a total lack of rainfall statisties. The Statistics of New Zealand do not give sufficient information for an intensive investigation. The yield records refer to a whole Province, while rainfall is measured at a few widely scattered meteorological stations only. Until reliable information from many centres is forthcoming, a satisfactory solution is not obtainable. The hope for this lies in the future, but meanwhile we have made some suggestions.*

I had also collected some information on temperature, and wind, in the wheat growing area, but unfortunately it was found impossible to get complete data, and as the official statistics were open to the same objection as those for rainfall, an attempt to ascertain correlation was abandoned.

On all these questions relating to the association between general climatic conditions and the wheat yield, much valuable information is being collected from year to year at the Canterbury Agricultural College. Some of this I have set out in graphic form elsewhere. $\dagger$

\section{Some Suggestions.}

But although we are far from claiming for our investigation the merit of comprehensiveness, there emerge from our work, as far as it goes, certain definite conclusions not without value in stimulating an industry, the prosperity of which largely conditions our national economic welfare and general well-being.

In the first place, farmers must devote more attention to scientific practice. Intensive methods of cultivation with a systematic rotation of crops have proved most effective, and should convince the most conservative

* See Chapter III., page 46.

tSee page 44. 
that any other method will bring ultimate loss. Our farming community, on the whole very intelligent, should have no difficulty in adapting itself to new conditions in the light of the convincing evidence. Too much stress cannot be laid upon the necessity for intensive culture and a skilful crop rotation system, the importance and beneficial effects of which have been proved beyond doubt.*

The solution of the labour problem presents greater difficulties. The real hope for improvement lies in the fostering of greater sympathy between farmers and labourers, in a better understanding of the whole labour problem by farmers in general, and in a new conception of the duties and responsibilities of a farm labourer on the part of our workers, and our whole democracy. The attainment of these much desired objects lies along many and devious paths. Farm labour must be classed as highly skilled, with a necessary probationary period. But many workers expect to receive full wages in return for untrained service, and the incompetence and irresponsibility of this section of labour has caused the farmer much annoyance, and contributed largely to determine his general attitude to labour problems. On the other hand the betterment of social life, together with improved working conditions for rural labourers, especially married men, would more than repay farmers the necessary outlay. The progress of rural education, notably agricultural, would go far towards attracting: more people to the country, while the abolition of an unwise protective policy would retard the present rate of rural exodus. Lastly, and most important of all, the adoption of a more liberal system of general education would broaden the outlook of all classes and foster a true appreciation of individual worth. In particular for this purpose attention should be paid to the

*See Chapter III. and Chapter VIII. 
teaching of civic rights and duties, history and economics, and everything making for a due appreciation of the citizen's place in the Dominion, and the Dominion's place in the world.

Not so many difficulties arise in finding methods for improving Nature's bounty, for our little country enjoys a climate, with a few exceptions, second to none in the world. Her soil is rich and fertile, and well watered by numerous streams and rivers. A more rational procedure with reference to manures would be of considerable benefit; while progress in irrigation in places would react very favourably, as, for example, in Central Otago, where a rich soil is found with a rainfall of little more than 10 inches.

In marketing there are many possible improvements to be desired. The most profitable advance would be the establishment of a grading system, but there are so many obstacles in the way that it is doubtful whether at present it would be successful. But I would suggest the establishment of some central institution to which farmers might submit their samples for grading. After being notified of the grade or sub-grade of their wheat, they could place it on the market, either directly themselves, or indirectly through the institution. Millers would no doubt regard the numerous varieties in New Zealand as an obstacle to the adoption of such a scheme; they say that New Zealand soils yield wheats of widely varying qualities. But our area is relatively small, and when grading is possible for such wide tracts as the Canadian wheat field, this objection is at first sight hardly worth consideration. Upon close scrutiny of the problem it is evident that the difficulties are not insuperable, while the advantages would outweigh the expenses in administration. Such an organisation should supply farmers and others with complete information in regard to marketing, and might even arrange for marketing 
rural produce on the lines of the State Market Commissions in many States of America.* But it should be free from political control.

The transportation problem presents some formidable questions, especially for those producers who are situated at a distance from the railway. It is unfortunate that our main line in the South Island should run so close to the seashore, throughout the length of the wheat producing area. It is also unfortunate that the railway claims of many districts, only very sparsely populated, should have received consideration from politicians in preference to those of the more densely peopled districts in the wheat area. Railway communication has been pushed to extremes in the former districts, notably in Central Otago and Southland, while little development has taken place in Canterbury during the last three decades.

A further important suggestion refers to the means for improving farm management. The principles of scientific management, in so far as they can be applied to agriculture in New Zealand, would improve the general efficiency of the rural producer. Our farmers must develop foresight and ingenuity, qualities which are necessary for good management in any sphere. A skilful rotation of crops; an eye to the net advantages to be gained in pursuing any one method of cultivation; the ability to discern the point when the margin of profitable cultivation has been reached in any process; a careful balancing of the two main pursuits-agricultural and pastoral-; tactful handling of his men so that he may secure their individual initiative and their goodwill and esteem; a knowledge of commercial functions - or sufficient discernment to select sound commercial specialists as agents to transact his trading

*See Article by Prof. Plehn in the "American Economic Review," March, 1918. Vol. VIII., No. 1, pages 1-27. 
ventures; all these are essential qualities of a successful farmer in these days of high specialisation and keen competition.

Finally, steps should be taken to disseminate accurate and complete information re the art of agriculture and its related sciences, more widely than is done at present. Some excellent opportunities for this already exist in the form of several publications, the most important of which are The Journal of Agriculture, The Canterbury Agricultural College Magazine, The Journal of the Canterbury Agricultural and Pastoral Association, and The Farmers' Union Advocate. By making greater provision for authoritative articles on agriculture, including its economics, a phase of the subject much neglected in New Zealand, by summarising official statistics, and by securing accurate market reports, these journals would stimulate progress along many of the lines I have already indicated. It is only by providing the farmer with material likely to increase his returns that the journals can hope to attain a wide circulation. At present, in spite of the excellent quality of much of the material that appears in the agricultural sections of the weekly papers, farmers as a body are but poorly read even in local agricultural literature.

This brief résumé of the various lines of improvement which this investigation has suggested, is by no means exhaustive. A careful consideration of the text throughout reveals many others, such as improvements in the land tenure system, some tangible form of Government encouragement in the way of establishing an Experimental Farm in South Canterbury, improved methods of harvesting, better facilities for exportation, and so forth. I have selected those most practicable and of immediate importance for statement here. 


\section{Future Prospects.}

What, then, is the prospect for the future, immediate and ultimate? The present decade may be regarded as the close of the first great period in the history of wheat production in New Zealand. We have reached a trough in the graph, the lowest since the middle "seventies." While there have been periodic fluctuations during the intervening years, there was a steady rise from 1870 until the early "nineties," then a period of stagnation, followed by a gradually falling tendency. The next 30 or 40 years may witness a similar general movement with higher average annual production throughout.

The present upward tendency of general prices which commenced in 1895 is likely to continue, although production in all spheres will be increased greatly; for the factors on the money side of the "equation of exchange" will probably all increase at a greater rate than the increase in production. This is the view advanced by Dr. Fisher,* who thinks that the present increase in the gold production will reach a maximum in a few years, and then gradually decline. But this does not mean that prices will fall immediately, for the supply of gold may still be in excess of the demand, and in any case the yearly addition is but a small fraction of the total supply. Moreover, gold is but a small fraction of the total circulating media, and, even though credit is based upon the amount of gold in circulation, the diminished supply of the latter will not affect the total supply greatly for a long period, so that a great expansion in credit may still continue. Professor Fisher has a masterly grasp of the subject, and his forecast is based upon absolutely reliable facts.

Now, we have seen clearly in Chapter VII., that in normal times New Zealand prices are determined by conditions operating in markets which are world-wide. Anything which affects prices in the outside world

*See "Will the Present Upward Trend of Prices Continue?" in the "American Economic Review," 1912; and his subsequent annual brief articles on the "Equation of Exchange and Forecast," in the same "Review." 
quickly reacts on New Zealand prices. Dr. McIlraith, in his Course of Prices in New Zealand, has shown that there is a close connection between New Zealand prices and English prices, and there seems to be no reason why this connection should weaken. The general scarcity of rural produce caused by the depredations of war has increased the rise in general prices. We may, therefore, conclude that prices in New Zealand will continue to rise.

Now, in the immediate future wheat prices are likely to remain high, not only because of the conditions stated above, but also because there will, in all probability, be a retardation in the rate of production for the world. Exports from the United States of America are decreasing yearly, and this country will gradually lose her commanding position in the world's markets. Russia is embroiled in a great and devastating war, from which she is not likely to be released for some time. Even after peace, that country, in common with many others, will produce for some time with greatly impaired factors. The rapidly rising standard of comfort in India will diminish her exports in the immediate future, even though her production may increase. China and Japan will demand an ever increasing quantity, and assist materially in keeping prices high.

In Canada and Argentina progress is inevitable during the next few years. These countries, especially the former, are ready to develop at a very rapid rate if only the opportunity is forthcoming, and in the immediate future prices will be high and production there will continue to progress. Wheat producers may therefore look forward to the coming ten years at least with comparative satisfaction to reasonably high prices.

Ultimately, however, we shall reach another stage in which wheat production may prove relatively unprofitable;* for the total supplies of the world will steadily increase and thus tend to lower prices or, at least, to

\footnotetext{
*See footnote on page 297.
} 
retard the upward trend of wheat prices at a time when general prices are rising. Russia and the other great European areas will have recovered from the effects of this titanic struggle, and will be refreshed and invigorated by the very war which caused so much misery, for a new spirit will rise within the various empires. Once more production will increase greatly, for wheat is the staple product of many countries. Thus, Siberia will probably open out her vast tracts for cultivation; and in Russia, too, expansion will proceed apace. Canada, Argentina, and Australia, where the possibilities of extension are at a maximum, will, under the stimulus of high prices, all have increased their production enormously. It is not unreasonable, therefore, to suppose that the supply will once more partially exceed the demand, a position which has been reached for a few years prior to the War. Prices will then fall, and in New Zealand a diminution in production will be experienced, but not a very great one, for our system of farming will render decrease on a large scale unwise. A period of stagnation is likely to ensue beyond which any further forecast would lead us into the distant future, where we should be treading on very uncertain ground.

But the most important consideration is the problem

*The general question of the cost of production has been fully discussed in Chapter IX. It remains here to add a note on the question of high land values. Many contend that the high price of land is a cause of the decrease in production. The factors responsible for high land values are discussed in Chapter IX., but it may be that the expectation of good returns from pastoral farming is an important one. But it must be remembered that it is the returns from mixed farming which determine land values in the wheat producing area, and high land values are not a cause of high prices. More accurate is the view that high prices tend to raise the price of land, and the question as to whether high profits from pastoral farming will cause a decrease in the production of wheat depends on the whole problem as to whether mixed farming is the best policy for the wheat producing area. It is contended throughout this work that mixed farming is the most efficient method. (See Chapter VI., Section $8,(a)$ ). 
of actual production in the near future. There is every reason to suppose that wheat production will be a profitable pursuit for many years. But there has been a serious reaction in the farming community against the pursuit, and this may prove embarrassing; and the people would be well advised to proceed upon a more sound understanding in dealing with the problem. Certainly it would seem that the farmers in Canterbury will find it to their interests to continue the practice of mixed farming, and thus to grow small quantities of wheat. A rising market will bring its own reward. Should shortage occur again, the Government will have more reliable information than during the recent "wheat crisis," and will doubtless have supplies from abroad under consideration. It is considered by some that it would be a wise policy to import our supplies of wheat and thus to obviate the controversies and difficulties which the wheat question gives rise to. If, however, the Government attempts to encourage the industry on the general lines indicated above, and to convince the rural community and the people generally of the extreme importance of wheat production to the Dominion, then the future, both immediate and ultimate, should be no cause for anxiety. The War, however destructive it seems, will benefit New Zealand materially in so far as it raises the price of primary produce, and perhaps most of all the wheat industry, in the output of which a general world-wide shortage is anticipated. If our investigation does nothing more than allay apprehension regarding the present apparently decadent state of the industry, a useful function will be performed. A young country, with abundant natural resources, an excellent climate, a rich fertile soil, a vigorous and energetic population, and last, and most important of all, a comparatively highly educated and well governed democracy, may look towards the future with serenity, and the expectation of increasing prosperity. 


\section{APPENDIX I.}

TABLE XXXVIII.

WHEAT IN NEW ZEALAND.

Exports, Imports, Area, Total Production, in New Zealand, with index numbers and actual prices in New Zealand and England, and index numbers of the price of agricultural land.

\begin{tabular}{|c|c|c|c|c|c|c|c|c|c|c|}
\hline \multirow[b]{2}{*}{ YEAR } & \multirow[b]{2}{*}{ Im- } & \multirow[b]{2}{*}{ Export } & \multirow{2}{*}{$\begin{array}{l}\text { Area } \\
\text { for } \\
\text { N.Z. }\end{array}$} & \multirow{2}{*}{$\begin{array}{c}\text { Total } \\
\text { Pro- } \\
\text { duetion }\end{array}$} & \multicolumn{5}{|c|}{ PRICES } & \multirow{2}{*}{\begin{tabular}{|c} 
Index \\
Nos. of \\
Priceof \\
Agric'll. \\
Land \\
\end{tabular}} \\
\hline & & & & & $\begin{array}{l}\text { Index } \\
\text { Nos. } \\
\text { N.Z. }\end{array}$ & $\mid \begin{array}{c}\text { Index } \\
\text { Nos. } \\
\text { Eng. }\end{array}$ & $\begin{array}{l}\text { Actu } \\
\text { N.Z }\end{array}$ & ual & $\begin{array}{l}\text { Actual } \\
\text { England }\end{array}$ & \\
\hline & $\begin{array}{l}000 \\
\text { bus. }\end{array}$ & $\begin{array}{l}000 \\
\text { bus. }\end{array}$ & $\begin{array}{l}.000 \\
\text { acres }\end{array}$ & $\begin{array}{l}.000 \\
\text { bus. }\end{array}$ & $\begin{array}{r}3-5 \text { ths } \\
=100\end{array}$ & $\left|\begin{array}{c}3-7 \operatorname{ths} \\
=100\end{array}\right|$ & $\begin{array}{l}\text { per } \\
\text { bus }\end{array}$ & & $\begin{array}{l}\text { per } \\
\text { bus. }\end{array}$ & $£ 17=100$ \\
\hline 1869 & 183 & 82 & 65 & 1619 & 124 & 168 & & 3 & 601 & 19 \\
\hline 1870 & 86 & 387 & 86 & 2348 & 111 & 164 & 3 & $9 \frac{1}{2}$ & $510 \frac{4}{2}$ & 19 \\
\hline 71 & 159 & 272 & 78 & 1834 & 137 & 198 & 4 & & $71^{2}$ & - \\
\hline 72 & 73 & 477 & 109 & 2448 & 129 & 199 & 4 & $4 \frac{\overline{3}}{4}$ & $7 \quad 1 \frac{1}{2}$ & 16 \\
\hline 73 & 59 & 537 & 132 & 3189 & 140 & 205 & 4 & $9 \frac{1}{4}$ & 74 & - \\
\hline 74 & 9 & 933 & 192 & 3392 & 135 & 194 & 4 & & $611 \frac{1}{2}$ & - \\
\hline 75 & 109 & 548 & 106 & 2974 & 122 & 158 & 4 & 2 & $57 \frac{3}{4}$ & 38 \\
\hline 76 & 59 & 686 & 91 & 2864 & 126 & 159 & 4 & $3 \frac{3}{4}$ & $\begin{array}{ll}5 & 9 \frac{7}{4}\end{array}$ & 56 \\
\hline 77 & 98 & 860 & 142 & 4054 & 176 & 198 & 6 & 0 & $71^{4}$ & 34 \\
\hline 78 & 68 & 1701 & 243 & 6336 & 136 & 162 & & $7 \frac{3}{4}$ & $59 \frac{8}{4}$ & 165 \\
\hline 79 & - & 2518 & 265 & 6077 & 116 & 153 & & $11 \frac{3}{4}$ & $\begin{array}{ll}5 & 5 \frac{3}{4}\end{array}$ & 66 \\
\hline 1880 & 96 & 3120 & 270 & 7610 & 122 & 155 & 4 & 2 & $56 \frac{1}{2}$ & 77 \\
\hline 81 & 23 & 3761 & 325 & 8148 & 120 & 158 & & $1 \frac{1}{4}$ & 58 & 129 \\
\hline 82 & 15 & 3189 & 366 & 8298 & 126 & 157 & 4 & $3 \frac{2}{2}$ & $\begin{array}{ll}5 & 7 \frac{1}{2}\end{array}$ & 92 \\
\hline 83 & 65 & 4898 & 391 & 10271 & 124 & 145 & 4 & $3^{6}$ & $52 \frac{1}{2}$ & 129 \\
\hline 84 & 5 & 2706 & 378 & 9827 & 106 & 124 & & $7 \frac{1}{4}$ & $45 \frac{1}{2}$ & 117 \\
\hline 85 & 4 & 1359 & 270 & 6867 & 87 & 115 & & $11 \frac{3}{4}$ & & 83 \\
\hline 86 & 9 & 1252 & 174 & 4242 & 110 & 108 & & $9 \frac{7}{4}$ & $310 \frac{7}{2}$ & 148 \\
\hline 87 & 10 & 630 & 253 & 6298 & 109 & 113 & 3 & $8 \frac{3}{4}$ & $40 \frac{3}{4}$ & 85 \\
\hline 88 & 2 & 2308 & 357 & 9424 & 88 & 111 & 3 & 0 & 3 113 & No Sales \\
\hline 89 & - & 2694 & 362 & 8770 & 113 & 103 & & $10 \frac{1}{2}$ & $38 \frac{1}{2}$ & 108 \\
\hline 1890 & - & 4467 & 336 & 8449 & 92 & 112 & 3 & $1 \frac{8}{4}$ & 40 & 91 \\
\hline 91 & - & 1455 & 301 & 5724 & 113 & 129 & & $10 \frac{7}{2}$ & & 76 \\
\hline 92 & 1 & 2461 & 402 & 10258 & 117 & 106 & 4 & 0 & & 89 \\
\hline 93 & - & 2619 & 381 & 8378 & 81 & 92 & 2 & 91 & & 123 \\
\hline 94 & 58 & 229 & 243 & 4892 & 73 & 80 & 2 & $5 \frac{3}{4}$ & $210 \frac{1}{4}$ & 80 \\
\hline 95 & 99 & 1 & 9 & 3613 & 86 & 80 & & $11 \frac{1}{4}$ & $210 \frac{7}{2}$ & 76 \\
\hline 96 & 5 & 453 & 245 & 6844 & 106 & 92 & 3 & $7 \frac{3}{4}$ & $33 \frac{1}{4}$ & 117 \\
\hline 97 & 61 & 72 & & 5927 & 125 & 106 & 4 & $3 \frac{17}{4}$ & $39 \frac{9}{4}$ & 124 \\
\hline 98 & 2 & 10 & 316 & 5670 & 124 & 119 & 4 & 2 & 43 & 120 \\
\hline 99 & - & 2902 & 399 & 13073 & 75 & 90 & 2 & 6 & $\begin{array}{ll}3 & 2 \frac{1}{2}\end{array}$ & 132 \\
\hline 1900 & - & 2867 & 270 & 8582 & 70 & 94 & 2 & $4 \frac{8}{4}$ & $34 \frac{1}{2}$ & 136 \\
\hline 01 & 2 & 2301 & 206 & 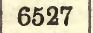 & 71 & 93 & 2 & $5 \frac{1}{8}$ & $\begin{array}{ll}3 & 4\end{array}$ & 112 \\
\hline 0 & - & 195 & 1 & 7 & 103 & 98 & 3 & 6 & & 153 \\
\hline 03 & - & 72 & 194 & 7458 & 122 & 93 & 4 & 2 & 34 & 158 \\
\hline 04 & - & 814 & 2 & 78 & 92 & 99 & 3 & 1 & $\begin{array}{ll}3 & 6 \frac{1}{2}\end{array}$ & 137 \\
\hline 05 & 1 & 967 & 258 & 9124 & 92 & 103 & 3 & 1 & & 149 \\
\hline 06 & - & 61 & 222 & 6799 & 94 & 99 & 3 & $2 \frac{1}{2}$ & $36 \frac{1}{2}$ & 212 \\
\hline 07 & 39 & 1 & 206 & 56 & 110 & 107 & 3 & 0 & 310 & 200 \\
\hline 08 & 26 & 1 & 193 & 5567 & 135 & 112 & 4 & $7 \frac{1}{2}$ & 40 & 217 \\
\hline 0 & 66 & 1419 & 252 & 8773 & 120 & 129 & & 1 & $4 \quad 7 \frac{1}{2}$ & 193 \\
\hline 1910 & 3 & 1294 & 311 & 8783 & 107 & 110 & 3 & 8 & $311 \frac{1}{2}$ & 217 \\
\hline 1. & 11 & 1254 & 322 & 8290 & 110 & 110 & 3 & 9 & $311 \frac{1}{2}$ & 212 \\
\hline 12 & 1 & 505 & 216 & 72 & 107 & 121 & & 8 & 44 & 227 \\
\hline 13 & - & 62 & 190 & 5180 & 112 & 112 & & 10 & 40 & 207 \\
\hline 14 & 121 & 17 & 167 & 5232 & 168 & 140 & 5 & 9 & 5 & 206 \\
\hline 15 & 546 & .4 & 230 & 6644 & 180 & 189 & 6 & 2 & $\begin{array}{ll}6 & 9\end{array}$ & \\
\hline 10 & & & 329 & 7108 & 156 & 202 & & & 7 & \\
\hline
\end{tabular}


TABLE XXXIX.

WHEAT IN NEW ZEALAND.

Area in acres, for New Zealand, Canterbury, and Otago, with total Yields and Populations.

\begin{tabular}{|c|c|c|c|c|c|c|c|c|c|}
\hline \multirow{3}{*}{ Year } & \multicolumn{3}{|c|}{ New Zealand } & \multicolumn{3}{|c|}{ Canterbury } & \multicolumn{3}{|c|}{ Otago } \\
\hline & $\begin{array}{c}\text { Area } \\
\text { Acres }\end{array}$ & \begin{tabular}{|c|} 
Total \\
Yields \\
Bush'ls
\end{tabular} & $\begin{array}{c}\text { Popula } \\
\text { tion }\end{array}$ & $\begin{array}{l}\text { Area } \\
\text { Acres }\end{array}$ & \begin{tabular}{|c} 
Total \\
Yields \\
Bush'ls
\end{tabular} & $\begin{array}{c}\text { Popula } \\
\text { tion }\end{array}$ & $\begin{array}{l}\text { Area } \\
\text { Acres }\end{array}$ & \begin{tabular}{|c} 
Total \\
Yields \\
Bush'ls
\end{tabular} & $\begin{array}{l}\text { Popula } \\
\text { tion }\end{array}$ \\
\hline & .000 & .000 & .000 & .000 &, 000 &, 000 & .000 & .000 &, 000 \\
\hline 1869 & 65 & 1619 & 227 & 33 & 724 & 41 & 21 & 712 & 60 \\
\hline & 86 & 2348 & & 52 & & 43 & 22 & & 64 \\
\hline 71 & 78 & 1834 & 8 & 46 & & 47 & 23 & & \\
\hline 72 & 109 & 2448 & & 63 & 1363 & 49 & 34 & 884 & 74 \\
\hline 7 & 32 & 3. & & 68 & & & 51 & 1489 & \\
\hline 7 & 132 & 3392 & 296 & 71 & 7 & 55 & 51 & 1490 & 83 \\
\hline 7 & 106 & 2974 & 342 & 70 & 1828 & 71 & 28 & 980 & 98 \\
\hline 7 & 91 & 2 & & 58 & & 79 & 26 & 950 & 110 \\
\hline 7 & 142 & 4054 & & 92 & 2603 & 84 & 41 & 1235 & 116 \\
\hline 7 & 243 & 63 & & 147 & & ת & 27 & & 114 \\
\hline 7 & 265 & 60 & & & & 96 & 7 & & 120 \\
\hline 188 & 270 & 7610 & & 4 & & 104 & 54 & 6 & 132 \\
\hline & 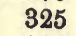 & 81 & & & & & 0 & & 34 \\
\hline 8 & 366 & 8298 & & & & 15 & 7 & 0 & 37 \\
\hline 8 & 391 & 10271 & & 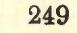 & & & 5 & & 41 \\
\hline 8 & 378 & 98 & & 1 & & & & & 48 \\
\hline & 270 & 68 & & 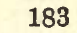 & & & 4 & 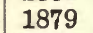 & \\
\hline 8 & & 42 & & 120 & & & 9 & 7 & 147 \\
\hline & & 629 & & & & & 1 & & 151 \\
\hline 8 & 1 & 94 & & 238 & & & 84 & 2519 & 55 \\
\hline 8 & 3 & 87 & & 2 & & & 81 & 2224 & 00 \\
\hline 189 & 336 & 84 & & 229 & & & 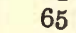 & 35 & 50 \\
\hline 9 & 301 & 57 & & 212 & & & r & 1240 & 153 \\
\hline 9 & & $102 t$ & & & & & 5 & & 55 \\
\hline 9 & L & 8 & & & & & & & 59 \\
\hline 9 & & & & 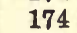 & & & 5 & 1162 & 164 \\
\hline 9 & & & & & & & & & 167 \\
\hline 9 & & & & 169 & & & & & 164 \\
\hline 9 & & & & & & & & & 167 \\
\hline & & & & & & & & & 169 \\
\hline 9 & 399 & 130 & & 250 & & & 100 & & 172 \\
\hline $19 c$ & & & & & & & & 21 & 17 \\
\hline 0 & & & & & & & & & \\
\hline 0 & & & & 0 & & & & & 76 \\
\hline & & & & & & & & & 180 \\
\hline 0 & 23 & & & 159 & & & & & \\
\hline 0 & & & & & & & & & 190 \\
\hline & 2 & & & 1 & & & & 1632 & \\
\hline 0 & $2 C$ & 56 & & 1 & & & 45 & 912 & 180 \\
\hline 0 & & & & & & & 56 & & 189 \\
\hline 0 & & & & 183 & & & & & \\
\hline 191 & 31 & & & 210 & & & & 1612 & 195 \\
\hline & 3 & & & 2 & & & 3 & 1125 & 10 \\
\hline & 21 & 72 & & 146 & & $1 \varepsilon$ & 31 & 884 & 199 \\
\hline & 19 & 51 & 10 & 148 & 3922 & 184 & 43 & 1234 & 20 \\
\hline & 167 & 5232 & 1096 & & & & & & \\
\hline
\end{tabular}


TABLE XI.

WHEAT IN NEW ZEALAND.

Yields for New Zealand, Canterbury and Otago, in bushels per acre, with decennial moving averages.

\begin{tabular}{|c|c|c|c|c|c|c|}
\hline \multirow{2}{*}{ Year } & \multicolumn{2}{|c|}{ NEW ZEALAND } & \multicolumn{2}{|c|}{ CANTERBURY } & \multicolumn{2}{|c|}{ OTAGO } \\
\hline & Yield & $\begin{array}{l}\text { Moving } \\
\text { Average }\end{array}$ & Yield & $\begin{array}{l}\text { Moving } \\
\text { Average }\end{array}$ & Yield & $\begin{array}{l}\text { Moving } \\
\text { Average }\end{array}$ \\
\hline 1869 & 25.2 & ... & 21.9 & ... & 33.9 & $\cdots$ \\
\hline 1870 & 27.3 & $\ldots$ & 27.8 & $\ldots$ & 29.2 & $\ldots$ \\
\hline 71 & 23.5 & ... & 22.3 & ... & 28.8 & ... \\
\hline 72 & 22.5 & $\ldots$ & 21.5 & ... & 26.0 & $\ldots$ \\
\hline 73 & 24.0 & 26.3 & 21.8 & 25.7 & 29.3 & 31.1 \\
\hline 74 & 25.5 & 26.0 & 23.8 & 25.9 & 29.8 & 30.5 \\
\hline 75 & 28.0 & 26.1 & 26.0 & 25.9 & 34.8 & 30.0 \\
\hline 76 & 31.5 & 26.3 & 30.8 & 26.0 & 36.5 & 30.9 \\
\hline 77 & 28.5 & 26.3 & 28.3 & 26.1 & 30.3 & 30.8 \\
\hline 78 & 26.5 & 26.5 & 32.3 & 26.4 & 32.3 & 30.9 \\
\hline 79 & 23.0 & 26.6 & 24.0 & 26.6 & 28.0 & 30.8 \\
\hline 1880 & 28.0 & 26.3 & 28.0 & 26.4 & 31.8 & 30.2 \\
\hline 81 & 25.0 & 25.6 & 23.8 & 25.7 & 29.8 & 29.5 \\
\hline 82 & 22.7 & 25.2 & 21.3 & 25.3 & 25.7 & 29.3 \\
\hline 83 & 26.3 & 25.2 & 25.5 & 24.5 & 30.0 & 29.0 \\
\hline 84 & 26.0 & 25.2 & 25.6 & 24.4 & 28.3 & 28.9 \\
\hline 85 & 25.4 & 25.0 & 24.3 & 24.0 & 29.3 & 28.5 \\
\hline 86 & 24.4 & 24.4 & 24.0 & 23.5 & 20.7 & 27.6 \\
\hline 87 & 24.9 & 24.6 & 23.7 & 23.8 & 28.0 & 27.8 \\
\hline 88 & 26.4 & 24.2 & 25.0 & 23.4 & 29.9 & 27.3 \\
\hline 89 & 24.2 & 23.6 & 22.9 & 22.8 & 27.3 & 26.6 \\
\hline 1890 & 25.2 & 23.5 & 24.3 & 22.7 & 28.0 & 26.2 \\
\hline 91 & 19.0 & 23.8 & 17.9 & 23.0 & 21.7 & 26.8 \\
\hline 92 & 25.0 & 23.6 & 24.9 & 22.7 & 27.5 & 26.9 \\
\hline 93 & 22.0 & 22.9 & 21.0 & 21.7 & 26.1 & 26.2 \\
\hline 94 & 20.2 & 23.6 & 19.6 & 22.8 & 21.9 & 26.8 \\
\hline 95 & 24.3 & 24.4 & 23.7 & 23.5 & 26.2 & 27.5 \\
\hline 96 & 28.0 & 25.7 & 27.0 & 24.9 & 32.0 & 28.7 \\
\hline 97 & 23.0 & 25.7 & 21.0 & 24.8 & 29.0 & 28.6 \\
\hline 98 & 18.0 & 27.3 & 15.1 & 26.6 & 22.1 & 29.8 \\
\hline 99 & 32.8 & 28.7 & 33.7 & 28.1 & 33.4 & 31.2 \\
\hline 1900 & 31.8 & 29.8 & 31.4 & 29.2 & 35.3 & 32.4 \\
\hline 01 & 31.6 & 30.1 & 31.8 & 29.5 & 33.0 & 32.2 \\
\hline 02 & 24.8 & 30.5 & 23.7 & 30.2 & 27.4 & 31.4 \\
\hline 03 & 38.3 & 31.6 & 39.2 & 31.6 & 37.5 & 32.2 \\
\hline 04 & 34.3 & 31.8 & 34.2 & 31.8 & 36.2 & 32.0 \\
\hline 05 & 35.4 & 31.4 & 35.0 & 31.4 & 37.9 & 30.9 \\
\hline 06 & 30.6 & 30.8 & 30.4 & 30.8 & 30.3 & 31.0 \\
\hline 07 & 27.2 & 31.7 & 28.1 & 31.9 & 20.7 & 31.2 \\
\hline 08 & 28.8 & 30.6 & 29.2 & 30.6 & 30.1 & 30.3 \\
\hline 09 & 34.8 & 30.3 & 35.6 & 30.4 & 31.6 & 29.6 \\
\hline 1910 & 28.2 & ... & 27.8 & ... & 24.6 & ... \\
\hline 11 & 25.7 & ... & 26.0 & ... & 34.1 & ... \\
\hline 12 & 33.7 & ... & $\mathbf{3 4 . 3}$ & ... & 28.5 & ... \\
\hline 13 & 27.3 & ... & 26.6 & ... & 28.7 & ... \\
\hline 14 & 31.4 & $\ldots$ & 31.6 & ... & 29.2 & ... \\
\hline
\end{tabular}


IABLE XLI.

WHEAT IN NEW ZEALAND.

Comparison of Index Numbers of Areas for New Zealand, Canterbury, and Otago, with Yields per acre.

\begin{tabular}{|c|c|c|c|c|c|c|}
\hline \multirow{3}{*}{ YEAR } & \multicolumn{2}{|c|}{ NEW ZEALAND } & \multicolumn{2}{|c|}{ CANTERBURY } & \multicolumn{2}{|c|}{ OTAGO } \\
\hline & $\begin{array}{c}\text { Index of } \\
\text { Area }\end{array}$ & Yields & $\begin{array}{c}\text { Index of } \\
\text { Area. }\end{array}$ & Yields & $\begin{array}{c}\text { Index of } \\
\text { Area }\end{array}$ & Yields \\
\hline & $\begin{array}{r}100= \\
300,000\end{array}$ & $\begin{array}{l}\text { Bushels } \\
\text { per acre }\end{array}$ & $\begin{array}{c}100= \\
207,000\end{array}$ & $\begin{array}{l}\text { Bushels } \\
\text { per acre }\end{array}$ & $\begin{array}{r}100= \\
60,000\end{array}$ & $\begin{array}{l}\text { Bushels } \\
\text { per aore }\end{array}$ \\
\hline 1869 & 21.5 & 25.2 & 17.0 & 21.9 & 35.6 & 33.9 \\
\hline 1870 & 28.7 & 27.3 & 27.0 & 27.9 & 36.5 & 29.2 \\
\hline 71 & 26.6 & 23.5 & 23.7 & 22.3 & 38.0 & 28.8 \\
\hline 72 & 36.2 & 22.5 & 32.3 & 21.5 & 56.1 & 26.0 \\
\hline 73 & 43.7 & 24.0 & 35.2 & 21.8 & 84.6 & 29.3 \\
\hline 74 & 44.1 & 25.5 & 37.0 & 23.8 & 83.4 & 29.8 \\
\hline 75 & 35.2 & 28.0 & 35.9 & 26.0 & 46.9 & 34.8 \\
\hline 76 & 30.3 & 31.5 & 29.7 & 30.8 & 43.3 & 36.5 \\
\hline 77 & 47.2 & 28.5 & 47.6 & 28.3 & 68.0 & 30.3 \\
\hline 78 & 81.1 & 26.5 & 75.8 & 32.3 & 127.7 & 32.3 \\
\hline 79 & 88.3 & 23.0 & 89.5 & 24.0 & 111.6 & 28.0 \\
\hline 1880 & 90.6 & 28.0 & 99.8 & 28.0 & 89.6 & 31.8 \\
\hline 81 & 108.3 & 25.0 & 107.4 & 23.8 & 150.2 & 29.8 \\
\hline 82 & 121.9 & 22.7 & 122.6 & 21.3 & 161.7 & 25.7 \\
\hline 83 & 130.3 & 26.3 & 128.3 & 25.5 & 174.7 & 30.0 \\
\hline 84 & 125.9 & 26.0 & 123.9 & 25.6 & 167.8 & 28.3 \\
\hline 85 & 90.0 & 25.4 & 95.0 & 24.3 & 106.8 & 29.3 \\
\hline 86 & 58.0 & 24.4 & 61.5 & 24.0 & 64.3 & 20.7 \\
\hline 87 & 84.3 & 24.9 & 87.3 & 23.7 & 100.9 & 28.0 \\
\hline 88 & 119.1 & 26.4 & 122.2 & 25.0 & 140.3 & 29.9 \\
\hline 89 & 120.7 & 24.2 & 123.2 & 22.9 & 135.6 & 27.3 \\
\hline 1890 & 112.0 & 25.2 & 117.7 & 24.3 & 109.1 & 28.0 \\
\hline 91 & 100.5 & 19.0 & 109.8 & 17.9 & 95.2 & 21.7 \\
\hline 92 & 134.1 & 25.0 & 146.6 & 24.9 & 141.5 & 27.5 \\
\hline 93 & 127.1 & 22.0 & 140.0 & 21.0 & 135.6 & 26.1 \\
\hline 94 & 80.9 & 20.2 & 89.7 & 19.6 & 88.4 & 21.9 \\
\hline 95 & 49.9 & 24.3 & 55.3 & 23.7 & 52.8 & 26.2 \\
\hline 96 & 81.5 & 28.0 & 87.2 & 27.0 & 83.6 & 32.0 \\
\hline 97 & 86.2 & 23.0 & 90.4 & 21.0 & 97.2 & 29.0 \\
\hline 98 & 105.3 & 18.0 & 103.5 & 15.1 & 134.1 & 22.1 \\
\hline 99 & 133.0 & 32.8 & 128.6 & 33.7 & 166.3 & 33.4 \\
\hline 1900 & 83.2 & 31.8 & 94.2 & 31.4 & 102.4 & 35.3 \\
\hline 01 & 68.8 & 31.6 & 76.0 & 31.8 & 74.1 & 33.0 \\
\hline 02 & 54.5 & 24.8 & 61.7 & 23.7 & 54.3 & 27.4 \\
\hline 03 & 64.8 & 38.4 & 70.2 & 39.2 & 71.4 & 37.5 \\
\hline 04 & 76.8 & $34 \cdot 3$ & 82.1 & 34.2 & 87.2 & 36.2 \\
\hline 05 & 86.0 & 35.4 & 96.4 & 35.0 & 90.7 & 37.9 \\
\hline 06 & 74.1 & 30.6 & 79.6 & 30.4 & 89.3 & 30.3 \\
\hline 07 & 68.7 & 27.2 & 78.5 & 28.1 & 73.7 & 20.7 \\
\hline 08 & 64.3 & 28.8 & 71.9 & 28.2 & 75.5 & 30.1 \\
\hline 09 & 84.1 & 34.8 & 94.2 & 35.6 & 94.1 & 31.6 \\
\hline 1910 & 103.7 & 28.2 & 108.2 & 27.8 & 123.3 & 24.6 \\
\hline 11 & 107.4 & 25.7 & 118.3 & 26.0 & 95.5 & 34.1 \\
\hline 12 & 71.8 & 23.7 & 75.1 & 24.3 & 55.8 & 28.5 \\
\hline 13 & 63.3 & 27.3 & 76.1 & 26.6 & 52.5 & 28.7 \\
\hline 14 & 55.6 & 31.4 & - & 31.6 & 71.6 & 29.2 \\
\hline
\end{tabular}




\section{APPENDIX II.}

\section{THE MEANING OF CORRELATION.}

In Chapters III. and IV.* an attempt has been made to ascertain the relationship between (1) yield of wheat per acre and rainfall in certain months of the year, and (2) the price of wheat in New Zealand and the total supply for New Zealand respectively.

The methods of ascertaining this relationship are many and varied, but in the text they have been restricted to three, two of which are of common usage, viz., the comparison of two series of figures or the representation of these by graphs. But it is always difficult to establish a causal connection between two groups of phenomena by these means only. Consequently it has been found necessary to make use of a statistical device which may present difficulties to those who are not familiar with statistical method. If it can be proved that some causal connection exists between two groups or series of data, then the series are said to be correlated. The degree of correlation cannot be ascertained with exactitude by the mere visualizing of series of figures or their graphic representation. A more accurate measurement is required, and this is best found in the application of the theory of mathematical probability to the problem. This can be done best by calculating the co-efficient of correlation, from which it can be ascertained accurately the degree to which the series are related. No attempt will be made here to state the whole theory of correlation, or to explain fully the method of calculating the coefficient of correlation. This brief statement is intended to serve as a guide to those who are unfamiliar with the use of statistics, and, in particular, with the methods of correlating two groups of phenomena.

It is obvious that it would avail little to attempt to correlate two groups of data between which there was no evident causal connection. In the cases to which the theory has been applied in the text, the data are suggestive of causal correlation, and if the coefficient of correlation conforms to the tests which are set out below, then it may be concluded that such causal connection does exist. Obviously, we may suppose that there is some organic relationship between the price of wheat and the supply. To prove this we proceed as follows.

The two series of data are tabulated in parallel columns. $t$ Then for each series the standard deviation is calculated. This is found by, (1) finding the average of the whole series; (2) calculating the deviations from this average with the correct sign prefixed for each item in the series; (3) squaring 
these deviations; (4) calculating the average of these squares; and (5) extracting the square root of this average. The next step is to find the sum of the products of the deviations from the averages in each series. Finally, the standard deviations are multiplied together and then multiplied by the number of items in the series. This gives the divisor by which to divide the sum of the products of the deviations in order to get the coefficient, which always lies between +1 and -1 .

The above explanation may be summarised in the following formula:-

$$
\text { Coefficient of correlation }=\frac{\sum(x y)}{n p q}
$$

Where $x$ and $y$ are the deviations from the averages of the series [and therefore $\Sigma(x y)$ is the sum of the products of these deviations], $p$ and $q$ are the standard deviations of the series, and $n$ is the number of items in the series.

The coefficient of correlation will be positive if the series move together, e.g., with the yield of wheat and the rainfall. It will be negative when the series move in the opposite directions, e.g., supply and price. In the former case the correlation is said to be direct, and in the latter it is inverse. The nearer the coefficient approaches unity, (either positively or negatively), the more evident is it that correlation does exist between the two series.

But correlation cannot be established by reference to the magnitude of the coefficient alone. "If we find that two variables fluctuate together in two or three different instances, it by no means follows that this is a proof of the existence of correlation any more than would the fact of throwing double sixes with a pair of dice three times in succession prove that there was any connection between the dice. Such coincidences are likely to be entirely due to chance."* Thus if, of 100 pairs of deviations, about 50 were concurrent and the remain. der divergent the element of chance would be great. But if a large majority of the deviations were concurrent then it would be reasonable to suppose that the element of chance is small. But it is generally present to some degree, and it therefore involves a probable error. The coefficient of correlation must be considered in relation to this error. Mathematicians have worked out the law of probable error, and it is necessary here to state only the formula, which is generally used.

The probable error $=0.6745 \times \frac{1-r^{2}}{\sqrt{n}}$ where $r=$ coefficient of correlation and $n=$ the number of items in the series.

*King : Elements of Statistics, p. 213. 
The coefficient of correlation may be very small and yet correlation may be a certainty if the coefficient is more than six times the probable error.

In the case we have been considering, of the relation between supply and price, the coefficient was - 4440 (i.e., inverse correlation), but the probable error was only $\cdot 079$. As this is less than one-sixth of the coefficient, correlation may be said to exist. In the case of wheat yield and rainfall for Canterbury, correlation was not established, for the coefficient was only $+\cdot 250$ and the probable error $\cdot 1$. As was explained in Chapter IV.* this was due to the fact that the rainfall may vary considerably from the average without greatly affecting the yield. Thus movements in the yield must have been due partly to other causes. This is shown by the relatively high probable error.

Further information upon the whole problem of correlation may be sought in

King : Elements of Statistical Method.

Bowley : Elements of Statistics.

Elderton: Primer of Statistics.

${ }^{*}$ See page 67. 


\section{APPENDIX III.}

\section{THE CALCULATION AND USE OF INDEX NUMBERS.}

Index numbers are used most frequently to measure changes in general or individual prices, but they have certain advantages for measuring other economic phenomena. The most simple use has been made of index numbers in this work and it will not be necessary to state all the problems to which they give rise. For in all cases changes in only individual prices or other phenomena have been measured, and thus it is not necessary to discuss the important question of sampling in its relation to the choice of commodities.

The method of calculating an index number can best be stated by reference to a particular instance of its use. The index numbers of prices of New Zealand wheat will be considered.* First it is necessary to choose a period of years (or a single year) as a base period with which to compare the prices in all other years. The base period should be one in which no abnormal circumstances have been at work. Such a period is found in the years 1890-99, which have been taken as the base in all the calculations. These years are particularly appropriate, for they contain a period of falling prices to 1895 and then rising prices to 1899 . The average of the period is then calculated. In the particular case under consideration the average price of New Zealand wheat from 1890 to 1899 was $3 \mathrm{~s}$. 5 d. per bushel. This was equated to 100 and then the corresponding numbers found for the prices year by year, with this equation as a basis. Thus in 1869 the average price of New Zealand wheat was $4 \mathrm{~s}$. 3d. per bushel. The index number for this year would be 124. It is then an easy matter to calculate the percentage change from the base period. In a similar way index numbers have been found for other phenomena, e.g., supplies of wheat from year to year, area in wheat, imports, exports, etc. These index numbers offer many advantages, for they are often more convenient to work with than the original figures, which may be unwieldy, or, or the contrary, too small. Comparisons between two series can much more readily be undertaken, and the index numbers are useful for the purposes of drawing graphs, especially where two sets of data have to be compared graphically. Further, in calculating the general trend of the changes in the phenomena index numbers are very useful. The general trend has been found by calculating decennial moving averages. Suppose that the index numbers commence in 1869 , then the moving average is ascertained in the following manner. Find the average of the years 1869-78, then of the years 1870-79, then 1871-80, and so on, dropping one year in each

\footnotetext{
*See Chapter VII.
} 
case and adding one year at the other end. In this way individual fluctuations are eliminated, and the general trend of the movement ascertained. Particularly interesting were the results found by this means in movements in yield of wheat compared with acreage.

The average used in all calculations was the simple arithmetic average. Such an average is simple, easy of calculation, applicable to any set of numbers, and lends itself to further statistical work. Despite the disadvantages arising from the fact that it is greatly influenced by extremes, and may be inaccurate if the data are incomplete, it is, probably, the most convenient average for calculating the index numbers necessary for this investigation.

In Table XXVII., the index numbers of the prices of English and New Zealand wheat have boen compared for the purposes of ascertaining which series is subject to the greatest and most frequent fluctuations. The methods used are explained briefly in the text,* but it may be stated here that changes in prices or other economic phenomena involve many considerations. There are (1) the frequency of change which may be observed best in a graph; (2) the average range of change which is calculated by the simple average of the individual movements; (3) the range of change, which is the difference between the smallest and greatest items in the series; and (4) the average of departures from the average, which is a measure to some extent of the degree of the fluctuations. The devices used to measure these changes in the case of the prices of English and New Zealand wheat are given in the text, and are of particular importance to the problem of price steadiness.

But it is not intended to discuss the whole problem of index numbers. The treatment given here is altogether incomplete from this point of view. It is hoped, however, that it will prove useful to those who are unfamiliar with index numbers. For a fuller treatment reference should be made to any of the following works:-

McIlraith : The Course of Prices in New Zealand.

Fisher: The Purchasing Power of Money.

Layton: An Introduction to the Study of Prices.

*See page 181. 


\section{BIBLIOGRAPHY}

The sources of information on economic theory have been those of Dr. Marshall and his school of English and American economists. Among the books used the chief are:-

Marshall.-Principles of Economics, Vol. I.

Taussig.-Principles of Economies, 2 Vols.

Hadley.-Economies.

Chapman.-Outlines of Political Economy.

Nicholson.-Principles of Economics, 3 Vols.

For problems connected with prices and speculation, the chief sources of information have been:-

Fisher.-Purchasing Power of Money.

Kinley.-Money.

Layton.-Introduction to the History of Prices in the Nineteenth Century.

Emery's work on the Grain Exchanges in the United States has proved very useful on Speculation, and I have followed closely his treatment.

For the early history of New Zealand, the chief works drawn upon are:-

Fitton.-New Zealand.

Rusden.-History of New Zealand, 3 Vols.

Hursthouse.-New Zealand, the Britain of the South.

Saunders.-History of New Zealand, 2 Vols.

Scholefield.-New Zealand in Evolution.

MeNab.-Historical Records of New Zealand, Vols. I. and II.

Hight and Bamford.-The Constitutional History and Law of New Zealand, Part I.

Le Rossignol and Stewart.-State Socialism in New Zealand.

MeIlraith.-Course of Prices in New Zealand.

Vogel.-Hand-book of New Zealand.

Siegfried.-Democracy in New Zealand.

Condliffe.-The External Trade of New Zealand.

The chief works on general agriculture, useful for the purposes of this essay are:-

Dondlinger.-The Book of Wheat.

Hunt.-Cereals in America.

Livingstone.-Field Crop Production.

Powell.-Co-operation in Agriculture.

Rutter.- Wheat Production in the United States, Canada, and the Argentine.

Prothero.-English Farming, Past and Present.

Wood.-The Story of a Loaf of Bread.

Edgar.-The Story of a Grain of Wheat.

"Encyclopedia Britannica."-Article on Wheat. 
"The World's Commercial Products."-Article on Wheat.

Statistics and information on technical points from outside sources have been sought, ehiefly among the following publications:-

The Australian Commonwealth Year Book.

The Journal of Agriculture for Victoria.

" " " " $\quad$ " Western Australia.

The"Agricultural Gazette of New South Wales.

Brunich.-A Pamphlet on Wheat Culture in Queensland.

The Report of the Canadian Seed Growers' Assoc., 1913.

The Experimental Station Record of the United States, recent numbers.

The Bulletin of Economic and Social Intelligence of the International Institute of Agriculture, Rome.

The Bulletin of Plant Diseases; of the same.

The Annual Report of the Agricultural Chemist of Queensland, recent numbers.

Trivett.-Wheat Growing in Relation to Rainfall in New South Wales, 1912.

Webb.-Dictionary of Statistics.

Shaw.- How to Increase the Yield of Wheat in California.

The chief New Zealand publications containing useful information are:-

The Statistics of New Zealand, Vol. MII.

The New Zealand Official Year Book.

The Report of the Commission on the Cost of Living in New Zealand, 1912, Parliamentary Papers H. 18.

The Report on the Cost of Living in New Zealand, 18911914.

The Report of the Extension of Commerce Committee into the New Zealand Flour Millers' Association, 1903. Parliamentary Papers I. 10.

The Report of the Evidence before the Agricultural Labourers' Case in Canterbury before the Arbitration Court (1908).

Various volumes of the Appendices to the Journal of the House of Representatives.

The Ordinances of the Legislative Council.

The Annual Reports of the Department of Agriculture.

The Journal of the Canterbury Agricultural and Pastoral Association.

The Canterbury Agricultural College Magazine.

The Annual Report of the Canterbury Chamber of Commerce.

The New Zealand Farmer.

The Farmers' Union Advoeate.

The Lyttelton Times and The Christchurch Press. 


\section{INDEX}

Alexander, Mr. R. E., 82

Ashley, Prof. Sir W. J., 250

Argentina, 16, 18

Australia, 19-21

Wheat pool, 281

Biffen, 81.82

Board of Agriculture, 65

Brown, Dr. W. Jethro, 273-274

Canada, 18

Canterbury Agricultural College, 64, 286, Chap. $\nabla$.

Capital, 205-208

Census and Statistics Office, 118

Climate, 26-27

In New Zealand, 39-52

College Hunter's, 92-94

Consumption of wheat, 2-4

Corn Laws, 179

Correlation, 119-123, Appendix ii.

Cost of Production, Ohap. ix.

Estimates of, 225-235

In relation to market price, 237 238

Leeston Soldiers' Settlement and, 240-241

Couteur, Le, 79

Cropping, 210-212

Cultivation, 27

In New Zealand, 52-54

Dairy farming, 127-129

Demand for wheat, 139

Inelastic, 156

Depopulation, 198.200

Depression of the eighties, 105-7

Diminishing returns, Law of, 113

Discount, rate of, 186

Education, 200, 294

Ely, Professor R. T., 249

Emery on Speculation, 146, 147, 149,151

Experimental error, 86.88

Experimental farms, 63.5

Exports, graph of, 101, Table xxxviii.

Fallowing, 52-54

Farmers' Union, The, 249-255

Ferrar, W., 81

Fertilisers, 24-26

In New Zealand, 37-39

Financing of farmers, 207-208

Fisher, Professor Irving, 159, 160, $163,167,295$

Flour Millers' Association, The, 242-248

Frozen mutton, 106-107
Gold, 98-99

Government encouragement to the wheat industry, 63

Grading, 58

Graduated Land Tax, 184

Hall, Mr. Edwin, 36

Hallett, F. F., 80

Harvesting, 28

In New Zealand, 54-56

High Farming, 107-109

Hilgendorf, Dr. F. W., 39, 228, Chap. v.

History of wheat production in New Zealand, Chap. vi.

Hunter's, 75

Imports, graph of, 100, Table xxxviii.

Index numbers, Appendix iii.

Jevons, Professors W.S. and H. S., 116-118

Labour, 59-63, 197-204

Land, 186-198

Price of, 297

Tenures, 190-195.

Large scale production, 102, 107 . 108

Layton, W. T., 166

Lochow, von, 80

Management, Farm, 293-294

Market, defined, 134-136

The wheat, 5-7, 136-137

Marketing, 7-9, 28-29, 56, 292-298 In New Zealand, 9-13

Marshall, Professor A., 218

Mass selection, $81,84-85$

MeIlraith, Dr. J. W., 175, 186 , 259,296

Mendel's Law, 81-82

Mixed farming, 108, 127

“New Zealand Farmer," 225

Nillson, Dr. H., 79

Organisation, 209

Pearl, 74

Pigou, Professor A. O., 282

Price of agricultural land, 104, 222

Price of wheat, contents of Chap. vii.

Prices, effects of falling and rising, 105-107

Forecast, 295-297

Of flour, 269

Public control of, 266-281

Relation of price of wheat to general level, 162-164, 169-170

Steadiness, 178-182 
Production, Chap. ii.

Cyclical changes in, 115-118

Distribution areas, 14-17

Graph of, 103

Profit from wheat growing, 286

Protection, 255-266

Quality of wheat, contents of Chap. iv.

Rainfall and yield, $40-52$

At Lincoln College, 45

In Canterbury, 42-43

In Victoria, $\mathbf{4 7 . 4 8}$

Rent, 220-222

Rimpau, 81

Rotation of crops, 25-26, 212-214

Rutherglen Viticultural College, 53

Sheep farming, 123-127

Siberia, 15

Single ear selection, $79-82,85-86$

Soils, 23-26

In New Zealand $\mathbf{3 3 . 3 7}$

Survey, 35-37
Southland, area in wheat, 188

Speculation, 144 et seq.

Effects on price, 148-149

Statistics in New Zealand, Appendix $i$.

"'Strong"' wheats, 71-3

Supply of wheat, 138

Equilibrium of supply and demand, 133-134, 140-144

Swedish Seed Association, 79, 83

Talavera, 79

Taussig, Professor F. W., 114

Taylor, T. E., 246

Trades unionism, 61-2

Tuscan, 73

Variation, calculation of coefficient of, 180-182

Varieties in New Zealand, 73.78

Vogel, Sir Julius, 99-100, 102

"Weak" wheats, 71.73 


\section{BOTANY}

For NEW ZEALAND STUDENTS

By F. X Keve, M.A., B.Sc.

$T^{H E}$ numerous illustrations all

of an instructive character.

Text specially compiled to meet the requirements of N.Z. Secondary Schools, as well as candidates preparing for Matriculation, Public Service, and Teachers' Examinations.

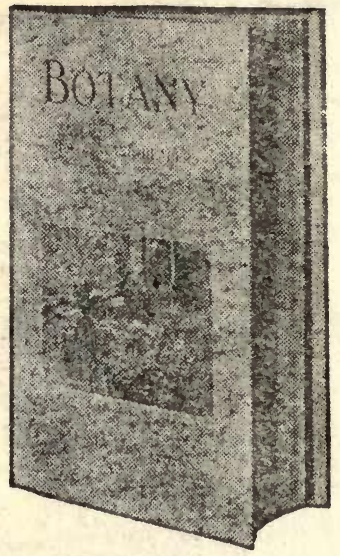

THIRD EDITION Revised

Price 4/6

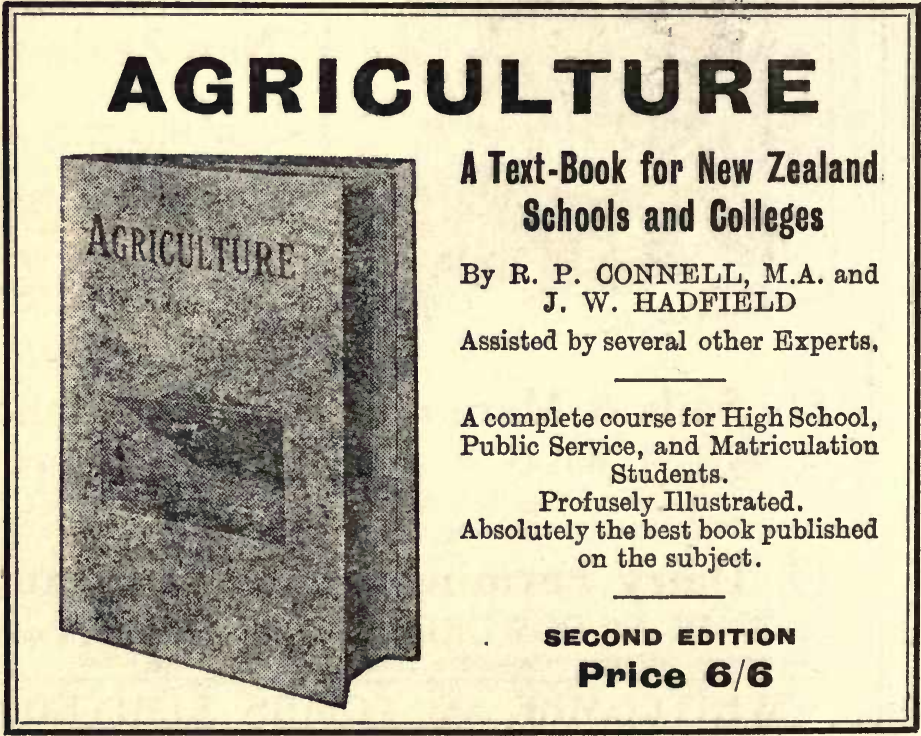




\section{NEW ZEALAND}

\section{Practical Handbooks}

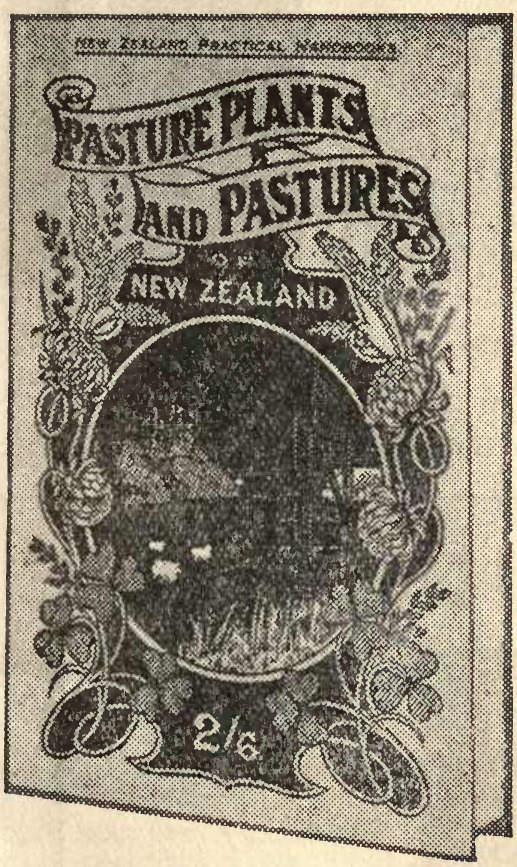

\section{Every \\ Student of Agriculture}

and intending farmer should be familiar with this invaluable series of cheap handbooks. Three numbers now ready :-

(1) Pasture Plants and Pastures of New Zealand by

F. W. HILGENDORF, M.A., D.Sc.

Biologist at Canterbury Agricultural College, Lincoln.

96 pages Crown 8 vo., with illustrations of principal grasses

Price 2/6

(2) Soils \& Manures in New Zealand by L. J. WILD, M.A., B.Sc. (N.Z.), F.G.S. (Lond.) Lecturer at Canterbury Agricultural College, Lincoln. 132 Crown 8vo. pages, illustrated. Price 2/6.

(3) Dairy Farming in New Zealand by W. D. POWDRELL, M.P., and other Dairy Experts 102 pages, Crown 8vo., illustrated. Price 2/6. 
UNIVERSITY OF CALIFORNIA LIBRARY, BERKELEY

\section{THIS BOOK IS DUE ON THE LAST DATE STAMPED BELOW}

Books not returned on time are subject to a fine of $50 \mathrm{c}$ per volume after the third day overdue, increasing to $\$ 1.00$ per volume after the sixth day. Books not in demand may be renewed if application is made before expiration of loan period.

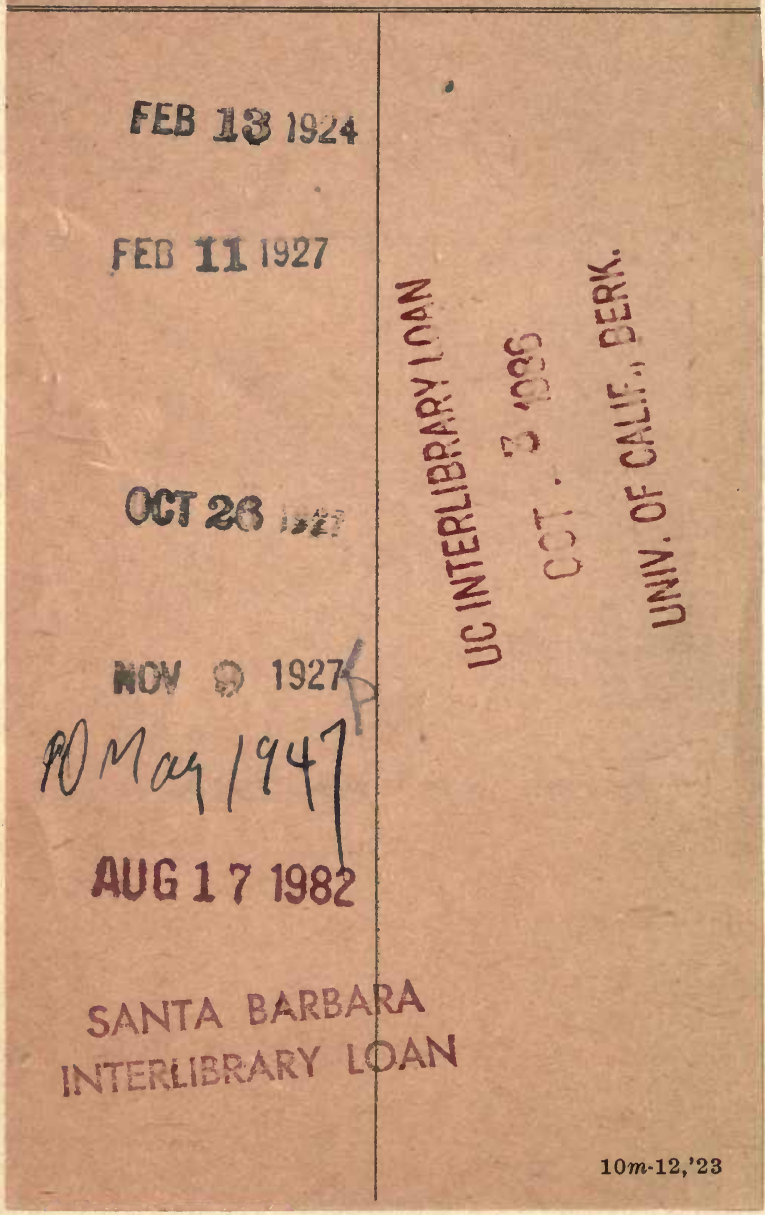


$Y_{B} 46285$ 
